Aus dem Institut für Neuro- und Sinnesphysiologie

(Prof. Dr. rer. nat. S. O. Rizzoli)

im Zentrum Physiologie und Pathophysiologie

der Medizinischen Fakultät der Universität Göttingen

\title{
Expansionsmikroskopie des Rattenhirns \\ zur subzellulären Lokalisation synaptischer Proteine
}

\author{
INAUGURAL-DISSERTATION \\ zur Erlangung des Doktorgrades \\ für Zahnmedizin \\ der Medizinischen Fakultät der \\ Georg-August-Universität zu Göttingen
}

vorgelegt von

Nils Alexander Kemna

aus

Bremen

Göttingen 2021 
Dekan:

\section{Betreuungsausschuss}

Betreuer/in

Ko-Betreuer/in:

\section{Prüfungskommission}

Referent/in

Ko-Referent/in:

Drittreferent/in:

Datum der mündlichen Prüfung: 14.02 .2022
Prof. Dr. rer. nat. S. O. Rizzoli

Prof. Dr. rer. nat. S. Jakobs

Prof. Dr. Stefan Jakobs 
Hiermit erkläre ich, die Dissertation mit dem Titel „Expansionsmikroskopie des Rattenhirns zur subzellulären Lokalisation synaptischer Proteine" eigenständig angefertigt und keine anderen als die von mir angegebenen Quellen und Hilfsmittel verwendet zu haben.

Göttingen, den 


\section{Inhaltsverzeichnis}

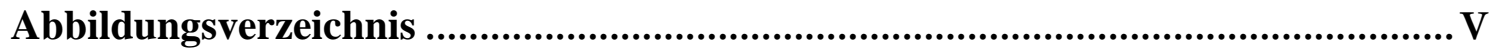

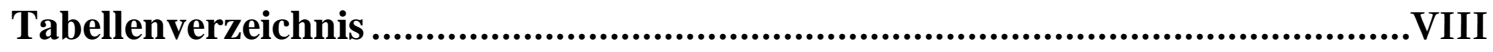

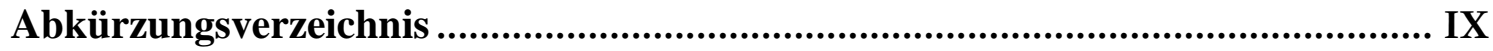

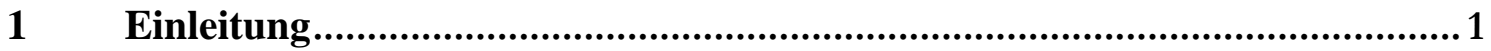

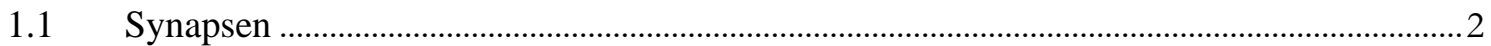

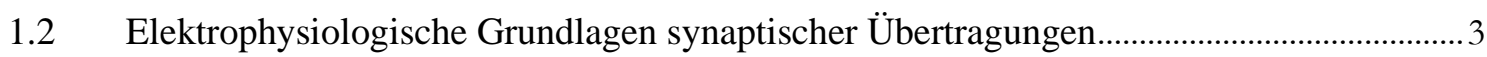

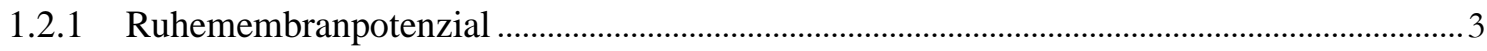

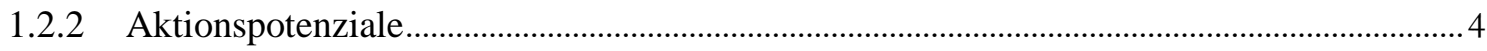

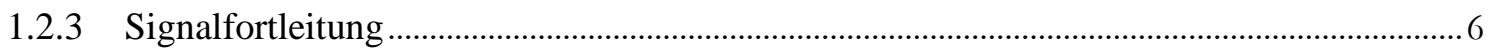

1.2.4 Synaptische Übertragung..............................................................................................

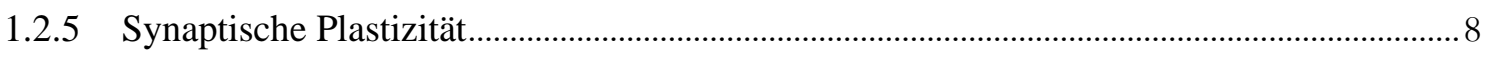

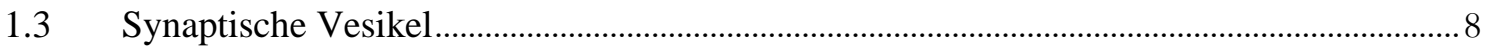

1.3.1 Aufbau Synaptischer Vesikel und Neurotransmitterbefüllung ..............................................

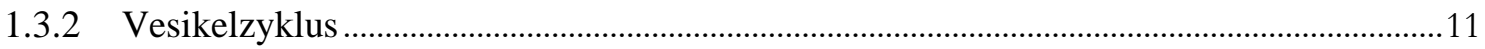

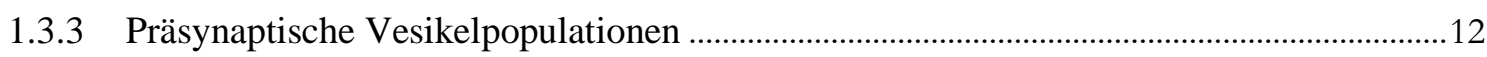

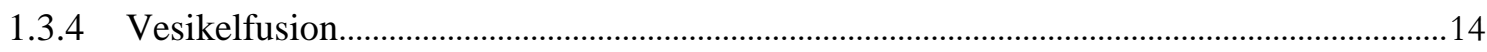

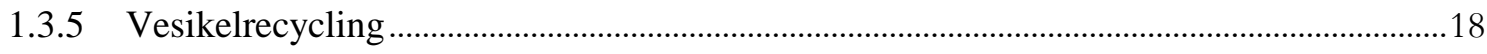

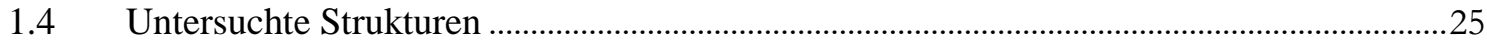

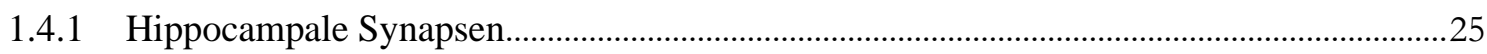

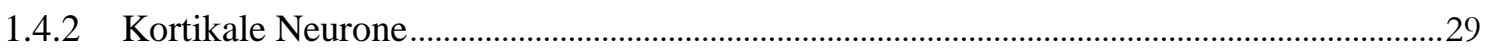

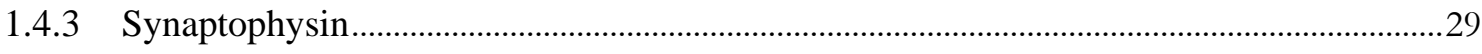

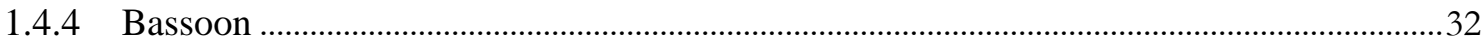

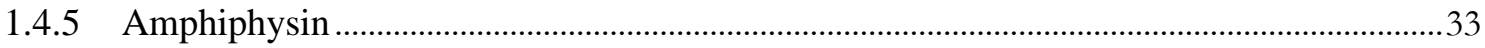

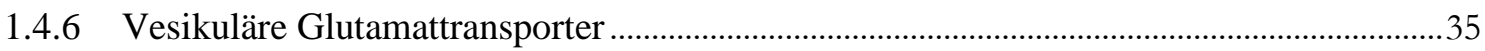

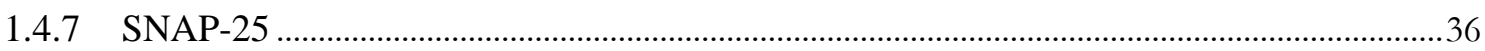

$1.5 \quad$ Hochauflösende Mikroskopie ................................................................................................

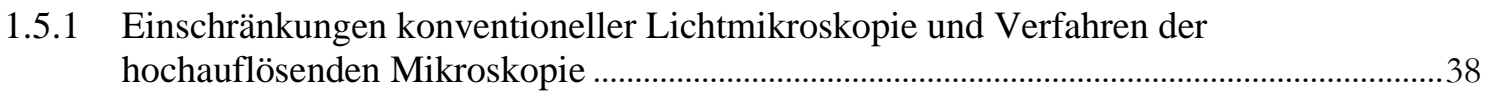

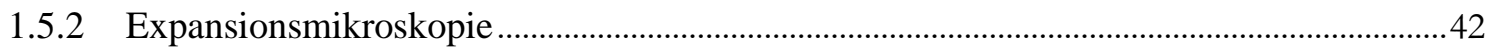

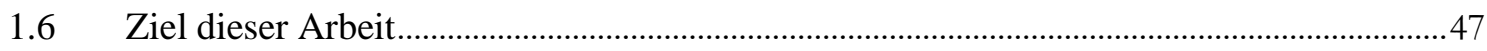

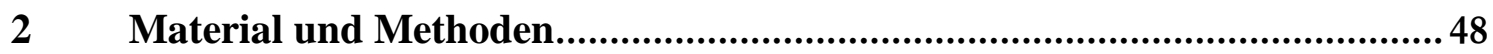




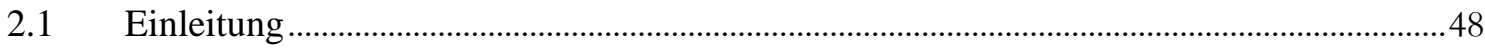

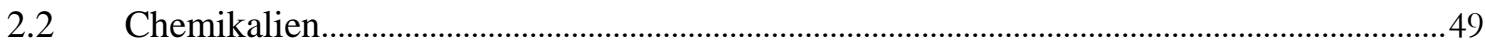

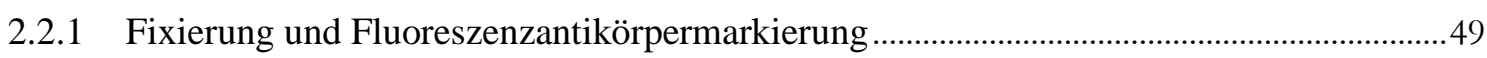

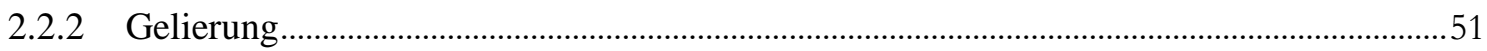

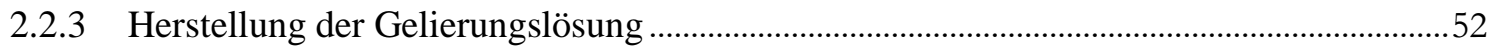

2.2.4 Proteinverankerung und Proteinverdauung ...............................................................................53

2.3 Labortechnisches Verfahren der Expansionsmikroskopie ......................................................54

2.3.1 Fixierung der Rattenhirne und Herstellung der Schnittpräparate ..........................................54

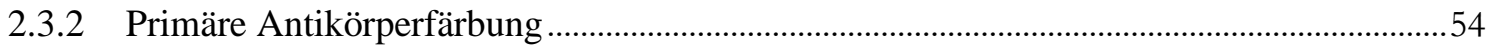

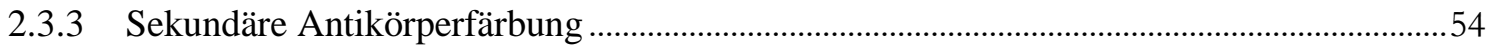

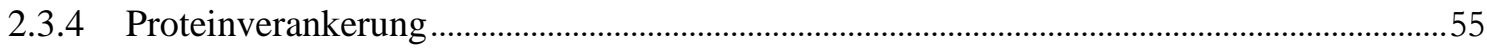

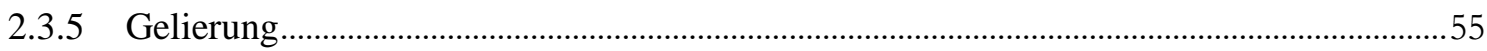

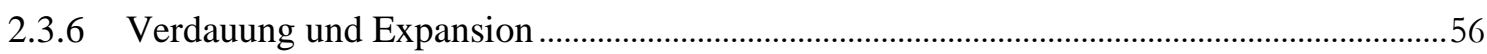

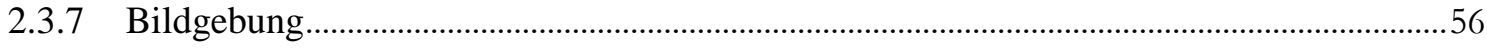

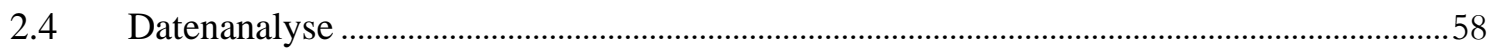

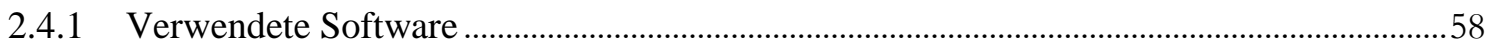

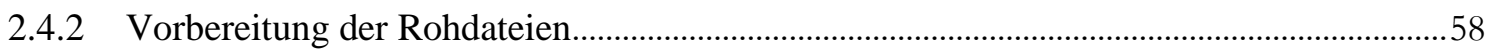

2.4.3 Bandpassfiltrierung und Summation der Fluoreszenzsignale .................................................59

2.4.4 Manuelle Auswahl der zu analysierenden Bereiche eines Einzelexperiments ...................62

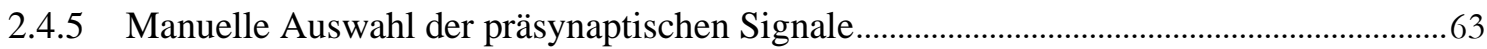

2.4.6 Summation der zu untersuchenden präsynaptischen Fluoreszenzsignale............................67

2.4.7 Analyse der Fluoreszenzsignalverteilungen............................................................................

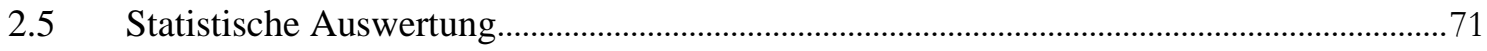

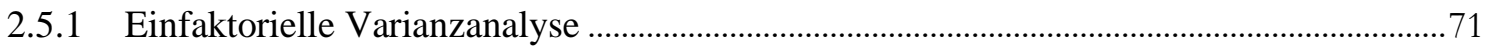

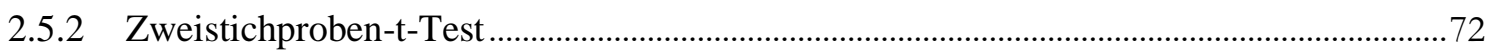

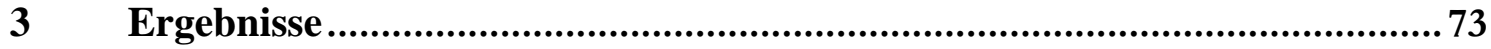

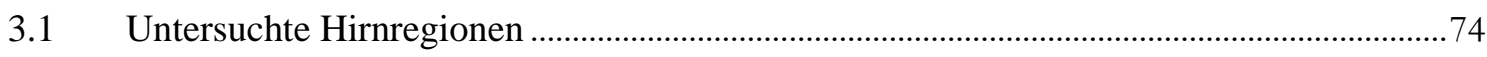

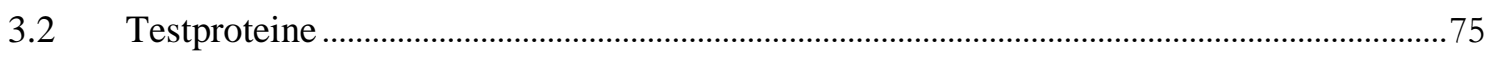

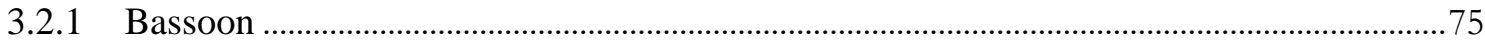

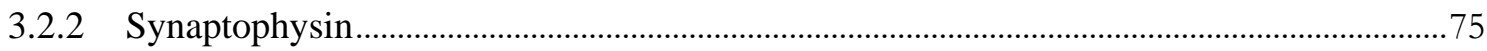

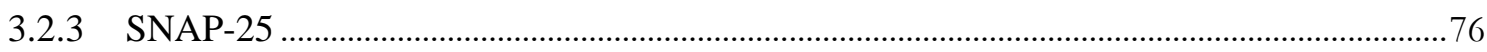

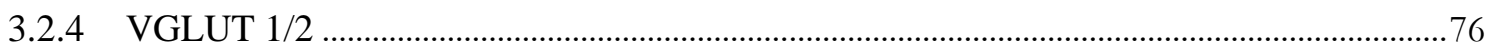

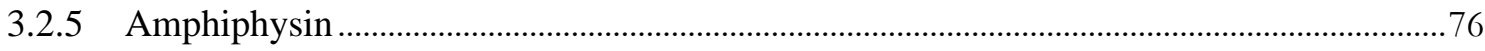




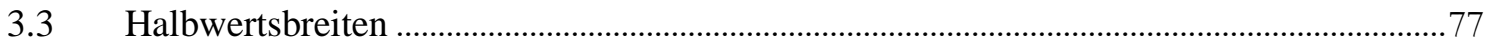

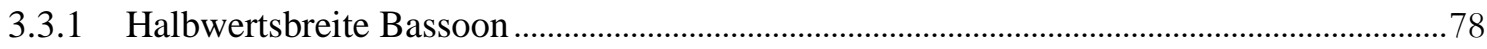

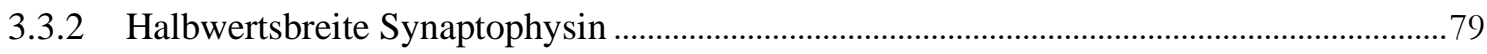

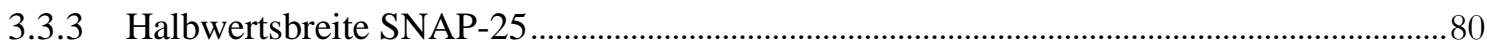

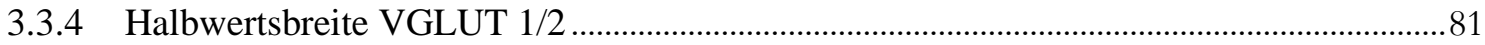

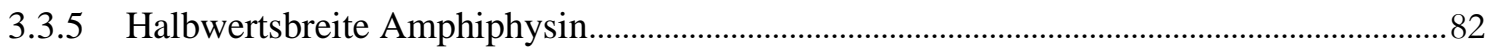

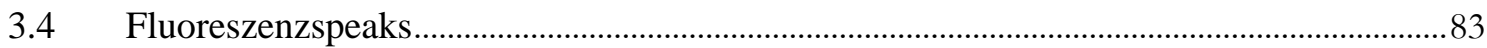

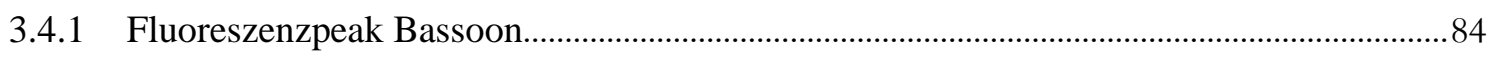

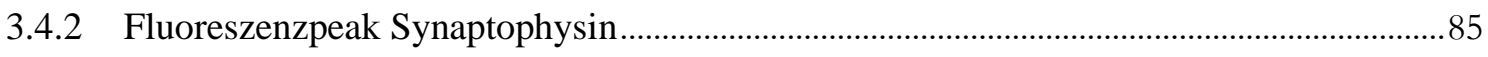

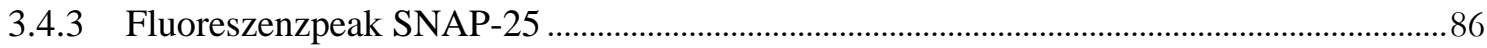

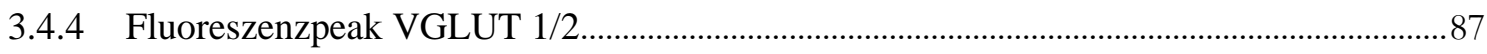

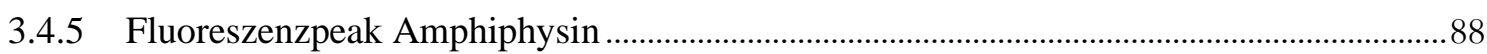

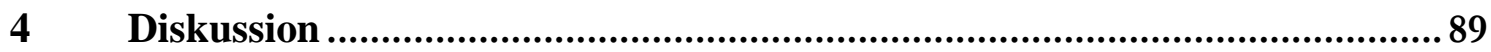

4.1 Subzelluläre Organisation der Testproteine ...................................................................... 90

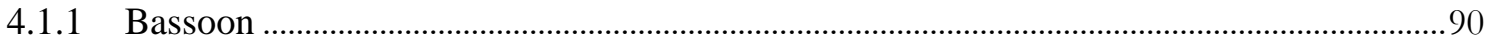

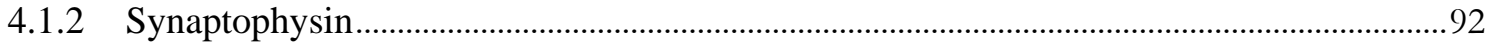

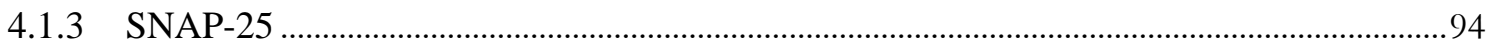

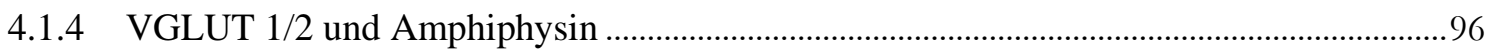

4.1.5 Fazit

4.2 Mögliche Ursachen variierender synaptischer Aktivität .................................................104

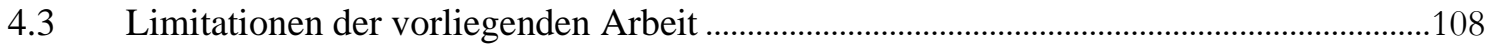

4.4 Ausblick für zukünftige Forschungsarbeiten ......................................................................110

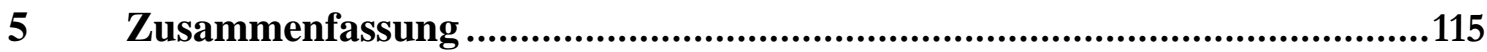

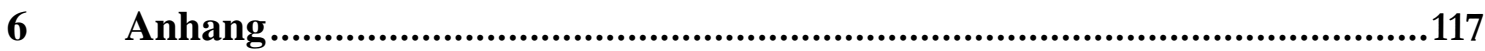

6.1 Anzahl untersuchter Fluoreszenzspots pro Testprotein pro Hirnregion ..........................117

6.1.1 Synaptophysin und Bassoon .......................................................................................117

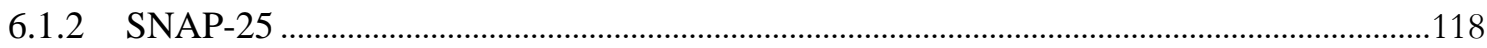

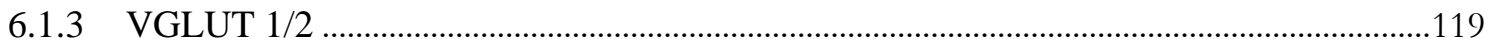

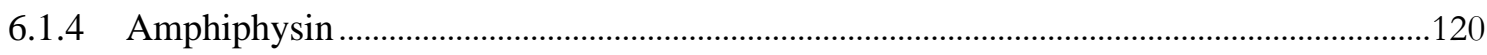

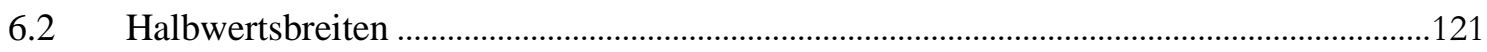

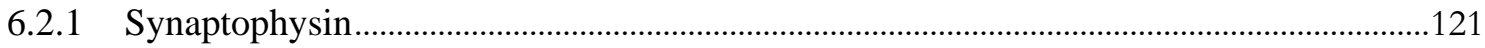

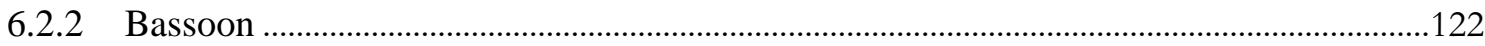

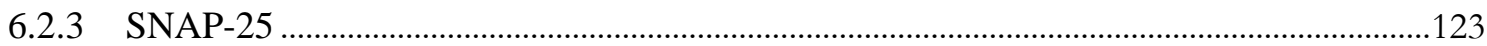




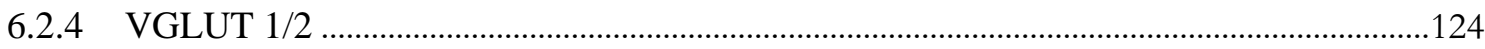

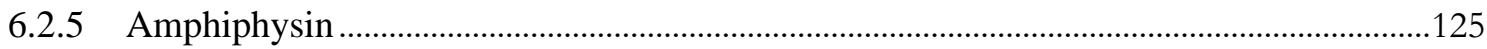

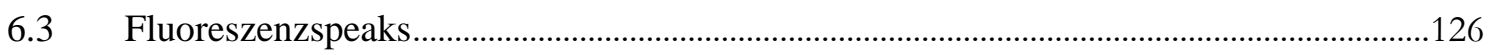

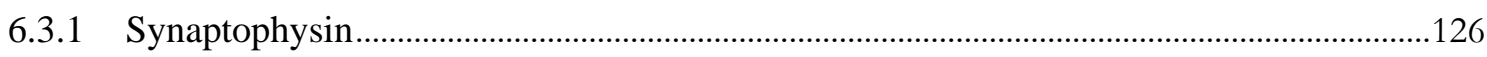

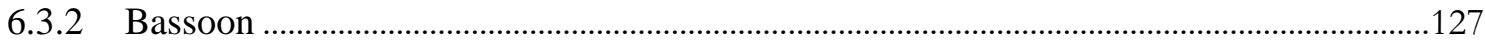

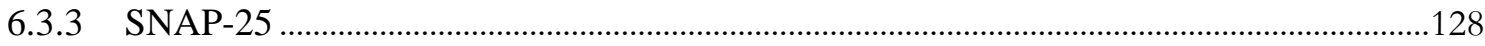

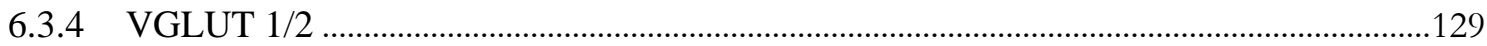

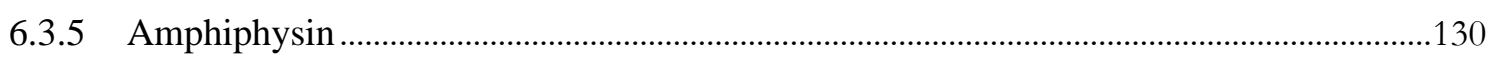

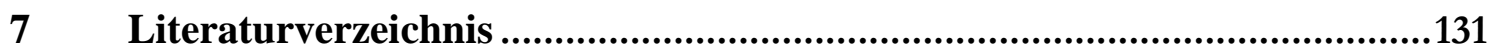




\section{Abbildungsverzeichnis}

Abbildung 1: Schematischer Aufbau einer Synapse. 3

Abbildung 2: Schematische Darstellung intrazellulärer Spannungsverhältnisse und Aktivitätszustände beteiligter Ionenkanäle während eines Aktionspotenzials.

Abbildung 3: Durchschnittliche Proteinzusammensetzung eines synaptischen Vesikels im dreidimensionalen Modell.

Abbildung 4: Schematische Darstellung der Hauptbestandteile des Andock- und Fusionsmechanismus synaptischer Vesikel.

Abbildung 5: Schematische Darstellung des Vesikelrecyclings unter Beteiligung der clathrinabhängigen Endozytose.

Abbildung 6: Übersichtsdarstellung präsynaptischer Endozytosemechanismen.

Abbildung 7: Dendritische Organisation hippocampaler Pyramidenzellen.

Abbildung 8: Übersichtsdarstellung hochauflösender Mikroskopieverfahren.

Abbildung 9: Molekularer und visueller Unterschied zwischen Zustand vor und nach Expansion eines Rattenhirnschnittes.

Abbildung 10: Optischer Auflösungsvergleich zwischen EXM und SIM.

Abbildung 11: Schematische Darstellung eines ursprünglich bei der Expansionsmikroskopie verwendeten Markers und Prinzip der Expansionsmikroskopie.

Abbildung 12: Strukturformel und Verankerungspartner des Acryloyl-X. . .46

Abbildung 13: Schematischer Aufbau einer Gelkammer. . .56

Abbildung 14: Schnittpräparat eines Rattenhirns nach Expansion bei 20-facher Vergrößerung.

Abbildung 15: Benutzeroberfläche der MATLAB-Routine "program_start" und Befehlskette zum Start der Routine.

Abbildung 16: Vergleich zwischen Einzelbild eines Bildstapels und erstelltem Fluoreszenzsummationsbildes (Beispiel 1).

Abbildung 17: Darstellung der MATLAB-Benutzeroberfläche und Darstellung summierter Fluoreszenzsignale der detektierten Bassoon-Fluoreszenzsignale (Beispiel 1).

Abbildung 18: Darstellung der farblichen Markierung der summierten Fluoreszenzsignale der detektierten Synaptophysin-Fluoreszenzsignale und der Fluoreszenzsignale eines Testproteins (Beispiel 1).

Abbildung 19: Manuelle Auswahl zu untersuchender Teilbereiche und vergrößerte, farbig markierte Darstellung der ausgewählten Fluoreszenzsignale (Beispiel 1).

Abbildung 20: Vergrößerte Darstellung der Fluoreszenzsignale des ausgeschnittenen Bereichs und Auswahl eindeutiger Fluoreszenzsignale (Beispiel 1).

Abbildung 21: Darstellung der Auswahl eines zweiten, zu analysierenden Teilbereichs des Einzelexperiments und ausgeschnittene, vergrößerte und farbig markierte Darstellung aller enthaltenen Fluoreszenzsignale (Beispiel 1).

Abbildung 22: Darstellung der summierten Fluoreszenzsignale des Bassoons zweier weiterer durchgeführter Einzelexperimente. 
Abbildung 23: Vergrößerte Darstellung der Fluoreszenzsignale aus Abbildung 21 und manuell ausgewählte, zu analysierende Signale (Beispiel 1).

Abbildung 24: Auswahl der zu untersuchenden Teilbereiche eines Einzelexperiments und Darstellung der Fluoreszenzsignale des oberen Teilbereichs (Beispiel 4).

Abbildung 25: Vergrößerte Darstellung der rechten Bildhälfte aus Abbildung 24, nach manueller Auswahl zu analysierender Fluoreszenzsignale.

Abbildung 26: Benutzeroberfläche der MATLAB-Routine "aling_images_Nils" und Befehlskette zum Start der Routine.

Abbildung 27: Darstellung der durchschnittlich pro Einzelexperiment detektierten Fluoreszenzsignale der einzelnen Fluoreszenzkanäle der Beispiele 1 und 2.

Abbildung 28: Benutzeroberfläche der MATLAB-Routine "get_lines" und Befehlskette zum Start der Routine.

Abbildung 29: Graphische Darstellung der detektierten Fluoreszenzsignale aller untersuchten Fluoreszenzbilder des Testproteins aus Beispiel 1 und Beispiel 2.

Abbildung 30: Durchschnittliche Halbwertsbreiten detektierter BassoonFluoreszenzsignale in verschiedenen Regionen des Rattenhirns im Säulendiagramm mit Ausweisung des Standardfehlers.

Abbildung 31: Durchschnittliche Halbwertsbreiten detektierter SynaptophysinFluoreszenzsignale in verschiedenen Regionen des Rattenhirns im Säulendiagramm mit Ausweisung der Standardfehlers.

Abbildung 32: Durchschnittliche Halbwertsbreiten detektierter SNAP-25Fluoreszenzsignale in verschiedenen Regionen des Rattenhirns im Säulendiagramm mit Ausweisung des Standardfehlers.

Abbildung 33: Durchschnittliche Halbwertsbreiten detektierter VGLUT-1/2Fluoreszenzsignale in verschiedenen Regionen des Rattenhirns im Säulendiagramm mit Ausweisung des Standardfehlers.

Abbildung 34: Durchschnittliche Halbwertsbreiten detektierter AmphiphysinFluoreszenzsignale in verschiedenen Regionen des Rattenhirns im Säulendiagramm mit Ausweisung des Standardfehlers.

Abbildung 35: Durchschnittliche Fluoreszenzpeaks detektierter BassoonFluoreszenzsignale in verschiedenen Regionen des Rattenhirns im Säulendiagramm mit Ausweisung des Standardfehlers.

Abbildung 36: Durchschnittliche Fluoreszenzpeaks detektierter Synaptophysin-

Fluoreszenzsignale in verschiedenen Regionen des Rattenhirns im Säulendiagramm mit Ausweisung des Standardfehlers.

Abbildung 37: Durchschnittliche Fluoreszenzpeaks detektierter SNAP-25Fluoreszenzsignale in verschiedenen Regionen des Rattenhirns im Säulendiagramm mit Ausweisung des Standardfehlers.

Abbildung 38: Durchschnittliche Fluoreszenzpeaks detektierter VGLUT-1/2Fluoreszenzsignale in verschiedenen Regionen des Rattenhirns im Säulendiagramm mit Ausweisung des Standardfehlers.

Abbildung 39: Durchschnittliche Fluoreszenzpeaks detektierter AmphiphysinFluoreszenzsignale in verschiedenen Regionen des Rattenhirns im Säulendiagramm mit Ausweisung des Standardfehlers. 
Abbildung 40: Dreidimensionales Modell der präsynaptischen Architektur. 103

Abbildung 41: Darstellung der durch X10-Mikroskopie erreichbaren Auflösungsverbesserung eines Weitfeldmikroskops.. 


\section{Tabellenverzeichnis}

Tabelle 1: Zusammensetzung der Rattenhirn-Fixierungslösung.......................................................49

Tabelle 2: Zusammensetzung der Blockierlösung ...........................................................................49

Tabelle 3: Zusammensetzung der Immersionslösung.............................................................................

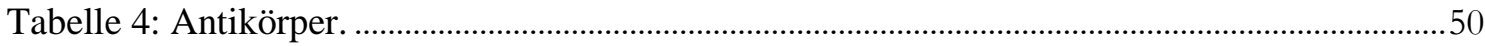

Tabelle 5: Zusammensetzung der Monomerlösung.........................................................................51

Tabelle 6: Zur Herstellung der Gelierungslösung benötigte Lösungen. ...............................................51

Tabelle 7: Zusammensetzung der Gelierungslösung pro untersuchtem Hirnschnitt und

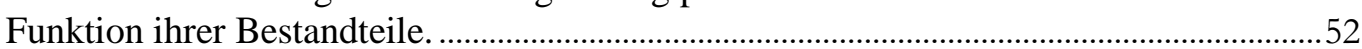

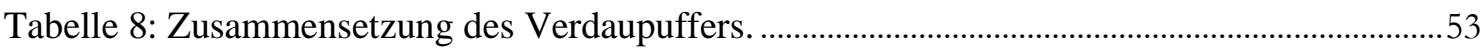

Tabelle 9: Zusammensetzung der Acryloyl-X-Lösung. ..........................................................................53

Tabelle 10: Übersicht untersuchter Regionen des Hippocampus und verwendete

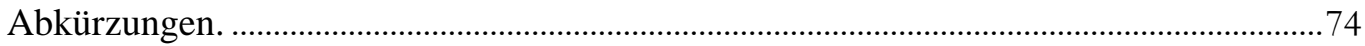

Tabelle 11: Übersicht untersuchter Regionen des Cortex cerebri und verwendete Abkürzungen. 


\section{Abkürzungsverzeichnis}

Acryloyl-X

ANOVA

AP

BAR-Domänen-Proteine

Bulk-Endozytose

EXM

FWHM

IEXM

PALM

PBS

ProEXM

RIM

RMP

SIM

SNAP-25

SNARE

STED

STORM

V-ATPase

VGLUT
([Acryloyl-]Amino)-Hexanosäure, Succinimidylester

Einfaktorielle Varianzanalyse

Aktionspotenzial

Bin/Amphiphysin/Rvs-Domänen-Proteine

Aktivitätsabhängige Massenendozytose

Expansionsmikroskopie

Halbwertsbreite

Iterative Expansionsmikroskopie

Photoactivated Localization Microscopy

Phosphatgepufferte Salzlösung

Protein-Retention Expansion Microscopy

Rab3 bindende Moleküle

Ruhemembranpotenzial

Structured Ilumination Microscopy

Synaptosomal-Associated Protein of $25 \mathrm{kDa}$

Soluble N-Ethylmaleimide-Sensitive-Factor Attachment Receptor

Stimulated Emission Depletion Microscopy

Stochastic Optical Reconstruction Microscopy

Protonen-ATPase

Vesikulärer Glutamattransporter 


\section{$1 \quad$ Einleitung}

Das Gehirn stellt als zentraler Anteil des Nervensystems das komplexeste Organ des Menschen dar. Es besteht aus durchschnittlich 86 Milliarden, auf Reizaufnahme und Weiterleitung spezialisierten Zellen, den Neuronen (Azevedo et al. 2009). An den Kontaktund Kommunikationsstellen benachbarter Neuronen, den Synapsen, erfolgt die Weitergabe von Informationen. Dieses hochkomplexe Netzwerk stellt die Grundlage für zentralnervöse Funktionen wie Bewusstsein, Gedächtnis und Lernen dar. Neurone bestehen aus einem Zellkörper, zahlreichen Dendriten samt Dornenfortsätzen sowie dem aus dem Axonhügel entspringenden Axon. Der Zellkörper beinhaltet die Zellorganellen. Die Dornenfortsätze erhalten Signale von Präsynapsen umgebender Neurone, die von dort über die Membran des Zellkörpers bis zum Axonhügel geleitet werden. Hier werden alle eintreffenden Informationen integriert und elektrisch über das Axon in Richtung seiner synaptischen Endknöpfchen, den Präsynapsen, weitergeleitet. Ausgeschüttete Neurotransmitter führen hier durch chemische Signalübertragung zu spezifischen Reaktionen in den postsynaptischen Bereichen der Dendriten nachgeschalteter Neuronen oder zu Reaktionen muskulärer und sekretorischer Effektorzellen. Neurone werden hinsichtlich ihrer axonalen Leitungsgeschwindigkeit, ihrer Morphologie sowie dem zugehörigen Transmitter differenziert. Funktionell unterscheidet man motorische, sensible und Interneurone. Die makroskopische Anatomie von Synapsen, der grundlegende Ablauf synaptischer Kommunikation und große Bestandteile des komplexen synaptischen Proteoms sind bekannt. Die Feinregulierung synaptischer Prozesse, die Funktionsweise hochkomplexer neuronaler Kreisläufe, die exakte molekulare Zusammensetzung und subzelluläre Verteilung des synaptischen Proteoms, insbesondere im Vergleich unterschiedlicher Bereiche des Gehirns und schlussendlich die Ursache, die unterschiedliche Funktionen verschiedener Hirnregionen ermöglicht, hingegen nicht. 


\subsection{Synapsen}

Synapsen unterteilen sich in elektrische und chemische Synapsen. Elektrische Synapsen ermöglichen durch Zell-Zell-Kanäle die direkte elektrische Kommunikation zweier Zellen. Man findet sie beispielsweise in der Retina von Wirbeltieren (Raviola und Gilula 1973). Die häufigsten Synapsen des zentralen- und peripheren Nervensystems sind chemische Synapsen. Sie vermitteln durch reizabhängige Freisetzung von Neurotransmittern, die zu entsprechenden Rezeptoren nachgeschalteter Zellen diffundieren, eine indirekte Kommunikation zwischen zwei Neuronen. Chemische Synapsen bestehen ultrastrukturell aus dem synaptischen Endknöpfchen, der sogenannten Präsynapse, dem ca. $20 \mathrm{~nm}$ breiten synaptischen Spalt und der Postsynapse. Die Präsynapse dient der Speicherung und Freisetzung von Neurotransmittern. Sie enthält ein ausgeprägtes Netzwerk aus Mikrotubuli und Aktinfilamenten, die dem Transport der zahlreich vorliegenden, mit Neurotransmitter beladenen synaptischen Vesikel dienen. Mitochondrien in der Präsynapse stellen die hierfür benötigte Energie bereit. Zahlreiche spannungsabhängige Calciumkanäle in der Membran der Präsynapse dienen der Steuerung der Signalübertragung (vgl. Weinberg 2012; siehe Abschnitt 1.2.4). An den synaptischen Spalt angrenzend liegen die aktive Zone der Präsynapse, in der synaptische Vesikel an die präsynaptische Zellmembran binden und im Zuge der synaptischen Übertragung mit dieser fusionieren (Rizzoli und Tabares 2016) sowie die periaktive Zone, in der das Recycling zuvor exozitierter Vesikelkomponenten stattfindet (Cano und Tabares 2016). Proteininteraktionen und spezifische Protein-Lipid-Komplexe könnten der Abgrenzung der aktiven Zonen dienen (Gundelfinger et al. 2003). Die Synapsen eines Neurons setzen im Zuge der Signalübertragung ihren Transmitter gemeinsam mit weiteren Cotransmittern frei, deren Funktion nicht ausreichend erforscht ist (Hnasko und Edwards 2012). Die Postsynapse dient der Aufnahme und Weiterleitung aller eintreffenden Signale. Ribosomen und raue endoplasmatische Retikula in den Dendriten produzieren spezifische ionotrope oder metabotrope Neurotransmitterrezeptoren, die durch Proteine wie beispielsweise PSD-95, Gephyrin oder Grip im Bereich der postsynaptischen Membran konzentriert werden (Dong et al. 1997; Dejanovic et al. 2014; Chen X et al. 2015). Sie ermöglichen nach erfolgter Transmitterbindung die exzitatorische und inhibitorische Signaltransduktion zwischen den Neuronen. Der Aufbau einer chemischen Synapse wird in Abbildung 1 schematisch dargestellt. 


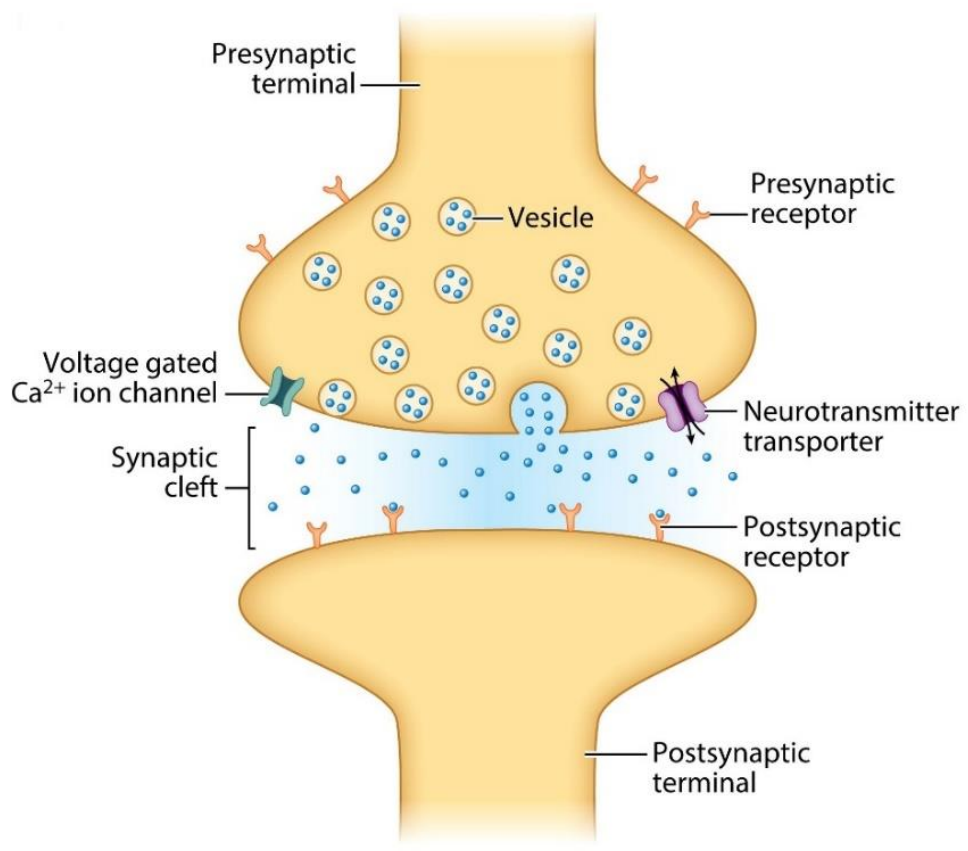

\section{Abbildung 1: Schematischer Aufbau einer Synapse.}

Präsynapsen setzen an Dendriten und Zellkörpern nachgeschalteter Neuronen an. Präsynaptisch eintreffende elektrische Reize führen zur Transmitterexozytose in den synaptischen Spalt, die zur erneuten Bildung elektrischer Potenziale im Bereich der postsynaptischen Membran führt (entnommen und modifiziert nach Shin et al. 2019). Die Verwendung erfolgt mit freundlicher Genehmigung von Annual Reviews, Inc.

\subsection{Elektrophysiologische Grundlagen synaptischer Übertragungen}

\subsubsection{Ruhemembranpotenzial}

Die Grundlage der Erregbarkeit von Nerven-, Sinnes- und Muskelzellen stellt die Ungleichverteilung von Natrium-, Kalium-, Calcium- und Chloridionen zwischen Extra-, und Intrazellulärraum dar. Spezifische Ionenkanäle verändern in Abhängigkeit von eintreffenden Reizen wie beispielsweise elektrischen Potenzialveränderungen, Neurotransmittern sowie chemischen und mechanischen Stimuli ihre Öffnungswahrscheinlichkeit. Ladungsverschiebungen über die Zellmembran ermöglichen so die Ausbildung und Änderung elektrischer Potenziale, die Kontrolle über das Zellvolumen, die Steuerung des Ionenstroms über Epithelien der sekretorischen und resorptiven Gewebe sowie die Signalübertragung zwischen benachbarten Zellen. Ionen, die durch eine semipermeable Membran voneinander getrennt sind, streben nach einem Diffusionsgleichgewicht, bei dem der Nettofluss über die Membran gleich null ist. 
Für jede Ionensorte ergibt sich somit ein elektrisches Gleichgewichtspotenzial, bei dessen Messung die Ladung des Extrazellulärraumes stets auf $0 \mathrm{mV}$ festgelegt wird. Die Berechnung des Gleichgewichtspotenzials für eine bestimmte Ionensorte erfolgt mithilfe der Nernst-Gleichung. Plasmamembranen sind im Ruhezustand stärker für Kaliumionen durchlässig als für alle anderen Ionensorten, sodass der Spannungsunterschied zwischen Extra-, und Intrazellulärraum maßgeblich durch die Verteilung und das Strömungsverhalten von Kaliumionen über die Plasmamembran der Zelle bestimmt wird. In allen erregbaren Zellen stellt sich so ein negatives Ruhepotenzial des Intrazellulärraumes gegenüber dem Zelläußeren ein, das Ruhemembranpotenzial (RMP). Die permanent aktive Natrium-Kalium-ATPase einer jeden Zelle entfernt unter Spaltung von Adenosintriphosphat pro Arbeitsdurchlauf drei Natriumionen aus dem Zellinneren und nimmt im Gegenzug zwei Kaliumionen aus dem Extrazellulärraum in die Zelle auf. Kalium wird initial intrazellulär angereichert. Der entstehende, nach außen gerichtete, Konzentrationsgradient führt zur Diffusion von Kaliumionen über offene, Kaliumselektive Ionenkanäle in den Extrazellulärraum. Der resultierende Nettoverlust an positiven Ladungen im Intrazellulärraum führt zu dessen Polarisation. In Folge dieser zunehmenden Polarisation werden positiv geladenen Kaliumionen elektrostatisch ins Zellinnere zurückgezogen, wodurch sich ein Fließgleichgewicht zwischen chemischen und elektrischen Fließgradienten ausbildet. Der Nettoionenfluss ist gleich Null, gemäß der Nernst'schen Gleichung stellt sich das Gleichgewichtspotenzial für Kaliumionen von ca. -90 mV ein. Das RMP einer Zelle ergibt sich als Mischpotenzial der Gleichgewichtspotenziale aller beteiligten Ionen. Je nach Zellpopulation (Neuronen, Skelettmuskelzellen, Herzmuskelzellen) differieren die Konzentrationen sowie die Membranpermeabilitäten für die beteiligten Ionen, sodass sich das RMP von Population zu Population unterscheidet. Die näherungsweise Berechnung erfolgt mit der Goldmann-Hodgkin-Katz-Gleichung (vgl. Hille 1992).

\subsubsection{Aktionspotenziale}

Membranabschnitte erregbarer Zellen können durch eintreffende Signale über Zell-ZellKanäle (Gap Junctions), synaptische Potenziale, Ladungsverschiebungen in benachbarten Membranbezirken und durch Signaltransduktion im Bereich der Sinneszellen aktiviert werden. Diese Signale führen zu Veränderungen der Membranpermeabilitäten, die eine Fortleitung von Informationen innerhalb eines Organismus ermöglichen.

Die schnelle Fortleitung von Informationen wird durch Veränderung der Natrium-, und Kaliumpermeabilität, ausgehend vom RMP, durch die Bildung von Aktionspotenzialen 
(AP) ermöglicht. Informationen werden hierbei durch die Frequenz der stereotyp verlaufenden APs codiert. Die Dauer eines AP unterscheidet sich aufgrund unterschiedlicher Expression beteiligter Ionenkanäle zwischen verschiedenen Zellpopulationen. Im Arbeitsmyokard, in Abhängigkeit der Herzfrequenz, dauert ein AP bis zu 400 ms, in der Skelettmuskulatur in etwa $20 \mathrm{~ms}$ und in Neuronen lediglich 1-2 ms.

Die folgende Beschreibung bezieht sich auf die Entstehung von APs, die ausgehend vom Axonhügel entlang des Axons orthograd in Richtung der synaptischen Endknöpfchen eines Neurons laufen. Eintreffende Erregungen führen zur Aktivierung spannungsabhängiger Natriumkanäle in der Plasmamembran. Das RMP verschiebt sich durch den initial langsamen Natriumeinstrom in Richtung - 45 mV. Gemäß des „Alles-oder-nichts-Prinzip“ erfolgt die Bildung eines AP nur bei Erreichen dieses Schwellenpotenzials (Adrian 1914). Zahlreiche Natriumkanäle werden zu diesem Zeitpunkt aktiviert, es kommt zum lawinenartigen Einstrom von Natriumionen in die Zelle. Innerhalb von weniger als einer Millisekunde wird das Membranpotenzial auf das Spitzenpotenzial von ca. $+30 \mathrm{mV}$ depolarisiert. Die spannungsabhängigen Natriumkanäle werden beim Erreichen des Spitzenpotenzials inaktiviert, während Kaliumkanäle spannungsabhängig aktiviert werden. Der resultierende Ausstrom von Kaliumionen aus dem Intrazellulärraum leitet die Repolarisation des Membranpotenzials ein. Die erhöhte Membranleitfähigkeit für Kaliumionen bleibt auch nach vollständiger Repolarisation der Zelle erhalten, so dass es zu einer leichten Hyperpolarisation des RMP kommt. Nach Ablauf des AP, bei ausbleibender erneuter Depolarisation der Zelle, stellt sich erneut das RMP ein (vgl. Hille 1992). Nach einem AP bleiben die spannungsabhängigen Natriumkanäle einige Millisekunden vollständig inaktiviert. In dieser absoluten Refraktärzeit ist die Zelle, beziehungsweise der zuvor aktivierte Membranbezirk nicht erregbar. Unabhängig von der Stärke neu eintreffender Erregungen können keine APs gebildet werden. Im Verlauf der Repolarisation erfolgt die schrittweise Reaktivierung der schnellen Natriumkanäle. In dieser relativen Refraktärzeit werden zur Auslösung eines AP höhere Reizstärken benötigt. Durch die Refraktärität wird die Ausbreitungsrichtung von Signalen entlang eines Axons und die maximale Frequenz der Aktionspotenzialbildung in Abhängigkeit der Zusammensetzung der beteiligten Ionenkanäle für jeden Neuronentyp festgelegt (vgl. Barnett und Larkman 2007). Abbildung 2 verdeutlicht die physiologischen Vorgänge während eines APs. 


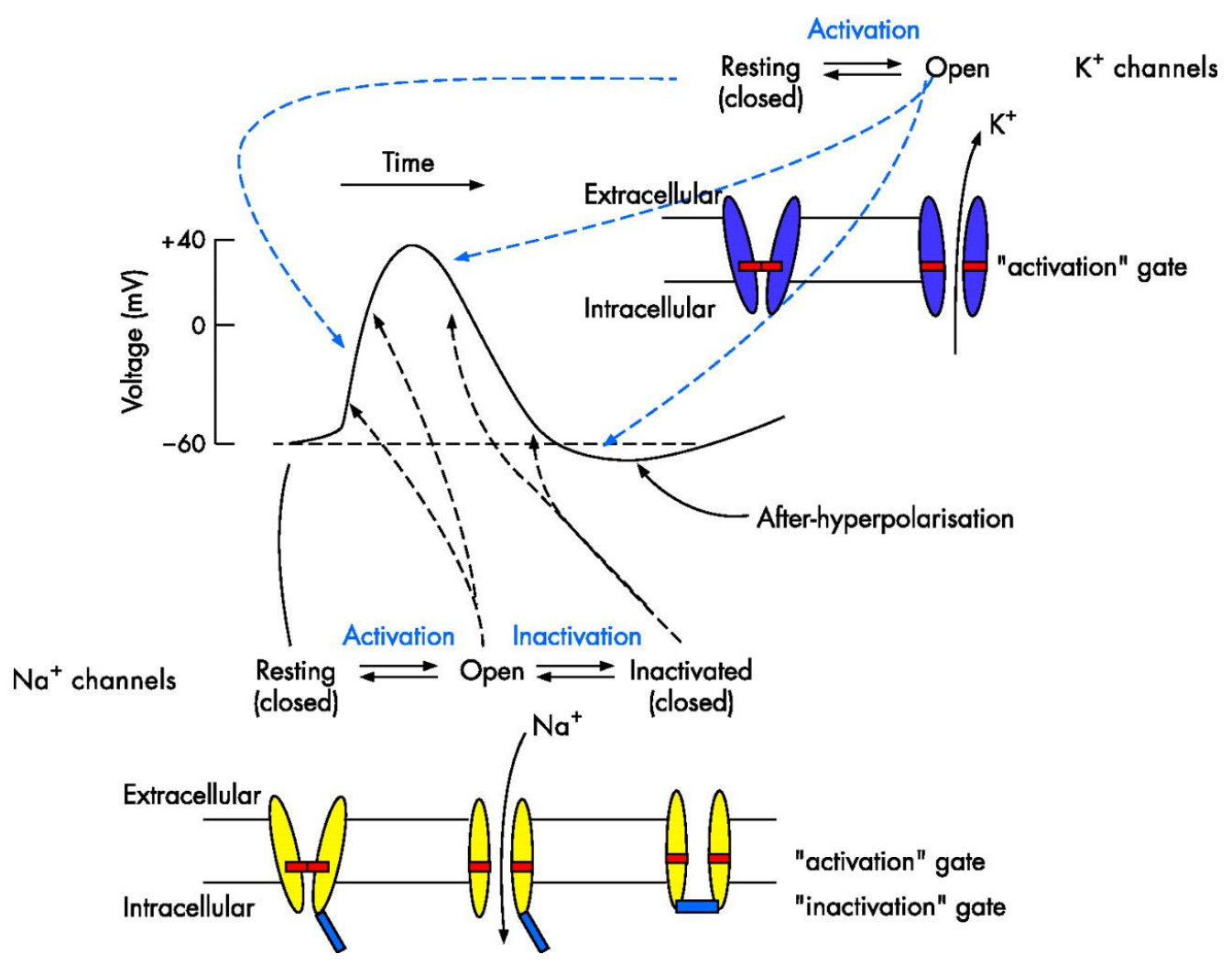

\section{Abbildung 2: Schematische Darstellung intrazellulärer Spannungsverhältnisse und Aktivitätszustände beteiligter Ionenkanäle während eines Aktionspotenzials.}

Die gestrichelte Schwarze Linie stellt das Ruhemembranpotenzial dar und setzt die Spannungsänderungen (durchgängige schwarze Linie) hierzu in Bezug. Die Pfeile demonstrieren den $\mathrm{Zu}-$ stand des entsprechenden Ionenkanals während einer bestimmten Phase des Aktionspotenzials (entnommen und modifiziert nach Barnett und Larkman 2007). Die Verwendung erfolgt mit freundlicher Genehmigung der BMJ Publishing Group Ltd.

\subsubsection{Signalfortleitung}

Die passive Ausbreitung einer Depolarisation von einem erregten Membranbezirk auf benachbarte, nicht erregte Abschnitte der Plasmamembran mittels lokaler Stromkreise ist der Auslöser für die elektrische Fortleitung von Reizen (Hodgkin 1937). Erregungen werden in nicht myelinisierten Membranabschnitten elektrotonisch fortgeleitet. Hierbei kommt es zu kontinuierlichen, langsam ablaufenden Umladungen benachbarter Membranbezirke durch zuvor erregte Bereiche. Die Reizamplitude nimmt durch Leckströme, sowie den elektrischen Widerstand schnell ab. Diese Art der Signalfortleitung findet man beispielsweise bei der Signalfortleitung über die Zellkörpermembran eines Neurons oder in den Axonen der äußeren Retinaschichten. Gliazellen bilden im zentralen-, und peripheren Nervensystem Myelinscheiden um Axone, die diese Leckströme, sowie die 
elektrische Kapazität der Axone vermindern und somit eine schnellere, regenerative Erregungsausbreitung ermöglichen. Durch zahlreich vorhandene Natrium- und Kaliumkanäle im Bereich der nicht myelinisierten Ranvier'schen-Schnürringe werden hierbei, bei Erreichen des Schwellenpotenzials, erneut APs hervorgerufen. Die Signalfortleitung entlang der Axone der meisten Nerven erfolgt so mittels regenerativer, saltatorischer Erregungsausbreitung, bei der die Erregung die durch Myelin isolierten Axonabschnitte mit hoher Geschwindigkeit überspringt (vgl. Hille 1992).

\subsubsection{Synaptische Übertragung}

In der Präsynapse eintreffende APs führen zur Depolarisation der präsynaptischen Membran. Der hierdurch bedingte erhöhte Calciumeinstrom führt zu gesteigerter synaptischer Aktivität (Katz und Miledi 1969). Es kommt zur Fusion synaptischer Vesikel mit der präsynaptischen Membran (Heuser und Reese 1981). Der, durch spannungsabhängige Calciumkanäle vermittelte, Ioneneinstrom initiiert Priming, Docking und Exozytose der Neurotransmitter der synaptischen Vesikel (Neher und Sakaba 2008) unter Beteiligung des Soluble N-Ethylmaleimide-Sensitive-Factor Attachment Receptor (SNARE) Komplexes (Hanson et al. 1997). Die freigegebenen Transmitter diffundieren über den synaptischen Spalt zu den Neurotransmitterrezeptoren an der postsynaptischen Membran und rufen dort spezifische Reaktionen hervor. Die Neurotransmitterexozytose erfolgt im Bereich der aktiven Zone, die hiermit einhergehende Endozytose von Vesikelprotein findet in der umgebenden periaktiven Zone statt (Haucke et al. 2011). Während die präsynaptische Membran repolarisiert und Bestandteile der fusionierten Vesikel endozytotisch wieder aufgenommen werden, steigt in Abhängigkeit der aktivierten Rezeptorpopulation die Permeabilität der postsynaptischen Membran für bestimmte Ionensorten. Hieraus resultieren erregende postsynaptische Potenziale oder inhibierende postsynaptische Potenziale. Alle, auf ein Neuron einwirkenden Reize werden elektrotonisch an dessen Axonhügel weitergeleitet und dort erneut miteinander verrechnet. Die Gesamtheit, der auf ein Neuron einwirkenden Reize wird am Axonhügel summiert, reicht diese summierte Erregung zum Erreichen des Schwellenpotenzials aus, werden erneut APs generiert, die über das Axon weitergeleitet werden. Bleibt die summierte Erregung jedoch unterschwellig, entstehen gemäß des Alles-oder-nichts Prinzips keine neuen APs (Adrian 1914). Der gesamte Prozess, von der Entstehung präsynaptischer APs, über die synaptische Übertragung, bis zur Auslösung postsynaptischer APs dauert lediglich ungefähr 1,3 ms (Südhof 2012a). 


\subsubsection{Synaptische Plastizität}

Synapsen adaptieren stetig hinsichtlich ihrer Aktivität und führen so zur Reorganisation ganzer neuronaler Kreisläufe. Dieser Prozess wird durch Erfahrungen, Aktivitäten oder auch psychoaktive Substanzen beeinflusst (Citri und Malenka 2008). Die Synaptische Plastizität unterteilt sich in die Mechanismen der Kurzzeitplastizität (Zucker und Regehr 2002) und der Langzeitplastizität (Bliss und Lømo 1973). Hierdurch kommt es zu Abschwächungen (Langzeitdepressionen) und Verstärkungen (Langzeitpotenzierung) synaptischer Verbindungen. Mechanismen der Langzeitpotenzierung scheinen im direkten Zusammenhang mit der Gedächtnisbildung sowie der Lernfunktion zu stehen (Martin et al. 2000; Whitlock et al. 2006). Die molekulare Organisation dieser Mechanismen ist aktuell Gegenstand der Forschung.

\subsection{Synaptische Vesikel}

\subsubsection{Aufbau Synaptischer Vesikel und Neurotransmitterbefüllung}

Chemische Synapsen setzen ihren Neurotransmitter per Exozytose aus kleinen Speicherorganellen frei, den Synaptischen Vesikeln. Sie liegen konzentriert in den präsynaptischen Endknöpfchen eines jeden Neurons vor. In die Präsynapse einlaufende Aktionspotenziale initiieren ihre calciumabhängige Exozytose mit Freigabe des Neurotransmitters in den synaptischen Spalt. Nach erfolgter Exozytose erfolgt die lokale Wiederverwertung vesikulärer Bestandteile. Takamori und Kollegen konnten mir Ihren Arbeiten den molekularen Aufbau synaptischer Vesikel zeigen. Die Plasmamembran eines synaptischen Vesikels besteht aus 5600 bis 7000 Phospholipiden und Cholesterinmolekülen, die mit bis zu 410 verschiedenen Proteinen assoziiert sind. Transmembranproteine nehmen hierbei bis zu $25 \%$ des Membranvolumens ein (Takamori et al. 2006). Hinsichtlich ihrer Morphologie, Größe und Vorkommen spezifischer Hauptproteine sind synaptische Vesikel homogen aufgebaut. Der gemittelte Durchmesser eines synaptischen Vesikels beträgt ca. 42 nm (Harris und Sultan 1995; Takamori et al. 2006). Gemäß Jahn und Südhof ist eine grobe Einteilung der vesikulären Proteine in integrale Membranproteine und peripher verankerte Proteine möglich. Integrale Membranproteine sind permanent vorhanden, während Oberflächenproteine möglicherweise lediglich zu einem bestimmten Zeitintervall, zur Regulation des Vesikelzyklus mit der Vesikeloberfläche assoziiert sind (Jahn und Südhof 1994). 
Eine solche stetige Beeinflussung durch zytoplasmatische Faktoren könnte die variierende stöchiometrische Proteinzusammensetzung verschiedener Vesikel erklären. Auch substanzielle Variationen hinsichtlich Proteinmenge und Frequenz zwischen Neuronen bzw. einzelnen Vesikeln sind nicht auszuschließen. Die häufigsten vesikulären Proteine sind Synaptobrevin 2, Synaptophysin, Synaptogamin 1 und Synapsin 1 (Takamori et al. 2006). Verschiedene Isoformen dieser Proteine findet man in Abhängigkeit der Lokalisation im zentralen Nervensystem auf allen synaptischen Vesikeln (Jahn und Südhof 1994). Fünf Hauptproteine scheinen für die Vesikelfunktion benötigt zu werden. Das SNAREProtein Synaptobrevin beteiligt sich an der Membranfusion, Synaptogamin detektiert Calciumionen, ein spezifischer Neurotransmittertransporter befüllt den synaptischen Vesikel (Rizzoli 2014), das Vesikelprotein 2a beteiligt sich vermutlich an der Fusion und der anschließenden Freigabe von Neurotransmittern (Wan et al. 2010) während Synaptophysin, bei weitestgehend unbekannter Funktion, unter anderem Funktionen bei der Endozytose synaptischer Vesikel übernehmen könnte (Kwon und Chapman 2011; siehe Abschnitt 1.4.3). Ein Durchschnittsvesikel besteht, gemäß den Untersuchungen von Takamori und Kollegen, hinsichtlich der häufigsten Isoformen aus 70 Synaptobrevinen, 32 Synapthophysinen, zwischen 9 und 14 Neurotransmittertransportern, 10 Rab3As, 8 Synapsinen und 15 Synaptogamin 1. Die tatsächliche Proteinanzahl liegt vermutlich höher (Takamori et al. 2006). Neurotransmitter werden vom präsynaptischen Neuron synthetisiert und durch begrenzt spezifischen, sekundär aktiven Transport in die synaptischen Vesikel eingelagert. Die hierfür aufgewendete Energie wird durch eine, nach Interaktion mit Synaptophysin und Synaptobrevin (Galli et al. 1996) in die Vesikelmembran eingelagerte Protonen-ATPase (V-ATPase) bereitgestellt (Moriyama et al. 1992; Morel 2003; Saroussi und Nelson 2009). Die Tätigkeit der V-ATPase führt zu einem Protonenkonzentrationsgefälle, das spezifischen Neurotransmitterrezeptoren die Befüllung synaptischer Vesikel mit Neurotransmittern durch Mechanismen wie beispielsweise Antiport ermöglicht (Edwards 2007). Eine zusätzliche Beteiligung der V-ATPase bei der Vesikelexozytose wird vermutet (Di Giovanni et al. 2010). Ein Vesikel besitzt laut Takamori und Kollegen ungefähr 10 Kopien einer der beiden Isoformen des vesikulären Glutamattransporters (VGLUT), die Anzahl an anderen Neurotransmittertransportern der entsprechenden Vesikel verhält sich vermutlich ähnlich. Die V-ATPase scheint mit durchschnittlich weniger als zwei Kopien pro Vesikel, im Gegensatz zu anderen funktionstragenden Proteinen, in relativ geringer Dichte vorzuliegen (Takamori et al. 2006). 
Eine vollständige Vesikelbefüllung kann jedoch bereits durch einen Transporter gewährleistet werden (Daniels et al. 2006). Die Transportraten sind nicht bekannt, jedoch würde bereits eine geringe Rate von zehn Molekülen pro Sekunde ausreichen, um unter Hochaktivitätsbedingungen eine ausreichende Vesikelbefüllung zu erreichen (Takamori et al. 2006). Vesikel, die vollständig mit ihrem Transmitter befüllt wurden, werden erst nach erfolgter Transmitterfreisetzung erneut mit Transmittern befüllt (Van der Kloot 2003). Die im zentralen Nervensystem dominierenden Neurotransmitter sind $\gamma$-Aminobuttersäure (GABA), L-Glutamat und Glycin. Weitere Neurotransmitter sind Acetylcholin, die Katecholamine Adrenalin, Noradrenalin und Dopamin sowie die Monoamine Histamin und Serotonin (Hille 1992). Abbildung 3 stellt den durchschnittlichen molekularen Aufbau eines synaptischen Vesikels dar.

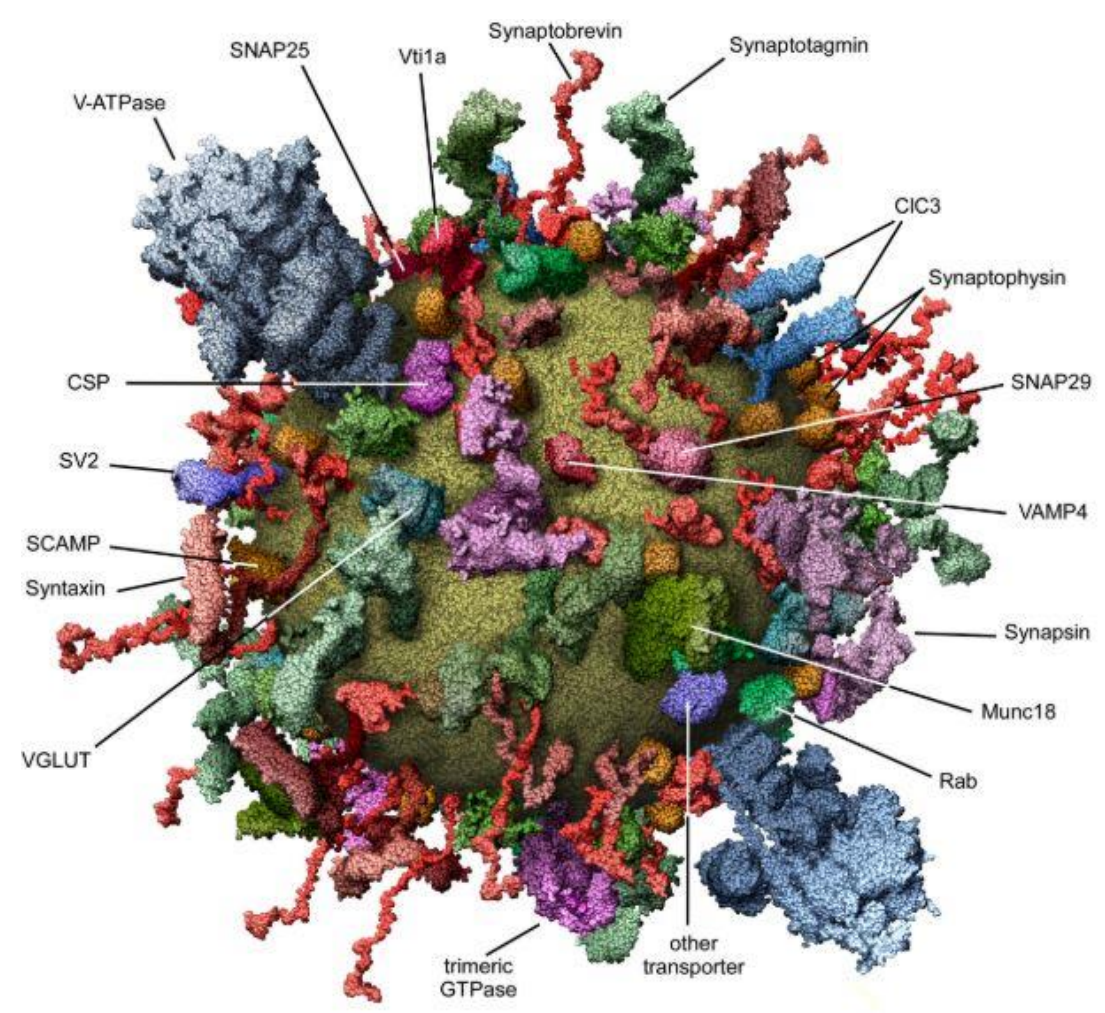

\section{Abbildung 3: Durchschnittliche Proteinzusammensetzung eines synaptischen Vesi- kels im dreidimensionalen Modell.}

Die Proteinzusammensetzung synaptischer Vesikel varriiert im Laufe des Vesikelzyklus. Bestimmte Hauptproteine sind für die Funktion des Vesikels essenziell (entnommen und modifiziert nach Takamori et al. 2006). Die Verwendung erfolgt mit freundlicher Genehmigung des Elsevier Verlages. 


\subsubsection{Vesikelzyklus}

Synaptische Vesikelproteine werden durch das endoplasmatische Retikulum im Zellkörper eines Neurons translatiert und anschließend an den Golgi-Apparat weitergegeben. Gemäß den Ausführungen von Rizzoli und Kollegen erfolgt die Produktion der zur Bildung synaptischer Vesikel benötigten Proteine unkoordiniert, sodass sich neu produzierte Proteine nicht in den korrekten stöchiometrischen Verhältnissen im Golgi-Apparat zusammenfinden. Die Bildung unausgereifter Vesikelvorstufen erscheint somit wahrscheinlich (Rizzoli 2014). Bestimmte Domänen dieser Vesikelvorläufer könnten die abschließende Reifung durch Ein-, und Auslagerung einzelner Proteine im Bereich der Präsynapse kontrollieren (Pennuto et al. 2003). Nach einer möglichen endosomalen Fusion erfolgt der axonale Transport synaptischer Vesikelproteine in den Vesikelvorstufen entlang von Mikrotubuli im Cotransport mit weiteren synaptischen Proteinen wie beispielsweise Bausteinen der aktiven Zonen (Ahmari et al. 2000; Wu YE et al. 2013). Der Transport verschiedener synaptischer Proteine erfolgt hierbei mit unterschiedlicher Geschwindigkeit (Li und Dahlström 1997), wodurch sich eine Vielzahl an zugrunde liegender Transportmechanismen vermuten lässt.

Gemäß der Ausführungen zum Ablauf des Vesikelzyklus von Rizzoli und Kollegen erfolgt nach Ankunft im präsynaptischen Endknöpfchen durch Fusion der Vesikelvorläufer mit bestimmten Membranbezirken die Reifung der Vesikel. Nach möglicherweise erneuter Fusion mit Endosomen werden die Vesikel mit ihrem Transmitter befüllt und verbleiben im Anschluss entweder mobil, docken an die aktiven Zonen an oder werden in das Vesikelcluster als Reservevesikel integriert. Im Zuge der synaptischen Übertragung kommt es durch Fusion der Vesikel mit der Membran der aktiven Zonen zur Transmitterfreigabe, der anschließenden Endozytose ihrer Bestandteile sowie deren Wiederverwertung beziehungsweise zur Aussortierung alter Vesikelbestandteile. Der Vesikelzyklus muss einer der bestkontrollierten Mechanismen der Biologie sein. Fehler könnten mit letalen Folgen einhergehen. Diese regulierenden Mechanismen, die eine zeitlich und räumlich aufeinander abgestimmte Zusammenlagerung aller Reaktionspartner garantieren sind aktuell Gegenstand der Forschung (Rizzoli 2014). 


\subsubsection{Präsynaptische Vesikelpopulationen}

Die Gesamtheit aller Vesikel eines synaptischen Endknöpfchens lässt sich vereinfacht in drei verschiedene funktionelle Gruppen unterteilen. Vesikel des readily releasable pool bilden ca. $1 \%$ der gesamten Vesikelpopulation ab, sie sind im Ruhezustand häufig an die aktive Zone angedockt und stehen zu $90 \%$ bei eintreffender neuronaler Stimulation direkt zur Exozytose bereit (Schikorski und Stevens 2001). Gemäß den Ausführungen von Rizzoli und Betz machen Vesikel des recycling pool 10 - $15 \%$ der Vesikelpopulation aus und werden leicht verzögert, bei moderater Stimulation, freigesetzt. Vesikel, die sich im reserve pool befinden machen 80 - $90 \%$ aller synaptischen Vesikel aus, werden jedoch nur bei sehr starker, häufig unphysiologischer Stimulation, der Exozytose zugeführt. Vesikel des reserve pool unterscheiden sich hinsichtlich ihrer Endozytosemechanismen im Zuge des Vesikelrecyclings sowie ihrer Mobilität von den aktiv recycelten Vesikeln (Rizzoli und Betz 2005). Eine Beteiligung dieser Vesikel, an der synaptischen Übertragung in vivo, ist nicht abschließend geklärt (Denker und Rizzoli 2010). Der reserve pool könnte, anstatt primär sekretorische Aufgaben zu übernehmen, als Depot für Neurotransmittermoleküle dienen (Rizzoli und Betz 2005) oder aber, laut Rizzoli, als Puffer für, im Zuge des Vesikelrecyclings verwendete Proteine wie beispielsweise Clathrin dienen und so das Vorhandensein benötigter Faktoren der synaptischen Übertragung sowie des Vesikelrecyclings innerhalb der Synapse garantieren. Weiterhin denkbar ist eine Beteiligung des reserve pool an der spontanen Fusion synaptischer Vesikel (Rizzoli 2014; siehe letzter Absatz Abschnitt 1.3.4). Die strikte morphologische und funktionelle Dreiteilung der Vesikelgruppen scheint unter physiologischen Bedingungen nicht der Realität zu entsprechen (Denker und Rizzoli 2010). Die gesamte Vesikelpopulation unterteilt sich laut Truckenbrodt und Kollegen möglicherweise in rein spontan fusionierende constitutively releasing vesicles und Vesikel die sowohl spontan als auch reizabhängig fusionieren. Die dieser Unterscheidung zugrunde liegenden Mechanismen sind jedoch nicht ausreichend erforscht (Truckenbrodt und Rizzoli 2014). In motorischen Endplatten von Fröschen konnten im Bereich der aktiven Zone angedockte Vesikel beobachtet werden, die bei physiologischer Stimulation nicht fusionieren (Rizzoli und Betz 2004). Hierbei könnte es sich um Vesikel des reserve pool handeln, die nur gelegentlich fusionieren (Kamin et al. 2010).

Denker und Rizzoli stellten ein Modell vor, in dem der recycling pool sich in vivo in zusätzliche Subpopulationen aufteilen könnte. Einige dieser Vesikel werden nicht direkt nach erfolgter Exozytose endozytiert, sondern verharren auf der Membranoberfläche und 
werden erst nach erneuter Stimulation abschließend aufgenommen. Die Funktion dieses surface pool bedarf weiterer Forschung (Denker und Rizzoli 2010). Frühe Studien konnten außerdem eine Vermischung von Vesikeln zwischen den drei Vesikelgruppen im Zuge des Vesikelrecyclings nachweisen (Richards et al. 2000) und veranschaulichen, dass die Wiederherstellung der direkt zur Exozytose bereiten Vesikel in Abhängigkeit der Wiederbefüllung der größeren Population der recycelnden Vesikel geschieht. Diese Erkenntnisse legen nahe, dass der readily releasable pool lediglich eine Subpopulation des recycling pool darstellt (Richards et al. 2003). Weiterhin erscheint auch die strikte Trennung zwischen recycling pool und reserve pool in vivo nicht existent zu sein. Vermischungen der Vesikel beider Gruppen finden ebenfalls statt, sodass sich Vesikel möglicherweise lediglich hinsichtlich ihrer Mobilität zu einem bestimmten Zeitpunkt unterscheiden lassen. Vesikel des recycling pool sind hochmobil, die des reserve pool durch mögliche Interaktion mit Gerüstproteinen nicht (Denker und Rizzoli 2010). Denker und Rizzoli äußerten die Vermutung, dass ein Vesikel in Abhängigkeit seiner aktuellen Mobilität sowohl dem recycling pool als auch dem reserve pool angehören. Durch variierende synaptische Aktivität könnten sowohl die Rekrutierung eines Reservesikels zu einem recycelnden Vesikel (Lee et al. 2012) als auch die Umwandlung eines aktiv recycelnden Vesikels zu einem Reservevesikel stattfinden. So könnten zuvor durch Reifung in den reserve pool aufgenommene Vesikel des recycling pool aktiv ersetzt werden. Diese Statusveränderung erfolgt anscheinend nach Durchlaufen eines Exo-, und Endozytosezyklus mit anschließender Reformierung des Vesikels. Die Zugehörigkeit zum reserve pool stellt möglicherweise den letzten Schritt im Zyklus zwischen Endozytose und erneuter Exozytose eines Vesikels dar (Denker und Rizzoli 2010). Die Regulierung der Mobilität eines synaptischen Vesikels scheint unter Beteiligung der Proteine Synapsin und Aktin zu erfolgen (Pieribone et al. 1995; Bloom et al. 2003), wobei Synapsin vergleichbar zu einem Kleber, durch Ausbildung von Querverbindungen zwischen Vesikeln, zu Mobilitätseinschränkungen führt (Kamin et al. 2010). Ein durchschnittlicher synaptischer Vesikel bindet acht Synapsinmoleküle (Takamori et al. 2006).

Dieser Wert variiert, gemäß den Studien von Kamin und Kollegen, jedoch in Abhängigkeit des Vesikelstatus während des Vesikelrecyclings. Vesikel verbleiben nach abgeschlossener Endozytose entweder mobil und somit zur erneuten Fusion geeignet oder gehen bei zunehmendem Mobilitätsverlust in den reserve pool über. Die Mobilität bleibt erhalten, solang der Vesikel synapsinfrei bleibt, beziehungsweise wenige Synapsinmoleküle gebunden wurden. Diese Mobilität geht innerhalb von Minuten bis Stunden nach 
Endozytose verloren. Dieser Vorgang könnte der weiter oben beschriebenen Reifung recycelnder Vesikel zu Reservevesikeln entsprechen (Kamin et al. 2010).

Die vereinfachte Unterteilung der Vesikelpopulation in verschiedene Gruppen beschränkt sich nicht nur auf einzelne Präsynapsen (Denker und Rizzoli 2010; Alabi und Tsien 2012). Es erfolgt ein Austausch synaptischer Vesikel zwischen verschiedenen Präsynapsen (Darcy et al. 2006). Sowohl die immobilen Reservevesikel als auch die mobilen, aktiv recycelnden Vesikel scheinen diesem Austausch zu unterliegen (Fernandez-Alfonso und Ryan 2008; Kamin et al. 2010). Dieser superpool an Vesikeln, der sich über zahlreiche präsynaptische Endigungen erstreckt, konnte in kultivierten Zellen (Krueger et al. 2003), Schnittpräparaten des Hippocampus (Staras et al. 2010) und in vivo (Herzog et al. 2011) nachgewiesen werden. Ungefähr $4 \%$ aller präsynaptischen Vesikel, scheinen, gemäß den Ausführungen von Staras und Kollegen, dem superpool anzugehören, wobei vor allem Vesikel des recycling pool zwischen den Präsynapsen ausgetauscht werden. Diese Vesikel scheinen bei neuronaler Stimulation eine Erweiterung des, in einer bestimmten Präsynapse vorliegenden, recycling pool darzustellen. Sie könnten große Bedeutung für die physiologische präsynaptische Funktion in ganzen neuronalen Kreisläufen haben (Staras et al. 2010) und sich durch Pansynaptische Umverteilung an der Regulation der synaptischen Plastizität beteiligen (Herzog et al. 2011).

\subsubsection{Vesikelfusion}

Das Andocken synaptischer Vesikel, im Bereich der aktiven Zonen, ihre Aktivierung sowie die Steuerung der Transmitterexozytose sind hochkomplexe Prozesse, die durch zahlreiche Proteininteraktionen gesteuert werden (Wang et al. 2009). Proteine des SNAREKomplexes liegen in diesen Membranabschnitten gruppiert, in erhöhter Konzentration vor, wodurch die aktiven Zonen als bevorzugte Bereiche zum Andocken und zur Exozytose synaptischer Vesikel definiert werden (Lang et al. 2001). Multidomänenproteine auf der intrazellulären Plasmamembran der aktiven Zone vermitteln die schnell ablaufende Vesikelfusion nach Calciumeinstrom. Diese Proteine werden als Cytomatrix der präsynaptischen aktiven Zone bezeichnet (Mittelstaedt und Alvarez-Baron 2008). Synaptogamin und Complexin regulieren die calciumvermittelte Auslösung der Vesikelfusion (Jahn und Fasshauer 2012). Zahlreiche weitere Proteine, wie beispielsweise Snapin, scheinen sich ebenfalls an der initialen Steuerung und Regulierung der Vesikelfusion zu beteiligen (Pan et al. 2009). Ein mobiler synaptischer Vesikel dockt zunächst in enger räumlicher Lagebeziehung zu Calciumkanälen im Bereich der aktiven Zone an. Hierdurch wird eine 
optimale Reaktion, auf bei Erregung einströmendes Calcium ermöglicht (Rizzoli 2014). Das Andocken der Vesikel wird vermutlich durch Interaktion mit Rab3 bindenden Molekülen (RIM) und RIM-bindenden Proteinen vermittelt (Liu et al. 2011). Weiterhin beteiligte Proteine sind beispielsweise Bassoon (Hallermann et al. 2010; siehe Abschnitt 1.4.4), dass hierbei möglicherweise mit Piccolo interagiert (Fenster et al. 2000) sowie verschiedene SNARE Proteine (Walter et al. 2010). Der gesamte Prozess ist hochkomplex und findet wahrscheinlich unter Beteiligung zahlreicher weiterer Moleküle statt (Harlow et al. 2001; Nagwaney et al. 2009; Szule et al. 2012). Gemäß den Ausführungen von Jahn und Scheller erfolgt, nachdem ein Vesikel an der aktiven Zone angedockt (Docking) hat, die Aktivierung des Exozytoseapparates (Priming) und die Fusion der vesikulären und präsynaptischen Plasmamembranen zur Freigabe des Neurotransmitters in den synaptischen Spalt. Entscheidend hierfür ist die Ausbildung eines Komplexes zwischen Proteinen der Membranen der aktiven Zone und des Vesikels. Dieser Vorgang wird durch den SNARE-Komplex ermöglicht (Jahn und Scheller 2006). Der SNARE-Komplex besteht aus den Proteinen Syntaxin, Synaptosomal-Associated Protein of 25 kDa (SNAP25) und Synaptobrevin (Hanson et al. 1997; Sutton et al. 1998). Die Funktion des SNAP25 wird im Abschnitt 1.4.7 detailliert beschrieben.

Synaptogamin bindet zunächst vier Calciumionen und hebt nach anschließender Konformationsänderung die sterische Blockade des SNARE-Komplexes durch Complexin auf, wodurch die Zusammenlagerung des SNARE-Komplexes ermöglicht wird (Tang et al. 2006). Der entstehende, bis in die Membranen reichende, trans-SNARE-Komplex nähert die beteiligten Membranen aneinander an, sodass es letztendlich zu deren Verbindung kommt (Lou und Shin 2016). Die Fusion der Membranen durch Lipidaustausch wird erst möglich, wenn die Lipiddoppelschichten auf ca. $1 \mathrm{~nm}$ aneinander angenähert wurden (Risselada und Grubmüller 2012). Die stabile Doppellipidstruktur der Membranen sowie gegenseitige Abstoßungsreaktionen durch polare Gruppen auf den Membranaußenseiten bedingen hierbei einen hohen Energieaufwand (Martens et al. 2007).

In diesem Zusammenhang wird eine destabilisierende Interaktion von Synaptogamin mit vesikulären und präsynaptischen Membranabschnitten diskutiert, die letztendlich deren Fusion ermöglichen (Martens et al. 2007; Chapman 2008). Die Aktivität der SNAREProteine wird hierbei vermutlich durch Bindung von Proteinen der SM-Proteinfamilie gesteuert (Südhof und Rothman 2009). 
Die synaptischen Proteine Munc13 (Aravamudan et al. 1999; Richmond et al. 1999, S. 13; Imig et al. 2014) und Munc18 (Burkhardt et al. 2008) beteiligen sich an der initialen Zusammenlagerung der SNARE-Proteine (Jahn und Fasshauer 2012). Sie beeinflussen die Vesikelfusion möglicherweise durch Bindung von Syntaxin 1, das so in einer Konformation gehalten wird, die eine Zusammenlagerung des SNARE-Komplexes begünstigt (Ma et al. 2013). Hierbei scheint nicht nur die Anwesenheit, sondern auch die Position von Munc13 bezüglich der Calciumeintrittsstellen im Bereich der aktiven Zone eine Rolle zu spielen (Zhou et al. 2013). Bei der Vesikelfusion unterscheidet man die Mechanismen der vollständigen Fusion mit der präsynaptischen Membran von der teilweisen Fusion im Sinne des Kiss-and-run-Konzepts (Gan und Watanabe 2018). Hierbei werden die Neurotransmitter durch eine Fusionspore freigegeben, die im Anschluss wieder abgeschnürt wird (Fesce et al. 1994). Obwohl die Existenz einer unvollständigen Vesikelfusion seit langem bekannt ist (Heuser et al. 1979) und Hinweise vorliegen, dass Kiss-and-run eine tragende Rolle für die Funktion des Nervensystems übernehmen könnte (Alabi und Tsien 2013), bleibt das Konzept umstritten (Granseth et al. 2009). Nach abgeschlossener Fusion beginnt die Zerlegung und Wiederverwertung der an der Fusion beteiligten Faktoren. Die Bestandteile der SNARE-Komplexe werden voneinander gelöst und aus dem Exozytosebereich entfernt, um einer erneuten Verwendung zur Verfügung zu stehen. Dies geschieht durch die Tätigkeit der ATPase NSF ( $N$-ethylmaleimide-sensitive factor) und ihrem Adapterprotein $\alpha$-SNAP ( $\alpha$-soluble NSF attachment protein) (Söllner et al. 1993a; Burgalossi et al. 2010). Bausteine der exozytierten synaptischen Vesikel werden im Rahmen des Vesikelrecyclings wiederaufgenommen (siehe Abschnitt 1.3.5). Die Neurotransmitterfreigabe durch Exozytose erfolgt nicht nur bei neuronaler Stimulation, sondern auch spontan (Fatt und Katz 1952; del Castillo und Katz 1954). Dieser Vorgang erfolgt im Gegensatz zur aktionspotenzialvermittelten Exozytose nicht ausschließlich in Abhängigkeit von Calciumionen, so dass Initiation der Fusion einiger Vesikel vermutlich auf abweichenden, synaptogaminunabhängigen, molekularen Mechanismen beruht (Truckenbrodt und Rizzoli 2014). 
Die spontane Vesikelfusion könnte eine tragende Rolle bei der Entwicklung (Saitoe et al. 2001), Reifung (Choi et al. 2014) und Aufrechterhaltung synaptischer Strukturen spielen (McKinney et al. 1999; Sutton et al. 2006). Truckenbrodt und Rizzoli vermuten, dass synaptische Vesikel zu frühen Zeitpunkten ihres Lebenszyklus gehäuft spontan fusionieren und diese Eigenschaft durch Verlust, beziehungsweise Austausch, bestimmter molekularer Strukturen, im Zuge ihrer Entwicklung zunehmend ablegen. Diese Vesikel könnten so zur Ausbildung synaptischer Strukturen beitragen und durch schrittweise Anpassung ihres Aufbaus zu Vesikeln reifen, die auf neuronale Stimulation reagieren können. Sich so entwickelnde Vesikel könnten in ausgereiften Synapsen sowohl den nur spontan fusionierenden constitutively releasing vesicles angehören oder aber auch synaptische Vesikel darstellen, die zusätzlich zur regulären Fusion nach neuronaler Stimulation der Spontanfusion, in Abhängigkeit aktionspotenzialunabhängiger Calciumfluktuationen, unterliegen (Truckenbrodt und Rizzoli 2014). Abbildung 4 verdeutlicht schematisch die Zusammensetzung und Funktion des SNARE-Komplexes.

$a$

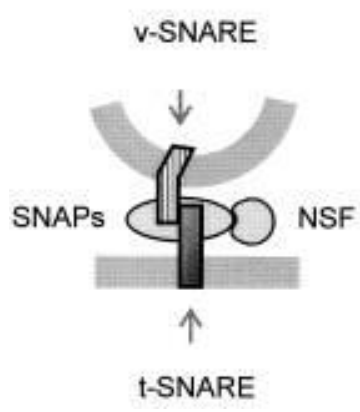

b

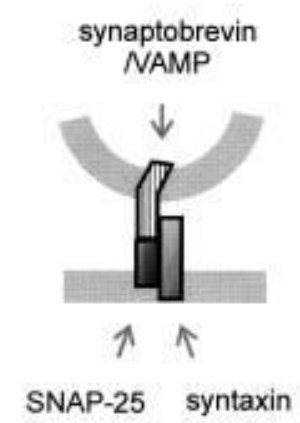

$c$

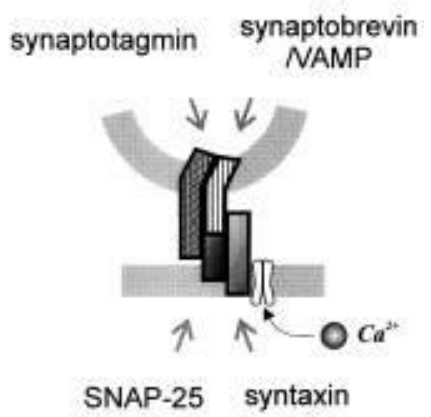

\section{Abbildung 4: Schematische Darstellung der Hauptbestandteile des Andock- und Fu- sionsmechanismus synaptischer Vesikel.}

a) Der SNARE-Komplex besteht aus vesikulären (v-SNARE), synaptischen (t-SNARE) und löslichen (SNAP und NSF) Bestandteilen. b) Synaptobrevin bildet den vesikulären Komplex-Bestandteil, Syntaxin den synaptischen Komplexbaustein und SNAP-25 den löslichen Faktor. Complexin (nicht abgebildet) verhindert die endgültige Zusammenlagerung des Komplexes im Ruhezustand c) Synaptogamin fördert calciumabhängig, durch Aufhebung der sterischen Blockade durch Complexin, die Zusammenlagerung des SNARE-Komplexes (entnommen und modifiziert nach Goda 1997). Die Verwendung erfolgt mit freundlicher Genehmigung der National Academy of Sciences, USA. 


\subsubsection{Vesikelrecycling}

Nach abgeschlossener Transmitterfreisetzung werden Bestandteile der synaptischen Vesikel endozytotisch wieder in die Präsynapse aufgenommen und dort durch Interaktion mit zytoplasmatischen Proteinen und Teilen des Zytoskeletts lokal wiederverwertet (Dittman und Ryan 2009). Dieses bereits 1973 entdeckte Prinzip des Vesikelrecyclings (Heuser und Reese 1973) dient der Aufrechterhaltung des Gleichgewichts zwischen Exo-, und Endozytose synaptischer Vesikel (Saheki und De Camilli 2012). Gemäß Haucke und Kollegen stellt die Verfügbarkeit freier, zum Andocken neuer Vesikel bereiter Membranbezirke der aktiven Zone einen limitierenden Faktor im Zuge der synaptischen Übertragung dar. Durch Kopplung der Neurotransmitter Exo-, und Endozytose im Zuge des Vesikelrecyclings (Haucke et al. 2011) wird fortlaufende synaptische Aktivität ermöglicht, indem Membranbezirke, in Vorbereitung für erneute Vesikelfusionen, von fusionierten Vesikelkomponenten bereinigt werden (Neher 2010; Watanabe und Boucrot 2017). Aufbau und Regulierung der physikalischen Verbindungen zwischen Exo-, und Endozytotischen Vorgängen sind nicht ausreichend erforscht (Haucke et al. 2011; Rizzoli 2014) und scheinen unter Beteiligung verschiedener Mechanismen zu erfolgen (Xie et al. 2017; Lou 2018). Nach vollständiger Vesikelfusion diffundieren Vesikelkomponenten wahrscheinlich gruppiert innerhalb der Plasmamembran (Willig et al. 2006; Opazo und Rizzoli 2010) und ermöglichen so die Rekrutierung der zur Endozytose benötigten Adapterproteine in ausreichender Konzentration (Rizzoli 2014). Die Exo-, und Endozytose synaptischer Vesikel verläuft nahezu zeitgleich, wobei endozytierte Vesikel, in elektronentomographischen Aufnahmen, nicht den unmittelbar zuvor fusionierten Vesikeln entsprechen (Watanabe et al. 2013b). Wienisch und Klingauf konnten zeigen, dass synaptische Vesikel, im Verlauf des Vesikelrecyclings, ihre molekulare Identität verlieren. Vesikuläre Komponenten gelangen nach abgeschlossener Membranfusion durch laterale Diffusion in den Bereich der periaktiven Zone und vermischen sich dort mit bereits vorsortierten vesikulären Proteinen und Membranabschnitten. Neu endozytierte Vesikel bestehen zu einem Großteil aus den bereits vorsortierten Vesikelbausteinen. Steigende neuronale Stimulation erhöht den Anteil unmittelbar zuvor exozitierter Vesikelkomponenten. Vorsortierte Vesikelkomponenten werden möglicherweise durch schnelle Endozytosemechanismen aufgenommen, wohingegen zuvor exozytierte Komponenten durch langsamere Endozytosemechanismen aufgenommen werden könnten. Diese Vermischung von Vesikelbausteinen macht einen Sortierungsschritt in Endosomen unabdingbar (Wienisch und Klingauf 2006). 
Die folgende Endozytose der Vesikelkomponenten erfolgt durch unterschiedliche Mechanismen, deren Aktivität in starker Abhängigkeit zur Temperatur steht (Renden und von Gersdorff 2007). Die clathrinabhängige Endozytose, die Kiss-and-run-Fusion, die schnelle kompensatorische Endozytose, die aktivitätsabhängige Massenendozytose (Bulk-Endozytose) und die ultraschnelle Endozytose (von Gersdorff und Matthews 1994; Saheki und De Camilli 2012; Rizzoli 2014) finden je nach zugrundeliegendem Synapsentyp und momentaner neuronaler Aktivität in unterschiedlicher Gewichtung statt. Möglicherweise wechseln Synapsen auch in Abhängigkeit ihrer aktuellen Aktivität und variierender Umgebungsfaktoren, wie beispielsweise Temperaturdifferenzen, zwischen diesen Mechanismen (vgl. Gan und Watanabe 2018). Die Endozytose synaptischer Vesikel erfolgt, unabhängig vom Endozytosemechanismus, in Abhängigkeit von Dynamin (Newton et al. 2006) und Aktin (Mooren et al. 2012). Lediglich wenige, unter hochintensiver neuronaler Stimulation beobachtete, Bulk-Endozytosemechanismen scheinen dynaminunabhängig zu arbeiten (Xu et al. 2008; Wu et al. 2014). Die Funktion des Dynamin wird weiter unten im Bezug zur clathrinabhängigen Endozytose exemplarisch erklärt.

Aktin übernimmt eine tragende Rolle im Zuge des Vesikelrecyclings (Sankaranarayanan et al. 2003; Mooren et al. 2012; Soykan et al. 2017). Es umgibt Teile der präsynaptischen Vesikelpopulation (Sankaranarayanan et al. 2003) und beteiligt sich an der Rekrutierung synaptischer Vesikel im Zuge der synaptischen Übertragung (Sakaba und Neher 2003). Nach abgeschlossener Vesikelexozytose könnte Aktin durch Interaktion mit Bin/Amphiphysin/Rvs-Domänen-Proteinen (BAR-Domänen-Proteinen) Funktionen bei der Invagination von Membranabschnitten übernehmen und durch Beeinflussung von Membranspannungen regulatorisch wirken (Mooren et al. 2012). Nach abgeschlossener Endozytose interagiert Aktin mit Dynamin zur Abschnürung der Vesikelknospe (Ferguson et al. 2009) und trägt durch aktive Polymerisation zur Entfernung der freigegebenen Vesikel von der Membran bei (Merrifield et al. 1999; Watanabe et al. 2013b). Freie Vesikel werden mit Hilfe von Aktin in ihr jeweiliges Vesikelcluster transportiert (Shupliakov et al. 2002), wobei sich Aktin vermutlich nicht aktiv am Transport synaptischer Vesikel beteiligt, sondern als passive Leitschiene für regulatorische Proteine dienen könnte (Sankaranarayanan et al. 2003). Dieses Prinzip lässt sich beispielsweise bei der Interaktion von Aktin mit Myosin bei der Aufnahme synaptischer Vesikel erkennen (Sun et al. 2006) und könnte beim intrazellulären Transport synaptischer Vesikel, ebenfalls durch Interaktion mit Myosin, Anwendung finden (Mooren et al. 2012). 
Die detaillierte Funktion des Aktins im Rahmen des Vesikelrecyclings ist aktuell jedoch nicht ausreichend erforscht (Mooren et al. 2012; Watanabe und Boucrot 2017). Weiterhin beteiligt sich auch Clathrin, in Zusammenarbeit mit verschiedenen Adapterproteinen (Kim und Ryan 2009; Willox und Royle 2012), an den meisten Endozytoseformen. Der Zeitpunkt, an dem Clathrin vorwiegend zum Einsatz kommt ist umstritten (siehe unten).

Die clathrinabhängige Endozytose führt zur Wiederverwertung vollständig mit der präsynaptischen Membran fusionierter synaptischer Vesikel mit Hilfe von Clathringerüsten. Die molekularen Vorgänge, die diesem Vorgang zugrunde liegen, sind weitreichend erforscht. Das zytoplasmatische Faserprotein Clathrin besteht aus jeweils drei leichten und schweren Polypeptidketten, die sich zu einem Triskelion zusammenlagern (Kirchhausen und Harrison 1981). Es besitzt die Fähigkeit zur Ausbildung eines Käfignetzes um Vesikel (Pearse 1975). Der in Phasen ablaufende Prozess beginnt ca. 1 Sekunde nach Beginn der synaptischen Stimulation und erreicht sein Aktivitätsmaximum nach ca. 30 Sekunden (Miller und Heuser 1984). Er führt nach Initiation der Hüllenbildung, Selektion der aufzunehmenden Fracht, der Bildung einer Vesikelknospe mit Hilfe des aus ungefähr 100 Triskelen bestehenden Käfignetzes, der Abschnürung der Vesikelknospe von der präsynaptischen Plasmamembran und dem anschließenden Zerfall der Clathrinhülle zur lokalen Wiederaufnahme synaptischer Vesikel (McMahon und Boucrot 2011). Die Ablösung des entstandenen Vesikels von der präsynaptischen Plasmamembran erfolgt nach Bildung einer ringförmigen Struktur aus Dynamin um die Verbindungsstelle der synaptischen und der vesikulären Membran (Takei et al. 1996). Durch Verdrehung der Dynaminketten gegeneinander kommt es zur Abschnürung des Vesikels (Roux et al. 2006; Faelber et al. 2012). Nach erfolgter Ablösung des Vesikels wird das gebundene Clathrin enzymatisch entfernt (Schlossman et al. 1984). Der Membranbezirk, an dem die Abschnürung erfolgte, verbleibt clathrinfrei und dient Proteinen, die der Ablösung der Clathrinhülle dienen, als Ansatzpunkt (McMahon und Boucrot 2011). Heat shock cognate 70 (HSC70) und sein aktivierender Kofaktor Auxilin (Ungewickell et al. 1995) führen nach Hydrolyse von Adenosintriphosphat zur Ablösung der Clathrinhülle (Xing et al. 2010). Weitere Proteine wie beispielsweise Endophilin scheinen sich sowohl an der Ablösung des Vesikels (Sundborger et al. 2011) als auch an der Entfernung der Clathrinhülle zu beteiligen (Milosevic et al. 2011). 
Die clathrinabhängige Endozytose macht $95 \%$ aller Endozytosevorgänge aus (Bitsikas et al. 2014) und scheint vor allem der Aufrechterhaltung der synaptischen Funktion in Ruhephasen, bei geringer synaptischer Aktivität zu dienen (McMahon und Boucrot 2011; Bitsikas et al. 2014). Abbildung 5 zeigt, vereinfacht dargestellt, den präsynaptischen Vesikelzyklus im Zuge der clathrinabhängigen Endozytose.

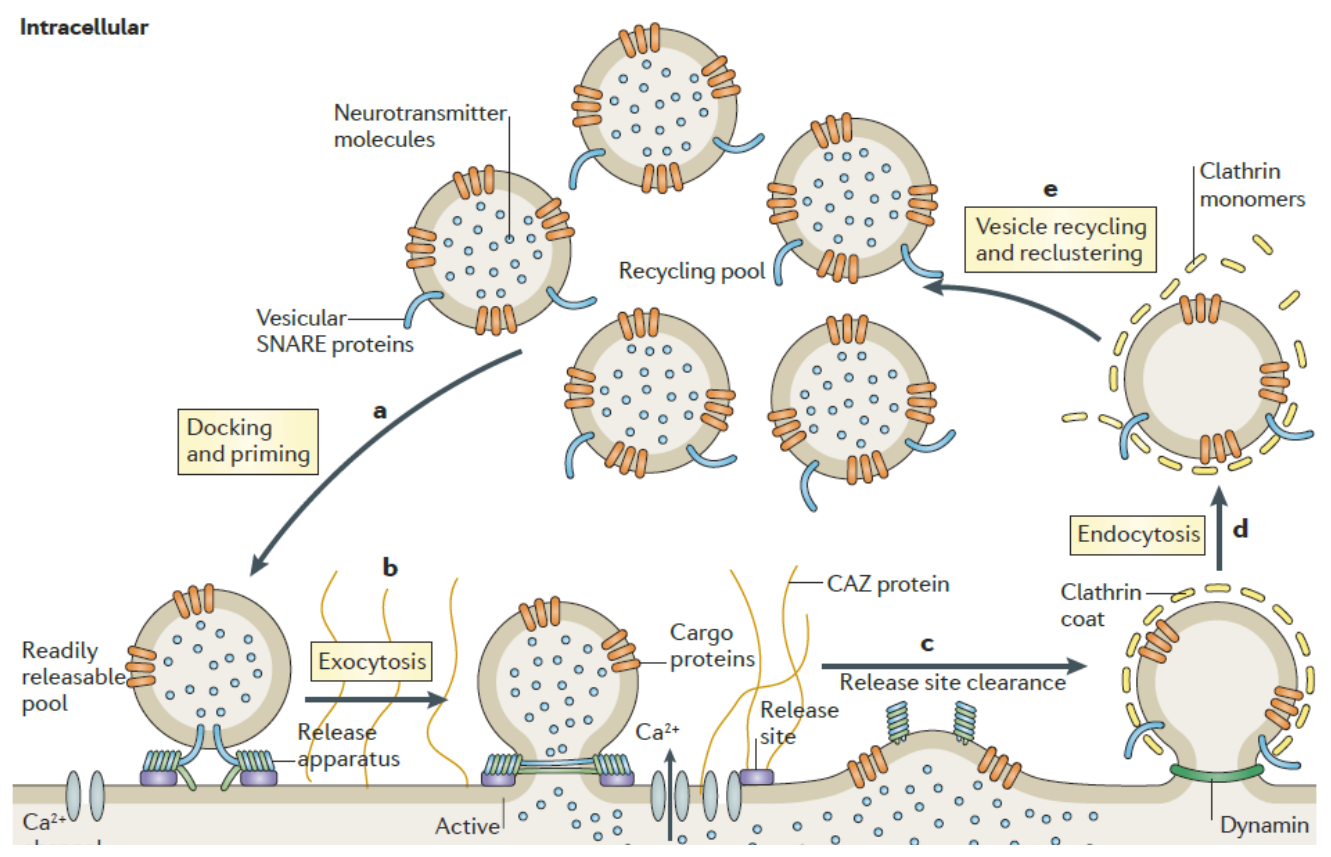

\section{Abbildung 5: Schematische Darstellung des Vesikelrecyclings unter Beteiligung der clathrinabhängigen Endozytose.}

a) Recycelnde Vesikel bilden nach erfolgtem Priming und Docking den zur Exozytose bereiten readily releasable pool. b) Calciumeinfluss führt zur Exozytose dieser Vesikel im Bereich der aktiven Zone mit Freigabe ihres Neurotransmitters in den synaptischen Spalt. c) Die aktive Zone kennzeichnet sich durch Proteine der Cytomatrix der präsynaptischen aktiven Zone (CAZ) und wird in Vorbereitung für erneute Exozytosevorgänge von Vesikelkomponenten bereinigt. d) Vesikelkomponenten werden im Bereich der periaktiven Zone durch verschiedene Endozytosemechanismen wieder in die Präsynapse aufgenommen (exemplarisch ist die primär clathrinabhängige Endozytose dargestellt). e) Neu endozytierte Vesikel werden neu verwertet, mit Neurotransmittern befüllt und funktionellen Vesikelgruppen zugeordnet, eine endosomale Sortierung in dieser Phase ist wahrscheinlich (nicht abgebildet) (entnommen und modifiziert nach Haucke et al. 2011). Die Verwendung erfolgt mit freundlicher Genehmigung des Springer Nature Verlages. 
Die Abschnürung eines clathrinumhüllten Vesikels dauert 30 bis 120 Sekunden (Ehrlich et al. 2004; Taylor et al. 2011) und ist damit vermutlich zu langsam, um unter Hochaktivitätsbedingungen, wie beispielsweise bei Einwirkung von Stresshormonen, Chemotaxis oder aber auch bei der Exozytose synaptischer Vesikel, beziehungsweise bei erhöhter synaptischer Aktivität eine ausreichende Endozytoserate sicherzustellen (Watanabe und Boucrot 2017). Verschiedene schnelle, clathrinunabhängige Endozytosemechanismen könnten hierbei eine tragende Rolle spielen (Clayton und Cousin 2009; Watanabe und Boucrot 2017). Im Gegensatz zur clathrinabhängigen Endozytose sind die molekularen Mechanismen der clathrinunabhängigen Endozytose nicht ausreichend erforscht (Watanabe und Boucrot 2017). Die folgende Beschreibung bezieht sich vor allem auf deren auslösende Faktoren sowie Größenunterschiede der endozytierten Vesikel.

Die ultraschnelle Endozytose erfolgt bei milder neuronaler Stimulation unter physiologischen Bedingungen innerhalb von 30 bis 100 Millisekunden nach dem Eintreffen von Aktionspotenzialen und führt zur Entstehung großer Vesikel mit einem Durchmesser von 60-80 nm (Watanabe et al. 2013b; Watanabe et al. 2013a; Watanabe et al. 2014). Diese Vesikel werden im Anschluss, nach endosomaler Fusion und clathrinabhängiger Abschnürung, innerhalb von fünf bis sechs Sekunden nach neuronaler Stimulation als synaptische Vesikel regeneriert (Watanabe et al. 2014). Endosomen könnten hierbei der Erkennung defekter synaptischer Vesikel und der Sortierung vesikulärer Proteine dienen (Hoopmann et al. 2010). Im Zuge der schnellen kompensatorischen Endozytose entstehen ebenfalls Vesikel, die größer als synaptische Vesikel sind (Paillart et al. 2003). Dieser Mechanismus lässt sich ebenfalls bei milder Stimulation beobachten, verläuft jedoch langsamer als die ultraschnelle Endozytose (Gan und Watanabe 2018). Die aktivitätsabhängige Massenendozytose wird bei physiologischen und nicht physiologischen Temperaturen unter hochfrequenter Stimulation ausgelöst (Clayton und Cousin 2009). Sie erfolgt in Relation zu anderen clathrinunabhängigen Endozytoseformen langsam. Sie benötigt Sekunden (Wu und Wu 2007) bis Minuten (Watanabe und Boucrot 2017) und führt zur Aufnahme großer Membranabschnitte bei variierender Vesikelgröße (Gan und Watanabe 2018). Die Massenendozytose könnte einen Sicherungsmechanismus darstellen (Rizzoli und Betz 2005; Clayton und Cousin 2009), um parallel zur schnellen Wiederherstellung des zur Freisetzung bereiten Vesikelclusters den reserve pool langsam, innerhalb mehrerer Minuten, wiederherzustellen (Richards et al. 2000). 
In Anbetracht der fehlenden Rekrutierung der Vesikel des reserve pool unter physiologischen Bedingungen (Rizzoli und Betz 2005) bleibt die genaue Funktion der Massenendozytose jedoch umstritten (Gan und Watanabe 2018).

Bei der mit 400-860 ms (Gandhi und Stevens 2003) relativ schnell ablaufenden Kiss-andrun-Fusion kommt es, gemäß der Ausführungen von He und Wu sowie Zhang und Kollegen, im Gegensatz zu anderen Fusions-, und Endozytosemechanismen nicht zum vollständigen Kollabieren des Vesikels. Der Transmitter wird durch partielle Verschmelzung der vesikulären und synaptischen Membranen durch eine Fusionspore in den synaptischen Spalt abgegeben. Nach abgeschlossener Freigabe wird diese Pore wieder geschlossen und der ursprüngliche Vesikel bleibt bestehen (He und Wu 2007; Zhang et al. 2009). Welche Rolle dieser Mechanismus unter physiologischen Bedingungen spielt wird weiterhin diskutiert (Wu et al. 2014). Die Kiss-and-run-Fusion scheint vor allem bei niedrigfrequenter synaptischer Aktivität stattzufinden, wohingegen die vollständige Vesikelfusion bei höheren, häufig vorkommenden Frequenzen bevorzugt stattfindet. So kann bei gesteigerter Aktivität eine höhere Anzahl an Transmittern freigesetzt werden (Granseth et al. 2006; Harata et al. 2006). Klassische, bei Raumtemperatur durchgeführte Studien deuteten darauf hin, dass die primär clathrinabhängige Endozytose den Hauptmechanismus zur Wiederaufnahme synaptischer Vesikel in zentralen Synapsen von Säugetieren darstellt (Heuser und Reese 1973; Heuser 1989). Aktuellere Untersuchungen lassen hingegen vermuten, dass bei physiologischen Temperaturen, bei milder bis starker neuronaler Stimulation, überwiegend schnelle, clathrinunabhängige Endozytose stattfindet (Gan und Watanabe 2018). Diese Vermutung wird durch die Beobachtung gestützt, dass die Endozytose bei gegenüber der Raumtemperatur gesteigerten Temperaturen schneller abläuft (Granseth und Lagnado 2008). Bei Raumtemperatur wird die ultraschnelle Endozytose blockiert, sodass die clathrinabhängige Endozytose überwiegt (Watanabe et al. 2014) und Wiederholung klassischer Studien bei physiologischen Temperaturen, führt zur Beobachtung überwiegend clathrinunabhängiger Endozytosevorgänge (Watanabe et al. 2013b; Delvendahl et al. 2016). Vermutlich wechseln Synapsen aktivitätsabhängig zwischen den verschiedenen Endozytoseformen (Delvendahl et al. 2016). Durch einen einzelnen eintreffenden Reiz wird ultraschnelle, clathrinunabhängige Endozytose im Bereich von periaktiven Zonen ausgelöst (Watanabe et al. 2013b; Delvendahl et al. 2016). 
Erst bei steigender synaptischer Aktivität kommt es bei physiologischen Temperaturen zur zusätzlichen clathrinabhängigen Endozytose (Delvendahl et al. 2016) sowie zur Aktivierung von Bulk-Endozytosemechanismen bei starker Steigerung der synaptischen Aktivität (Clayton und Cousin 2009). Synaptische Vesikel werden somit vorwiegend im Bereich der präsynaptischen Membran clathrinunabhängig endozytiert und fusionieren im Anschluss mit Endosomen, aus denen sie erst dann, clathrinabhängig, regeneriert werden (Kononenko et al. 2014; Watanabe et al. 2014). Dieser Prozess dauert ca. 10 bis 20 Sekunden (Gan und Watanabe 2018). Abbildung 6 stellt die aufgeführten Endozytosemechanismen vergleichend dar.

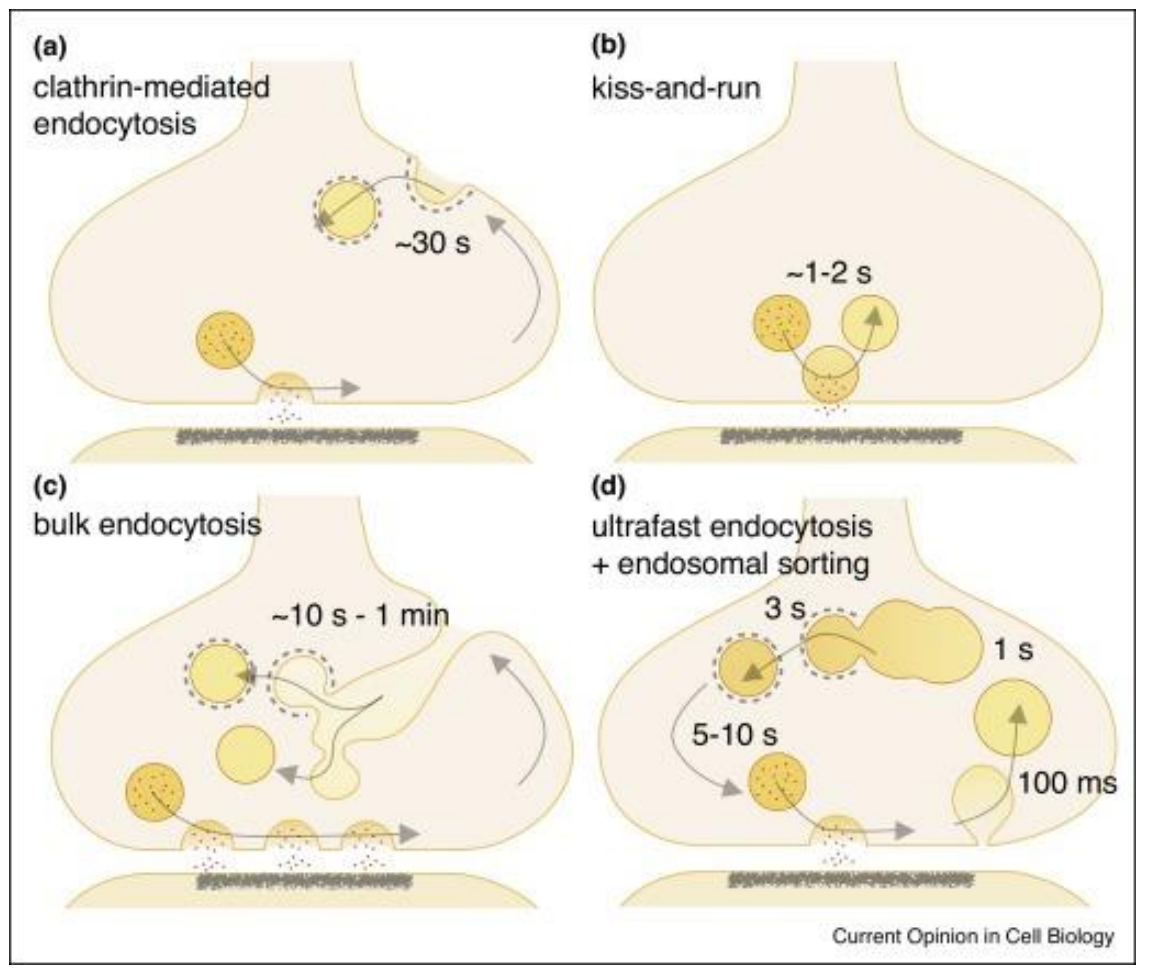

\section{Abbildung 6: Übersichtsdarstellung präsynaptischer Endozytosemechanismen.}

a) Vollständige Fusion eines Vesikels mit anschließender clathrinabhängiger Endozytose.

b)

Kiss-and-run-Fusion unter temporärer Bildung einer Fusionspore. c) Aktivitätsabhängige Massenendozytose nach hochfrequenter Stimulation mit anschließender Neuformierung synaptischer Vesikel durch clathrinabhängige oder clathrinunabhängige Mechanismen. d) Vollständige Fusion synaptischer Vesikel mit anschließender ultraschneller Endozytose und anschließender clathrinabhängiger Neubildung synaptischer Vesikel nach endosomaler Fusion (entnommen und modifiziert nach Watanabe und Boucrot 2017). Die Verwendung erfolgt mit freundlicher Genehmigung des Elsevier Verlages. 
Die clathrinabhängige Endozytose im Bereich der synaptischen Membran könnte einen Reservemechanismus darstellen, der bei Kapazitätsausschöpfung der ultraschnellen Endozytose aktiviert wird (Watanabe et al. 2014) oder aber, laut Gan und Watanabe, ergänzend zur schnellen, primär clathrinunabhängigen, Endozytose arbeiten. Schnelle Endozytosemechanismen könnten der Aufnahme der vesikulären Membran und einiger synaptischer Proteine dienen, wohingegen die langsamere, clathrinabhängige Endozytose der Aufnahme der restlichen synaptischen Proteine dient (Gan und Watanabe 2018).

\subsection{Untersuchte Strukturen}

\subsubsection{Hippocampale Synapsen}

Die Hippocampus-Formation verarbeitet Signale der sensorischen Systeme und nimmt eine zentrale Rolle bei der Ausbildung des deklarativen Langzeitgedächtnisses ein (Squire 1992). Sie beteiligt sich an Lernprozessen (Squire und Zola 1996) und überträgt im Rahmen der Gedächtniskonsolidierung Informationen vom Kurzzeit-, in das Langzeitgedächtnis (Squire und Alvarez 1995). Als Teil des limbischen Systems bestehen ausgeprägte Verbindungen zu Hirnarealen, die sich an der Regulation von Emotionen und vegetativen Prozessen beteiligen. Nach erfolgter Informationsintegration im Hippocampus erfolgt deren Speicherung im Neokortex (McClelland und Goddard 1996). Zwischen Hippocampus und neokortikalen Arealen bestehen ausgeprägte, gegenseitige afferente und efferente Verbindungen (Lavenex et al. 2002). Weitere Afferenzen stammen aus dem Thalamus, dem Septum, dem Corpus amygdaloideum, dem Rhinencephalon sowie dem Gyrus cinguli. Zusätzliche Efferenzen ziehen im Fornix zum Septum, zur Amygdala, dem Hypothalamus sowie den Corpora mamillaria. Hippocampale Synapsen weisen eine große Varianz hinsichtlich Größe, Morphologie und Anzahl der enthaltenen präsynaptischen Vesikel auf (Harris und Sultan 1995). Pyramidenzellen stellen, gemäß den Ausführungen von Megías und Kollegen, den dominierenden Zelltyp des Hippocampus dar. Hippocampale Pyramidenzellen des Rattengehirns haben ca. 12.000 Dendriten mit einer Gesamtlänge von ungefähr $12 \mathrm{~mm}$. Die Dendriten der Pyramidenzellen variieren hinsichtlich ihres Durchmessers, der Dornenfortsatzdichte und der Zusammensetzung der mit ihnen in Kontakt stehenden Synapsen. Sie erhalten näherungsweise berechnet $32.351 \pm$ 5486 synaptische Einflüsse aus ihrer Umgebung. 94,7 \% dieser Einflüsse entsprechen exzitatorischen Signalen, 5,3\% entsprechen inhibitorischen Einflüssen. 
Interneurone erhalten im Vergleich deutlich weniger synaptische Einflüsse (3000-16.000) die zu 4 - $30 \%$ inhibitorisch wirken. 60,9\% der Synapsen setzen im Bereich des apikalen Dendritenbaumes einer Pyramidenzelle an, 39,1 \% am basalen Dendritenbaum. Das Verhältnis zwischen auf eine Synapse einwirkenden exzitatorischen und inhibitorischen Einflüssen variiert hierbei zwischen verschiedenen Regionen des Hippocampus und scheint in Abhängigkeit zum vorliegenden Dendritentyp zu stehen (Megías et al. 2001). Exzitatorische Synapsen kennzeichnen sich durch starke Ausprägung der postsynaptischen Verdichtung und dadurch, dass ihre Präsynapsen gehäuft an Dornenfortsätzen der Dendriten ihrer nachgeschalteten Zellen ansetzen, wohingegen inhibitorische Synapsen überwiegend am Zellkörper und den initialen Axonsegmenten im Bereich dendritischer Schäfte ansetzen (Megías et al. 2001; Harris und Weinberg 2012). Schikorski und Stevens konnten durchschnittliche morphologische Parameter einzelner Synapsen durch Untersuchungen an Maushirngewebe ermitteln. Eine exzitatorische Präsynapse hat ein Volumen von $0,086 \pm 0,049 \mu \mathrm{m}^{3}$ sowie eine einzelne aktive Zone, die einen Bereich von 0,039 $\pm 0,022$ $\mu \mathrm{m}^{2}$ umfasst. Sie steht einer durchschnittlichen postsynaptischen Verdichtung mit einer Fläche von $0,043 \pm 0,031 \mu^{2}$ gegenüber. Die Dornenfortsätze haben im durchschnittliches ein Volumen von $0,038 \pm 0,036 \mu \mathrm{m}^{3}$. Die Präsynaptische Vesikelpopulation liegt bei $270 \pm 176$ Vesikeln, von denen 10,3 \pm 5,6 an die aktive Zone angedockt sind. Untersuchungen an entsprechenden Zellkulturen ergaben abweichende Ergebnisse (Schikorski und Stevens 1997). Die angedockten Vesikel entsprechen größtenteils dem readily releasable pool (Schikorski und Stevens 2001). Der recycling pool beinhaltet durchschnittlich die dreifache Vesikelanzahl des readily releasable pool einer Präsynapse (Murthy und Stevens 1999). Die restlichen Vesikel sind dem reserve pool zuzuordnen (siehe Abschnitt 1.3.3). Einige hippocampale Synapsen weichen von diesen Durchschnittswerten ab (Harris und Sultan 1995). Die Mossy-fiber-Synapsen besitzen beispielsweise ein Präsynaptisches Volumen von 2-13 $\mu \mathrm{m}^{3}$, durchschnittlich ca. 20 aktive Zonen sowie 16.000 synaptische Vesikel (Rollenhagen und Lübke 2010). Die vorwiegend kleinen funktionellen Vesikelgruppen hippocampaler Synapsen sind wahrscheinlich an niedrigfrequente Stimulation und daraus resultierender niedrigfrequenter Neurotransmitterabgabe adaptiert (Gan und Watanabe 2018). Mizuseki und Buzsáki zeigten, dass hippocampale Pyramidenzellen vorwiegend einzelne Aktionspotenziale, in niedrigen Frequenzbereichen zwischen 0,1 und $10 \mathrm{~Hz}$, generieren. Die Feuerrate eines individuellen Neurons scheint nicht zu variieren. 
In unterschiedlichen Aktivitätszuständen generiert die Mehrheit aller Neurone Aktionspotenziale in Frequenzen unter $1 \mathrm{~Hz}$, wohingegen eine kleine hochaktive Neuronenpopulation in höheren Frequenzbereichen tätig ist. Neurone, die Aktionspotenziale in hoher Frequenz generieren, codieren wahrscheinlich mehr Information in neuronalen Kreisläufen (Mizuseki und Buzsáki 2013). Einzelne Aktionspotenzialfraktionen werden in hochfrequenten Stößen (bursts) generiert, bei denen Aktionspotenziale in Abständen von 6-10 ms gehäuft nachweisbar sind (Harris et al. 2001; Mizuseki et al. 2012). In Abhängigkeit der Hirnaktivität zu einem bestimmten Zeitpunkt, kommt es zu regionalen Verhältnisunterschieden hinsichtlich des Aktivitätsmusters bestimmter Neuronenpopulationen, die spezifische Aktionspotenzialfrequenzen generieren. Unterschiedliche Regionen, Subregionen und deren Schichten unterscheiden sich in verschiedenen Situationen hinsichtlich ihrer elektrisch messbaren Aktivitätsmuster. Diese Unterschiede könnten ursächlich für funktionelle Unterschiede einzelner Hippocampus-Regionen sein (Mizuseki et al. 2012). Die dendritische Organisation hippocampaler Pyramidenzellen wird in Abbildung 7 dargestellt. 


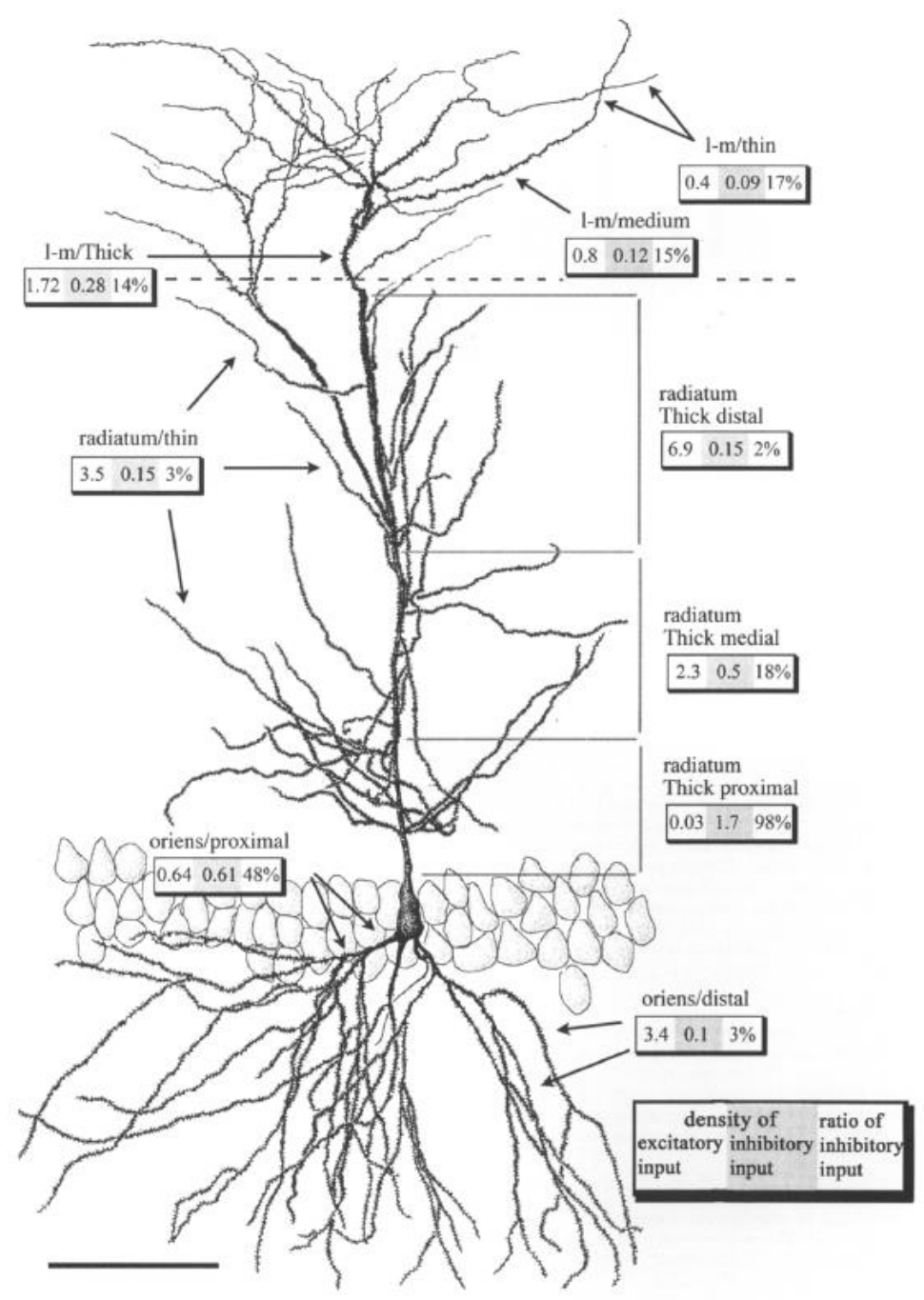

\section{Abbildung 7: Dendritische Organisation hippocampaler Pyramidenzellen.}

Oriens/proximal: Basale Dendriten. Kaum Dornenfotzsätze, weiter distal gelegene Dendriten (oriens/distal) mit hoher Dornenfortsatzdichte. Stratum radiatum: Vier Unterklassen. Der ausgeprägte apikale Dendritenstamm wird in einen proximalen (radiatum/thick/proximal) ohne Dornenfotzsätze, einen medialen (radiatum/thick/medial), mit wenigen Dornenfotzsätzen und einen distalen Abschnitt (radiatum/Thick/distal) mit vielen Dornenfortsätzen unterteilt. Ausgehend vom Stamm: Dünne Seitenarme (radiatum/thin). Stratum lacunosum-moleculare (1-m): Drei Subklassen. Die „radiatum-thick“ - Dendriten setzen sich in relativ dicke Dendriten $\mathrm{m} /$ thick), mit abnehmender Dornenfortsatzdichte fort. Diese werden fortlaufend dünner bei abnehmender Dornenfortsatzdichte (1-m/medium). In distalen, sehr dünnen Bereichen der apikalen Dendriten (1-m/thin) finden sich kaum Dornenfortsätze. Kästen neben den Dendritenklassen: Regional deutlich variierende Dichte ansetzender exzytatorischer und inhibitorischer Synapsen in elektronenmikroskopischen Aufnahmen in Anzahl/1 $\mu \mathrm{m}$ (linke und mittlere Zahl), prozentualer Anteil exzytatorischer Synapsen (rechte Zahl). Maßstabsleiste $=100 \mu \mathrm{m}$ (entnommen und modifiziert nach Megías et al. 2001). Die Verwendung erfolgt mit freundlicher Genehmigung des Elsevier Verlages. 


\subsubsection{Kortikale Neurone}

Der Cortex cerebri bildet den größten Teil des Gehirns von Säugetieren. Er wird klassischerweise in 46 funktionell voneinander abgrenzbare, nach ihrem Erstbeschreiber benannte, Brodmann-Areale unterteilt. Dieses ursprüngliche, simple Konzept der strukturellen und funktionellen Abgrenzung unterschiedlicher Areale wurde durch fortlaufende Forschung stetig erweitert. Die funktionelle Separation innerhalb des Cortex cerebri scheint, laut Amunts und Zilles, auf zahlreichen Subebenen zu geschehen. In Kombination mit möglicherweise überlappenden Strukturen zwischen funktionellen Arealen sowie einer ausgeprägten intrakortikalen Vernetzung ergibt sich eine hochkomplexe Organisationsstruktur, deren genaue Strukturierung weiterer Forschung bedarf (Amunts und Zilles 2015). Gemäß den Ausführungen von Parnavelas weisen Subareale der klassischen Brodmann-Areale, trotz häufig unterschiedlicher Funktion, große Gemeinsamkeiten in ihrem zytoarchitektonischen Aufbau vor. Die Zellkörper kortikaler Neurone sind größtenteils in sechs Schichten angeordnet und unterscheiden sich hinsichtlich ihrer Morphologie und Dichte im jeweiligen Gebiet. In seiner Gesamtheit beinhaltet der Cortex cerebri ungefähr die Hälfte aller Neurone des Gehirns, die sich in zwei Hauptklassen einteilen lassen. 75 $\%$ der kortikalen Neurone sind exzitatorische Pyramidenzellen, die Glutamat als ihren primären Neurotransmitter verwenden. Axone kortikaler Pyramidenzellen projizieren stark vernetzt zu weit entfernten, intrakortikalen Arealen und anderen Bereichen des Gehirns (Parnavelas 2002). Nichtpyramidale, inhibitorische Interneurone stellen die zweite Hauptgruppe kortikaler Neuronen dar. Sie variieren hinsichtlich ihrer Morphologie, dem Aufbau ihrer Dendritenbäume, der Ausprägung ihrer axonalen Verzweigungen und interagieren mittels $\gamma$-Aminobuttersäure vorwiegend mit Neuronen in unmittelbarer Nähe (Parnavelas 2002; Lim et al. 2018). Der Cortex cerebri befähigt Säugetiere zu höheren, zentralnervösen Leistungen wie beispielsweise der sensomotorischen Integration, sozialer Interaktion und der Speicherung von Erinnerungen. Die Funktion des Gehirns scheint hierbei auf ausgeprägter Varianz der Subtypen kortikaler Neuronen zu beruhen (Zeisel et al. 2015). Die Rolle dieser ausgeprägten neuronalen Diversifikation hinsichtlich funktioneller Aspekte ist aktuell Gegenstand der Forschung (Lodato und Arlotta 2015).

\subsubsection{Synaptophysin}

Synaptophysin ist ein saures Glykoprotein mit einer molekularen Masse von $38 \mathrm{kDa}$, dass sich in präsynaptischen Endigungen des gesamten zentralen Nervensystems als integraler Bestandteil synaptischer Vesikel nachweisen lässt (Jahn et al. 1985; Wiedenmann und 
Franke 1985). Das Protein besitzt vier Transmembrandomänen, jeweils ein Amino-, und Carboxylende auf der zytosolischen Seite der vesikulären Membran (Südhof et al. 1987) und lagert sich zu homomultimeren Komplexen zusammen (Thomas et al. 1988; Johnston und Südhof 1990). Synaptophysin gehört gemeinsam mit Synaptobrevin 2, Synaptogamin 1 und Synapsin zu den am häufigsten vorkommenden präsynaptischen Proteinen und macht ungefähr $10 \%$ aller synaptischen Vesikelproteine aus (Takamori et al. 2006). Synaptophysin dient der molekularen Markierung präsynaptischer Vesikel (Jahn et al. 1985; Wiedenmann und Franke 1985; Kwon und Chapman 2011) und ermöglicht die Untersuchung der synaptischen Dichte in einer vorliegenden Probe (Valtorta et al. 2004). Die vielfältigen Funktionen des Synaptophysin sind aktuell Gegenstand der Forschung. Bisherige Untersuchungen ergaben teilweise gegensätzliche Ergebnisse.

Synaptophysin beteiligt sich an der Regulierung der Neurotransmitterexozytose von Glutamat, Dopamin und Acetylcholin (Alder et al. 1992a; Alder et al. 1992b; Shibaguchi et al. 2000). Einerseits konnten eine verstärkende Wirkung des Proteins bezüglich der synaptischen Übertragung beobachtet werden. Überexpression des Proteins führte in den Studien von Alder und Kollegen zu erhöhten Frequenzen spontaner synaptischer Übertragungen sowie geringeren Latenzzeiten zwischen eintreffenden Reizen und ausgelösten synaptischen Reaktionen. Synaptophysin erhöht demnach die Wahrscheinlichkeit mit der Vesikel fusionieren und/oder führt zu einer Zunahme freisetzungsbereiter Vesikel im Bereich der aktiven Zone. Eine fördernde Beteiligung des Proteins an späten Schritten der Transmitterexozytose erscheint demnach wahrscheinlich (Alder et al. 1995). Andererseits konnte eine inhibitorische Funktion des Synaptophysins und Proteinen, die derselben Proteinfamilie angehören, bezüglich der Transmitterexozytose beobachtet werden (Sugita et al. 1999; Raja et al. 2019). Bei fehlendem Synaptophysin 1, Synaptophysin 2, Synaptogyrin 1 und Synaptogyrin 2 konnten Raja und Kollegen hierbei eine erhöhte Effizienz der synaptischen Übertragung beobachten. Möglicherweise stellen Mitglieder der Synaptophysin/Synaptogyrin-Familie bidirektionale Regulatoren der Exozytose dar. Die Beeinflussungsrichtung könnte hierbei durch sekundäre Botenstoffe moduliert werden (Raja et al. 2019).

Synaptophysin bildet gemeinsam mit Synaptobrevin 2 einen funktionellen Komplex (Calakos und Scheller 1994; Washbourne et al. 1995; Pennuto et al. 2002). Dieser Komplex dissoziiert unmittelbar vor der Vesikelfusion (Pennuto et al. 2002). Jeweils sechs Synaptophysinmoleküle und Synaptobrevin 2 Dimere bilden einen hexameren Ring (Adams et al. 2015). Dieser Komplex scheint sich sowohl an exozytotischen als auch an 
endozytotischen Prozessen zu beteiligen, wobei die genaue funktionelle Bedeutung des Komplexes jedoch Gegenstand der Forschung verbleibt (Gordon und Cousin 2014). Der Komplex könnte durch Bereitstellung einer, bei Bedarf schnell verfügbaren, Synaptobrevin 2 Reserve an der Feinregulierung der Neurotransmitterexozytose beteiligt sein (Becher et al. 1999) und, laut Adams und Kollegen, der Gruppierung vesikulärer SNAREProteine in Vorbereitung der Transmitterexozytose dienen. Der Komplex könnte somit einen Katalysator der Neurotransmitterexozytose darstellen, der den prefusionären Zustand vesikulärer SNARE-Proteine darstellt (Adams et al. 2015). Weiterhin beteiligt sich der Synaptophysin-Synaptobrevin 2 Komplex an der endozytotischen Aufnahme des Synaptobrevins (Gordon et al. 2011) sowie dessen Einbau in die vesikuläre Membran (Pennuto et al. 2003). Diese Qualitätskontrolle der Vesikelbildung durch Synaptophysin scheint teilweise redundant zur Funktion des Synaptogyrin zu sein (Stevens et al. 2012). Untersuchungen von Rajappa und Kollegen, mittels hochauflösender Mikroskopieverfahren, konnten eine essenzielle Funktion des Synaptophysin-Synaptobrevin 2-Komplex bei der Bereinigung der aktiven Zone von Synaptobrevin 2 nachweisen. Exozytiertes Synaptobrevin 2 kann so nicht zur Blockade nachfolgender Fusionen führen (Rajappa et al. 2016). Der Einbau der vesikulären V-ATPase geschieht ebenfalls nach Interaktion mit dem Synaptophysin-Synaptobrevin 2-Komplex (Galli et al. 1996; siehe Abschnitt 1.3.1). Weitere Interaktionen des Komplexes beziehungsweise des Synaptophysins mit Myosin V (Prekeris und Terrian 1997), Dynamin (Daly und Ziff 2002) und dem Adapterprotein 1 (Horikawa et al. 2002) konnten nachgewiesen werden. Die Funktionen verschiedener struktureller Elemente des Synaptophysins bezüglich der Vesikelendozytose sind nicht essenziell, fördern aber in ihrer Gesamtheit deren kinetisch effizienten Ablauf zur Aufrechterhaltung der endozytotischen Kapazität einer Präsynapse (Kwon und Chapman 2011). Im Verlauf der Vesikelendozytose könnte Synaptophysin durch Interaktion mit Cholesterol ein Grundgerüst zur Ausbildung leicht gekrümmter Membranabschnitte bilden (Thiele et al. 2000).

Dies könnte die Rekrutierung von BAR-Domänen-Proteinen (Galic et al. 2012) und, gemäß der Ausführungen von Rizzoli, weiterer endozytotischer Kofaktoren ermöglichen, die die Bildung eines Vesikels ermöglichen. Dieser Prozess könnte die Basis für den Ablauf der Vesikelendozytose aus Plasmamembranabschnitten, wie beispielsweise im Zuge des Vesikelrecyclings, im Bereich der präsynaptischen Membran aber auch nach endosomaler Fusion aufgenommener Vesikel bilden (Rizzoli 2014). Trotz seiner hohen Konzentration in Präsynapsen und nachweisbar modulierenden Eigenschaften auf die 
Effizienz der synaptischen Übertragung ist Synaptophysin nicht essenziel für die synaptische Übertragung (McMahon et al. 1996; Kwon und Chapman 2011). Seine Funktionen scheinen teilweise redundant zu dem sehr ähnlichen, aber weniger stark im zentralen Nervensystem verteilten Synaptophysin 2 (McMahon et al. 1996) oder dem weniger homologen Synaptogyrin zu sein (McMahon et al. 1996; Janz et al. 1999). Die zahlreichen Interaktionspartner weisen Synaptophysin als wichtigen Regulator während verschiedener Schritte des Vesikelrecyclings aus (Felkl und Leube 2008) und lassen eine modulierende Funktion hinsichtlich höherer Hirnfunktionen vermuten (Schmitt et al. 2009). Synaptophysin und Synaptogyrin scheinen, gemäß der Studien von Janz und Kollegen, nicht essenziell für die reine Neurotransmitterexozytose zu sein, übernehmen aber tragende, gegenseitig redundante, Funktionen bezüglich der Mechanismen der synaptischen Plastizität im Bereich des Hippocampus. Bei fehlendem Synaptophysin und Synaptogyrin konnten Einschränkungen der Kurz-, und Langzeitplastizität nachgewiesen werden (Janz et al. 1999). Weiterhin sind, bei vorliegendem Synaptophysindefizit höhere Geistesfunktionen, die im Zusammenhang mit dem Hippocampus stehen, beeinträchtigt. Synaptophysin könnte im Komplex mit Synaptobrevin durch Beeinflussung der Ausprägung synaptischer Kontakte ein wichtiger Faktor im Rahmen der synaptischen Plastizität sein (Becher et al. 1999). Synaptophysin übernimmt eine Rolle bei der aktivitätsabhängigen Formation synaptischer Kontakte (Tarsa und Goda 2002) und scheint die Lern-, und Gedächtnisfunktion zu beeinflussen (Schmitt et al. 2009). Synaptophysin ermöglicht die eindeutige molekulare Markierung synaptischer Vesikel (Takamori et al. 2006) und damit auch von Präsynapsen.

\subsubsection{Bassoon}

Bassoon ist ein aus 4000 Aminosäuren aufgebautes Coiled-Coil-Protein mit einer molekularen Masse von 400 kDa (Dieck et al. 1998; Wang et al. 2009). Gemäß der Erstbeschreibung des Bassoons durch Dieck und Kollegen, lässt sich das Protein in allen Regionen des Rattenhirns nachweisen. Erhöhte Bassoonkonzentrationen finden sich im $\mathrm{Ce}$ rebellum und dem Hippocampus. Subzellulär konzentriert es sich vorwiegend in Axonendigungen als essenzieller Bestandteil der aktiven Zone, wo es mit Synaptophysin und Piccolo kolokalisiert. Bassoon besteht ultrastrukturell aus mehreren Doppelwendeln, zwei Zinkfingerdomänen und mehreren Polyglutaminen (Dieck et al. 1998). Bassoon interagiert mit zahlreichen weiteren präsynaptischen Proteinen wie beispielsweise CAST(1)-Proteinen, Munc13, Rim-Proteinen und Piccolo, wobei insbesondere die 
physische und funktionelle Verbindung der großen Multidomänenproteine Bassoon und Piccolo stark ausgeprägt ist, sodass sie gemeinsam der Strukturerhaltung der aktiven Zone dienen und die Grundlage eines hochkomplexen Proteinnetzwerkes bilden, das präsynaptische Funktion ermöglicht (Wang et al. 2009). Gundelfinger und Kollegen untersuchten die Funktion der Proteine Bassoon und Piccolo. Beide Proteine weisen große sequenzielle Ähnlichkeiten auf und kooperieren durch gemeinsame, überlappende, als auch gegenseitig ergänzende, proteinspezifische Funktionen. Durch Strukturanpassungen bilden sie so die Grundlage zur Ausbildung supramolekularer Komplexe, die beispielsweise der Zusammenfindung von Proteinen der aktiven Zone, der Neurotransmitterexozytose, der Verbindung zwischen Aktin-, und Dynaminaktivität im Rahmen der Vesikelendozytose, der Aufrechterhaltung synaptischer Strukturen, der Verknüpfung von Signalwegen sowie der Kommunikation zwischen Synapse und Nucleus dienen (Gundelfinger et al. 2016). Zahlreiche weitere funktionelle Beteiligungen, wie beispielsweise an der Neubeladung aktiver Zonen mit freisetzbaren Vesikeln (Hallermann et al. 2010), am axonalen Transport von Bausteinen der aktiven Zone (Fejtova et al. 2009), der Aufrechterhaltung der vesikulären Organisation in Gruppen (Mukherjee et al. 2010) sowie der Rekrutierung calciumspezifischer Ionenkanäle und deren korrekten Positionierung im Bereich der aktiven Zone (Davydova et al. 2014) erscheinen wahrscheinlich. Ivanova und Kollegen stellten in einer Literaturübersicht die weiteren Funktionen des Bassoons in Kooperation mit Piccolo zusammenfassend dar. Die Proteine beteiligen sich, in Kooperation, an der aktivitätsabhängigen, molekularen Reorganisation der Präsynapse. Durch Beteiligung am Ubiquitin-Proteasom-System und Beeinflussung der Expression von Genen, die die neuronale Aktivität regulieren, erscheint eine Beteiligung an Mechanismen der synaptischen Plastizität denkbar. Bassoon übernimmt eine tragende Rolle im Rahmen physiologischer und möglicherweise auch pathologischer Hirnfunktionen (Ivanova et al. 2016) und ermöglicht die molekulare Markierung der aktiven Zone einer Präsynapse.

\subsubsection{Amphiphysin}

Amphiphysin ist ein hydrophiles Protein, das sich in erhöhter Konzentration im Zytosol präsynaptischer Endigungen des gesamten zentralen Nervensystem nachweisen lässt. (Lichte et al. 1992; Wu et al. 2009). Amphiphysin liegt hierbei sowohl löslich als auch in Assoziation mit Zwischenstufen in Endozytose befindlicher Vesikel vor (Bauerfeind et al. 1997). Es ermöglicht somit die molekulare Markierung des endozytotischen Apparates im Bereich von Präsynapsen. 
Amphiphysin interagiert mit dem häufig kolokalisiertem Dynamin, Clathrin (McMahon et al. 1997; Wigge und McMahon 1998; Takei et al. 1999), Aktin (Bauerfeind et al. 1997), Bestandteilen der Plasmamembran und zahlreichen weiteren an der synaptischen Vesikelendozytose beteiligten Proteinen (Wu et al. 2009). Amphiphysin unterliegt hierbei, nach Depolarisation der präsynaptischen Membran, der calciumabhängigen Dephosphorylierung durch Calcineurin (Bauerfeind et al. 1997) und übernimmt gemeinsam mit weiteren, der calcineurinabhängigen Aktivierung unterliegenden Proteinen wie beispielsweise Clathrin, Adapterkomplex 2 (AP2), Adapterprotein 180 (AP180), Dynamin, Endophilin, Synaptojanin, Intersectin, Syndapin, Auxilin und HSC70 tragende Funktionen im Rahmen der synaptischen Vesikelendozytose (Cremona et al. 1999; Cousin und Robinson 2001). Dieser Aktivierungsmechanismus scheint sowohl bei der clathrinabhängigen, als auch bei der Bulk-Endozytose entscheidend zu sein (Clayton et al. 2007). Amphiphysin liegt in zwei Isoformen vor. Wigge und Kollegen konnten Amphiphysin 2 identifizieren. Amphiphysin 1 und Amphiphysin 2 sind zu $49 \%$ identisch. Sie weisen große Ähnlichkeiten hinsichtlich subzellulärer Verteilung, funktioneller Domänen und der Steuerung ihres Aktivitätszustandes durch Phosphorylierung auf. Beide Isoformen agieren wahrscheinlich als heterodimerer Komplex mit einer molekularen Masse von 220 bis 250 kDa. Dieses Heterodimer scheint unter anderem der Rekrutierung von Dynamin zu Membranbezirken der sich abschnürenden Vesikelknospen zu dienen (Wigge et al. 1997). Die BAR-Domäne des Amphiphysins dient der Erkennung und Ausbildung von Membrankrümmungen (Peter et al. 2004).

Nach Erkennung vorhandener Membrankrümmungen erfolgt durch Insertion amphiphiler Helices in Plasmamembranabschnitte die zunehmende lokale Krümmungen der entstehenden Vesikelmembran (McMahon und Gallop 2005). Dieser Prozess wird durch die aktuelle Form der Membran, Membranspannungen und die vorliegende BAR-Proteindichte auf der Membranoberfläche reguliert, sodass bei initial niedrigen BAR-Proteindichten die Rekrutierung zusätzlicher Amphiphysine durch Spannungsmodulatoren wie beispielsweise Aktin unterstützt werden könnte (Simunovic et al. 2015). Bei geringen Proteinkonzentrationen überwiegt die Krümmungserkennungsfunktion, wohingegen bei steigenden Proteinkonzentrationen die membranverformende Tätigkeit des Amphiphysins überwiegt (Sorre et al. 2012). Durch ihre SH3-Domäne (David et al. 1994) dienen Amphiphysine weiterhin der Rekrutierung von Dynamin zu den entsprechenden, stark gekrümmten, Ansatzstellen am Hals der Vesikelknospen im Laufe der Endozytose (Shupliakov et al. 1997). Weitere Kofaktoren, wie beispielsweise Endophilin und 
Intersectin, beteiligen sich an diesem Prozess (Rao und Haucke 2011). Nach erfolgter Rekrutierung des Amphiphysins an gekrümmte Membranabschnitte und zunehmender Membrankrümmung stimuliert Amphiphysin die GTPase Aktivität des Dynamins, wodurch die vollständige Abschnürung synaptischer Vesikelknospen gefördert wird (Yoshida et al. 2004). Amphiphysin ermöglicht so, in Kooperation mit Intersectin und Endophilin, die Rekrutierung, Anlagerung und Aktivierung des Dynamins im Laufe der Endozytose, wodurch der Hals der Vesikelknospe zunächst zunehmend eingeengt und abschließend vollständig abgeschnürt wird (Sundborger und Hinshaw 2014). Zusätzliche Funktionen des Proteins, wie beispielsweise eine Beteiligung an der Aktinpolymerisation erscheinen möglich (Mundigl et al. 1998). Amphiphysin stellt neben seiner unterstützenden Funktion bei der Vesikelknospung und Abschnürung, durch seine interaktionsfähigen Domänen, ein zentrales Verbindungsprotein zahlreicher endozytotischer Proteine und Regulatoren dar (Di Paolo et al. 2002; Wu et al. 2009). Die Funktionen des Amphiphysin scheinen trotz partieller Redundanz unter Ruhebedingungen essenziell für die Funktion des Gehirns zu sein. Untersuchungen an Mäusen bei fehlendem Amphiphysin, unter neuronaler Stimulation, ließen deutliche Einschränkungen des synaptischen Vesikelrecyclings erkennen, die im Zusammenhang mit Einschränkungen höherer Hirnfunktionen wie beispielsweise dem Lernen, sowie erhöhter Sterblichkeit standen (Di Paolo et al. 2002).

\subsubsection{Vesikuläre Glutamattransporter}

Vesikuläre Glutamattransporter dienen der Befüllung synaptischer Vesikel mit dem Neurotransmitter Glutamat (Bellocchio et al. 2000; Takamori et al. 2000). Sie ermöglichen die eindeutige Markierung glutamaterger, synaptischer Kontakte (El Mestikawy et al. 2011). In vivo lassen sich die drei Isoformen VGLUT1, VGLUT2 und VGLUT3 nachweisen, die hinsichtlich ihrer Aminosäuresequenz zu $72 \%$ identisch sind (Takamori et al. 2002) und analoge Funktionsmechanismen aufweisen. VGLUT befüllen synaptische Vesikel in Abhängigkeit von Adenosintriphosphat (Disbrow et al. 1982; Naito und Ueda 1985) entlang eines Protonengradienten (Disbrow et al. 1982; Herzog et al. 2001) unter Beteiligung der vesikulären V-ATPase (Galli et al. 1996; siehe Abschnitt 1.3.1). Jeweils ein Typ des VGLUT reicht zur vollständigen Befüllung eines synaptischen Vesikels aus (Daniels et al. 2006).

VGLUT1 (Takamori et al. 2000) lässt sich vor allem in neuronalen Subpopulationen des Hippocampus, des Cortex cerebri und des Cortex cerebelli nachweisen (Ni et al. 1995). VGLUT2 (Herzog et al. 2001; Takamori et al. 2001) entspricht hinsichtlich seiner 
Aminosäurensequenz zu 75 - $79 \%$ dem VGLUT1 (Bai et al. 2001) und lokalisiert vor allem in subkortikalen Strukturen wie beispielsweise dem Thalamus und dem Hirnstamm (El Mestikawy et al. 2011). VGLUT3 lässt sich im Gegensatz zu VGLUT1 und VGLUT2 sowohl in primär glutamatergen, exzitatorischen Synapsen als auch vor allem in primär nicht glutamatergen Synapsen nachweisen (Fremeau et al. 2002; Gras et al. 2002; Schäfer et al. 2002; Takamori et al. 2002). VGLUT3 lässt sich in Relation zu den beiden anderen Isoformen in kleinerer Anzahl, bei stärkerer Streuung im Gehirn nachweisen (Gras et al. 2002; Schäfer et al. 2002). VGLUT1 und VGLUT2 verteilen sich größtenteils komplementär (Kaneko und Fujiyama 2002; Herzog et al. 2006), wohingegen VGLUT3 hinsichtlich seiner Verteilung in einigen Hirnregionen mit den beiden anderen Isoformen überlappt, wobei die physiologische Bedeutung dieses Verteilungsmusters nicht ausreichend erforscht ist (Takamori et al. 2002). Funktionelle Unterschiede zwischen den Isoformen des VGLUT erscheinen denkbar (Kaneko und Fujiyama 2002). Neurone beinhalten teilweise sowohl VGLUT3 als auch Acetylcholin-, und Serotonintransporter, wobei Glutamat, im zentralen Nervensystem, anscheinend auch Funktionen als Cotransmitter übernimmt (Gras et al. 2002; Schäfer et al. 2002). Evidenzen deuten darauf hin, dass auch VGLUT1 und VGLUT2 in primär nicht-glutamatergen Synapsen vorliegen können (Boulland et al. 2009).

El Mestikawy und Kollegen vermuteten weiterführend, dass VGLUT nicht nur der Befüllung synaptischer Vesikel mit Glutamat als primären oder sekundären Neurotransmitter dienen könnten, sondern auch zusätzliche, regulatorische Funktionen innerhalb der Präsynapse übernehmen. Es bedarf weiterer Forschung um die genaue Funktion des Glutamats und seiner vesikulären Transporter zu definieren (El Mestikawy et al. 2011).

\subsubsection{SNAP-25}

SNAP-25 (Synaptosomal-Associated Protein of $25 \mathrm{kDa}$ ) beteiligt sich als SNARE-Protein (N-Ethylmaleimide Sensitive Factor Attachment Protein Receptor) durch Zusammenlagerung mit Syntaxin-1 und Synaptobrevin2/VAMP2 (Vesicle Associated Membrane Protein) (Söllner et al. 1993b) maßgeblich an der Exozytose synaptischer Vesikel (Hanson et al. 1997; Washbourne et al. 2002). Durch Zusammenlagerung zum SNARE-Komplex wird die Anlagerung synaptischer Vesikel im Bereich der aktiven Zone, sowie deren calciumvermittelte Fusion mit der präsynaptischen Membran ermöglicht (Jahn und Fasshauer 2012). Weiterhin übernimmt SNAP-25 durch calciumabhängige Interaktion mit Synaptogamin Funktionen beim Andocken (Docking) synaptischer Vesikel an der aktiven 
Zone, deren Vorbereitung (Priming) zur Exozytose sowie der Auslösung der schnellen Exozytose (Mohrmann et al. 2013). SNAP-25 interagiert mit unterschiedlicher Typen spannungsabhängiger Calciumkanäle (Wiser et al. 1996) und wirkt inhibierend auf diese ein (Pozzi et al. 2008). Es scheint eine wichtige Rolle bei der Regulierung des präsynaptischen Calciumeinstroms zu übernehmen (Zamponi 2003). SNAP-25 führt zu reduzierter Calciumempfindlichkeit im Bereich der Präsynapse und könnte so, durch Kontrolle der Calciumdynamik, regulatorische Funktionen im Zuge des Vesikelrecyclings übernehmen (Verderio et al. 2004). Weiterhin beteiligt sich SNAP-25 gemeinsam mit Synaptobrevin an der langsamen, clathrinabhängigen Endozytose im Bereich hippocampaler Synapsen, sodass eine Beteiligung von SNAP-25 an der Ausbalancierung zwischen Vesikelexozytose und Endozytose, bei unklarem molekularen Mechanismus, als möglich erscheint (Zhang et al. 2013). SNAP-25 kann auch in postsynaptischen Dornenfortsätzen nachgewiesen werden (Hussain et al. 2019) und sich dort möglicherweise am postsynaptischen Glutamatrezeptorverkehr (Selak et al. 2009; Lau et al. 2010) sowie der Morphogenese postsynaptischer Dornenfortsätze beteiligen (Tomasoni et al. 2013). Eine Beteiligung von SNAP-25 an der Langzeitpotenzierung im Rahmen der synaptischen Plastizität erscheint möglich (Jurado et al. 2013).

SNAP-25 beteiligt sich möglicherweise durch Änderung der präsynaptischen Transmitterfreisetzung oder aber auch durch SNAP-25 abhängige postsynaptische Veränderung an der Ausbildung verschiedener Synaptopathien (Antonucci et al. 2016). Das Aufmerksamkeits defizit-Hyperaktivitätssyndrom (Barr et al. 2000; Kustanovich et al. 2003), die Schizophrenie und die bipolare Störung (Fatemi et al. 2001) sind durch prä-, und postsynaptische Veränderungen charakterisiert (Penzes et al. 2011) wodurch eine Funktionsübernahme von SNAP-25 in beiden Kompartimenten wahrscheinlich wird (Antonucci et al. 2016). SNAP-25 ermöglicht die immunologische Markierung der synaptischen Plasmamembran. 


\subsection{Hochauflösende Mikroskopie}

\subsubsection{Einschränkungen konventioneller Lichtmikroskopie und Verfahren der hochauflösenden Mikroskopie}

Das Auflösungsvermögen konventioneller Lichtmikroskope wird durch die Wellenlänge des sichtbaren Lichts begrenzt. Sie können Objekte, die näher als die halbe Wellenlänge des sichtbaren Lichts beieinander liegen, optisch nicht voneinander trennen (Abbe 1873). Diese Diffraktionsbarriere begrenzt die Lichtmikroskopie unter idealen Bedingungen auf eine maximale laterale Auflösung von ungefähr 200 nm (Fornasiero und Rizzoli 2014). Die Darstellung subzellulärer Strukturen unterhalb der Diffraktionsbarriere war lange Zeit lediglich mit Hilfe der Elektronenmikroskopie möglich. Die aufwendige Präparation elektronenmikroskopischer Proben geht mit häufiger Artefaktbildung einher und kann unter bestimmten Bedingungen zur Induktion synaptischer Vesikelfusionen führen, sodass sich die Elektronenmikroskopie nicht optimal zur Untersuchung synaptischer Vorgänge und Strukturen eignet (Smith und Reese 1980). Die fehlenden Möglichkeiten zur Darstellung vitaler Zellen, sowie zur farbigen Markierung von Zielstrukturen bei elektronenmikroskopischen Untersuchungen bedingen das große Potenzial von Weiterentwicklungen zur Auflösungsverbesserung lichtmikroskopischer Verfahren hinsichtlich biologischer Untersuchungen.

Strukturierte Beleuchtungsverfahren (Structured Ilumination Microscopy (SIM)), Prinzipien der photoaktivierten Lokalisationsmikroskopie, wie beispielsweise die Lokalisationsmikroskopie am Beispiel der stochastischen optischen Rekonstruktion (Stochastic Optical Reconstruction Microscopy (STORM)), die photoaktivierte Lokalisationsmikroskopie (Photoactivated Localization Microscopy (PALM)) und die Stimulierte Emissions-Depletions Mikroskopie (Stimulated Emission Depletion Microscopy (STED)) ermöglichen es einzeln, oder in Kombination angewandt, das Abbe-Limit lichtmikroskopisch zu durchbrechen (Fornasiero und Rizzoli 2014).

Die, von Gustafsson entwickelte, SIM erzielt eine Verbesserung des lateralen Auflösungsvermögens unter Ausnutzung des Moiré-Effektes. Eine zu untersuchende, unbekannte, fluoreszenzmarkierte Struktur wird hierbei durch eine bekannte, in die Fokusebene projizierte Gitterstruktur überlagert. Es werden mehrere Aufnahmen bei wechselnder Positionierung des Lichtgitters über der Probe erstellt. Nach abgeschlossener Detektion kann die unbekannte Struktur anhand der Überlagerungsbilder errechnet werden. SIM ermöglicht eine Verdopplung des lateralen Auflösungsvermögens gegenüber 
Konfokalmikroskopen (Gustafsson 2000). Durch 3D-SIM kann auch das axiale Auflösungsvermögen gegenüber Konfokalmikroskopen verdoppelt werden (Schermelleh et al. 2008). Schermelleh und Kollegen stellten verschiedene Hochauflösende Mikroskopieverfahren im Vergleich dar. SIM geht mit der Möglichkeit zur Verwendung herkömmlicher Fluoreszenzmarker einher und ermöglicht, durch die hohe Arbeitsgeschwindigkeit, die Darstellung dynamischer Prozesse in lebenden Zellen. Die Verbesserung des Auflösungsvermögens durch SIM ist im Vergleich zu STORM und STED jedoch gering. Diese Verfahren erreichen bei der Untersuchung von Zellen ein laterales Auflösungsvermögen von bis zu $30 \mathrm{~nm}$ (Schermelleh et al. 2010).

Bei der, von Rust entwickelten, STORM wird pro Einzelaufnahme nur eine kleine Teilmenge aller vorhandenen Fluorophore angeregt. Bei jeder erneuten Aufnahme werden zuvor aktivierte Fluorophore deaktiviert. Im Gegenzug werden gleichzeitig neue Fluorophore aktiviert. Dieser Vorgang wird tausendfach wiederholt, sodass möglichst alle vorhandenen Fluorophore einer Probe einzeln aktiviert und detektiert werden können. Mittels Gaußscher Kurvenanpassung wird abschließend die Lokalisation eines jeden aktivierten und detektierten Fluorophores bestimmt, um ein hochauflösendes Bild zu rekonstruieren (Rust et al. 2006). STORM ermöglicht hohe axiale Auflösungen sowie, durch die Anwendung energiearmer Laser, die Möglichkeit eine hohe Anzahl unterschiedlicher Fluoreszenzsignale gleichzeitig darzustellen, wobei der Zeitaufwand gegenüber anderen Mikroskopieverfahren stark erhöht ist und der Anwendungsbereich, durch die eingeschränkte Möglichkeit zur Untersuchung lebender Zellen, begrenzt wird (Fornasiero und Rizzoli 2014).

PALM arbeitet analog zu STORM, indem anstatt photoaktivierbarer Fluorophore photoaktivierbare fluoreszierende Proteine verwendet werden (Betzig et al. 2006). Weitere Verbesserungen des Auflösungsvermögens von STORM und PALM sind nicht zu erwarten, da die erreichbare Auflösung durch die Menge der von einer Probe emittierten Photonen beschränkt wird (Schermelleh et al. 2010).

Bei dem, von Hell und Wichmann publizierten, Verfahren der STED Mikroskopie wird ein zentraler, fluorophor-anregender Laser durch einen Fluorophor-inaktivierenden STED-Strahl überlagert. Der STED-Strahl weist in seinem Zentrum eine Intensität von null auf, sodass Fluoreszenzsignale angeregter Fluorophore lediglich im Zentrum des STED-Strahls registriert werden können (Hell und Wichmann 1994). Eine vorliegende Probe wird so in ihrem Verlauf gescannt, wobei emittierte Photonen nur im sehr kleinen 
Zentrum des „doughnutförmigen“ Überlagerungsstrahls detektiert werden können, wodurch die Diffraktionsbarriere durchbrochen werden kann (Schermelleh et al. 2010). Im Vergleich zu STORM ermöglicht STED eine weitere Verbesserung des lateralen Auflösungsvermögens. Durch das isoSTED Verfahren wird zusätzlich eine deutliche Verbesserung des axialen Auflösungsvermögens erreicht (Schmidt et al. 2008). Fluorophore, die bei STED verwendet werden, müssen eine hohe Photostabilität aufweisen, um unter Einwirkung des zentralen, anregenden Lasers nicht zu zerfallen und es können lediglich zwei Farbkanäle mittels STED untersucht werden (Fornasiero und Rizzoli 2014). Die hier beschriebenen hochauflösenden Mikroskopieverfahren sind aufgrund des eingeschränkten Angebotes an optimierten Fluorophoren zur mehrfarbigen hochauflösenden Mikroskopie und vor allem aufgrund des hohen Kostenfaktors, durch die benötigte technische Ausrüstung und den erhöhten Ausbildungsbedarf zur Durchführung hochauflösender Mikroskopie, nicht standardmäßig in Laboren verbreitet (Truckenbrodt et al. 2019). Abbildung 8 stellt die Funktionsweisen der verschiedenen hochauflösenden Mikroskopieverfahren vergleichend dar. 

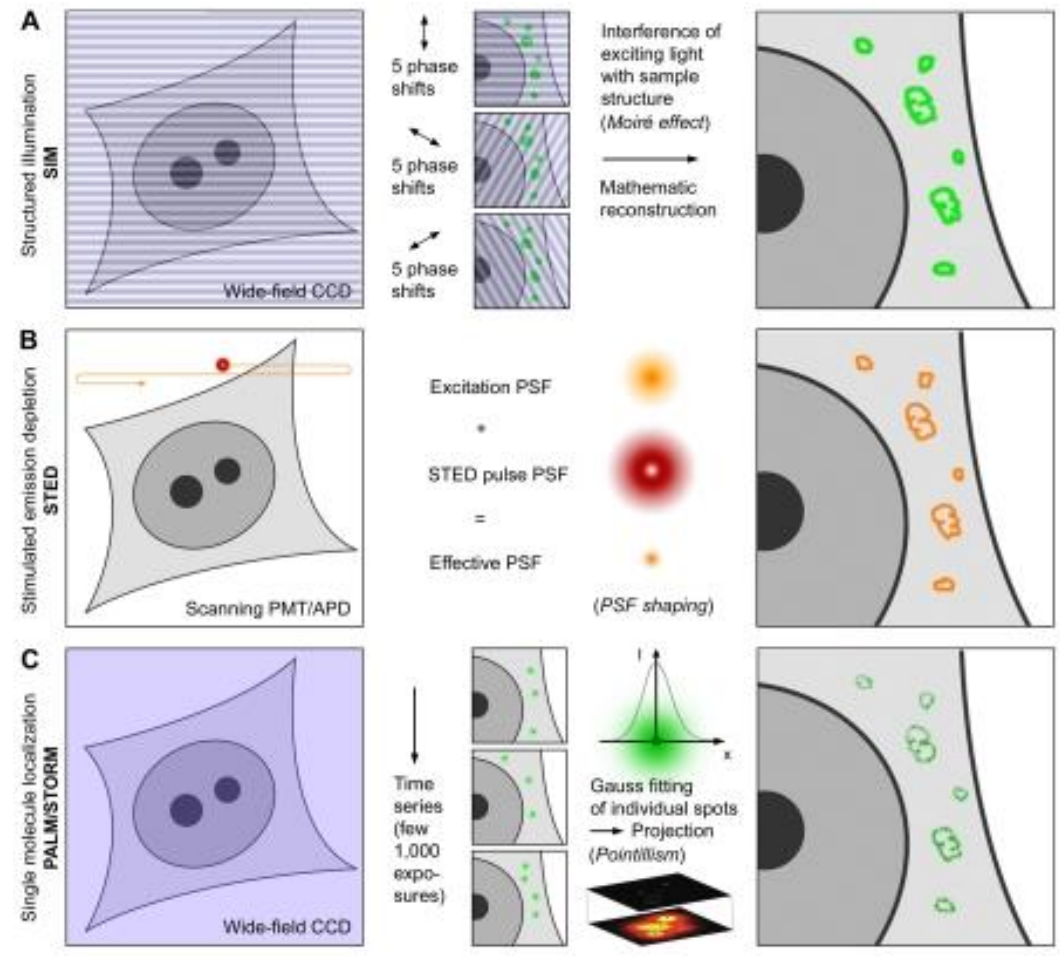

\section{Abbildung 8: Übersichtsdarstellung hochauflösender Mikroskopieverfahren.}

A) SIM: Die bekannte, die Zielstrukturen (grün) überlagernde, Gitterstruktur wird im Zuge der Bildgebung wiederholt verlagert. Durch mathematische Rekonstruktion mit Hilfe der Überlagerungsbilder wird die Zielstruktur darstellbar. B) STED: Ein zentraler, anregender Laser (orangener Kreis) wird durch einen inaktivierenden Laserstrahl (roter Kreis) überlagert. Der kombinierte Strahl scannt die Probe kontinuierlich ab. Eine zentrale Phasenplatte senkt die Intensität des inaktivierenden Lasers auf null. Emittiertes Licht kann nur zentral detektiert werden. Die Punktspreizfunktion (PSF) wird im Zentrum des kombinierten Strahls auf ein Volumen unterhalb des Abbe-Limits reduziert. C) PALM/STORM: Pro Einzelaufnahme wird nur eine Teilmenge aller vorhandenen Fluorophore angeregt (grüne Punkte) und detektiert. Durch Gaußsche Kurvenanpassung wird im Anschluss die Lokalisation der Fluorophore bestimmt und das Gesamtbild rekonstruiert (entnommen und modifiziert nach Schermelleh et al. 2010). Die Verwendung erfolgt mit freundlicher Genehmigung der Rockefeller University Press. 


\subsubsection{Expansionsmikroskopie}

Subzelluläre präsynaptische Strukturen, wie beispielsweise synaptische Vesikel, sind mit einem Durchmesser von ca. $40 \mathrm{~nm}$ sehr klein und liegen häufig eng gruppiert mit zahlreichen weiteren Vesikeln und angrenzenden Strukturen vor. Konventionelle lichtmikroskopische Verfahren können einzelne Vesikel oder synaptische Proteine nicht auflösen (Watanabe 2016). Etablierte hochauflösende Mikroskopieverfahren, die auf der Steigerung des optischen Auflösungsvermögens beruhen, ermöglichen zwar die fluoreszenzmarkierte Untersuchung subzellulärer Strukturen, sind jedoch mit erheblichem finanziellem und technischem Aufwand verbunden (siehe Abschnitt 1.5.1).

Das Prinzip der Expansionsmikroskopie (EXM) wurde 2015 von Chen und Kollegen publiziert. EXM ergänzt die Möglichkeiten zur Durchbrechung der Diffraktionsbarriere. EXM erzielt eine Verbesserung des optischen Auflösungsvermögens diffraktionslimitierter Mikroskope durch dreidimensionale, physische Vergrößerung einer Probe um das ca. 4,5-fache. Die, mit beispielsweise einem Konfokalmikroskop, effektiv erreichbare Auflösung wird sowohl lateral als auch axial um diesen Faktor gesteigert. Zellen oder Gewebe werden gemeinsam mit Fluoreszenzmarkern in ein Polyelektrolytgel eingebettet und an diesem verankert. Nach Auflösung vorhandener Proteinstrukturen, durch proteolytische Vorbehandlung, expandiert das Gel durch Wasserzugabe und zieht die, an ihm verankerten Fluoreszenzmarker, bei weitestgehend ausbleibenden Verzerrungen, in allen Ebenen des Raums auseinander. Nach abgeschlossener Expansion ermöglicht die Expansionsmikroskopie die Darstellung subzellulärer Kleinststrukturen mit einer lateralen Auflösung von 60-70 nm mit Hilfe eines gewöhnlichen Konfokal-, oder Epifluoreszenzmikroskops. Das erreichbare axiale Auflösungsvermögen liegt bei $200 \mathrm{~nm}$. Gewebe, wie beispielsweise Gehirngewebe, können mittels EXM bis zu einer axialen Tiefe von ca. $100 \mu \mathrm{m}$ untersucht werden. Andere hochauflösende Mikroskopieverfahren ermöglichen lediglich die Untersuchung bis zu einer axialen Tiefe von ca. $10 \mu \mathrm{m}$ (Chen F et al. 2015). Mittels EXM können sowohl Proteine als auch RNA in beispielsweise intaktem Rattengehirngewebe, markiert, am Polyelektrolytgel verankert und untersucht werden (Chen F et al. 2016). Die, zur Durchführung der EXM, benötigten Materialien sind weit verbreitet. Die stark wasserbindenden Eigenschaften der verwendeten Polyacrylamidgele sind seit langem bekannt (Tanaka et al. 1980) und finden beispielsweise Einsatz in Windeln. 
Die Verwendung von Acrylatestern zur antigenerhaltenden Einbettung biologischer Proben wurde bereits im Rahmen der Elektronenmikroskopie angewandt (Newman et al. 1983; Micheva und Smith 2007). Die Expansionsmikroskopie kombiniert somit bekannte Einsatzmöglichkeiten verbreiteter Materialien miteinander und ermöglicht somit hochauflösende Mikroskopie unter deutlich geringerem finanziellem und technischem Aufwand als mir anderen hochauflösenden Mikroskopieverfahren. Abbildung 9 verdeutlicht den molekularen Mechanismus der Gelexpansion und zeigt den visuellen Unterschied zwischen dem nicht-expandierten und dem expandierten Zustand eines expansionsmikroskopisch präparierten Rattenhirnschnittes.

A

(i)

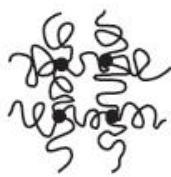

(ii)
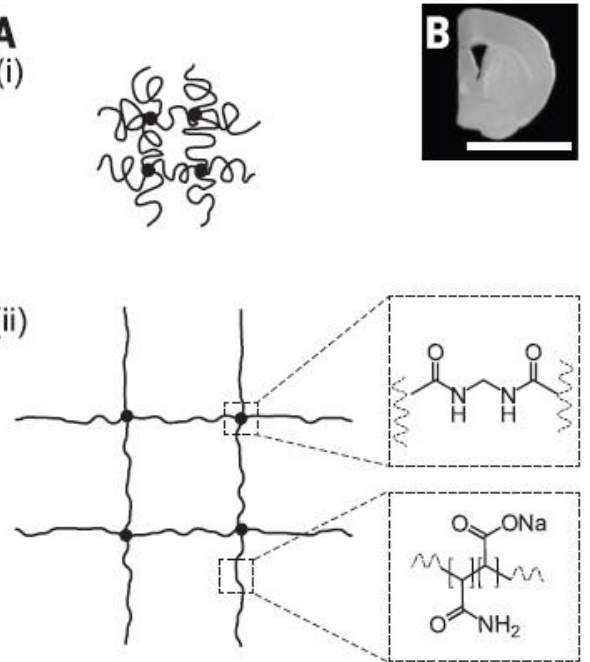

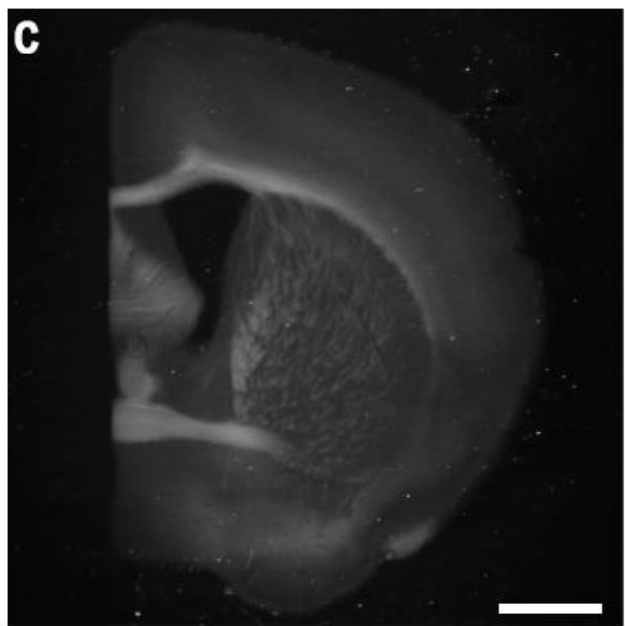

\section{Abbildung 9: Molekularer und visueller Unterschied zwischen Zustand vor und nach Expansion eines Rattenhirnschnittes.}

A(I) Schematische Darstellung des Polyelektrolytnetzwerkes vor Wasserzugabe, Punkte stellen die Quervernetzer da, Linien die Polymerketten. A(II) expandiertes Netzwerk nach Wasserzugabe. B) Fotografie eines fixierten Hirnschnitts (Maus) C) Fotografie desselben Hirnschnitts nach Wasserzugabe mit deutlich erkennbarer Expansion. Maßstableiste $=5 \mathrm{~mm}$ (entnommen und modifiziert nach Chen F et al. 2015). Die Verwendung erfolgt mit freundlicher Genehmigung von The American Association for the Advancement of Science.

Im Vergleich zu SIM, STED und STORM werden mit EXM ähnliche, teilweise sogar verbesserte Ergebnisse hinsichtlich der Darstellung verschiedener Strukturen erzielt werden (Chen F et al. 2015). Abbildung 10 stellt das optische Auflösungsvermögen von EXM und SIM anhand immunologisch markierter Mikrotubuli gegenüber. 

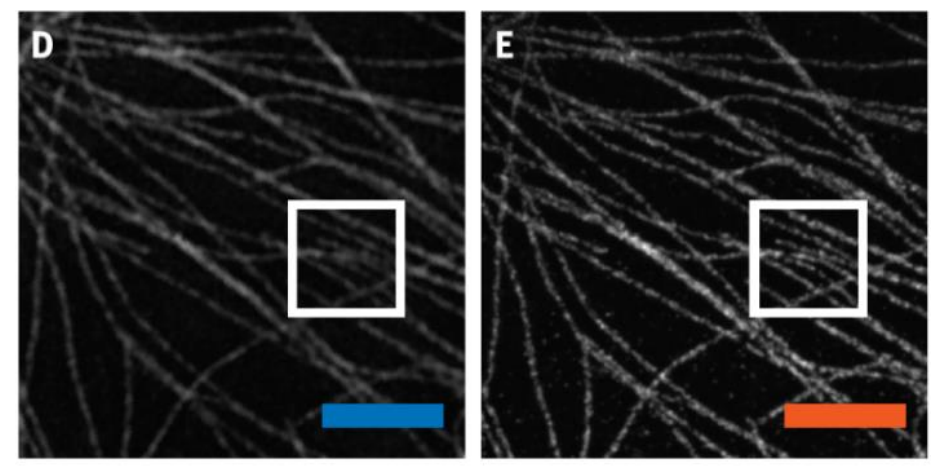

\section{Abbildung 10: Optischer Auflösungsvergleich zwischen EXM und SIM.}

Mikrotubulinetzwerke werden nach Expansion durch ein Konfokalmikroskop (E, rote Maßstabsleiste) schärfer aufgelöst als mittels SIM (D, blaue Maßstabsleiste) (entnommen und modifiziert nach Chen F et al. 2015). Die Verwendung erfolgt mit freundlicher Genehmigung von The American Association for the Advancement of Science.

Die Präparation vorliegender Proben zur Untersuchung mittels EXM ist aufgrund einzuhaltender Inkubationszeiten zeitaufwendig, der benötigte aktive Arbeitseinsatz ist gering (Gesamtdauer des Prozesses: 3 Tage, aktiver Arbeitseinsatz ca. 5 Stunden) und die Bildgebung erfolgt im Vergleich zu anderen hochauflösenden Mikroskopieverfahren schnell (wenige Minuten). Tillberg und Kollegen schlussfolgerten, dass die meisten hochauflösenden Mikroskopieverfahren zur Bildgebung deutlich mehr Zeit benötigen als diffraktionslimitierte Verfahren, da sie wesentlich mehr Voxel pro Volumeneinheit auflösen müssen. Die physische Trennung der Voxel im Zuge der EXM ermöglicht einen, mit diffraktionslimitierten Mikroskopen vergleichbaren, hohen Voxeldurchsatz bei gleichzeitig ähnlicher Voxelgröße im Vergleich zu anderen hochauflösenden Mikroskopieverfahren (Tillberg et al. 2016).

Ursprünglich wurden, gemäß der Erstpublikation von Chen und Kollegen, zur EXM Biomoleküle mittels trifunktioneller Oligonukleotidmarker markiert. Sie binden sowohl an ihre Zielstruktur als auch an das Polymernetzwerk und können so die Verdauung durch Proteasen überstehen. Ein Fluorophor diente der Visualisierung der Zielstruktur, ein Oligonukleotid ermöglicht die Hybridisierung an eine komplementäre Struktur wie beispielsweise einen sekundären Antikörper und die Methacryloylgruppe ermöglicht die Verankerung der Fluoreszenzmarker am Polymernetzwerk (Chen F et al. 2015). Abbildung 11 zeigt die Struktur eines ursprünglich bei der EXM verwendeten trifunktionellen Markers und dessen Funktionsprinzip im Zuge der Probenpräparation. 

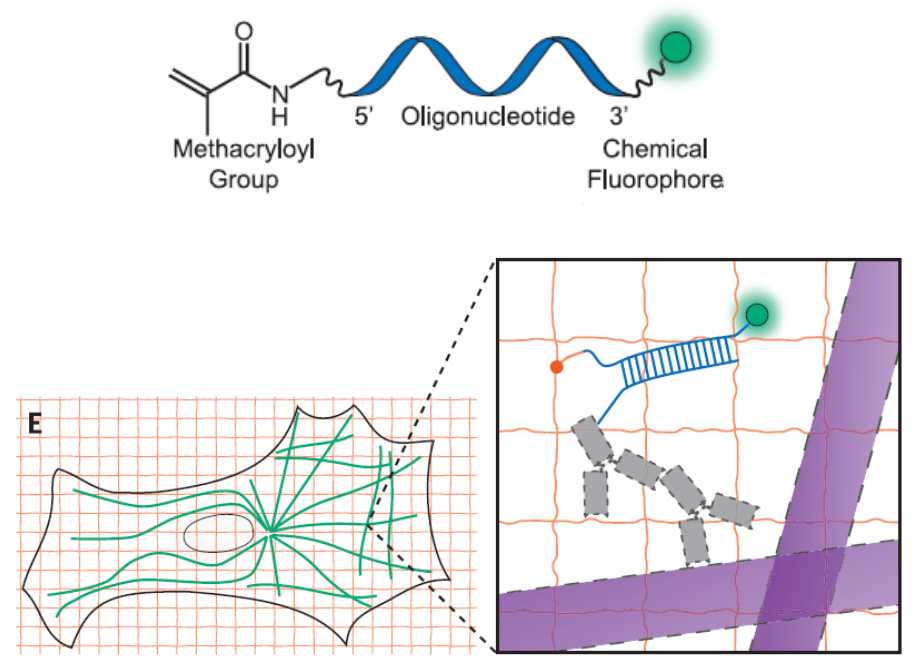

\section{Abbildung 11: Schematische Darstellung eines ursprünglich bei der Expansions- mikroskopie verwendeten Markers und Prinzip der Expansionsmikroskopie.}

Oben: Trifunktioneller Marker mussten aufwendig synthetisiert werden. Unten-links: Schematische Darstellung des Gewebe-Polymer-Composites: Zelle (schwarze Umrandung), Mikrotubuli (Grün) und Polymernetzwerk (Orange). Unten-rechts: Über die Methacryloylgruppe (orangener Punkt) in das Polymernetzwerk eingebetteter Marker, bindet an einen sekundären Antikörper (obere graue Struktur), der über einen primären Antikörper (untere graue Struktur) an einen Mikrotubulus (violett) bindet. Der Marker verbleibt nach Proteolyse der Proteinstrukturen (gestrichelte Linien) an dieser Position verankert (entnommen und modifiziert nach Chen $\mathrm{F}$ et al. 2015). Die Verwendung erfolgt mit freundlicher Genehmigung von The American Association for the Advancement of Science.

Weiterführende Untersuchungen, von Chozinski und Kollegen, zeigten, dass die aufwendig herzustellenden individuellen trifunktionellen Fluoreszenzmarker durch kommerziell verfügbare Fluoreszenzmarker ersetzt werden können. Durch Vorbehandlung der zu untersuchenden Proben mit Methacrylsäure N-Hydroxysuccinimidylester (MA-NHS) beziehungsweise Glutaraldehyd (GA) wird die Anwendung konventioneller, sekundärer Fluoreszenzantikörper ermöglicht. Durch diese Vorbehandlung verbleiben auch nach abgeschlossener Proteaseverdauung ausreichend viele Antikörperfragmente am Polymernetzwerk gebunden, deren Fluoreszenzsignale registriert werden können. Zur Untersuchung von Gehirngewebe eignet sich besonders die Vorbehandlung der Proben mit MANHS da Hintergrundsignale vermindert auftreten, die Vorbehandlung mit GA hingegen birgt Vorteile bei der Untersuchung kultivierter Zellen. Hierdurch wurde das Verfahren weiter vereinfacht, vergünstigt und die Bildgebung hinsichtlich ihrer Helligkeit gegenüber dem ursprünglichen Vorgehen um den Faktor 3-4 verbessert (Chozinski et al. 2016). 
Eine weitere Vereinfachung des Verfahrens erfolgte durch die Entwicklung der Proteinretentions-Expansionsmikroskopie (Protein-Retention Expansion Microscopy (ProEXM)) durch Tillberg und Kollegen. Hierbei wird durch Verwendung des kommerziell verfügbaren Quervernetzermoleküls ([Acryloyl-]Amino)-Hexanosäure, Succinimidylester (Acryloyl-X) die direkte Verankerung proteasestabiler, fluoreszierender Antikörper am Acrylatgel sowie die Darstellung fluoreszierender Proteine ermöglicht. ProEXM verankert kommerziell verfügbare, sekundäre Antikörper und fluoreszierender Proteine und erhält deren Fluoreszenz nach unspezifischer Proteolyse der zu untersuchenden Probe (Tillberg et al. 2016). ProEXM stellt das aktuell einfachste und am weitesten verbreitete Protokoll zur Durchführung der Expansionsmikroskopie dar und bildet die Grundlage dieser Arbeit. Die Struktur des Quervernetzers Acryloyl-X wird in Abbildung 12 dargestellt.

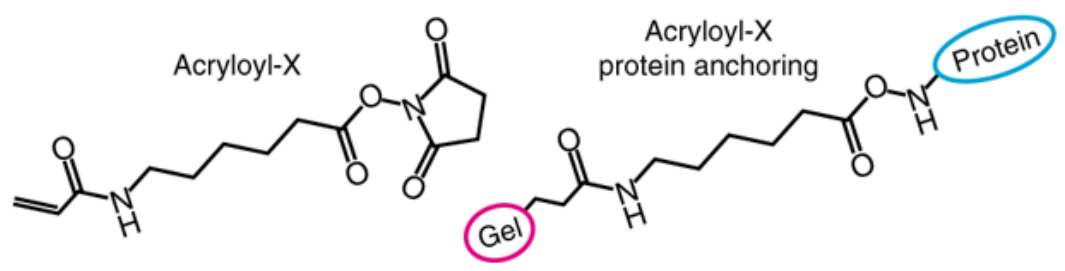

\section{Abbildung 12: Strukturformel und Verankerungspartner des Acryloyl-X.}

Acryloyl-X ermöglicht die direkte Verankerung eines Proteins (zum Beispiel Fluoreszenzantikörper) am Polyelektrolytgel (entnommen und modifiziert nach Truckenbrodt et al. 2019). Die Verwendung erfolgt mit freundlicher Genehmigung des Springer Nature Verlages.

Vorbereitend zur ProEXM werden fixierte Proben in das Polyelektrolytgel eigebettet und an dem Polymernetzwerk verankert. Zielstrukturen werden mit Fluoreszenzantikörpern markiert. Die Verankerung der Probe am Polyelektrolytgel erfolgt mittels Acryloyl-X. Das Polyelektrolyt besteht aus Natriumacrylatmonomeren, dem Comonomer Acrylamid, sowie dem quervernetzer N-N'-Methylenbisacrylamid. Durch Zugabe des Initiators Ammoniumpersulfat sowie des Akzelerators Tetramethylethylendiamin wird eine radikalische Polymerisation gestartet, aus der ein Gewebe-Polymer-Composite hervorgeht. Im Anschluss werden nicht am Gel verankerte Proteinstrukturen durch Zugabe einer Protease zersetzt, sodass eine Expansion der verankerten Moleküle samt Fluoreszenzmarker ermöglicht wird. Nach abgeschlossener Proteolyse und folgender Dialyse in Wasser expandieren die Polyelektrolytegele stark und führen somit zu einer Expansion der eingebetteten und verankerten Probe (vgl. Protokolle in Asano et al. 2018 und Abschnitt 2). 


\subsection{Ziel dieser Arbeit}

Das Grundprinzip synaptischer Übertragung, sowie die Funktion zahlreicher synaptischer Proteine sind bekannt. Das detaillierte Zusammenspiel dieser Proteine, die Regulierung synaptischer Prozesse, sowie die genaue subzelluläre Verteilung synaptischer Proteine in verschiedenen Neuronentypen aus unterschiedlichen Bereichen des zentralen Nervensystems sind jedoch weitestgehend unbekannt. Zum Verständnis von Unterschieden in Frequenz und Stärke synaptischer Übertragung zwischen Neuronen verschiedenen Typs und letztendlich zum Verständnis der Funktion des zentralen Nervensystems sind diese Informationen jedoch essenziell. Komplexe zentralnervöse Vorgänge wie beispielsweise die Gedächtnisbildung, die Verknüpfung zwischen sensorischen Reizen und motorischen Reaktionen, die Entstehung von Emotionen oder den Prozess der Entscheidungsfindung können nur durch umfassendes Wissen über die Organisation von Zellen und Molekülen in neuronalen Kreisläufen beantwortet werden. Eine weitgehende Erforschung der molekularen Organisation der neuronalen Organisation würde dem Verständnis neurologischer Erkrankungen und der entsprechenden Entwicklung spezifischer Therapeutika zugutekommen. Synapsen konnten bis vor einigen Jahren lediglich durch technisch hochkomplexe und kostenintensive, hochauflösende bildgebende Verfahren dargestellt werden, was eine standardisierte Verbreitung in biologischen Laboren bis heute verzögert hat. EXM ermöglicht die breitgefächerte subzelluläre Untersuchung mehrerer Proteine in verschiedenen Neuronen- und Synapsentypen sowie in mehreren Gehirnregionen gleichzeitig mit geringerem Aufwand als alternative hochauflösende Mikroskopieverfahren. In dieser Arbeit wurden die präsynaptischen Proteine Synaptophysin, Amphiphysin, Bassoon, SNAP-25 und VGLUT 1/2 hinsichtlich Vorkommen und Verteilung in den Regionen des Hippocampus, des somatosensorischen Kortex und des motorischen Kortex anhand von expansionsmikroskopisch vergrößerten Rattenhirnschnitten untersucht. Synaptophysin und VGLUT dienten der Markierung synaptischer Vesikel, Bassoon markierte die präsynaptische aktive Zone, Amphiphysin diente der Markierung in Endozytose befindlicher Vesikel und SNAP-25 markierte die synaptische Plasmamembran. Die dieser Arbeit zugrundeliegende Proteinretentions-Expansionsmikroskopie ermöglichte die physische Vergrößerung der untersuchten Rattenhirnschnitte um den durchschnittlichen Faktor 4. Subzelluläre synaptische Strukturen im Bereich von unter 70 Nanometer konnten so mit einem Epifluoreszenzmikroskop, mit wesentlich geringerem Aufwand als bei Anwendung alternativer hochauflösender Mikroskopieverfahren, hinsichtlich ihrer Verteilung untersucht werden. 


\section{Material und Methoden}

Die Beschaffung der Ratten zur Herstellung der benötigten koronaren Hirnschnitte erfolgte von spezialisierten Laboren sowie kommerziellen Anbietern. Alle Tiere wurden gemäß den Vorschriften der Universität Göttingen und des Landesamtes für Verbraucherschutz und Lebensmittelsicherheit in Braunschweig behandelt. Die Präparatherstellung und Aufnahme der epifluoreszenzmikroskopischen Bilder wurden von Dr. Sven Truckenbrodt (Institut für Neuro- und Sinnesphysiologie, Georg-August-Universität, Humboldtallee 23, 37073 Göttingen, Deutschland) durchgeführt. Das Aktenzeichen der Tötungsantragsnummer lautet: T17/08.

\subsection{Einleitung}

In dieser Arbeit wurden die präsynaptischen Testproteine Synaptophysin, Bassoon, Amphiphysin, VGLUT 1/2 und SNAP-25, anhand expansionsmikroskopisch präparierter Epifluoreszenzaufnahmen, hinsichtlich ihrer subzellulären Verteilung und relativen Mengen, im Vergleich verschiedener Regionen des Hippocampus und des Cortex Cerebri des Rattenhirns untersucht (siehe Abschnitt 7.1 im Anhang; Anzahl der jeweils untersuchten präsynaptischen Signale pro Testprotein, pro Hirnregion). Hierbei wurden drei verschiedene Teilbereiche eines jeden Hirnschnittes hinsichtlich der Halbwertsbreite (FWHM) und der Intensität (Fluoreszenzpeak) der detektierten Fluoreszenzsignale der Testproteine untersucht. Die untersuchten Hirnschnitte wurde mit spezifischen primären und sekundären Antikörpern gegen Synaptophysin, Bassoon und das jeweils zu untersuchende, zusätzliche Testprotein markiert. Synaptophysin und Bassoon, als Hauptproteine der durchgeführten Untersuchung, wurden in jedem Rattenhirnschnitt immunologisch markiert und dienten zusätzlich bei der Untersuchung der weiteren Testproteine als Markierung für wahrscheinlich präsynaptische Signale. In Assoziation detektierte Fluoreszenzsignale dieser beiden Proteine wurden als wahrscheinlich präsynaptische Signale angesehen. Bei isoliert detektierten Fluoreszenzsignalen dieser beiden Proteine und/oder des zusätzlichen Testproteins wurden die Signale als Artefakte angesehen und von der anschließenden Analyse ausgeschlossen. Die Analyse und Auswertung der detektierten Fluoreszenzsignale erfolgte anhand durchschnittlicher Fluoreszenzbilder der Testproteine in den unterschiedlichen Hirnregionen.

Die Kombination der EXM mit der Auswertung durchschnittlicher Fluoreszenzbilder präsynaptischer Fluoreszenzsignale wurde in dieser Form zuvor nicht angewandt. Der 
interessierte Leser findet zusätzliche Beschreibungen, hinsichtlich der Erstellung durchschnittlicher Fluoreszenzaufnahmen und deren Auswertung, in Löschberger et al. 2012 und Wilhelm et al. 2014. Ausführliche labortechnische Verfahrensanweisungen für expansionsmikroskopische Untersuchungen verschiedener biologischer Substrate finden sich in Asano et. Al 2018 (siehe Quellenverzeichnis). Die anwendungsspezifische Untersuchung der, durch Dr. Sven Truckenbrodt präparierten Hirnschnitte, wird ausführlich in Abschnitt 2.4 beschrieben. Die, zur Durchführung der dieser Arbeit zugrundeliegenden Variante der Expansionsmikroskopie, verwendeten Chemikalien, Lösungen und Antikörper werden, zum besseren Verständnis, im Folgenden in den Tabellen 1, 2, 3, 4, 5, 6, 7, 8 und 9 aufgeführt. Das labortechnische Verfahren der Expansionsmikroskopie wird zum besseren Verständnis der durchgeführten Datenanalyse aus Abschnitt 2.4 in Abschnitt 2.3 beschrieben.

\subsection{Chemikalien}

\subsubsection{Fixierung und Fluoreszenzantikörpermarkierung}

Tabelle 1: Zusammensetzung der Rattenhirn-Fixierungslösung.

\begin{tabular}{l|l|l}
\hline Chemikalie & $\begin{array}{l}\text { Lagerlösung } \\
\text { in Volumenprozent }\end{array}$ & $\begin{array}{l}\text { Endverdünnung } \\
\text { in Volumenprozent }\end{array}$ \\
\hline Paraformaldehyd & 16 & 4 \\
in phosphatge- & & \\
pufferter Salzlö- & & \\
sung (PBS) & & \\
\hline
\end{tabular}

Tabelle 2: Zusammensetzung der Blockierlösung.

\begin{tabular}{l|r}
\hline Chemikalie & \multicolumn{2}{|c}{ Volumenprozent in PBS-Lösung } \\
\hline Bovie Serum Albumin (BSA) & 5,0 \\
\hline Triton X-100 & 0,1 \\
\hline
\end{tabular}


Tabelle 3: Zusammensetzung der Immersionslösung.

\begin{tabular}{|c|c|c|}
\hline Chemikalie & $\begin{array}{l}\text { Lagerlösung } \\
\text { (Menge) }\end{array}$ & $\begin{array}{l}\text { Zusammensetzung } \\
\text { in Endkonzentration }\end{array}$ \\
\hline PBS & $10 x$ & $1 \mathrm{x}$ \\
\hline Saccharose & $150 \mathrm{~g}$ & $30 \%(\mathrm{w} / \mathrm{v})$ \\
\hline Glycin & $3,75 \mathrm{~g}$ & $100 \mathrm{mM}$ \\
\hline Wasser & $\begin{array}{l}\text { Bis zu einem Gesamtvolu- } \\
\text { men von } 500 \mathrm{ml} \text { hinzuge- } \\
\text { fügt }\end{array}$ & \\
\hline
\end{tabular}

Tabelle 4: Antikörper.

\begin{tabular}{l|l|l|l}
\hline Testprotein & Primärer Antikörper & Sekundärer Antikörper & $\begin{array}{l}\text { Lagerlösun- } \\
\text { gen } \\
\text { in mg/ml }\end{array}$ \\
\hline Synaptophysin & $\begin{array}{l}\text { Meerschweinchen, } \\
\text { polyklonal, Synaptic Sys- } \\
\text { tems, 101 004 }\end{array}$ & $\begin{array}{l}\text { Anti-Meerschweinchen, } \\
\text { Alexa 488, Jackson, } \\
706-545-148\end{array}$ & 1 \\
\hline Bassoon & $\begin{array}{l}\text { Maus, monoklonal, } \\
\text { Enzo, SAP7F407 }\end{array}$ & $\begin{array}{l}\text { Anti-Maus, CF633, } \\
\text { Biotium, 20124 }\end{array}$ & 1 \\
\hline SNAP-25 & $\begin{array}{l}\text { Hase, polyklonal, } \\
\text { Synaptic Systems, 111 } \\
002\end{array}$ & $\begin{array}{l}\text { Anti-Hase, Alexa 546, } \\
\text { Thermo Fisher Scientific, } \\
\text { A-11035 }\end{array}$ & 1 \\
\hline VGLUT 1/2 & $\begin{array}{l}\text { Hase, polyclonal, } \\
\text { Synaptic Systems, 135 } \\
503\end{array}$ & $\begin{array}{l}\text { Anti-Hase, Alexa 546, } \\
\text { Thermo Fisher Scientific, }\end{array}$ & \\
\hline Amphiphysin & $\begin{array}{l}\text { Hase, polyklonal, } \\
\text { Synaptic Systems, 120 } \\
002\end{array}$ & $\begin{array}{l}\text { Anti-Hase, Alexa 546, } \\
\text { Thermo Fisher Scientific, } \\
\text { A-11035 }\end{array}$ & 1 \\
\hline
\end{tabular}




\subsubsection{Gelierung}

Tabelle 5: Zusammensetzung der Monomerlösung.

\begin{tabular}{l|r|r|r}
\hline Chemikalie & $\begin{array}{l}\text { Lagerlösung } \\
\text { in } \mathbf{g} / \mathbf{1 0 0} \mathbf{~ m l *}\end{array}$ & $\begin{array}{l}\text { Endkonzentration } \\
\text { in g/100 } \mathbf{~ m l ~}\end{array}$ & $\begin{array}{l}\text { Volumen } \\
\text { in ml }\end{array}$ \\
\hline Natriumacrylat & 38 & 8,6 & 2,25 \\
\hline Acrylamid & 50 & 2,5 & 0,5 \\
\hline N,N'-Metylenbisacrylamid & 2 & 0,15 & 0,75 \\
\hline Natriumchlorid & 29,2 & 11,7 & 4 \\
\hline PBS & $10 x$ & $1 \times$ & 1 \\
\hline Wasser & & & 0,9 \\
\hline & & Gesamt & $\mathbf{9 , 4}$ \\
\hline
\end{tabular}

*mit Ausnahme PBS

Tabelle 6: Zur Herstellung der Gelierungslösung benötigte Lösungen.

\begin{tabular}{l|l|r|r}
\hline Lösung & Zusammensetzung & $\begin{array}{l}\text { Lagerlösung } \\
\text { in } \mathbf{~ g / 1 0 0 ~} \mathbf{~ m l}\end{array}$ & $\begin{array}{l}\text { Endkonzentration } \\
\text { in g/100 ml }\end{array}$ \\
\hline Inhibitorlösung & $\begin{array}{l}\text { 4-Hydroxy-2,2,6,6-tetra- } \\
\text { methylpiperidinyloxyl } \\
\text { (4-hydroxy-TEMPO) }\end{array}$ & 0,5 & 0,01 \\
\hline Akzeleratorlösung & $\begin{array}{l}\text { Tetramethylethylendia- } \\
\text { min }\end{array}$ & 10 & 0,2 \\
\hline Initiatorlösung & Ammoniumpersulfat & 10 & 0,2 \\
\hline
\end{tabular}


Tabelle 7: Zusammensetzung der Gelierungslösung pro untersuchtem Hirnschnitt und Funktion ihrer Bestandteile.

\begin{tabular}{l|r|l}
\hline Lösung & Volumen in $\boldsymbol{\mu l}$ & Funktion \\
\hline Monomerlösung & 188 & Ausbildung eines Polymernetzwerkes \\
\hline Inhibitorlösung & 4 & $\begin{array}{l}\text { Inhibiert die vorzeitige Polymerisation } \\
\text { der Monomere }\end{array}$ \\
\hline Akzeleratorlösung & 4 & Beschleunigt die Radikalbildung \\
\hline Initiatorlösung & 4 & Initiiert die Gelierung \\
\hline Gesamt & $\mathbf{2 0 0}$ & \\
\hline
\end{tabular}

\subsubsection{Herstellung der Gelierungslösung}

Die Herstellung der Gelierungslösung erfolgte vorbereitend durch Vermengung der Monomerlösung, der Inhibitorlösung und der Akzeleratorlösung (siehe Tabellen 5 und 6) in Reaktionsgefäßen, unter Eiskühlung mit Hilfe eines Vortexmischers. Das Volumen und die Zusammensetzung der vermengten Lösungen können Tabelle 7 entnommen werden. Für jeden Hirnschnitt wurden $200 \mu \mathrm{l}$ Gelierungslösung hergestellt. Die Initiatorlösung wurde erst im weiteren Verlauf der Hirnschnittpräparation, nach ausreichender Inkubation der Hirnschnitte mit Monomerlösung, hinzugegeben, um eine ausreichende Durchsetzung der Hirnschnitte mit Monomeren zu erzielen und eine vorzeitige Gelierung zu vermeiden (siehe Abschnitt 1.5.2). 


\subsubsection{Proteinverankerung und Proteinverdauung}

Tabelle 8: Zusammensetzung des Verdaupuffers.

\begin{tabular}{|c|c|c|}
\hline Chemikalie & \begin{tabular}{|l} 
Menge \\
In variierenden \\
Einheiten
\end{tabular} & $\begin{array}{l}\text { Endkonzentration } \\
\text { In variierenden Einheiten } / 100 \mathrm{ml} \\
\text { Lösung* }\end{array}$ \\
\hline Triton-X & $2,5 \mathrm{~g}$ & $0,5 \mathrm{~g}$ \\
\hline EDTA & $0,146 \mathrm{~g}$ & $0,027 \mathrm{~g}$ \\
\hline Tris $(\mathrm{pH} 8)$ & $25 \mathrm{ml}$ & $5 \mathrm{ml}$ \\
\hline $\mathrm{NaCl}$ & $23,38 \mathrm{~g}$ & $4,67 \mathrm{~g}$ \\
\hline Guanidin HCL & 8 M Lagerlösung & $0,8 \mathrm{M}$ \\
\hline Wasser $\left(\mathrm{ddH}_{2} \mathrm{O}\right)$ & $\begin{array}{l}\text { Bis zu einem Ge- } \\
\text { samtvolumen von } \\
500 \mathrm{ml} \text { hinzuge- } \\
\text { fügt }\end{array}$ & \\
\hline Proteinase $\mathrm{K}$ & $\begin{array}{l}\text { Verdünnung } \\
1: 100\end{array}$ & $\begin{array}{l}800 \text { Einheiten }(=8 \text { Einheiten } / \mathrm{ml}) \\
\text { Zugabe erst unmittelbar vor Schritt } \\
2.3 .6\end{array}$ \\
\hline Gesamt & $500 \mathrm{ml}$ & \\
\hline
\end{tabular}

*mit Ausnahme Guanidin HCL, Wasser und Proteinase K

Tabelle 9: Zusammensetzung der Acryloyl-X-Lösung.

\begin{tabular}{l|l|lr}
\hline Chemikalie & $\begin{array}{l}\text { Lagerlösung } \\
\text { in mg/ml Dimethyl- } \\
\text { sulfoxid }\end{array}$ & $\begin{array}{l}\text { Endkonzentration nach } \\
\text { Verdünnung in PBS } \\
\text { in } \mathbf{~ m g / m l ~}\end{array}$ \\
\hline $\begin{array}{l}\text { 6-([Acryloyl]Amino) Hexanosäure, } \\
\text { Succinimidylester } \\
\text { (Acryloyl-X, SE) }\end{array}$ & & 0,1 \\
\hline
\end{tabular}




\subsection{Labortechnisches Verfahren der Expansionsmikroskopie}

\subsubsection{Fixierung der Rattenhirne und Herstellung der Schnittpräparate}

Die Rattenhirnschnitte wurden aus Gehirnen adulter Ratten (Alter 6 bis 8 Wochen) präpariert, die mittels $\mathrm{CO}_{2}$ euthanisiert wurden. Nach Perfusion, zur Blutentfernung, mittels PBS erfolgte die Fixierung der Gehirne bei Raumtemperatur über Nacht in Fixierungslösung (siehe Tabelle 1). Nach Fixierung und Entfernung der Rattenhirne aus den Rattenschädeln erfolgte die anschließende Konservierung der Rattenhirne in Hirnschnittimmersionslösung (siehe Tabelle 3) bei $4^{\circ} \mathrm{C}$ über 24 Stunden. Die Rattenhirne wurden anschließend in einer Lösung, bestehend aus 30 \% Saccharose in phosphatgepufferter Salzlösung (PBS), eingebettet und mittels Trockeneis und 2-Methylbutan eingefroren. Mit Hilfe eines Kryotoms wurden 20-25 $\mu$ m dicke Schnittpräparate der Rattenhirne hergestellt. Die Schnittpräparate wurden anschließend bei $4^{\circ} \mathrm{C}$ in PBS, in Mikrotiterplatten für Gewebekulturen mit zwölf Näpfchen gelagert.

\subsubsection{Primäre Antikörperfärbung}

Die Schnittpräparate wurden zunächst für 30 Minuten bei Raumtemperatur in Blockierlösung permeabilisiert (siehe Tabelle 2). Dieser Arbeitsschritt sollte unspezifische Antikörperbindungen reduzieren. Die primären Antikörperlösungen (siehe Tabelle 4) wurden mittels PBS und 2,5 \% BSA im Verhältnis 1:100 verdünnt. Im Anschluss wurden die Schnittpräparate über Nacht in Blockierlösung bei $4^{\circ} \mathrm{C}$ auf einem Rüttler mit, zur jeweiligen Zielstruktur passenden, primären Antikörpern versetzt. Abschließend erfolgten vier Waschungen über je 10 Minuten mit Blockierlösung, um ungebundene Antikörper zu entfernen.

\subsubsection{Sekundäre Antikörperfärbung}

Die sekundären Antikörperlösungen (siehe Tabelle 4) wurden mittels PBS und 2,5\% BSA im Verhältnis 1:100 verdünnt. Die zuvor gewaschenen und in Blockierlösung gelagerten Schnittpräparate wurden über einen Zeitraum von 2 Stunden bei Raumtemperatur mit spezifischen sekundären Antikörpern versetzt. Im Anschluss erfolgten vier Waschungen über je 10 Minuten mit Blockierlösung, um nicht gebundene sekundäre Antikörper zu entfernen. 


\subsubsection{Proteinverankerung}

Die Blockierlösung wurde zunächst entfernt. Die Schnittpräparate wurden im Anschluss über Nacht bei Raumtemperatur mit Acryloyl-X-Lösung versetzt (siehe Tabelle 9), um eine ausreichende Verankerung des Acryloyl-X an den Proteinstrukturen zu gewährleisten. Dieser Schritt ermöglichte im weiteren Verlauf der Hirnschnittpräparation die Verankerung der Testproteine, einschließlich der an ihnen gebundenen Antikörper, an das Polymernetzwerk des Polyelektrolytgels. Im Anschluss erfolgten zwei Waschungen, über je 15 Minuten, mit PBS.

\subsubsection{Gelierung}

Überschüssige PBS wurde von den Hirnschnitten entfernt. Die Hirnschnitte wurden zwei Mal mit Gelierungslösung versetzt, pro Inkubation wurden hierbei $100 \mu$ l Gelierungslösung verwendet. Zunächst wurden die Hirnschnitte für 5 Minuten bei $4{ }^{\circ} \mathrm{C}$ in Mikrotiterplatten für Gewebekulturen mit zwölf Näpfchen mit Gelierungslösung versetzt. Hierbei wurde verbleibendes PBS vollständig gegen die Gelierungslösung ausgetauscht. Im Anschluss erfolgte der Austausch der Gelierungslösung und die Hirnschnitte wurden für weitere 25 Minuten mit Gelierungslösung inkubiert, um eine ausreichende Durchsetzung der Präparate mit Monomeren zu erzielen. Abschließend erfolgte durch Zugabe von Initiatorlösung (siehe Tabelle 6) die Initiation der Polymerisation. Im Anschluss wurden die Hirnschnitte in eine Gelkammer übertragen (siehe Abbildung 13) und weitere 2 Stunden in einem Inkubator bei $37^{\circ} \mathrm{C}$ mit Gelierungslösung versetzt. Die Inkubationszeit sollte einen ausreichenden Polymerisationsgrad des entstandenen Polyelektrolytgels sicherstellen. Während der Inkubationszeit erfolgten die Polymerisation der Gelmatrix und die Verankerung des Acryloyl-X und seiner gebundenen Proteinstrukturen (siehe Abschnitt 1.5.2) am entstehenden Polymer, sodass es zur Verknüpfung der jeweiligen Testproteine mit diesem kam. 


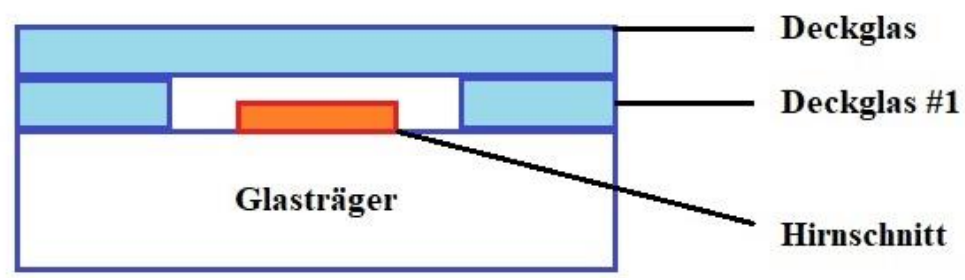

\section{Abbildung 13: Schematischer Aufbau einer Gelkammer.}

Das Schnittpräparat wird auf einem Glasträger übertragen. Durch seitliche Positionierung von Deckglasstreifen (Größe 1) kann das Schnittpräparat mit einem Deckglas während der Polymerisation des Polyelektrolytgels abgedeckt werden.

\subsubsection{Verdauung und Expansion}

Nach Abgeschlossener Gelierung wurden die Proben über Nacht, bei Raumtemperatur, in Mikrotiterplatten für Gewebekulturen mit zwölf Näpfchen mit Verdaupuffer versetzt (siehe Tabelle 8). Nach diesem Arbeitsschritt lagen die, mit Antikörpern markierten, Testproteine in ihrer ursprünglichen Position im Rattenhirnschnitt, am Polyelektrolytgel verankert vor. Andere Proteinstrukturen wurden durch den Verdaupuffer zersetzt, sodass eine Expansion des Polyelektrolytgels durch Wasserzugabe ermöglicht wurde. Die Hirnschnitte wurden im Anschluss in Plastikschälchen mit einer Kantenlänge von 15 cm umgelagert, um ausreichend Raum für die Expansion zu schaffen. Hierzu erfolgten 3 bis 5 Waschungen mit zweifach destilliertem Wasser über jeweils 15 Minuten. Sobald visuell keine Expansion der Hirnschnitte mehr erkennbar war, erfolgte kein weiterer Austausch des zweifach destillierten Wassers. Die Lagerung der expandierten Hirnschnitte erfolgte anschließend in zweifach destilliertem Wasser, in den Plastikschälchen. Die gewünschte Expansion der Hirnschnitte um den Faktor $\sim 4$ wurde abschließend validiert (vgl. Validierung in Truckenbrodt et al. 2019).

\subsubsection{Bildgebung}

Überschüssiges Wasser wurde entfernt, das Polyelektrolytgel, in das die expandierten Hirnschnitte eingebettet waren, mit Hilfe eines Skalpells zugeschnitten und in individuell hergestellte Bildgebungskammern überführt. Die Bildgebungskammern bestanden aus Kunststoff-Petrischalen mit einem Durchmesser von $60 \mathrm{~mm}$, deren Böden bis auf einen 4 bis $5 \mathrm{~mm}$ breiten Rand ausgefräst wurden. Auf den belassenen Kunststoffrand wurde Zwei-Komponenten Dentalsilikon aufgetragen und hiermit ein Deckglas 
(Durchmesser $50 \mathrm{~mm}$, Stärke 1,5) über der zentralen Öffnung der modifizierten Petrischale befestigt. Nach erneuter Entfernung überschüssigen Wassers wurde ein zweites Deckglas (Durchmesser 50 mm, Stärke 1,5) über dem Gel platziert. Dieses Vorgehen verhinderte ein Abdriften des Polyelektrolytgels während der Bildgebung. Die anschließende Bildgebung erfolgte mit einem invertierten Niko Ti Epifluoreszenzmikroskop (Nikon Corporation, Chiyoda, Tokyo, Japan) mit Plan Apochromat 100x 1,4 NA Ölimmersions-Objektiv, einer HBO 100W Lampe und einer IXON X3897 Andor Kamera (Belfast, Nordirland, Vereinigtes Königreich). Das Mikroskop wurde mit der NIS Elements AR Software betrieben (Version 4.20; Nikon). Es wurden Übersichtsbilder der Schnittpräparate bei 20-facher Vergrößerung erstellt, die unterschiedlichen Hirnregionen des Hippocampus und des Cortex Cerebri makroskopisch identifiziert und Fluoreszenzsignale der jeweils immunologisch markierten Testproteine der unterschiedlichen Hirnregionen in axial angeordneten Schichten detektiert. Abbildung 14 zeigt eine Übersichtsaufnahme eines expandierten Rattenhirnschnittes.

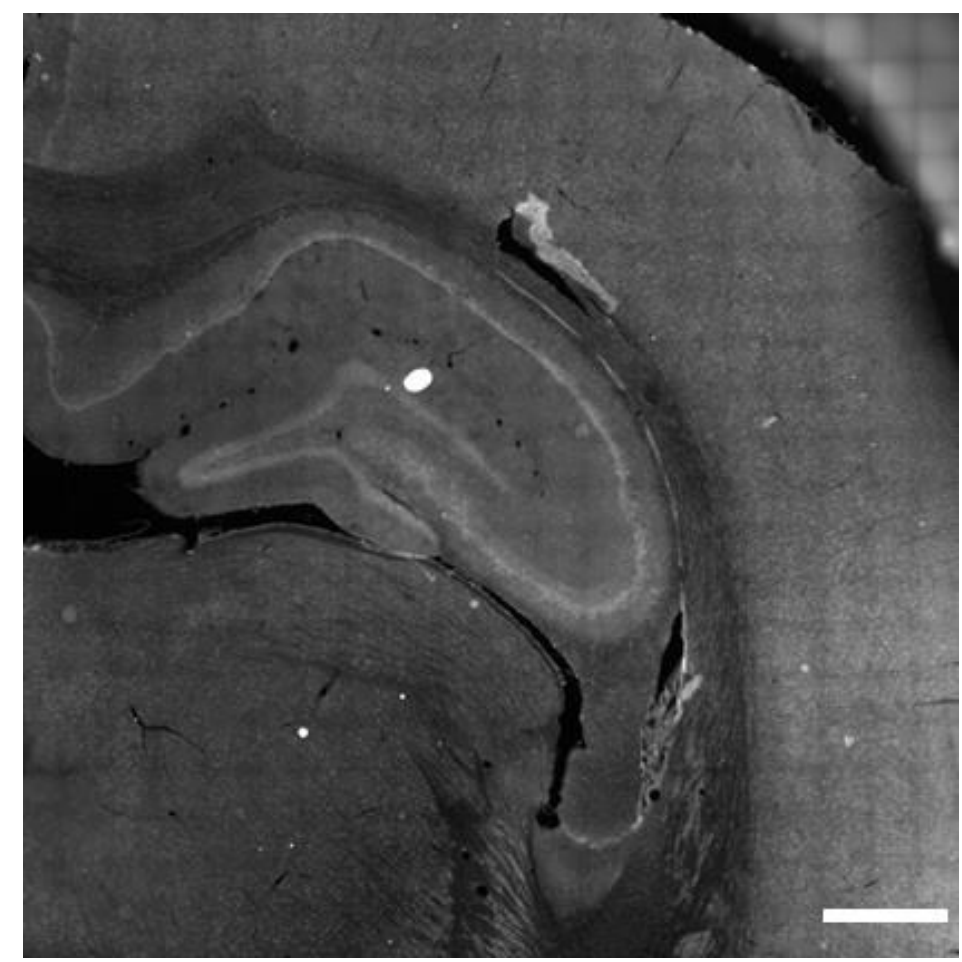

\section{Abbildung 14: Schnittpräparat eines Rattenhirns nach Expansion bei 20-facher Vergrößerung.}

Übersichtsaufnahme, bei 20-facher Vergrößerung, eines expandierten Rattenhirnschnittes. Der Hippocampus und angrenzende Regionen der Cortex Cerebri sind bei weitestgehend ausgebliebenden Verzerrungen deutlich erkennbar. Maßstabsleiste $=5 \mathrm{~mm}$. 


\subsection{Datenanalyse}

\subsubsection{Verwendete Software}

Rohdateien, der erhaltenen Epifluoreszenzaufnahmen, wurden mit der Software ImageJ (ImageJ, National Institutes of Health, Bethesda, MD, USA) zur weiteren Analyse vorbereitet. Die vorgelegten Bilddaten wurden mit Hilfe anwendungsspezifisch geschriebener Routinen (Programmiert von Prof. Dr. Silvio O. Rizzoli) für die Software MATLAB (The MathWorks Inc., Natick, MA, USA) analysiert. Die statistische Auswertung und deren graphische Darstellung erfolgte mit der Software SigmaPlot 10 (Systat Software Inc., Erkrath, Germany). Die verwendeten MATLAB-Routinen sind auf Anfrage bei Prof. Dr. Silvio O. Rizzoli erhältlich.

\subsubsection{Vorbereitung der Rohdateien}

Die erhaltenen Rohdateien wurden mit ImageJ entpackt und die, pro Epifluoreszenzaufnahme enthaltenen, drei Fluoreszenzkanäle voneinander getrennt. Die Analyse eines Hirnschnittes bestand hierbei aus insgesamt drei Bildstapeln mit jeweils 15 axial angeordneten Einzelbildern pro untersuchtem Hirnschnitt, die drei unterschiedlichen Epifluoreszenzsignalkanälen entsprachen. Die Daten des Epifluoreszenzkanal 0 bildeten die detektierten Synaptophysinfluoreszenzsignale ab, Fluoreszenzkanal 1 bildete die detektierten Fluoreszenzsignale des jeweiligen zusätzlichen Testproteins ab und Fluoreszenzkanal 2 entsprach den detektierten Bassoonfluoreszenzsignalen. Die Analyse dieser zusammengehörigen Daten wird im Folgenden als Einzelexperiment bezeichnet. Einzelbilder am oberen und/oder unteren Ende der Bildstapel ohne detektierte Fluoreszenzsignale wurden individuell über die Befehlskette „Plugins“ $\rightarrow$,Stacks-Reducing“ $\rightarrow$,Align slices in Stack“ $\rightarrow$, Substack Maker“ $\rightarrow$,OK“ entfernt. Schnittpräparate, die in das expandierte Polyelektrolytgel eingebettet waren, unterlagen im Laufe der einige Minuten dauernden Bildgebung leichten Bewegungen. Resultierende, leichte Lateralverschiebungen zwischen den einzelnen Schichten wurden durch korrekte axiale Ausrichtung der Einzelbilder anhand der detektierten Fluoreszenzsignale ausgeglichen. Die automatisierte axiale Anordnung der Einzelbilder wurde über die Befehlskette „Plugins“ $\rightarrow$ „Stacks-Shuffling“ $\rightarrow$,, Align slices in Stack“ $\rightarrow$,,Translation“ $\rightarrow$,,OK“ gestartet. Die Dateien wurden im „.TIF“-Format abgespeichert. 


\subsubsection{Bandpassfiltrierung und Summation der Fluoreszenzsignale}

Die Bandpassfiltrierung, die Erstellung von Fluoreszenzsummationsbildern und die manuelle Auswahl der zu analysierenden Teilbereiche und Fluoreszenzsignale eines jeden Hirnschnitts erfolgten mit der MATLAB-Routine ,program_start“. Nach Eintragung des korrekten Ordnerverzeichnisses der zu analysierenden Fluoreszenzaufnahmen, in die Zeile 7 der MATLAB-Routine, wurde die Routine durch die Befehlskette „Debug“ $\rightarrow$ „Run program_start“ gestartet (siehe Abbildung 15). Die Einzelbilder eines jeden Bildstapels wurden zunächst mittels eines Bandpassfilters filtriert, um vorhandene, nicht interpretierbare Störsignale zu entfernen. Signalpunkte mit der höchsten detektierten Signalintensität in Relation zur durchschnittlich detektierten Signalintensität entsprachen Ansammlungen des jeweils markierten Testproteins im jeweiligen Experiment und wurden von der MATLAB-Routine als Referenz verwendet. Fluoreszenzsignale, die hinsichtlich ihrer detektierten Signalintensität, stark von dieser Referenz abwichen sowie unscharf fokussierte Objekte, konnten so entfernt werden. Anschließend wurden die Signalintensitäten der Einzelbilder der dreidimensionalen Bildstapel auf eine Ebene summiert. In Abbildung 16 wird ein unvorbereitetes Einzelbild eines Bildstapels, im Vergleich mit einem filtriertem Fluoreszenzsummationsbild exemplarisch dargestellt. Die MATLABRoutine stellte die Fluoreszenzsummationsbilder eines jeden Fluoreszenzkanals, eines Einzelexperiments zur besseren Unterscheidung farbig dar (siehe Abbildungen 17 und 18). Die erhaltenen zweidimensionalen Fluoreszenzsummationsbilder dienten der weiteren Analyse. Einzelbilder der Bildstapel wiesen eine zu geringe Fluoreszenzsignalintensität für die, im Folgenden durchgeführte, automatische Analyse vor. Die bildliche Darstellung einzelner Arbeitsschritte erfolgt zum besseren Verständnis des Vorgehens exemplarisch anhand von vier unterschiedlichen Einzelexperimenten (Beispiele 1,2,3,4) mit entsprechender Kennzeichnung in den Bildbeschreibungen. Der Arbeitsablauf für Beispiel 1 wird im Folgenden vollständig bildlich dargestellt. 


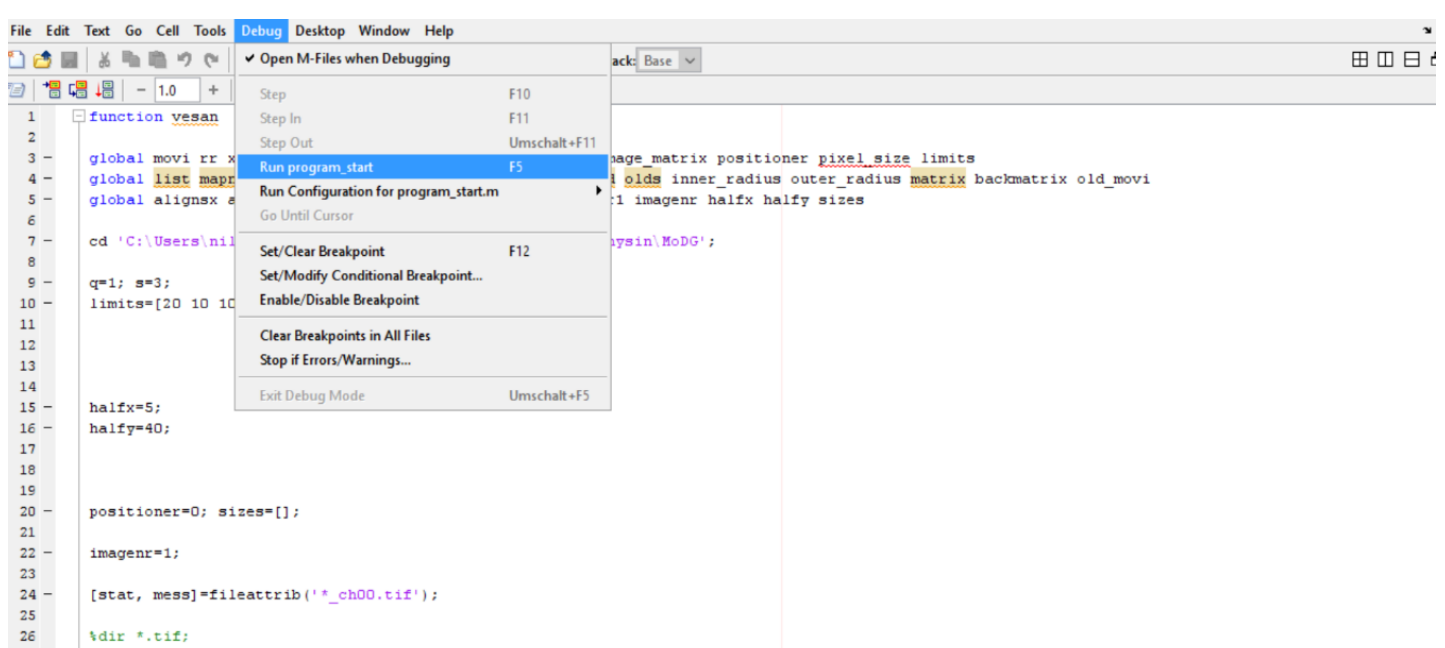

Abbildung 15: Benutzeroberfläche der MATLAB-Routine "program_start" und Befehlskette zum Start der Routine.

Das Ordnerverzeichnis der zu untersuchenden Epifluoreszenzaufnahmen wurde in Zeile 7 der MATLAB-Routine eingetragen. Die MATLAB-Routine wurde durch die Befehlskette „Debug“ $\rightarrow$ „Run program_start“" gestartet.
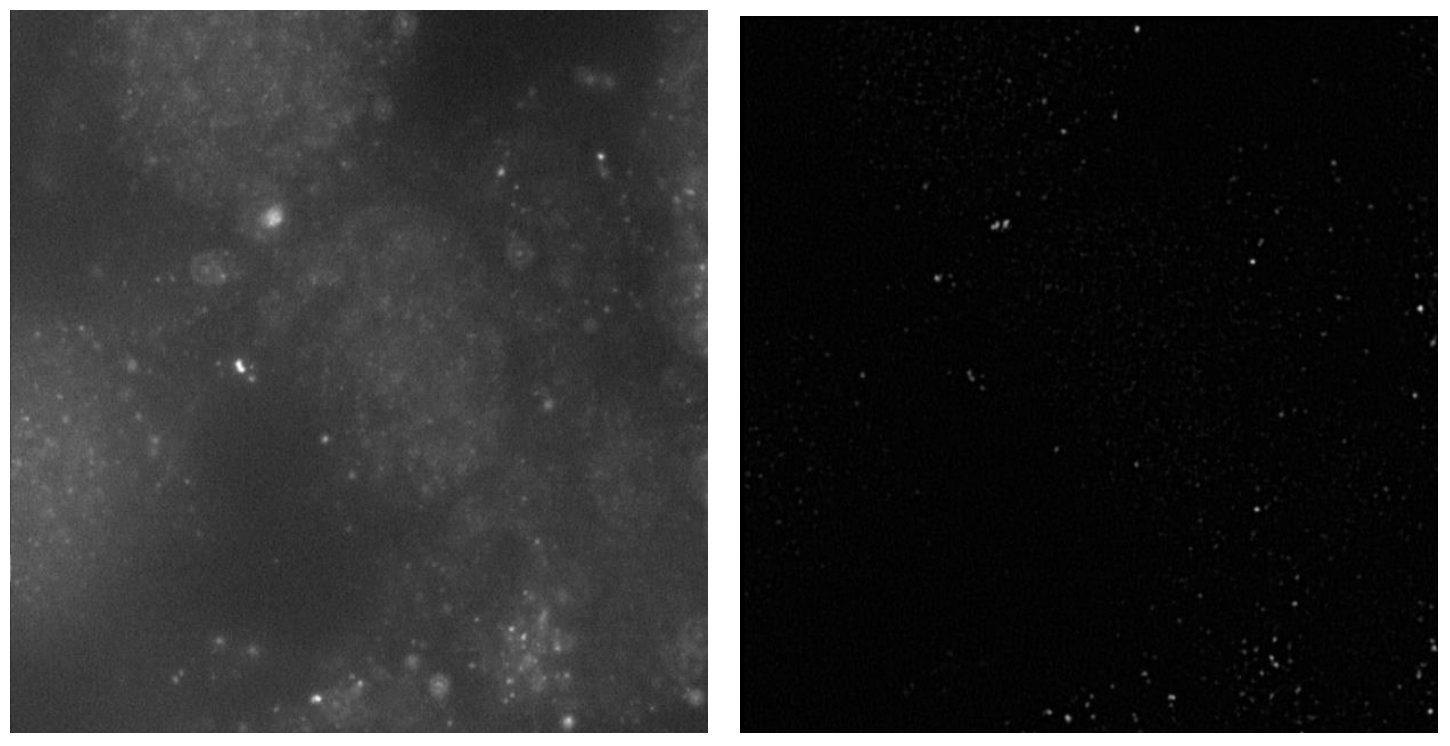

\section{Abbildung 16: Vergleich zwischen Einzelbild eines Bildstapels und erstelltem Fluo- reszenzsummationsbildes (Beispiel 1).}

Links: Einzelbilder innerhalb der Bildstapel wurden mit Hilfe eines Bandpassfilters filtriert. Rechts: Fluoreszenzsignale der dreidimensionalen Bildstapel wurden im Anschluss auf eine zweidimensionale Ebene summiert. Deutlich erkennbare Störsignale (links) konnten so, bei Zunahme der Signalintensität einzelner Signalansammlungen, reduziert werden (rechts). 


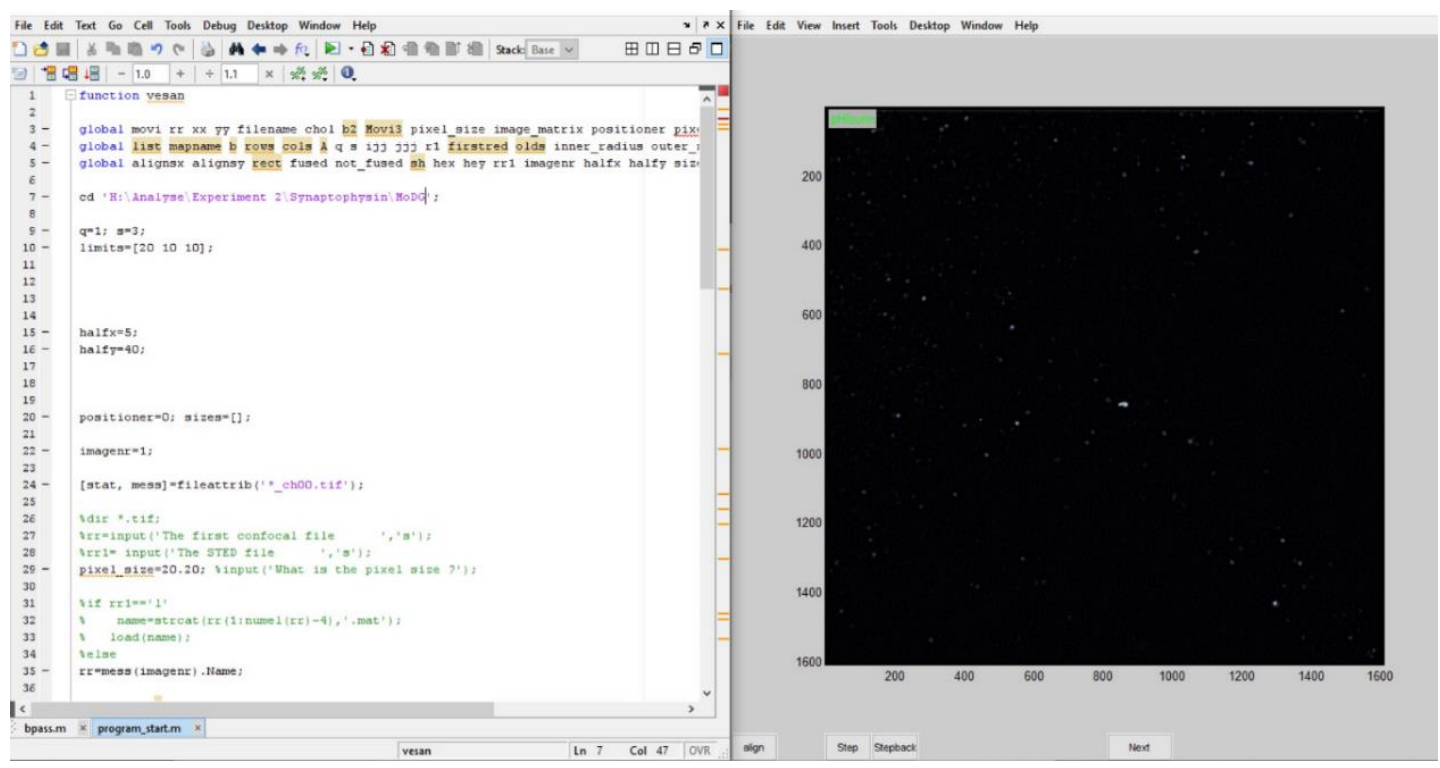

Abbildung 17: Darstellung der MATLAB-Benutzeroberfläche und Darstellung summierter Fluoreszenzsignale der detektierten Bassoon-Fluoreszenzsignale (Beispiel 1).

Nach abgeschlossener Berechnung der MATLAB-Routine „program_start“ wurden die auf ein zweidimensionales Bild summierten Fluoreszenzsignale der drei unterschiedlichen Fluoreszenzkanäle eines jeden Einzelexperiments farbig dargestellt. Signale des Fluoreszenzkanal 2 (Bassoon) wurden blau dargestellt.

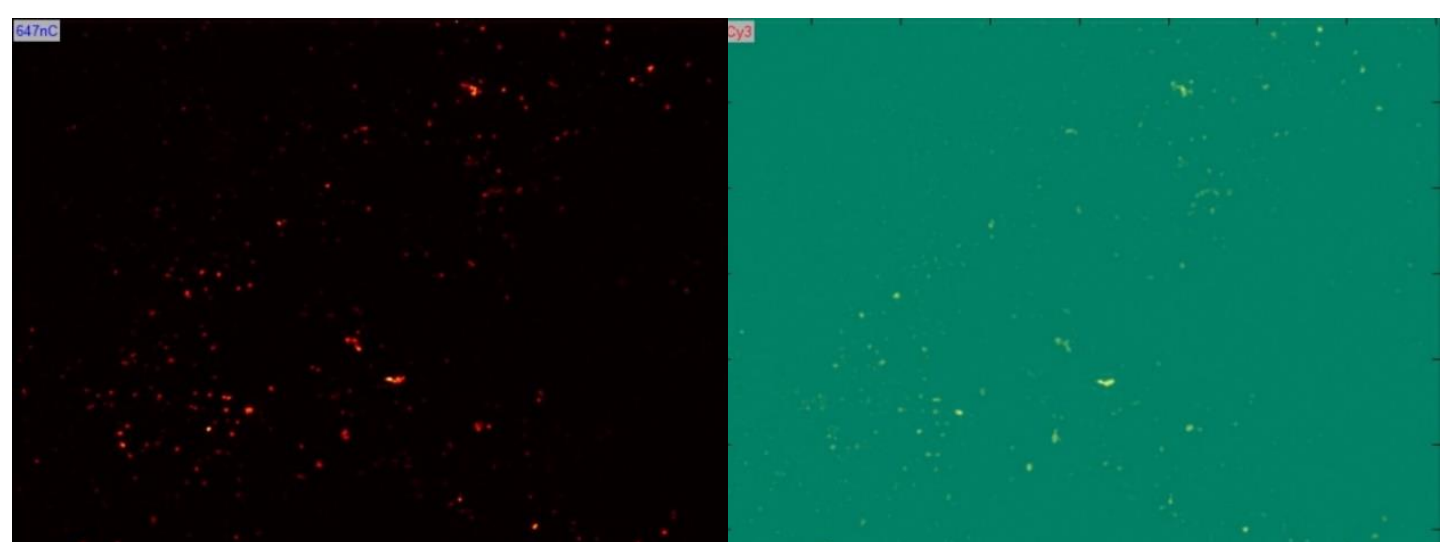

Abbildung 18: Darstellung der farblichen Markierung der summierten Fluoreszenzsignale der detektierten Synaptophysin-Fluoreszenzsignale und der Fluoreszenzsignale eines Testproteins (Beispiel 1).

Links: Die summierten Fluoreszenzsignale des Fluoreszenzkanal 0 (Synaptophysin) wurden rot dargestellt. Rechts: Die summierten Fluoreszenzsignale des Fluoreszenzkanal 1 (Testprotein) wurde zur besseren Unterscheidung grün überlegt dargestellt 


\subsubsection{Manuelle Auswahl der zu analysierenden Bereiche eines Einzelexperiments}

Auf den erstellen Fluoreszenzsummationsbilder wurden zu analysierende Bereiche manuell ausgewählt. Hierbei wurden jeweils die Bereiche mit der optisch höchsten Signaldichte und Signalintensität ausgewählt. Die Kennzeichnung des zu analysierenden Bereichs erfolgte anhand einer gelben Linie auf jeweils einem Fluoreszenzsummationsbild der drei zusammengehörigen Fluoreszenzkanäle (siehe Abbildungen 19, 21, 22 und 24). Die Markierung des auszuwählenden Bereiches erfolgte mit Hilfe der Computermaus, bei gedrückter linker Maustaste. Durch Loslassen der linken Maustaste wurde die Bereichsmarkierung beendet und die Berechnung der MATLAB-Routine gestartet. Dieser Arbeitsschritt erfolgte für jedes Testprotein pro vorliegender Fluoreszenzaufname, in der das Testprotein markiert war, dreimal. So wurden pro erstellter Fluoreszenzaufname drei Teilbereiche analysiert. Die MATLAB-Routine übertrug die ausgewählten Teilbereiche automatisch auf alle drei zusammengehörigen Fluoreszenzkanäle (der Abbildungen 17 und 18) eines Einzelexperiments und ermöglichte so die passende Zusammenlagerung der Fluoreszenzsignale aller Kanäle in den ausgewählten Bereichen. Die ausgewählten Bereiche wurden nach abgeschlossener Berechnung ausgeschnitten und vergrößert. Alle enthaltenen Fluoreszenzsignale wurden farbig markiert dargestellt (siehe Abbildung 20). Links: Ein zu untersuchender Teilbereich wird manuell durch eine gelbe Linie markiert und durch

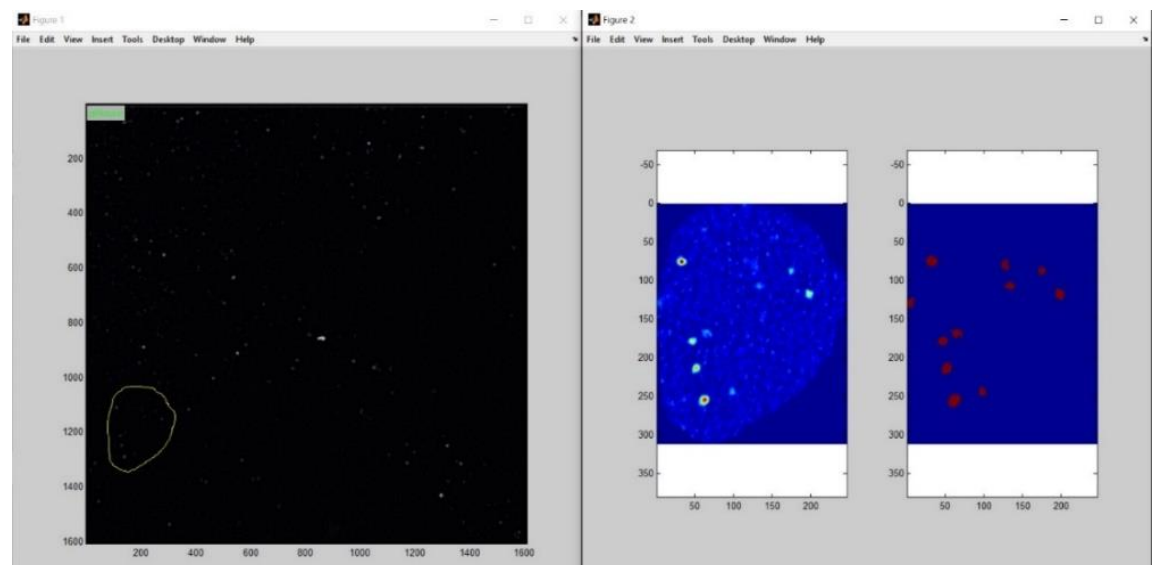

\footnotetext{
Abbildung 19: Manuelle Auswahl zu untersuchender Teilbereiche und vergrößerte, farbig markierte Darstellung der ausgewählten Fluoreszenzsignale (Beispiel 1).

die MATLAB-Routine „program_start“ ausgeschnitten. Rechts: Die enthaltenen Fluoreszenzsignale werden vergrößert und farbig markiert dargestellt. Rote Signalpunkte: $\mathrm{Zu}$ untersuchende Signale vor manueller Anpassung. Unscharf begrenzte Bereiche mit geringer Intensität und/oder fehlenden Fluoreszenzsignalen aller markierten Proteine entsprechen Störsignalen.
} 


\subsubsection{Manuelle Auswahl der präsynaptischen Signale}

Die zuvor ausgewählten Teilbereiche wurden durch die MATLAB-Routine ,program_start“ aus allen zusammengehörigen Fluoreszenzsummationsbildern ausgeschnitten und als farbige, vergrößerte Fluoreszenzsummationsbilder der Teilbereiche der drei Fluoreszenzkanäle dargestellt. Anschließend erfolgte eine manuelle Filtrierung weiterhin vorhandener Signalartefakte. Durch Verschiebung des Reglerbalkens mit Hilfe einer Computermaus konnten präsynaptische Signale gezielt ausgewählt und Fluoreszenzsignale, die wahrscheinlich Störsignalen beziehungsweise Signalartefakten entsprachen, entfernt werden (siehe Abbildung 20). Hierdurch konnte die Analyse auf starke, wahrscheinlich präsynaptische Fluoreszenzsignale konzentriert werden (vergleiche Abbildung 21 und 23). Durch anschließende Betätigung der Schaltfläche „Calculate“ (rechts neben dem Reglerbalken; siehe Abbildung 20) wurde dieser Arbeitsschritt der MATLAB-Routine gestartet und die zur weiteren Analyse ausgewählten Fluoreszenzsignale in Form von Textdateien (,,.txt") abgespeichert. Abbildungen 24 und 25 zeigen, anhand eines weiteren Beispiels, die manuelle Auswahl zu analysierender Fluoreszenzsignale.

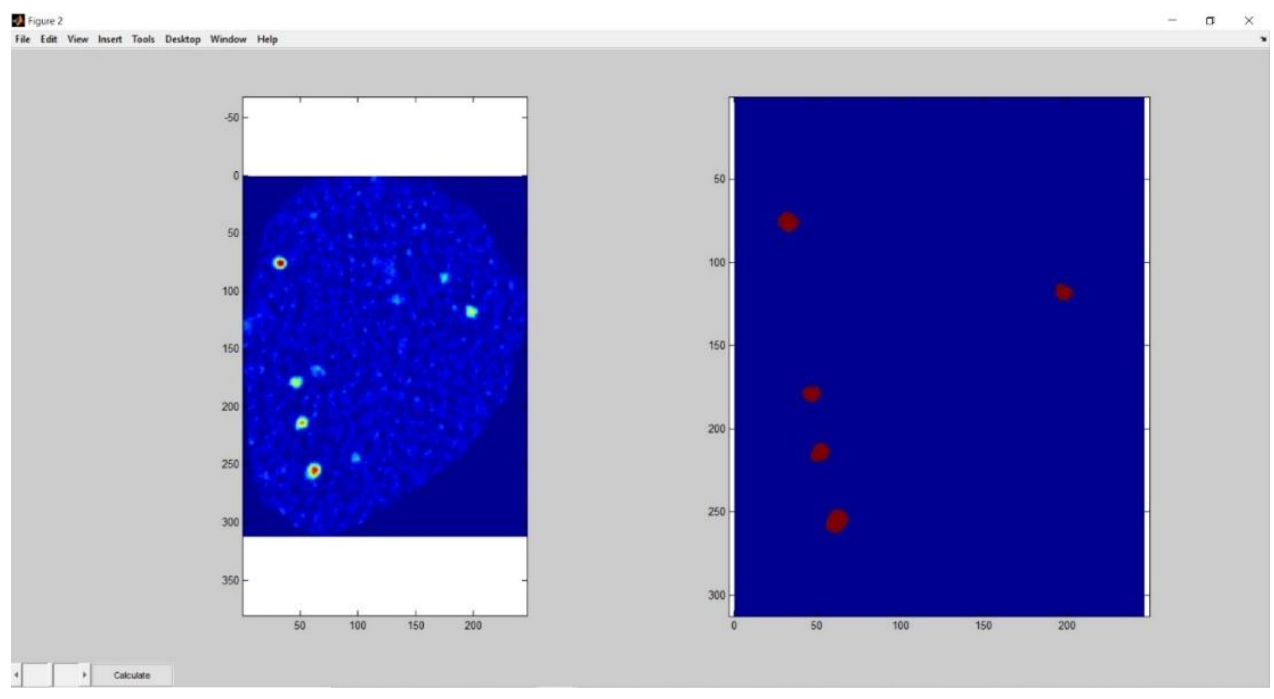

\section{Abbildung 20: Vergrößerte Darstellung der Fluoreszenzsignale des ausgeschnitte- nen Bereichs und Auswahl eindeutiger Fluoreszenzsignale (Beispiel 1).}

Rechts: Durch Verschiebung des Reglerbalkens und Betätigung der Schaltfläche „Calculate“ (Bildrand unten links) wurden eindeutige präsynaptische Signale ausgewählt und potenzielle Störsignale entfernt (vergleiche Abbildung 19). Links: Summierte Darstellung der drei Fluoreszenzkanäle im zu untersuchenden Teilbereich des vorliegenden Hirnschnittes aus Abbildung 19. 


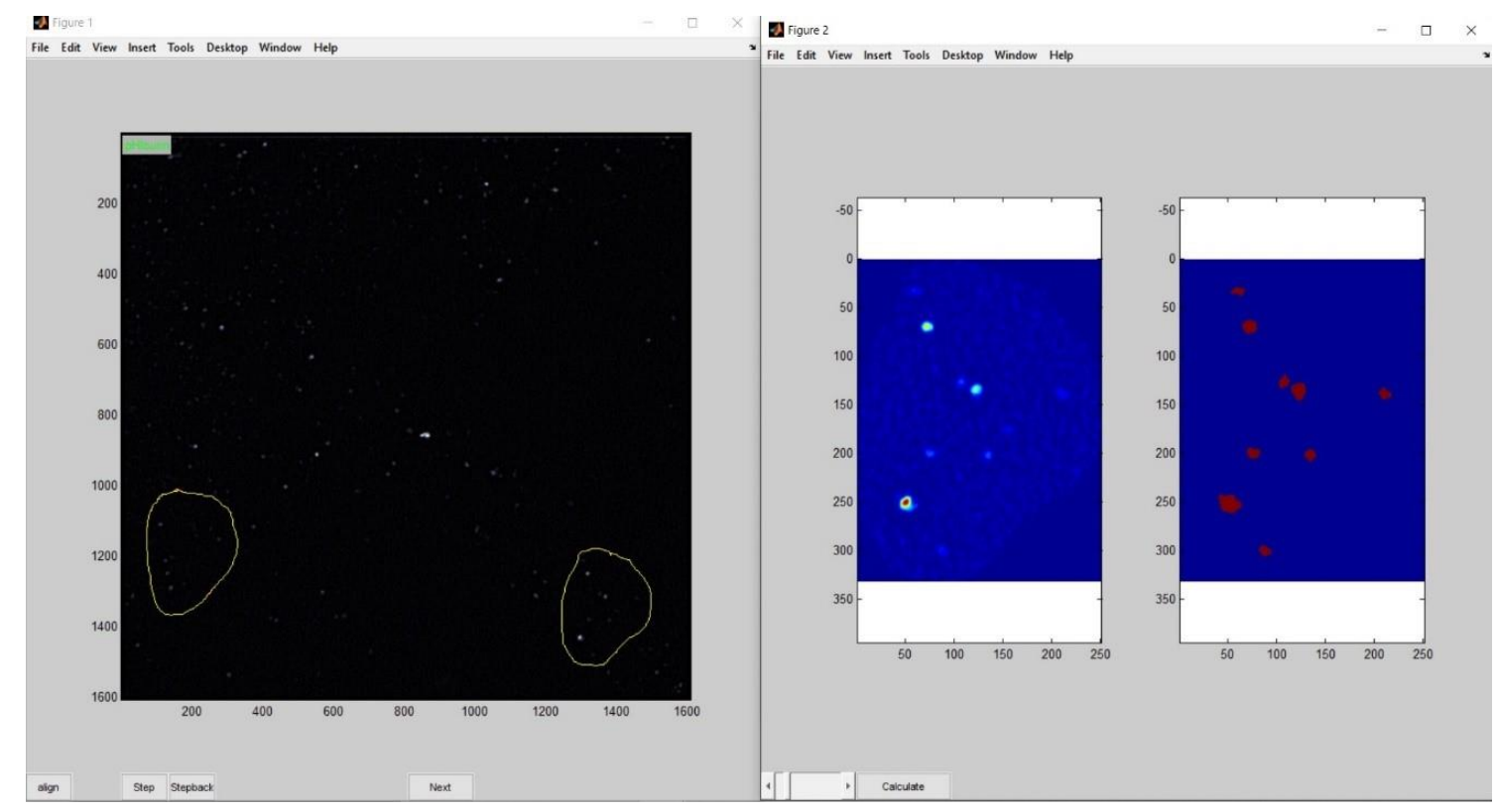

Abbildung 21: Darstellung der Auswahl eines zweiten, zu analysierenden Teilbereichs des Einzelexperiments und ausgeschnittene, vergrößerte und farbig markierte Darstellung aller enthaltenen Fluoreszenzsignale (Beispiel 1).

Links: Nach Arbeitsschritt 2.4.5 erfolgt die Markierung eines zweiten Teilbereichs des Fluoreszenzsummationsbildes. Rechts: Anschließende Auswahl der zu analysierenden Fluoreszenzsignale.
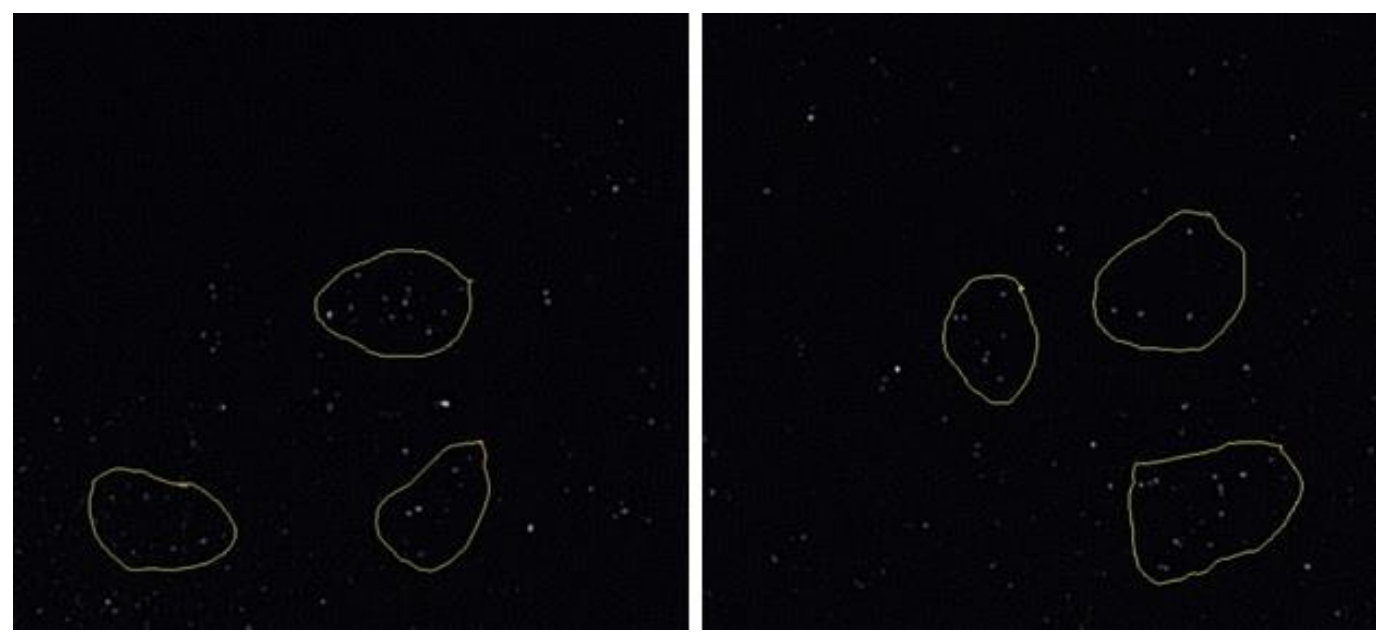

Abbildung 22: Darstellung der summierten Fluoreszenzsignale des Bassoons zweier weiterer durchgeführter Einzelexperimente.

In jedem Einzelexperiment wurden drei Teilbereiche mit hoher Signaldichte und Intensität manuell ausgewählt (gelbe Umrandung). Links: Beispiel 2. Rechts: Beispiel 3. 


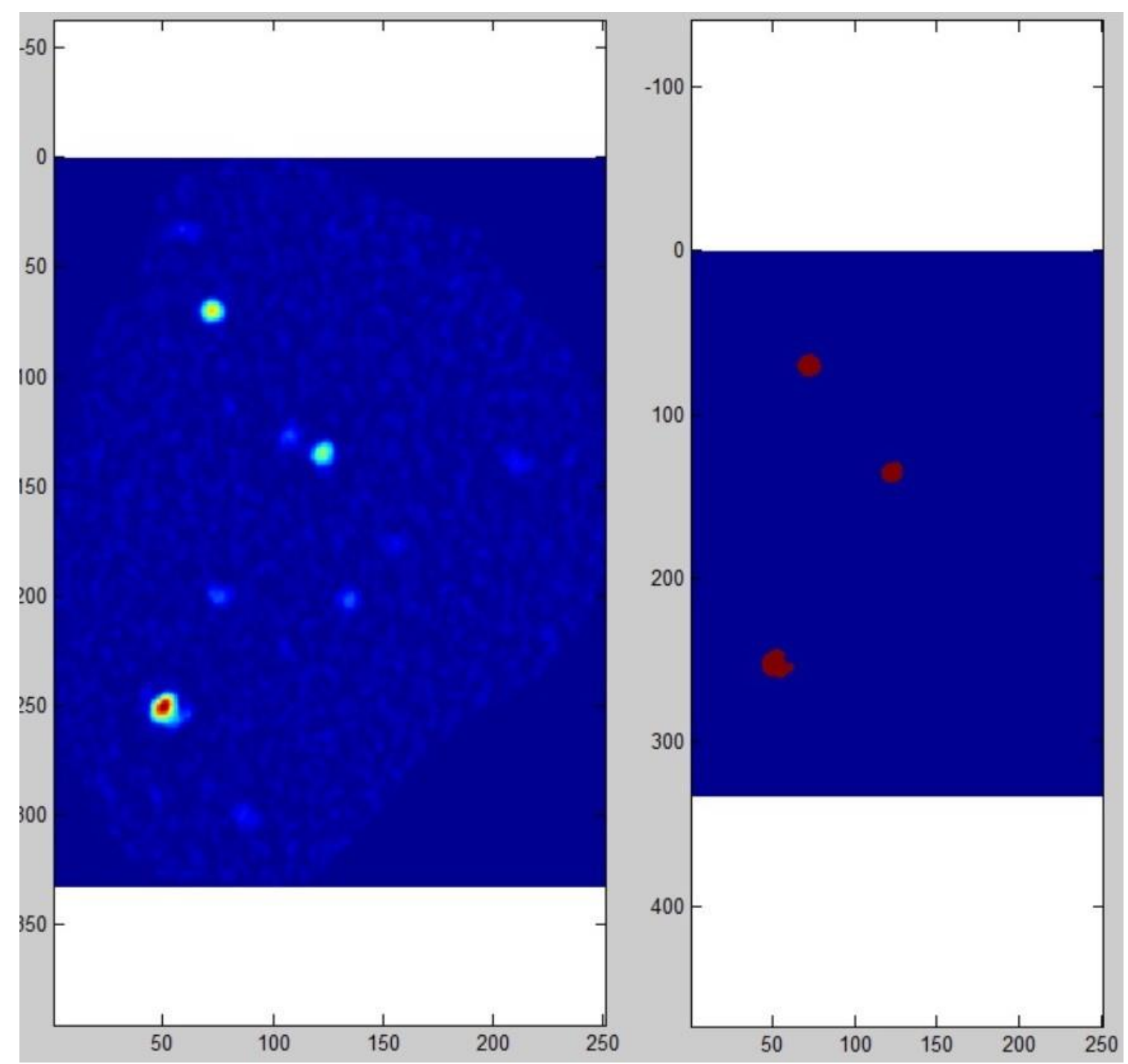

Abbildung 23: Vergrößerte Darstellung der Fluoreszenzsignale aus Abbildung 21 und manuell ausgewählte, zu analysierende Signale (Beispiel 1).

Nach manueller Auswahl der zu analysierenden Fluoreszenzsignale konnten, im Vergleich zu allen detektierten Fluoreszenzsignalen des Teilbereiches der entsprechenden Epifluoreszenzaufnahme (vgl. Abbildung 21), Störsignale deutlich reduziert werden. 


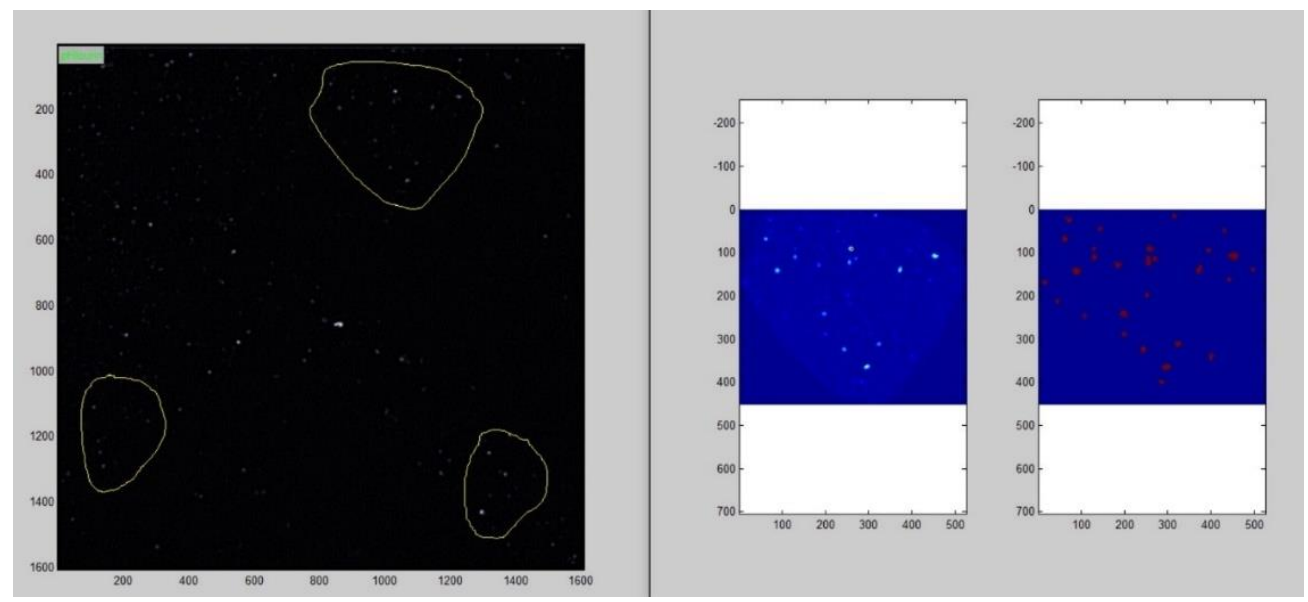

Abbildung 24: Auswahl der zu untersuchenden Teilbereiche eines Einzelexperiments und Darstellung der Fluoreszenzsignale des oberen Teilbereichs (Beispiel 4).

Links: Pro Epifluoreszenzaufnahme wurden drei Teilbereiche untersucht. Rechts: Die Darstellung aller Fluoreszenzsignale des obersten, ausgewählten Teilbereichs zeigt eine hohe Signaldichte, die zu einem großen Teil nicht eindeutig präsynaptischen Signalen entspricht.

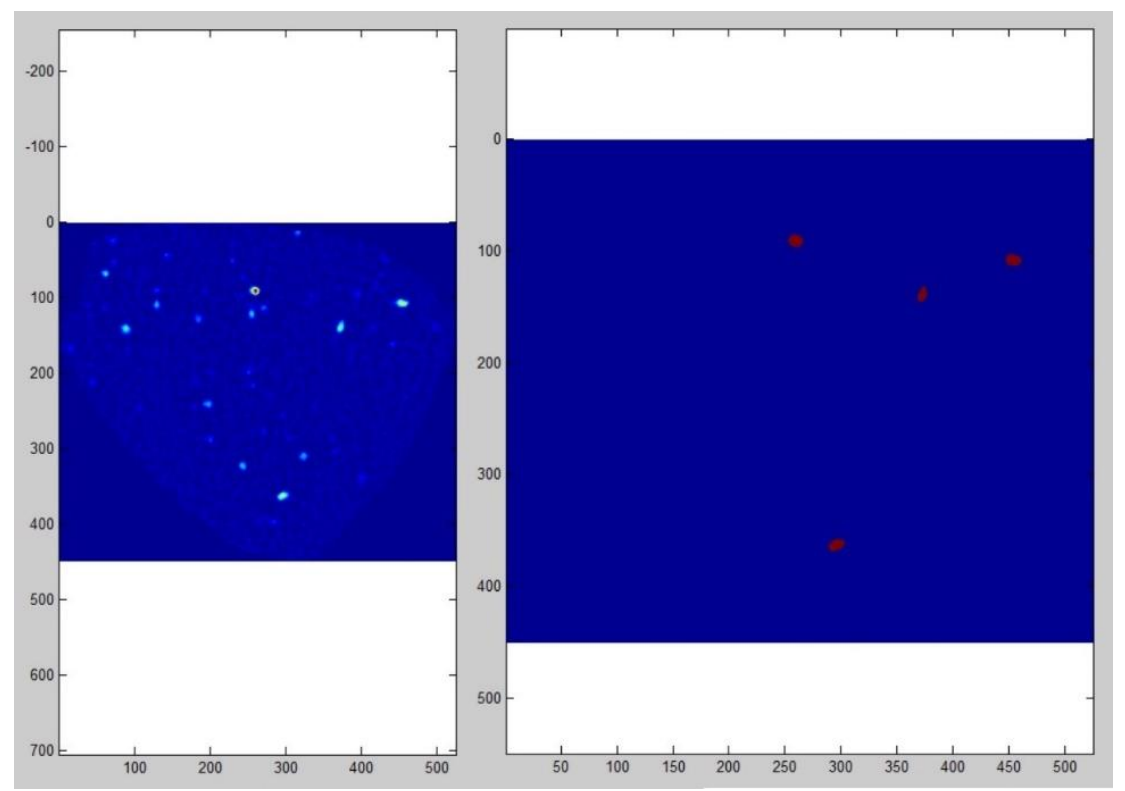

Abbildung 25: Vergrößerte Darstellung der rechten Bildhälfte aus Abbildung 24, nach manueller Auswahl zu analysierender Fluoreszenzsignale.

Nach manueller Reduktion potenzieller Störsignale entspricht die Menge zu analysierender Fluoreszenzsignale einem kleinen Teil aller detektierten Fluoreszenzsignale (vgl. Abbildung 24) (Beispiel 4). 


\subsubsection{Summation der zu untersuchenden präsynaptischen Fluoreszenzsignale}

Die MATLAB-Routine „,aling_images_Nils“ definierte in allen drei Fluoreszenzkanälen einen quadratischen Bereich mit einer Kantenlänge von 201 Pixeln um die ausgewählten Fluoreszenzsignale beziehungsweise die ausgewählten Präsynapsen. Der Bassoon-Fluoreszenzkanal definierte hierbei die aktiven Zonen der zu untersuchenden Präsynapsen. Die Bassoon-Fluoreszenzsignale wurden automatisiert im Zentrum des Quadrates platziert und dienten als Referenz zur korrekten Ausrichtung der ausgewählten Präsynapsen einer Hirnregion. Dies erfolgte in jedem Fluoreszenzkanal getrennt. Nach Eintragung des Ordnerverzeichnisses, in dem die zuvor erstellten Textdateien der ausgewählten Fluoreszenzsignale lagen, in Zeile 3 der MATLAB-Routine, wurde die Berechnung durch die Befehlskette „Debug“ $\rightarrow$,Run aling_images_Nils“ gestartet (siehe Abbildung 26). Die in Arbeitsschritt 2.4.5 ausgewählten präsynaptischen Signale wurden so aus den Fluoreszenzsummationsbildern quadratisch ausgeschnitten und anhand der detektierten BassoonFluoreszenzsignale korrekt übereinander ausgerichtet. Durch Summation der Intensität dieser ausgerichteten Signale wurden durchschnittliche Fluoreszenzbilder der pro Einzelexperiment analysierten Präsynapsen erstellt. Die Darstellung erfolgte für jeden der drei Fluoreszenzkanälen getrennt (siehe Abbildung 27). Die Dateien wurden automatisch in das korrekte Ordnerverzeichnis abgespeichert.

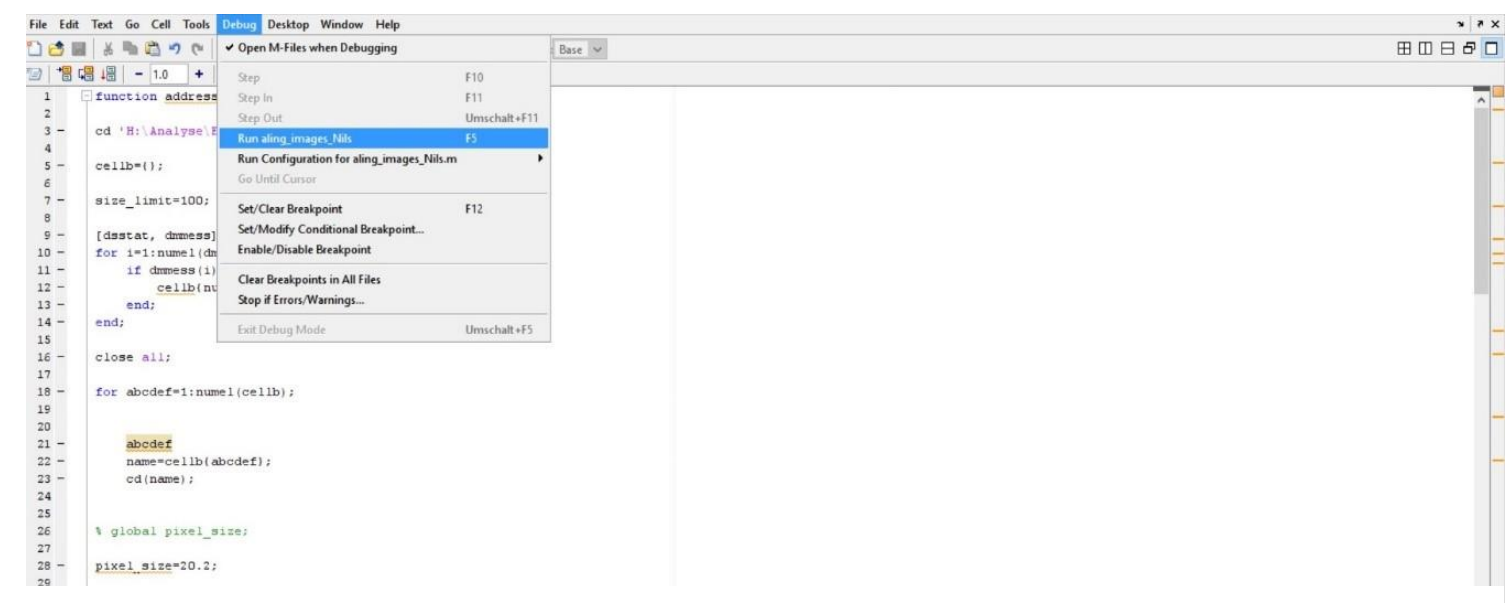

\section{Abbildung 26: Benutzeroberfläche der MATLAB-Routine "aling_images_Nils" und Befehlskette zum Start der Routine.}

Das Ordnerverzeichnis der Textdateien der zu untersuchenden Fluoreszenzsignale wurde in Zeile 3 der MATLAB-Routine eingetragen. Die MATLAB-Routine wurde durch die Befehlskette „Debug“ $\rightarrow$,Run aling_images_Nils“"gestartet. 

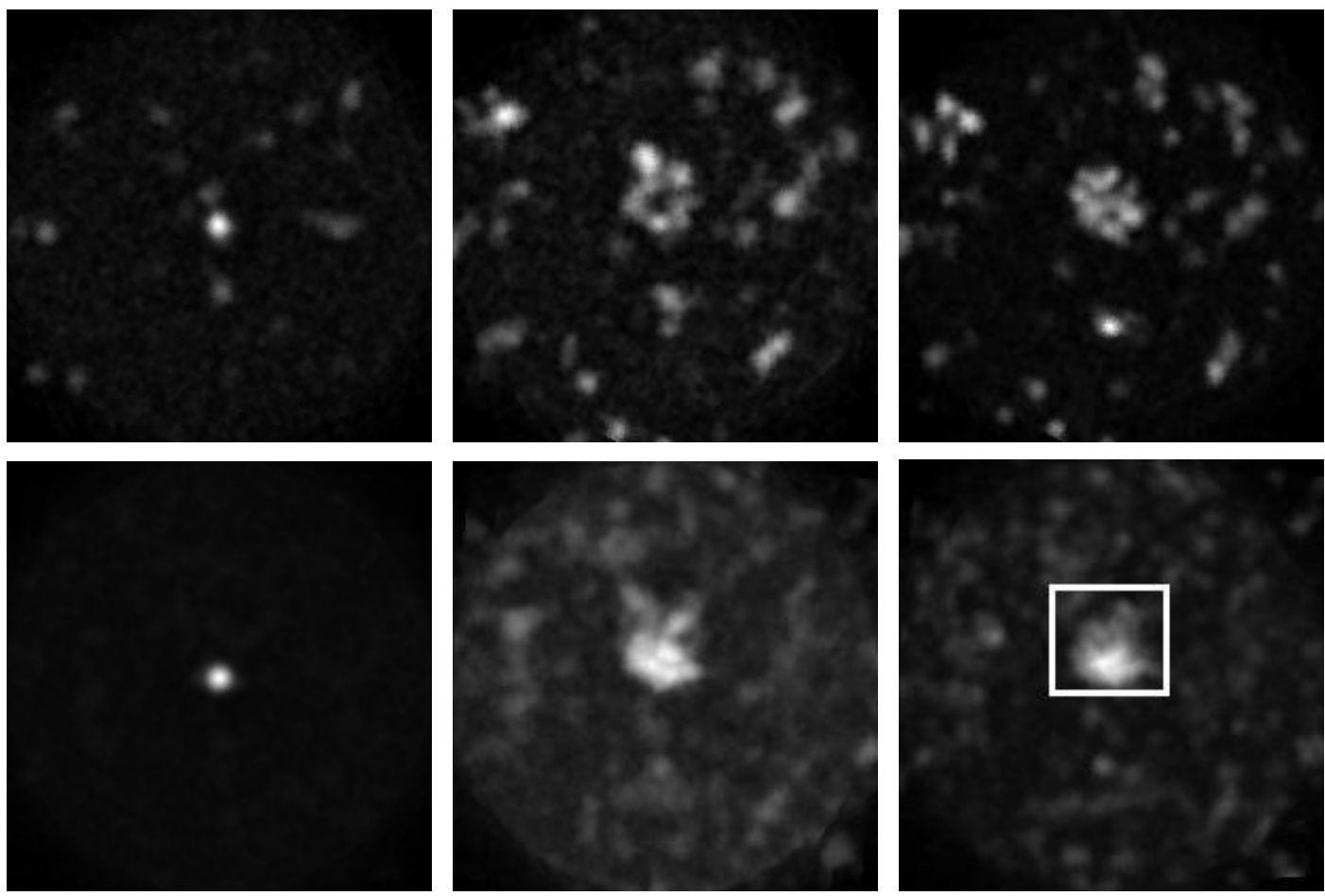

Abbildung 27: Darstellung der durchschnittlich pro Einzelexperiment detektierten Fluoreszenzsignale der einzelnen Fluoreszenzkanäle der Beispiele 1 und 2.

Von links nach rechts im zentralen Bereich der Bilder dargestellt: Summierte Bassoon-Fluoreszenzsignale, summierte Synaptophysin-Fluoreszenzsignale, summierte Testprotein-Fluoreszenzsignale aller pro Einzelexperiment analysierter Präsynapsen. Nach Durchführung des Arbeitsschrittes 2.4.6 wurden die summierten Fluoreszenzsignale in den einzelnen Fluoreszenzkanälen getrennt voneinander dargestellt. Die obere Reihe stellt die erhaltenen durschnittlichen Präsynapsen aus Beispiel 1 dar, die untere die, aus Beispiel 2. In beiden Beispielen wurde das gleiche Testprotein markiert. Die erhaltenen durchschnittlichen Fluoreszenzbilder erscheinen optisch ähnlich aber lassen Unterschiede hinsichtlich der Proteinverteilung und Menge vermuten. Weißer Kasten: Schematische Darstellung des Bereichs, den die durchschnittliche Präsynapse einnimmt. 


\subsubsection{Analyse der Fluoreszenzsignalverteilungen}

Die durchschnittlichen Fluoreszenzsummationsbilder wurden durch die MATLAB-Routine ,get_lines“ hinsichtlich ihrer Signalintensitätsverteilung analysiert. Nach Eintragung des korrekten Ordnerverzeichnisses der zu analysierenden durchschnittlichen Fluoreszenzaufnahmen aller Einzelexperimente in die Zeile 3 der MATLAB-Routine wurde die Routine durch die Befehlskette „Debug“ $\rightarrow$,Run get_lines“ gestartet (siehe Abbildung 28). Hierbei wurden Linienscans (Linescans), ausgehend vom jeweils linken Bildrand, durch die Mitte der durchschnittlichen aktiven Zone (Summation aller Bassoon-Fluoreszenzsignale) gelegt. Dementsprechend wurden Linienscans in der gleichen Position in die durchschnittlichen Fluoreszenzsummationsbilder der beiden weiteren Fluoreszenzkanäle gelegt. So konnten Signalintensitäten für alle drei Fluoreszenzkanäle in den durschnittlichen Fluoreszenzsummationsbildern im Verlauf der Linienscans gemessen und miteinander verglichen werden. Die Verteilung der Signalintensitäten entlang der Referenzlinien wurde graphisch dargestellt (siehe Abbildung 29). Anhand der graphischen Darstellungen aller Experimente erfolgte im Anschluss die Analyse hinsichtlich der Halbwertsbreiten der detektierten Fluoreszenzsignale der jeweiligen Testproteine sowie des jeweiligen Fluoreszenzpeaks.

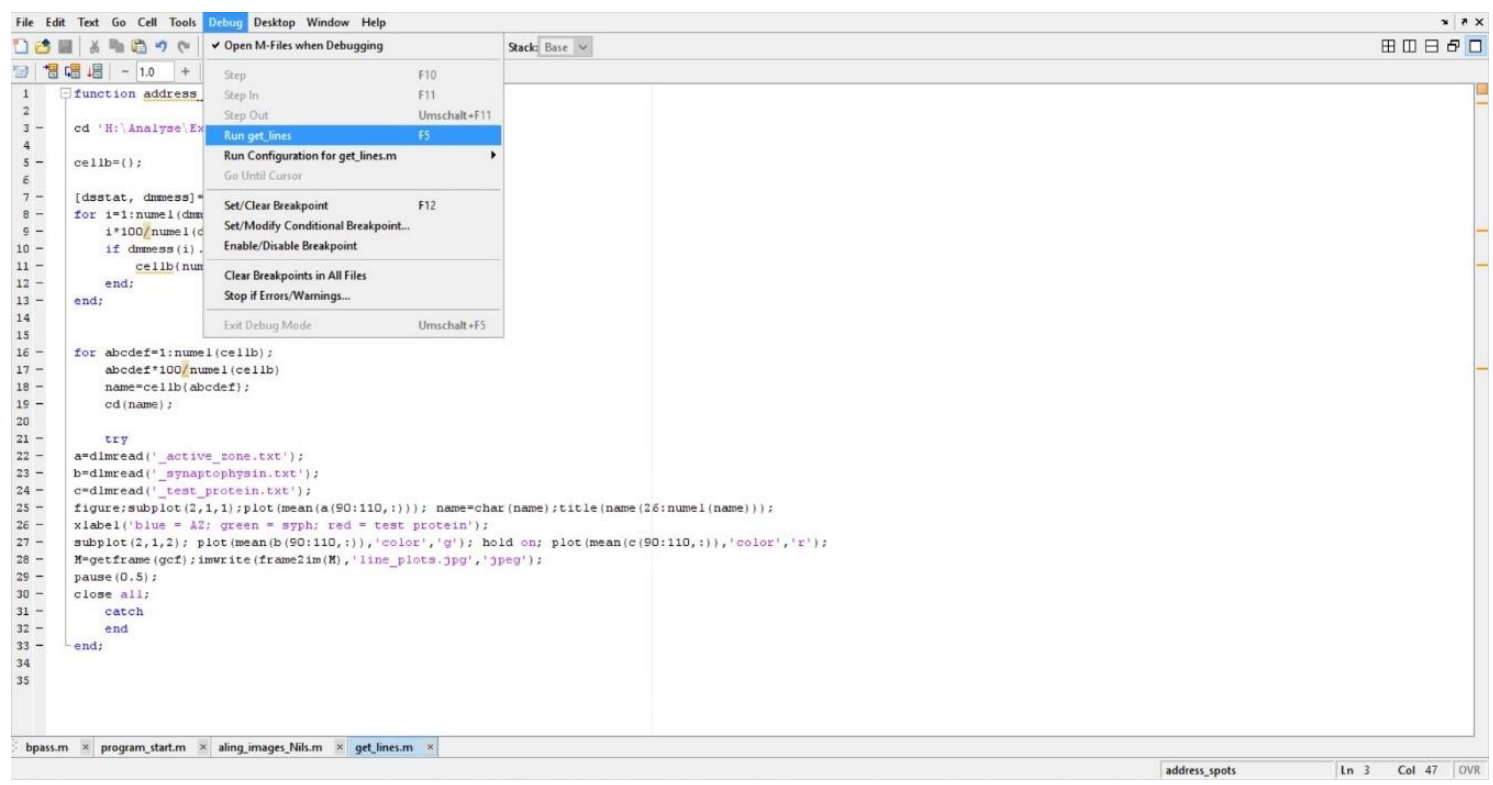

Abbildung 28: Benutzeroberfläche der MATLAB-Routine "get_lines" und Befehlskette zum Start der Routine.

Das Ordnerverzeichnis der zu untersuchenden Epifluoreszenzaufnahmen wurde in Zeile 3 der MATLAB-Routine eingetragen. Die MATLAB-Routine wurde durch die Befehlskette „Debug“ $\rightarrow$,Run get_lines“ gestartet. 


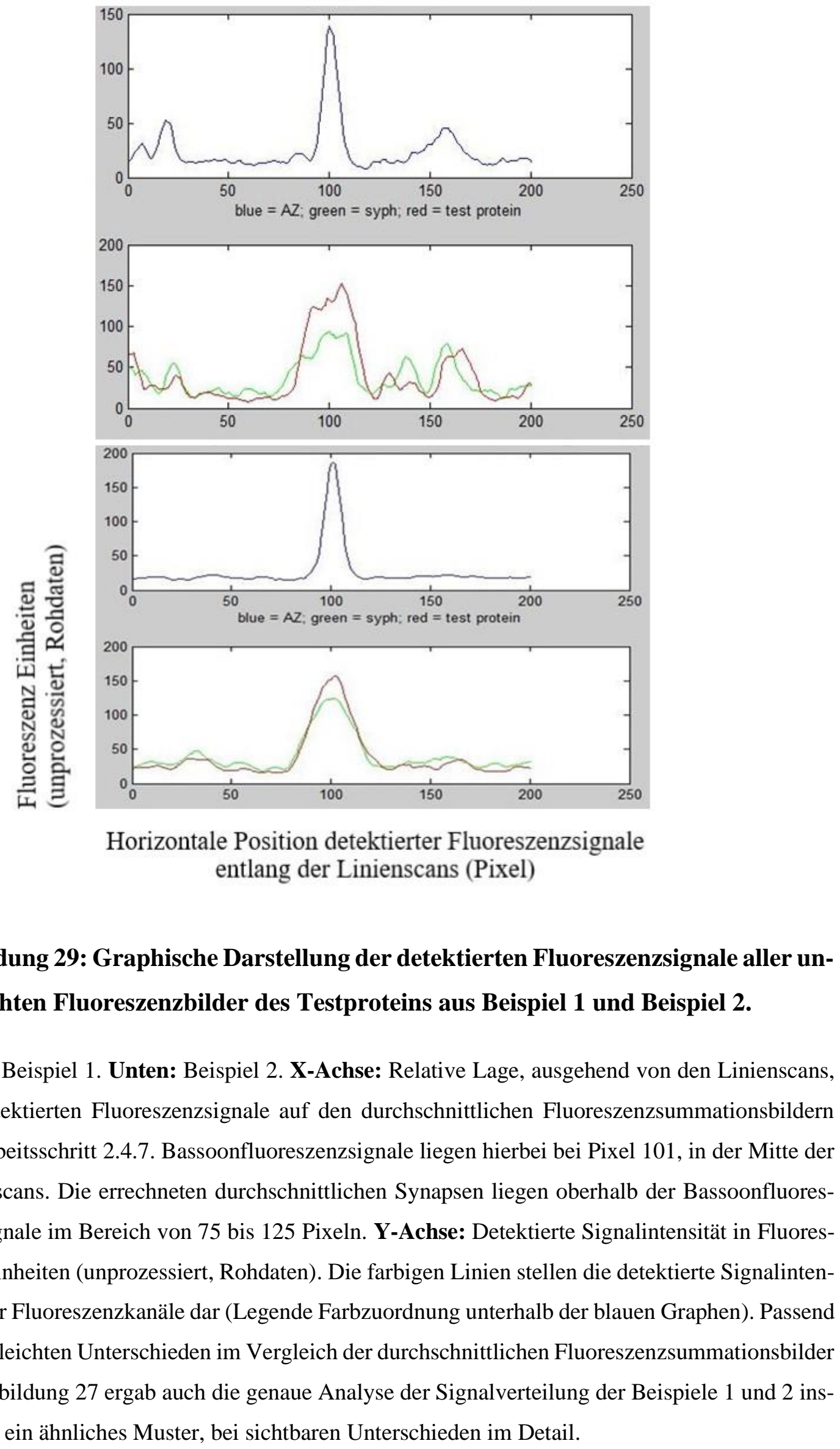

\section{Abbildung 29: Graphische Darstellung der detektierten Fluoreszenzsignale aller un- tersuchten Fluoreszenzbilder des Testproteins aus Beispiel 1 und Beispiel 2.}

Oben: Beispiel 1. Unten: Beispiel 2. X-Achse: Relative Lage, ausgehend von den Linienscans, der detektierten Fluoreszenzsignale auf den durchschnittlichen Fluoreszenzsummationsbildern aus Arbeitsschritt 2.4.7. Bassoonfluoreszenzsignale liegen hierbei bei Pixel 101, in der Mitte der Linienscans. Die errechneten durchschnittlichen Synapsen liegen oberhalb der Bassoonfluoreszenzsignale im Bereich von 75 bis 125 Pixeln. Y-Achse: Detektierte Signalintensität in Fluoreszenz Einheiten (unprozessiert, Rohdaten). Die farbigen Linien stellen die detektierte Signalintensität der Fluoreszenzkanäle dar (Legende Farbzuordnung unterhalb der blauen Graphen). Passend zu den leichten Unterschieden im Vergleich der durchschnittlichen Fluoreszenzsummationsbilder aus Abbildung 27 ergab auch die genaue Analyse der Signalverteilung der Beispiele 1 und 2 insgesamt ein ähnliches Muster, bei sichtbaren Unterschieden im Detail. 


\subsection{Statistische Auswertung}

Die Daten wurden mit Hilfe eines Experten mit zwanzigjähriger Erfahrung in der Auswertung Fluoreszenzmikroskopischer Bilder (Prof. Dr. Silvio O. Rizzoli) begutachtet. Daten, die keine signifikanten Präsynaptischen Signale darstellten oder generell nicht ausreichende Signalstärken aufwiesen, wurden vor der statistischen Auswertung entfernt. Die graphischen Darstellungen der detektierten Fluoreszenzsignale wurden mit einer standardisierten MATLAB-Routine mittels Gaußscher Kurvenanpassung zur statistischen Auswertung vorbereitet und mit der Software SigmaPlot 10 hinsichtlich Halbwertsbreiten und Fluoreszenzpeaks ausgewertet.

\subsubsection{Einfaktorielle Varianzanalyse}

Die einfaktorielle Varianzanalyse (ANOVA) ist die am häufigsten verwendete Methode, um Mittelwerte mehrerer Datengruppen miteinander zu vergleichen, da hierbei die Fehlerwahrscheinlichkeit, im Vergleich zu multiplen t-Tests, deutlich geringer ausfällt. Hierbei soll die Nullhypothese, dass es zwischen den zu vergleichenden Testgruppen keine Unterschiede gibt, mittels der alternativen Hypothese, dass es Unterschiede gibt, widerlegt, beziehungsweise bestätigt werden. Vereinfacht beschrieben wird untersucht, ob sich die Mittelwerte in mehr als zwei verschiedenen, zu untersuchenden, Testgruppen unterscheiden, indem geprüft wird, ob die Varianz innerhalb einer Gruppe kleiner ist als die Varianz zwischen den einzelnen Testgruppen. Entspricht die Gesamtvarianz also der Varianz innerhalb der Gruppen liegen keine Unterschiede vor, ist dies nicht der Fall, liegen statistisch signifikante Unterschiede vor. Durch diesen Vergleich der Mittelwerte der Testgruppen untereinander können signifikante Unterschiede zwischen den Testgruppen erkannt werden. Mathematisch wird, vereinfacht erklärt, die Varianz im Vergleich der Testgruppen untereinander durch die Varianz innerhalb der einzelnen Testgruppen dividiert. Das Signifikanzniveau „p“ liegt bei der einfaktoriellen Varianzanalyse bei einem Wert von unter 0,05 ( $\mathrm{p}<0,05)$. Lag das errechnete Signifikanzniveau einer Untersuchung unter $\mathrm{p}=0,05$ sind unterschiedliche Mittelwerte in den Vergleichsgruppen mit einer Wahrscheinlichkeit von über $95 \%$ nicht zufällig entstanden. In dieser Arbeit wurde ANOVA auf die Halbwertsbreite und den Fluoreszenzpeak der dargestellten Fluoreszenzsignale angewandt. Bei vorliegenden signifikanten Unterschieden waren abweichende Gesetzmäßigkeiten hinsichtlich der Proteinverteilung und/oder der Proteinmenge des jeweiligen Testproteins zwischen den jeweiligen Testgruppen anzunehmen. 


\subsubsection{Zweistichproben-t-Test}

Der Zweistichproben-t-Test wird verwendet, wenn man zwei Variablen hinsichtlich ihrer Mittelwerte miteinander vergleichen möchte. Der Zweistichproben-t-Test entspricht, vereinfacht erklärt, einer Varianzanalyse mit lediglich zwei Vergleichsgruppen. Die Nullhypothese besagt, dass sich die Mittelwerte beider Testgruppen nicht voneinander unterscheiden, beziehungsweise, dass Differenzen per Zufall entstanden sind. Diese Hypothese soll durch den Zweistichproben-t-Test bestätigt oder widerlegt werden. Die Mittelwerte zweier, voneinander unabhängiger Proben aus Grundgesamtheiten mit gleicher Varianz werden hinsichtlich signifikanter Unterschiede in ihrem Vergleich untersucht. Sofern die ANOVA signifikante Unterschiede hinsichtlich der Halbwertsbreiten beziehungsweise Fluoreszenzpeaks im Vergleich der jeweiligen Hirnregionen bezüglich eines Testproteins ergab, wurden Zweistichproben-t-Test mit zusätzlicher Bonferroni-Korrektur durchgeführt, um zu untersuchen zwischen welchen Hirnregionen sich im jeweiligen Experiment signifikante Unterschiede ergaben. Bei nicht durchgeführter Bonferroni-Korrektur wäre dadurch, dass jede Testgruppe mit jeder weiteren verglichen wurde, die Anzahl der Vergleiche deutlich höher als die Anzahl der Vergleichsgruppen. Die hieraus resultierende hohe Fehlerwahrscheinlichkeit wurde durch die Bonferroni-Korrektur reduziert. Hierbei errechnet man das neue Signifikanzniveau, indem das zuvor verwendete Signifikanzniveau der ANOVA $(\mathrm{p}=0,05)$ durch die Anzahl der mittels Zweistichproben-t-Test durchgeführten Vergleiche geteilt wird. In dieser Arbeit wurden die Mittelwerte aller Gehirnregionen mittels t-Test miteinander verglichen sofern die ANOVA für Halbwertsbreite und/oder Fluoreszenzpeaks der Fluoreszenzsignale in der jeweiligen Untersuchung auf signifikante Unterschiede hinwiesen. 


\section{Ergebnisse}

In dieser Arbeit wurden die Testproteine Bassoon, Synaptophysin, SNAP-25, VGLUT 1/2 und Amphiphysin hinsichtlich subzellulärem Vorkommen und Verteilung in hippocampalen und kortikalen Präsynapsen aus verschiedenen Regionen des Rattengehirns anhand fluoreszenzmikroskopischer Aufnahmen untersucht. Bei den Testproteinen handelte es sich um Proteine, die stellvertretend zur Markierung essenzieller präsynaptischer Strukturen gewählt wurden. Synaptophysin und VGLUT 1/2 dienten der Markierung synaptischer Vesikel, VGLUT 1/2 dienten insbesondere der Markierung exzitatorischer Synapsen, Bassoon markierte die aktive Zone, Amphiphysin diente stellvertretend zur Identifizierung endozytotisch aktiver Proteine und SNAP-25 markierte die präsynaptische Plasmamembran. Die Testproteine werden im Abschnitt 1.4 ausführlich besprochen. Die Grundlage dieser Arbeit bildeten Rattenhirnschnitte, die vorbereitend in ein stark wasserbindendes Polyacrylamidgel eingebettet und chemisch an diesem verankert wurden. Die molekulare Markierung der Testproteine erfolgte hierbei durch spezifische primäre Antikörper und sekundäre Fluoreszenzantikörper. Nach proteolytischer Vorbehandlung verblieben die mit Fluoreszenzantikörpern versehenen Testproteinfragmente in korrekter Position am Polyacrylamidgel verankert und es wurde durch Wasserzugabe eine physische Größenzunahme der vorbereiteten Rattenhirnschnitte um den Faktor $\sim 4$ ermöglicht. Die verankerten Fluoreszenzantikörper wurden so in allen Ebenen des Raumes voneinander getrennt. Dieses Verfahren nennt sich Expansionsmikroskopie und ermöglicht, durch physische Vergrößerung der zu untersuchenden Proben, die Untersuchung präsynaptischer Proteine unter Anwendung eines Epifluoreszenzmikroskops bei einer lateralen Auflösung von 60-70 nm. Das Verfahren der Expansionsmikroskopie wird in Abschnitt 1.5.2 ausführlich erklärt. Nach manueller Auswahl zu untersuchender Fluoreszenzsignale in unterschiedlichen Bereichen der vorgelegten Rattenhirnschnitte, wurden mittels anwendungsspezifischer MATLAB-Routinen (Programmiert von Prof. Dr. Silvio O. Rizzoli) durchschnittliche Präynapsen für jede untersuchte Hirnregion berechnet. Detektierte Fluoreszenzsignale des jeweiligen Testproteins wurden graphisch dargestellt und nach Gaußscher Kurvenanpassung hinsichtlich durchschnittlicher Halbwertsbreiten und Fluoreszenzpeaks in verschiedenen Regionen des Hippocampus und des Cortex Cerebri des Rattenhirns ausgewertet. 
Ergebnisse wurden in Form von Säulendiagrammen dargestellt. Die statistische Auswertung und graphische Darstellung der erhobenen Daten erfolgte mit SigmaPlot 10. Benötigtes Material und die Methodik der durchgeführten Analyse werden in Abschnitt 2 ausführlich beschrieben. Die untersuchten Regionen des Hippocampus und des Cortex Cerebri werden in den Tabellen 10 und 11 aufgelistet. Detaillierte tabellarische Darstellungen der Ergebnisse finden sich in den Abschnitten 7.2 und 7.3 im Anhang.

\subsection{Untersuchte Hirnregionen}

Tabelle 10: Übersicht untersuchter Regionen des Hippocampus und verwendete Abkürzungen.

\begin{tabular}{l|l}
\hline Region & Abkürzung \\
\hline Gyrus dentatus (Stratum granulare) & GrDG \\
\hline Gyrus dentatus (Stratum moleculare) & MoDG \\
\hline Stratum oriens (Feld CA1) & OrCA1 \\
\hline Stratum oriens (Feld CA2) & OrCA2 \\
\hline Stratum oriens (Feld CA3) & OrCA3 \\
\hline Gyrus Dentatus (Stratum multiforme) & PoDG \\
\hline Stratum pyramidale (Feld CA1) & PyCA1 \\
\hline Stratum pyramidale (Feld CA2) & PyCA2 \\
\hline Stratum pyramidale (Feld CA3) & PyCA3 \\
\hline Stratum radiatum (Feld CA1) & RadCA1 \\
\hline Stratum radiatum (Feld CA2) & RadCA2 \\
\hline Stratum radiatum (Feld CA3) & RadCA3 \\
\hline
\end{tabular}


Tabelle 11: Übersicht untersuchter Regionen des Cortex cerebri und verwendete Abkürzungen.

\begin{tabular}{l|l}
\hline Region & Abkürzung \\
\hline Primär motorischer Kortex (Lamina molecularis) & M1I \\
\hline Primär motorischer Kortex (Lamina granularis externa) & M1II \\
\hline Primär motorischer Kortex (Lamina granularis interna) & M1IV \\
\hline Primär motorischer Kortex (Lamina pyramidalis interna) & M1V \\
\hline Primär motorischer Kortex (Lamina multiformis) & M1VI \\
\hline Primär somatosensorischer Kortex (Lamina molecularis) & S1I \\
\hline Primär somatosensorischer Kortex (Lamina granularis externa) & S1II \\
\hline Primär somatosensorischer Kortex (Lamina pyramidalis in- & S1V \\
terna) & \\
\hline Primär somatosensorischer Kortex (Lamina multiformis) & S1VI \\
\hline
\end{tabular}

\subsection{Testproteine}

\subsubsection{Bassoon}

Bassoon ist ein großes Protein und essenzieller Bestandteil der aktiven Zonen im gesamten Rattengehirn. Bassoon konzentriert sich stark auf den Bereich der präsynaptisch aktiven Zone. Es beteiligt sich an der Strukturerhaltung der aktiven Zone und bildet in Kooperation mit zahlreichen weiteren präsynaptischen Proteinen die Grundlage zur Aufrechterhaltung zahlreicher präsynaptischer Funktionen (siehe Abschnitt 1.4.4).

\subsubsection{Synaptophysin}

Synaptophysin ist ein saures Glykoprotein und integraler Bestandteil synaptischer Vesikel in präsynaptischen Endigungen des gesamten Rattengehirns. Die genauen Funktionen des Synaptophysins sind trotz seines gehäuften Vorkommens im gesamten zentralen Nervensystem nicht ausreichend erforscht. Die Funktionen des Synaptophysins sind nach aktuellem Stand der Forschung nicht essenziell für den Ablauf der synaptischen Übertragung. Das Protein könnte durch Interaktion mit zahlreichen präsynaptischen Proteinen multiple funktionelle Beteiligungen und regulatorische Funktionen im Rahmen der Exo, und Endozytose synaptischer Vesikel übernehmen (siehe Abschnitt 1.4.3). 


\subsubsection{SNAP-25}

SNAP-25 befindet sich in allen Bereichen der synaptischen Plasmamembran und beteiligt sich als essenzieller Bestandteil des SNARE-Komplexes maßgeblich an der Exozytose synaptischer Vesikel. Regulatorische Funktionen im Rahmen des Vesikelrecyclings und der Ausbalancierung zwischen Exo-, und Endozytose synaptischer Vesikel erscheinen möglich (siehe Abschnitt 1.4.7).

\subsubsection{VGLUT 1/2}

Die Isoformen des VGLUT finden sich in unterschiedlicher Verteilung in den Membranen präsynaptischer Vesikel des gesamten Rattengehirns und dienen primär der Befüllung synaptischer Vesikel mit dem Neurotransmitter Glutamat. Sie ermöglichen die eindeutige Markierung glutamaterger synaptischer Kontakte. Funktionelle Unterschiede zwischen den bekannten Isoformen, regulatorische Funktionen bezüglich präsynaptischer Funktionen sowie eine Funktionsübernahme des VGLUT in nicht-glutamatergen Synapsen erscheinen möglich (siehe Abschnitt 1.4.6).

\subsubsection{Amphiphysin}

Die zwei Isoformen des Amphiphysins lassen sich im Zytosol und in Assoziation mit endozytotischen Zwischenstufen synaptischer Vesikel in präsynaptischen Endigungen des gesamten Rattengehirns nachweisen. Amphiphysin interagiert mit zahlreichen, an der Vesikelendozytose beteiligten, Proteinen und dient aufgrund seiner tragenden Funktionen im Rahmen der synaptischen Vesikelendozytose der molekularen Markierung des endozytotischen Apparates präsynaptischer Endigungen (siehe Abschnitt 1.4.5). 


\subsection{Halbwertsbreiten}

Die detektierten Halbwertsbreiten (FWHM) der Testproteine wurden als Maß für die Fläche, auf der sich das jeweilige Testprotein innerhalb der durchschnittlichen, zweidimensionalen Präsynapsen einer Hirnregion verteilt, verwendet. So wurde ein Vergleich der Proteinverteilung eines Testproteins zwischen verschiedenen Hirnregionen sowie der Vergleich der Verteilung verschiedener Testproteine innerhalb der untersuchten Präsynapsen ermöglicht (siehe Abschnitt 4.1).

Die im folgenden aufgelisteten Säulendiagramme der Abbildungen 30, 31, 32, 33 und 34 stellen die durchschnittlichen Halbwertsbreiten detektierter Fluoreszenzsignale des jeweiligen Testproteins in verschiedenen Hirnregionen der Ratte dar. Auf der X-Achse sind die untersuchten Hirnregionen des Hippocampus und des Cortex Cerebri aufgezeichnet. Die Y-Achse zeigt die ermittelten Halbwertsbreiten in Pixeln. Ein Pixel hat eine Seitenlänge von 12,2 nm. Oberhalb der Säulendiagramme werden das Signifikanzniveau (p) der durchgeführten ANOVA sowie das Ergebnis des, bei einem Siginifikanzniveau der ANOVA von $\mathrm{p}<0,05$, durchgeführten $\mathrm{t}$-Tests einschließlich Bonferroni-Korrektur ausgewiesen. 


\subsubsection{Halbwertsbreite Bassoon}

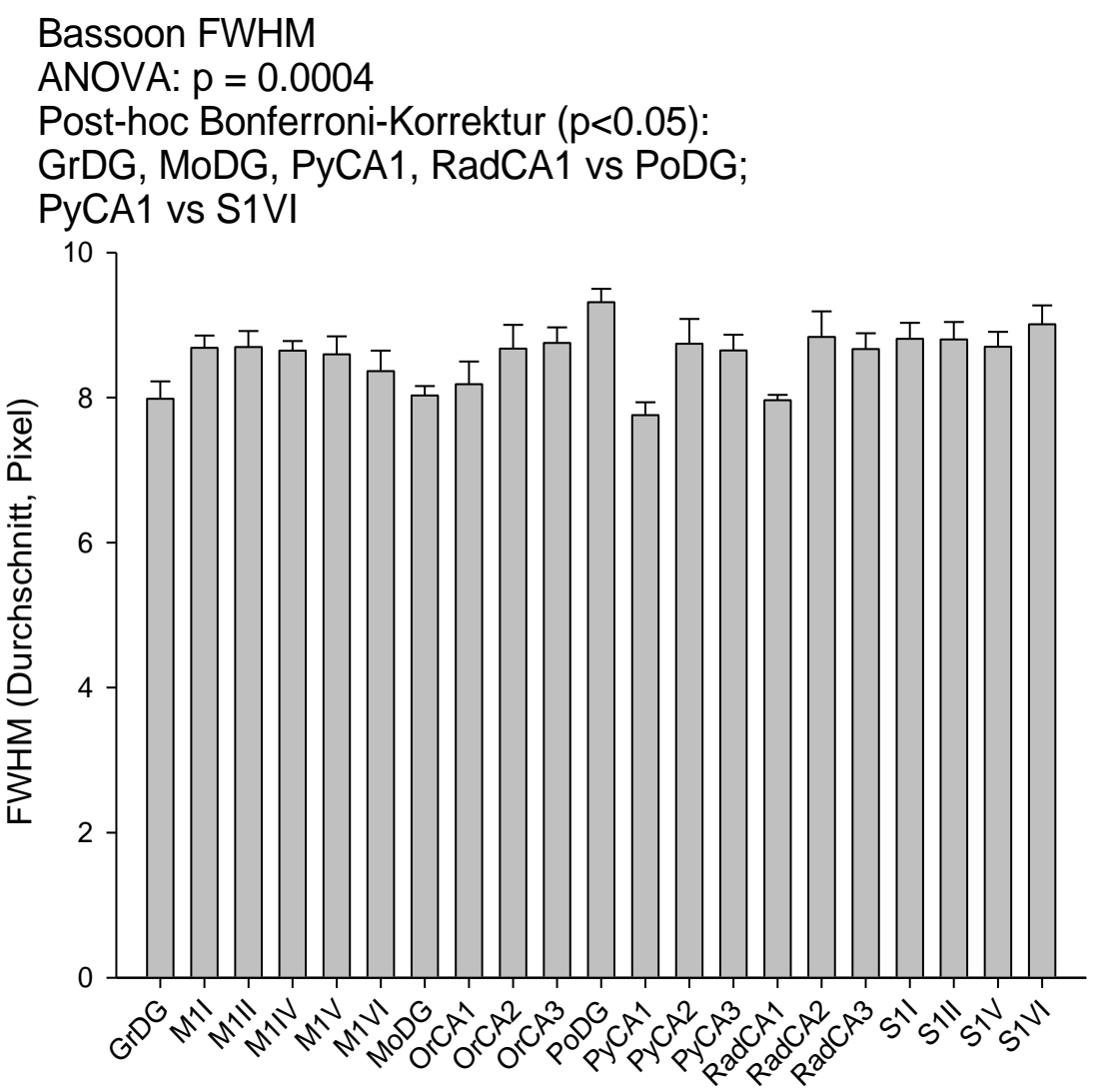

Abbildung 30: Durchschnittliche Halbwertsbreiten detektierter Bassoon-Fluoreszenzsignale in verschiedenen Regionen des Rattenhirns im Säulendiagramm mit Ausweisung des Standardfehlers. 1 Pixel=12,2*12,2 nm.

Die Halbwertsbreite des Bassoons betrug gemittelt über alle untersuchten Hirnregionen $\approx 104,5 \pm 2,8 \mathrm{~nm}$. Die geringste Halbwertsbreite ergab sich mit $\approx 94,6 \pm 2,2 \mathrm{~nm}$ in der Region PyCA1. Die höchste Halbwertsbreite wurde mit $\approx 113,7 \pm 2,2 \mathrm{~nm}$ in der Region PoDG festgestellt. Die durchschnittliche Experimentanzahl (n) lag bei $\mathrm{n} \approx 6,3$. Das errechnete Signifikanzniveau der durchgeführten ANOVA lag bei $p=0,0004$ und gab an, dass zwischen einzelnen Halbwertsbreiten der Versuchsgruppen signifikante Unterschiede vorlagen. Der anschließende t-Test mit Bonferroni-Korrektur ergab signifikante Unterschiede zwischen der Halbwertsbreiten des Bassoons in den Regionen GrDG, MoDG, PyCA1 und RadCA1 im Vergleich mit der Region PoDG sowie zwischen der Region PyCA1 und der Region S1VI. Die Verteilung der Halbwertsbreiten stellte sich in allen untersuchten Regionen ähnlich dar. In den Regionen PyCA1 und RadCA1 lag eine Tendenz zu geringeren Halbwertsbreiten vor. In der Region PoDG lag eine Tendenz zu größeren Halbwertsbreiten vor. Die durchschnittliche Halbwertsbreite der untersuchten hippocampalen Regionen betrug $\approx 103,3 \pm 2,8 \mathrm{~nm}$. Die durchschnittliche Halbwertsbreite der untersuchten kortikalen Regionen betrug $\approx 106,2 \pm 2,7 \mathrm{~nm}$. 


\subsubsection{Halbwertsbreite Synaptophysin}

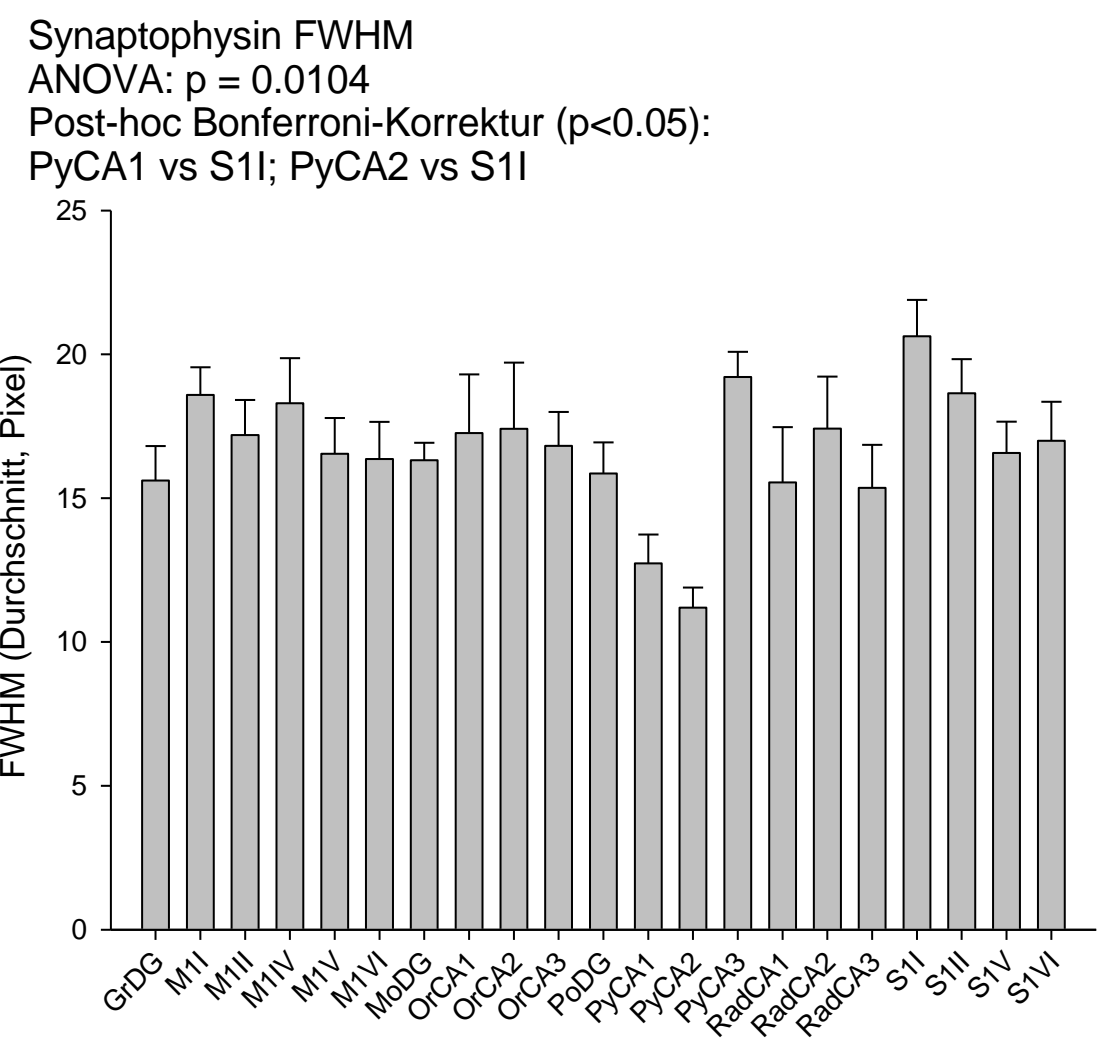

Abbildung 31: Durchschnittliche Halbwertsbreiten detektierter SynaptophysinFluoreszenzsignale in verschiedenen Regionen des Rattenhirns im Säulendiagramm mit Ausweisung der Standardfehlers. 1 Pixel=12,2*12,2 nm.

Die Halbwertsbreite des Synaptophysins betrug gemittelt über alle untersuchten Hirnregionen $\approx 203,7 \pm 15,9 \mathrm{~nm}$. Die geringste Halbwertsbreite ergab sich mit $\approx 136,6 \pm 8,5 \mathrm{~nm}$ in der Region PyCA2. Die höchste Halbwertsbreite wurde mit $\approx 251,7 \pm 15,3 \mathrm{~nm}$ in der Region S1I festgestellt. Die durchschnittliche Experimentanzahl (n) lag bei $\mathrm{n} \approx 6,6$. Das errechnete Signifikanzniveau der durchgeführten ANOVA lag bei $p=0,0104$ und gab an, dass zwischen einzelnen Halbwertsbreiten der Versuchsgruppen signifikante Unterschiede vorlagen. Der anschließende t-Test mit Bonferroni-korrektur ergab signifikante Unterschiede im Vergleich der Halbwertsbreiten des Synaptophysins in den Regionen PyCA1 und PyCA2 mit der Region S1I. Die Verteilung der Halbwertsbreiten stellte sich in allen untersuchten Regionen ähnlich dar. In den Regionen PyCA1 und PyCA2 lag eine Tendenz zu geringeren Halbwertsbreiten vor. In den Regionen PyCA3 und S1I lag eine Tendenz zu höheren Halbwertsbreiten vor. Die durchschnittliche Halbwertsbreite der untersuchten hippocampalen Regionen betrug $\approx 193,9 \pm 16,5 \mathrm{~nm}$. Die durchschnittliche Halbwertsbreite der untersuchten kortikalen Regionen betrug $\approx 216,7 \pm 15,1 \mathrm{~nm}$. 


\subsubsection{Halbwertsbreite SNAP-25}

SNAP-25 FWHM

ANOVA: $p=0.8456$

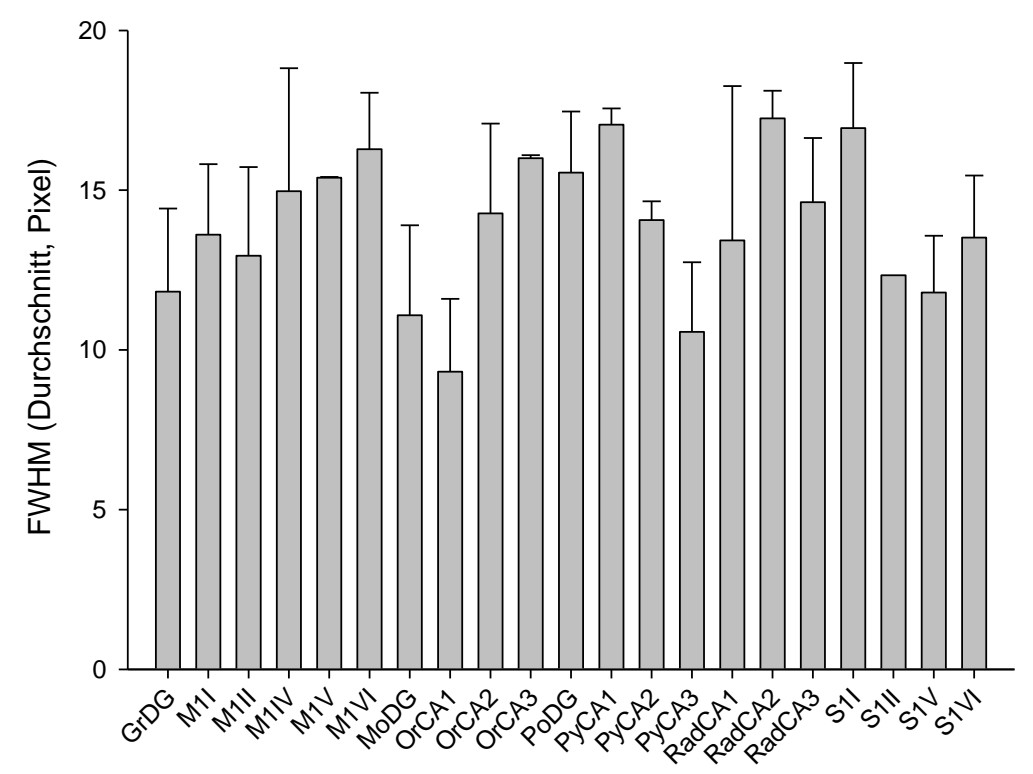

Abbildung 32: Durchschnittliche Halbwertsbreiten detektierter SNAP-25-Fluoreszenzsignale in verschiedenen Regionen des Rattenhirns im Säulendiagramm mit Ausweisung des Standardfehlers. 1 Pixel=12,2*12,2 nm.

Die Halbwertsbreite des SNAP-25 betrug gemittelt über alle untersuchten Hirnregionen $\approx 170,1 \pm 23,2 \mathrm{~nm}$. Die geringste Halbwertsbreite ergab sich mit $\approx 113,7 \pm 27,8 \mathrm{~nm}$ in der Region OrCA1. Die höchste Halbwertsbreite wurde mit $\approx 210,4 \pm 10,5 \mathrm{~nm}$ in der Region RadCA2 festgestellt. Die durchschnittliche Experimentanzahl (n) lag bei $\mathrm{n} \approx 2$. Das errechnete Signifikanzniveau der durchgeführten ANOVA lag bei $\mathrm{p}=0,8456$ und gab an, dass zwischen einzelnen Halbwertsbreiten der Versuchsgruppen keine signifikanten Unterschiede vorlagen. Die Verteilung der Halbwertsbreiten stellte sich in allen untersuchten Regionen ähnlich dar. In den Regionen MoDG, OrCA1 und PyCA3 ließ sich eine Tendenz zu geringeren Halbwertsbreiten erkennen. In den Regionen PyCA1 und RadCA2 ließ sich eine Tendenz zu höheren Halbwertsbreiten erkennen. Schwankungen der durchschnittlichen Halbwertsbreiten um die, über alle Testgruppen gemittelte, Halbwertsbreite, waren im Vergleich zu der Verteilung der Halbwertsbreiten der Fluoreszenzsignale der Testproteine Bassoon und Synaptophysin deutlicher ausgeprägt. Die durchschnittliche Halbwertsbreite der untersuchten hippocampalen Regionen betrug $\approx 167,8 \pm 23,9 \mathrm{~nm}$. Die durchschnittliche Halbwertsbreite der untersuchten kortikalen Regionen betrug $\approx$ $173,2 \pm 22,2 \mathrm{~nm}$. 


\title{
3.3.4 Halbwertsbreite VGLUT 1/2
}

\author{
VGLUT FWHM \\ ANOVA: $p=0.3741$
}

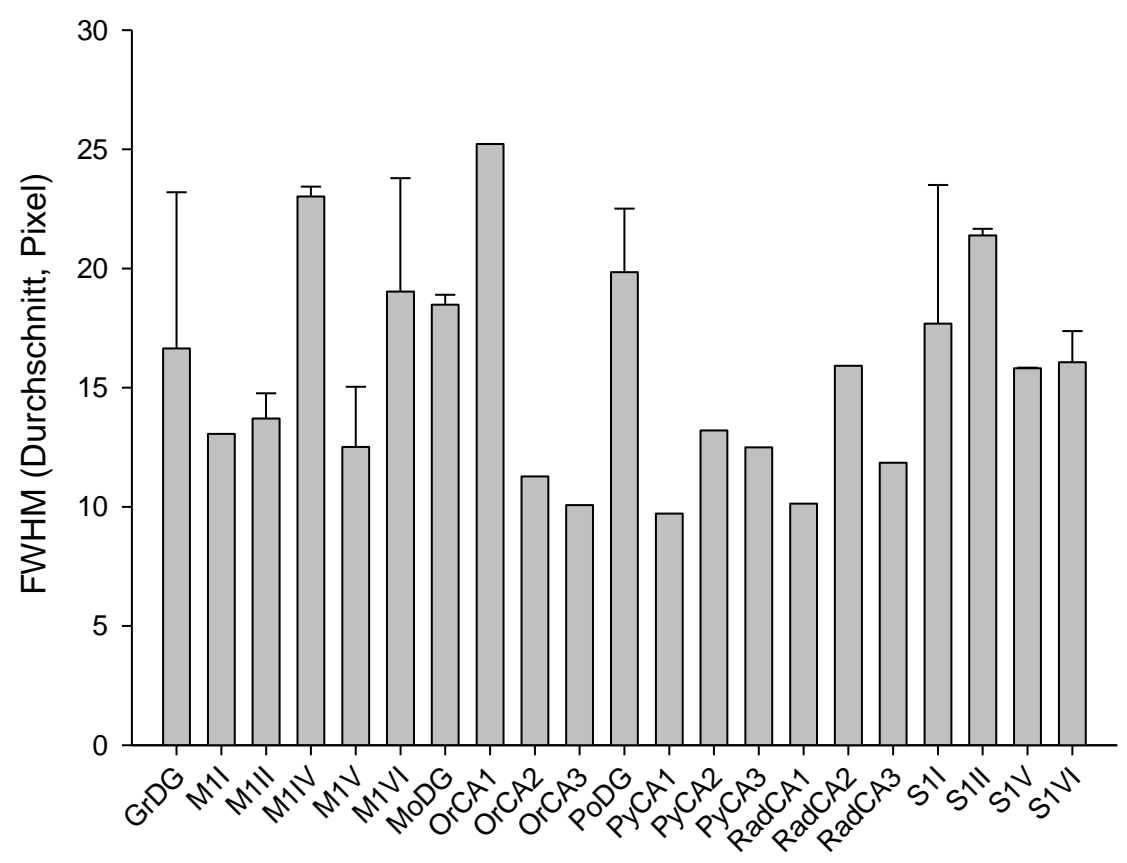

\section{Abbildung 33: Durchschnittliche Halbwertsbreiten detektierter VGLUT-1/2-Fluo- reszenzsignale in verschiedenen Regionen des Rattenhirns im Säulendiagramm mit} Ausweisung des Standardfehlers. 1 Pixel=12,2*12,2 nm.

Die Halbwertsbreite der VGLUT 1/2 betrug gemittelt über alle untersuchten Hirnregionen $\approx 190,0 \pm 15,0 \mathrm{~nm}$. Die geringste Halbwertsbreite ergab sich mit $\approx 118,5 \mathrm{~nm}$ in der Region PyCA1. Die höchste Halbwertsbreite wurde mit $\approx 307,7 \mathrm{~nm}$ in der Region OrCA1 festgestellt. Die durchschnittliche Experimentanzahl (n) lag bei $n \approx 1,5$. Das errechnete Signifikanzniveau der durchgeführten ANOVA lag bei $\mathrm{p}=0,3741$ und gab an, dass zwischen einzelnen Halbwertsbreiten der Versuchsgruppen keine signifikanten Unterschiede vorlagen. Die Verteilung der Halbwertsbreiten stellte sich in allen untersuchten Regionen ähnlich dar. In den Regionen OrCA1, PyCA1 und RadCA1 ließ sich eine Tendenz zu geringeren Halbwertsbreiten erkennen. In den Regionen M1IV, OrCA1, PoDG und S1II ließ sich eine Tendenz zu höheren Halbwertsbreiten erkennen. Schwankungen der durchschnittlichen Halbwertsbreiten um die, über alle Testgruppen gemittelte, Halbwertsbreite waren im Vergleich zu der Verteilung der Halbwertsbreiten der Fluoreszenzsignale der Testproteine Bassoon, Synaptophysin und SNAP-25 deutlicher ausgeprägt. Die durchschnittliche Halbwertsbreite der untersuchten hippocampalen Regionen betrug $\approx 177,8 \pm$ 9,8 nm. Die durchschnittliche Halbwertsbreite der untersuchten kortikalen Regionen betrug $\approx 206,4 \pm 21,9 \mathrm{~nm}$. 


\subsubsection{Halbwertsbreite Amphiphysin}

Amphiphysin FWHM

ANOVA: $p=0.7078$

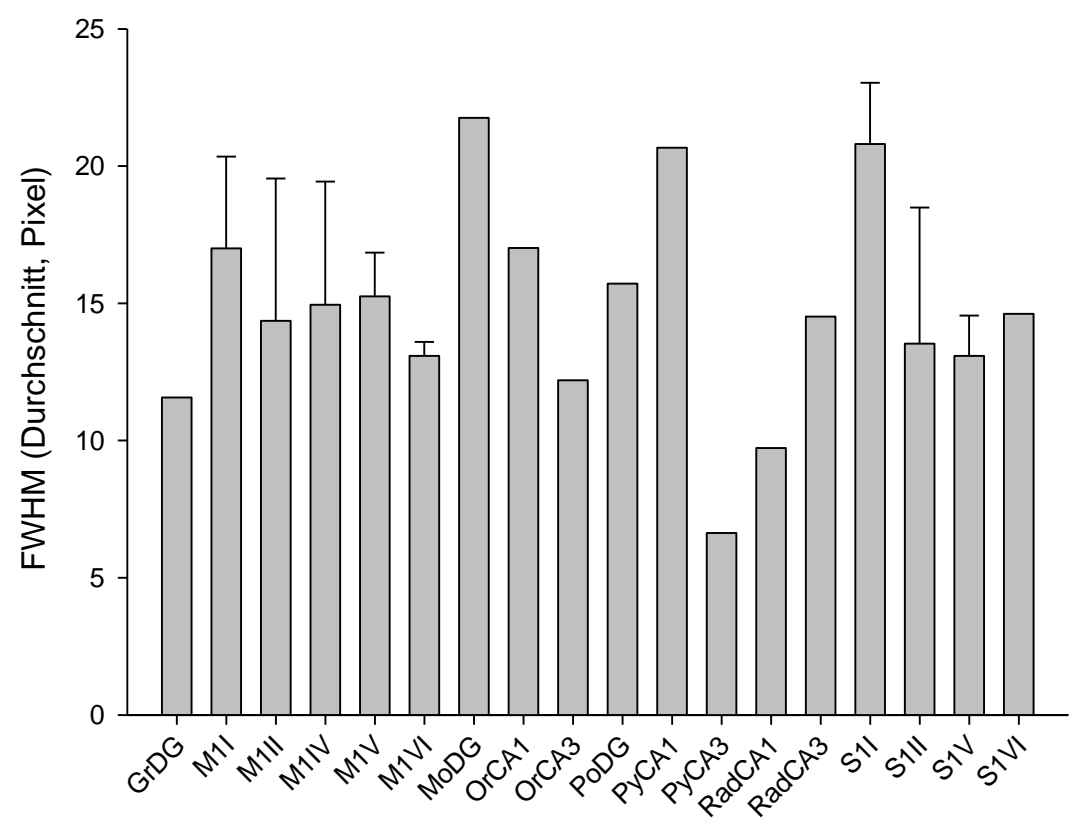

Abbildung 34: Durchschnittliche Halbwertsbreiten detektierter Amphiphysin-Fluoreszenzsignale in verschiedenen Regionen des Rattenhirns im Säulendiagramm mit Ausweisung des Standardfehlers. 1 Pixel=12,2*12,2 nm.

Die Halbwertsbreite des Amphiphysins betrug gemittelt über alle untersuchten Hirnregionen $\approx 180,6 \pm 16,1 \mathrm{~nm}$. Die geringste Halbwertsbreite ergab sich mit $\approx 80,9 \mathrm{~nm}$ in der Region PyCA3. Die höchste Halbwertsbreite wurde mit $\approx 265,4 \mathrm{~nm}$ in der Region MoDG festgestellt. Die durchschnittliche Experimentanzahl $(n)$ lag bei $n \approx 1,4$. Das errechnete Signifikanzniveau der durchgeführten ANOVA lag bei $\mathrm{p}=0,7078$ und gab an, dass zwischen einzelnen Halbwertsbreiten der Versuchsgruppen keine signifikanten Unterschiede vorlagen. Die Verteilung der Halbwertsbreiten stellte sich in allen untersuchten Regionen ähnlich dar. In den Regionen PyCA3 und RadCA1 ließ sich eine Tendenz zu geringeren Halbwertsbreiten erkennen. In den Regionen MoDG, PyCA1 und S1I ließ sich eine Tendenz zu höheren Halbwertsbreiten erkennen. Schwankungen der durchschnittlichen Halbwertsbreiten um die, über alle Testgruppen gemittelte, Halbwertsbreite waren im Vergleich zu der Verteilung der Halbwertsbreiten der Fluoreszenzsignale der Testproteine Bassoon, Synaptophysin und SNAP-25 deutlicher ausgeprägt. Die durchschnittliche Halbwertsbreite der untersuchten hippocampalen Regionen betrug $\approx 175,9 \mathrm{~nm}$. Die durchschnittliche Halbwertsbreite der untersuchten kortikalen Regionen betrug $\approx 185,3 \pm$ $32,2 \mathrm{~nm}$. 


\subsection{Fluoreszenzspeaks}

Die detektierten Fluoreszenzpeaks der Testproteine wurden als Maß für die Menge des jeweiligen Testproteins innerhalb der durchschnittlichen Präsynapsen verschiedener Hirnregionen verwendet. Hierdurch wurden zusätzlich Vergleiche hinsichtlich des Anreicherungsgrades verschiedener Testproteine innerhalb der untersuchten Präsynapsen ermöglicht (siehe Abschnitt 4.1).

Die im folgenden aufgelisteten Säulendiagramme der Abbildungen 35, 36, 37, 38 und 39 stellen die durchschnittlichen Fluoreszenzpeaks detektierter Fluoreszenzsignale des jeweiligen Testproteins in verschiedenen Hirnregionen der Ratte dar. Auf der X-Achse sind die untersuchten Hirnregionen des Hippocampus und des Cortex Cerebri aufgezeichnet. Die Y-Achse zeigt die detektierten Fluoreszenzpeaks in Prozent über der Grundlinie (\% über Grundlinie) nach Gaußscher Kurvenanpassung. Oberhalb des Säulendiagramms wird das Signifikanzniveau (p) der durchgeführten ANOVA ausgewiesen. 


\subsubsection{Fluoreszenzpeak Bassoon}

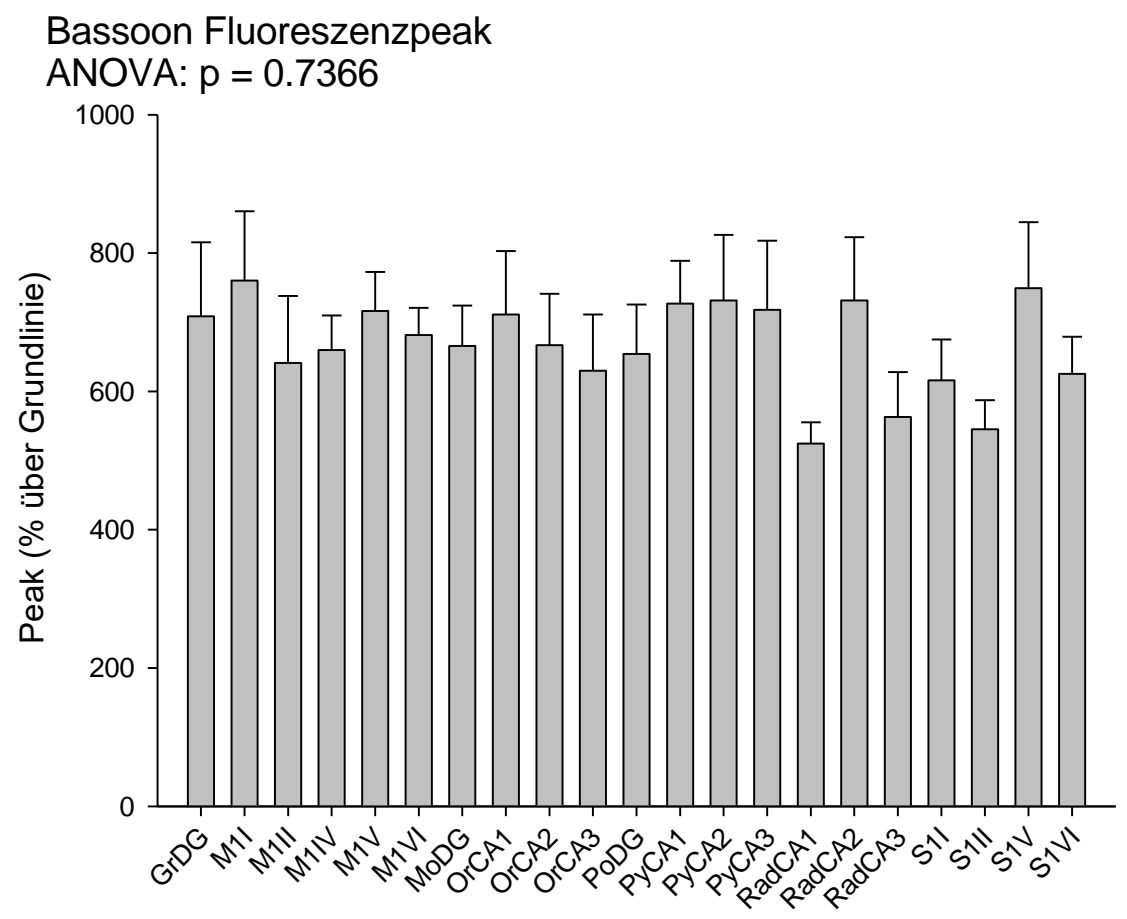

Abbildung 35: Durchschnittliche Fluoreszenzpeaks detektierter Bassoon-Fluoreszenzsignale in verschiedenen Regionen des Rattenhirns im Säulendiagramm mit Ausweisung des Standardfehlers.

Der über alle untersuchten Hirnregionen, gemittelte Fluoreszenpeak des Bassoons lag bei $\approx 667,9 \pm 72,4 \%$ über Grundlinie. Der geringste Fluoreszenzpeak ergab sich mit $\approx$ $524,5 \pm 30,9 \%$ über Grundlinie in der Region RadCA1. Der am stärksten ausgeprägte Fluoreszenzpeak wurde mit $\approx 760,3 \pm 100,2 \%$ über Grundlinie in der Region M1I festgestellt. Die durchschnittliche Experimentanzahl (n) lag bei $\mathrm{n} \approx 6,6$. Das errechnete Signifikanzniveau der durchgeführten ANOVA lag bei $\mathrm{p}=0,7366$ und gab an, dass zwischen einzelnen Halbwertsbreiten der Versuchsgruppen keine signifikanten Unterschiede vorlagen. Die durchschnittlichen Fluoreszenzpeaks stellten sich in allen untersuchten Regionen ähnlich dar. Schwankungen der durchschnittlichen Fluoreszenzpeaks um den, über alle Testgruppen gemittelten, Fluoreszenzpeak waren schwach ausgeprägt. In den Regionen RadCA1, RadCA3, S1I, S1II und S1VI ließ sich eine Tendenz zu geringeren Fluoreszenzpeaks erkennen. In den Regionen M1I und S1V ließ sich eine Tendenz zu höheren Fluoreszenzpeaks erkennen. Der durchschnittliche Fluoreszenzpeak der untersuchten hippocampalen Regionen betrug $\approx 669,3 \pm 77,3 \%$ über Grundlinie. Der durchschnittliche Fluoreszenzpeak der untersuchten kortikalen Regionen lag bei $\approx 666,1 \pm 65,8 \%$ über Grundlinie. 


\subsubsection{Fluoreszenzpeak Synaptophysin}

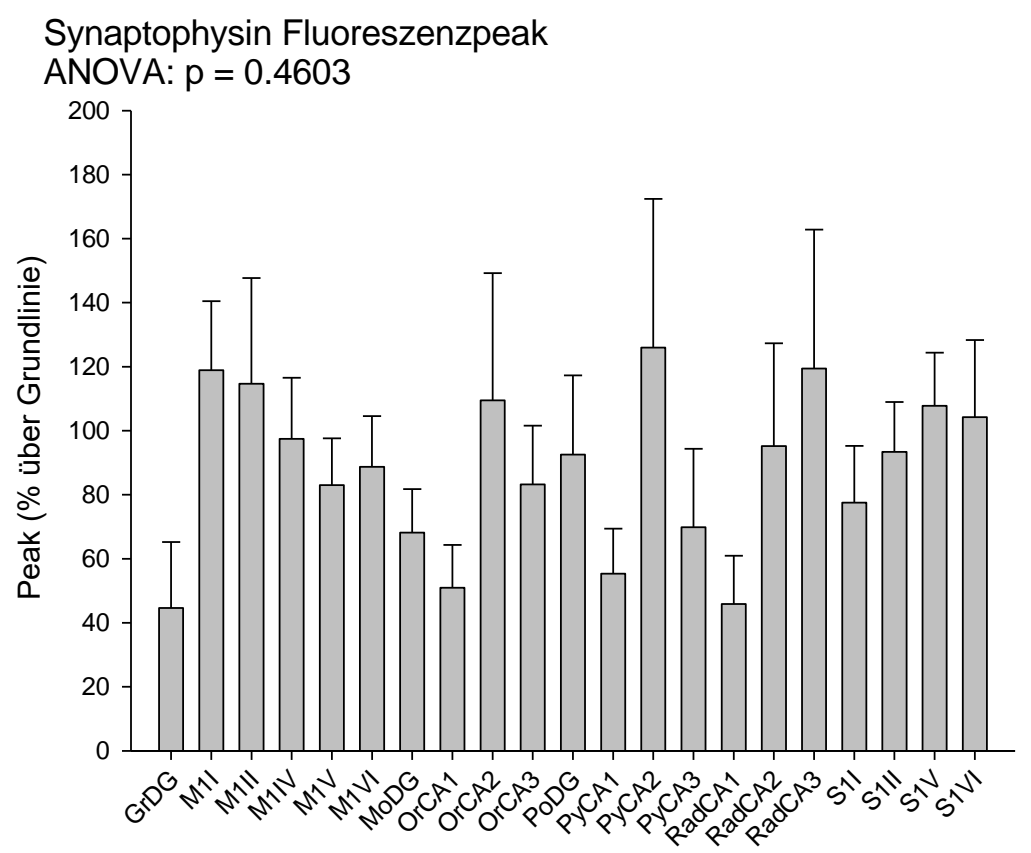

Abbildung 36: Durchschnittliche Fluoreszenzpeaks detektierter SynaptophysinFluoreszenzsignale in verschiedenen Regionen des Rattenhirns im Säulendiagramm mit Ausweisung des Standardfehlers.

Der über alle untersuchten Hirnregionen, gemittelte Fluoreszenpeak des Synaptophysins lag bei $\approx 87,9 \pm 23,0 \%$ über Grundlinie. Der geringste Fluoreszenzpeak ergab sich mit $\approx$ 44,6 \pm 20,6 \% über Grundlinie in der Region GrDG. Der am stärksten ausgeprägte Fluoreszenzpeak wurde mit $\approx 126,0 \pm 46,5 \%$ über Grundlinie in der Region PyCA2 festgestellt. Die durchschnittliche Experimentanzahl (n) lag bei $\mathrm{n} \approx 6,5$. Das errechnete Signifikanzniveau der durchgeführten ANOVA lag bei $\mathrm{p}=0,4603$ und gab an, dass zwischen einzelnen Halbwertsbreiten der Versuchsgruppen keine signifikanten Unterschiede vorlagen. Die durchschnittlichen Fluoreszenzpeaks stellten sich in allen Hirnregionen ähnlich dar. Schwankungen der Fluoreszenzpeaks um den, über alle Testgruppen gemittelten, Fluoreszenzpeak waren im Vergleich zur Untersuchung hinsichtlich durchschnittlicher Fluoreszenzpeaks des Bassoons deutlicher. In den Regionen GrDG, OrCA1, PyCA1 und RadCA1 ließ sich eine Tendenz zu geringeren Fluoreszenzpeaks erkennen. In den Regionen M1I, M1II, OrCA2, PyCA2, RadCA3,S1V und S1VI ließ sich eine Tendenz zu höheren Fluoreszenzpeaks erkennen. Der durchschnittliche Fluoreszenzpeak der untersuchten hippocampalen Regionen betrug $\approx 80,1 \pm 25,5 \%$ über Grundlinie. Der durchschnittliche Fluoreszenzpeak der untersuchten kortikalen Regionen lag bei $\approx 98,4 \pm 19,8$ $\%$ über Grundlinie. 


\subsubsection{Fluoreszenzpeak SNAP-25}

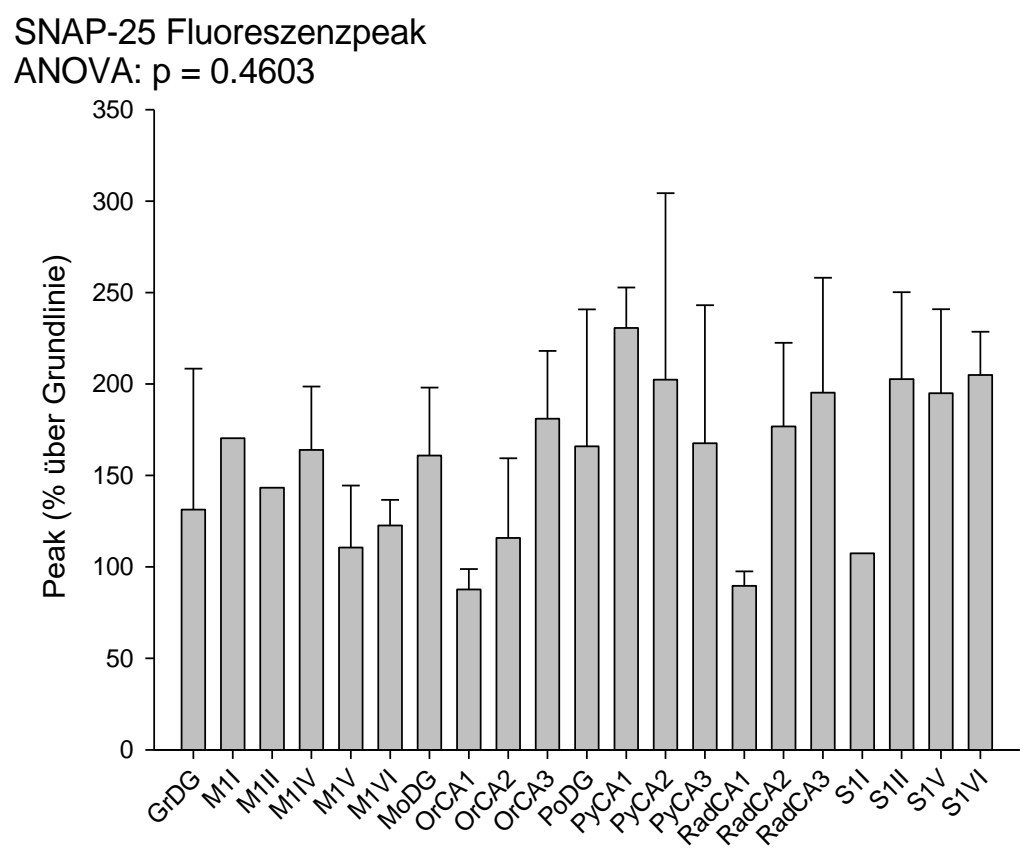

Abbildung 37: Durchschnittliche Fluoreszenzpeaks detektierter SNAP-25-Fluoreszenzsignale in verschiedenen Regionen des Rattenhirns im Säulendiagramm mit Ausweisung des Standardfehlers.

Der über alle untersuchten Hirnregionen, gemittelte Fluoreszenpeak des SNAP-25 lag bei $\approx 158,4 \pm 37,9 \%$ über Grundlinie. Der geringste Fluoreszenzpeak ergab sich mit $\approx$ $87,6 \pm 11,2 \%$ über Grundlinie in der Region OrCA1. Der am stärksten ausgeprägte Fluoreszenzpeak wurde mit $\approx 230,6 \pm 22,2 \%$ über Grundlinie in der Region PyCA1 festgestellt. Die durchschnittliche Experimentanzahl $(n)$ lag bei $n \approx 1,9$. Das errechnete Signifikanzniveau der durchgeführten ANOVA lag bei $p=0,4603$ und gab an, dass zwischen einzelnen Halbwertsbreiten der Versuchsgruppen keine signifikanten Unterschiede vorlagen. Die durchschnittlichen Fluoreszenzpeaks stellten sich in allen untersuchten Regionen ähnlich dar. Schwankungen der durchschnittlichen Fluoreszenzpeaks um den, über alle Testgruppen gemittelten, Fluoreszenzpeak waren im Vergleich zur Untersuchung hinsichtlich durchschnittlicher Fluoreszenzpeaks des Bassoons deutlicher. In den Regionen OrCA1, RadCA1 und S1I ließen sich Tendenzen zu geringeren Fluoreszenzpeaks erkennen. In der Region PyCA1 ließ sich eine Tendenz zu höheren Fluoreszenzpeaks erkennen. Der durchschnittliche Fluoreszenzpeak der untersuchten hippocampalen Regionen betrug $\approx 158,7 \pm 49,8 \%$ über Grundlinie. Der durchschnittliche Fluoreszenzpeak der untersuchten kortikalen Regionen lag bei $\approx 157,9 \pm 22,2 \%$ über Grundlinie. 


\subsubsection{Fluoreszenzpeak VGLUT 1/2}

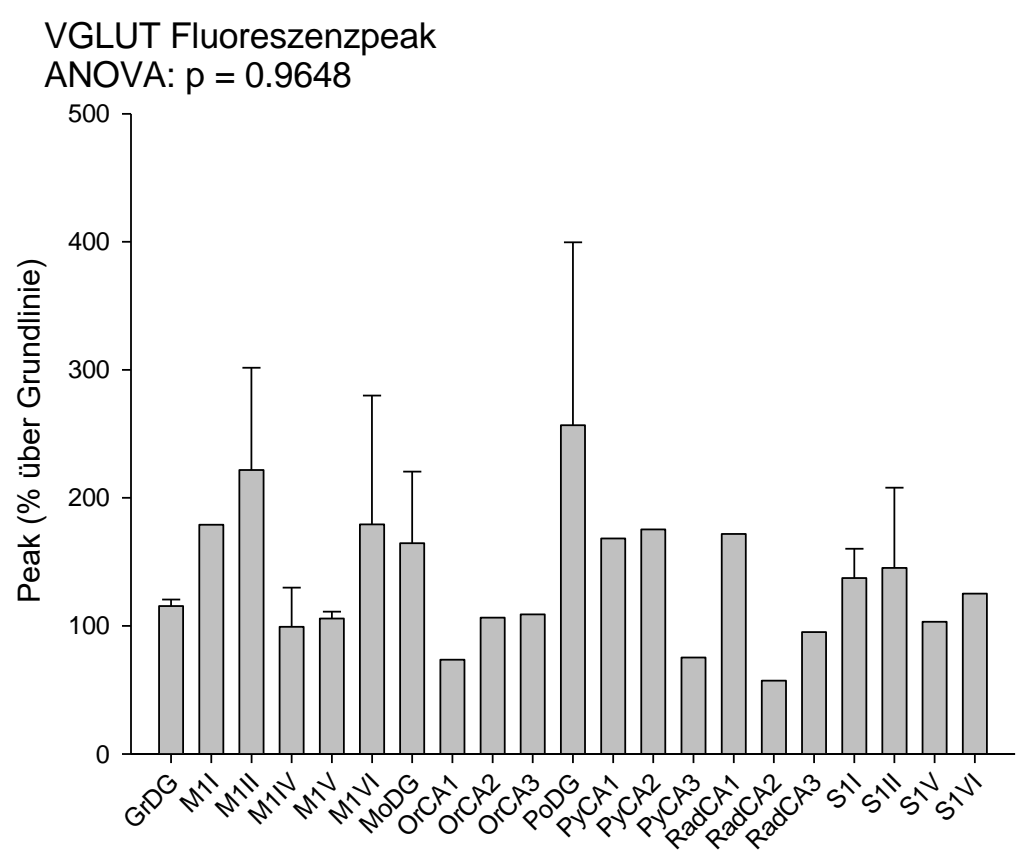

Abbildung 38: Durchschnittliche Fluoreszenzpeaks detektierter VGLUT-1/2-Fluoreszenzsignale in verschiedenen Regionen des Rattenhirns im Säulendiagramm mit Ausweisung des Standardfehlers.

Der über alle untersuchten Hirnregionen, gemittelte Fluoreszenpeak der VGLUT 1/2 lag bei $\approx 136,4 \pm 24,1 \%$ über Grundlinie. Der geringste Fluoreszenzpeak ergab sich mit $\approx$ 57,3 \% über Grundlinie in der Region RadCA2. Der am stärksten ausgeprägte Fluoreszenzpeak wurde mit $\approx 256,8 \pm 142,8 \%$ über Grundlinie in der Region PoDG festgestellt. Die durchschnittliche Experimentanzahl (n) lag bei $\mathrm{n} \approx 1,4$. Das errechnete Signifikanzniveau der durchgeführten ANOVA lag bei $p=0,9648$ und gab an, dass zwischen einzelnen Halbwertsbreiten der Versuchsgruppen keine signifikanten Unterschiede vorlagen. Die durchschnittlichen Fluoreszenzpeaks stellten sich in allen untersuchten Regionen ähnlich dar. Schwankungen der durchschnittlichen Fluoreszenzpeaks um den, über alle Testgruppen gemittelten, Fluoreszenzpeak waren im Vergleich zur Untersuchung hinsichtlich durchschnittlicher Fluoreszenzpeaks des Bassoons deutlicher. In den Regionen OrCA1 und RadCA2 ließen sich Tendenzen zu geringeren Fluoreszenzpeaks erkennen. In den Regionen M1II und PoDG ließen sich Tendenzen zu höheren Fluoreszenzpeaks erkennen. Der durchschnittliche Fluoreszenzpeak der untersuchten hippocampalen Regionen betrug $\approx 130,8 \pm 17,0 \%$ über Grundlinie. Der durchschnittliche Fluoreszenzpeak der untersuchten kortikalen Regionen lag bei $\approx 144,0 \pm 33,6 \%$ über Grundlinie. 


\subsubsection{Fluoreszenzpeak Amphiphysin}

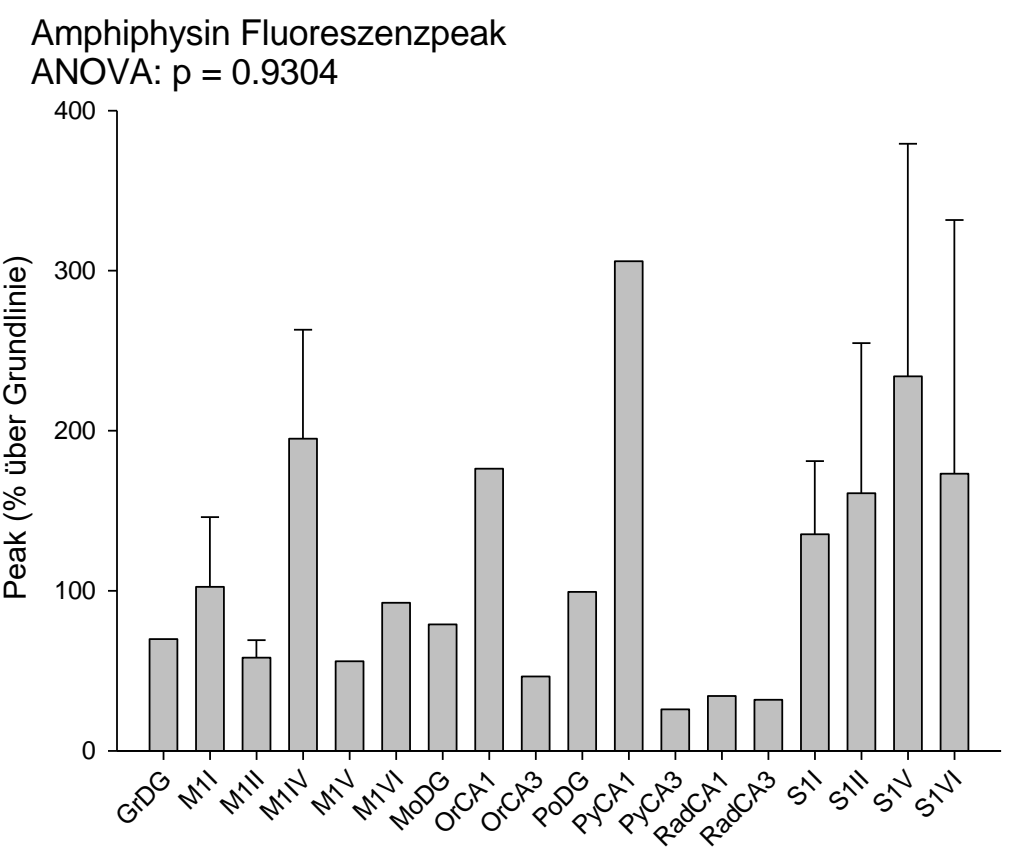

Abbildung 39: Durchschnittliche Fluoreszenzpeaks detektierter Amphiphysin-Fluoreszenzsignale in verschiedenen Regionen des Rattenhirns im Säulendiagramm mit Ausweisung des Standardfehlers.

Der über alle untersuchten Hirnregionen, gemittelte Fluoreszenpeak des Amphiphysins lag bei $\approx 115,4 \pm 31,4 \%$ über Grundlinie. Der geringste Fluoreszenzpeak ergab sich mit $\approx 25,9 \%$ über Grundlinie in der Region PyCA3. Der am stärksten ausgeprägte Fluoreszenzpeak wurde mit $\approx 305,9 \%$ über Grundlinie in der Region PyCA1 festgestellt. Die durchschnittliche Experimentanzahl (n) lag bei $\mathrm{n} \approx 1,4$. Das errechnete Signifikanzniveau der durchgeführten ANOVA lag bei $\mathrm{p}=0,9304$ und gab an, dass zwischen einzelnen Halbwertsbreiten der Versuchsgruppen keine signifikanten Unterschiede vorlagen. Bei nicht vorliegenden statistisch signifikanten Unterschieden zwischen den Testgruppen, stellten sich Schwankungen der durchschnittlichen Fluoreszenzpeaks um den, über alle Testgruppen gemittelten, Fluoreszenzpeak deutlicher dar als bei den Untersuchungen hinsichtlich des Fluoreszenzpeaks der Testproteine Bassoon, Synaptophysin, SNAP-25 und VGLUT 1/2. In den Regionen PyCA3, RadCA1 und RadCA3 ließen sich Tendenzen zu geringeren Fluoreszenzpeaks erkennen. In den Regionen M1IV, OrCA1, PyCA1, S1V und S1VI ließen sich Tendenzen zu höheren Fluoreszenzpeaks erkennen. Der durchschnittliche Fluoreszenzpeak der untersuchten hippocampalen Regionen betrug $\approx 96,5 \%$ über Grundlinie. Der durchschnittliche Fluoreszenzpeak der untersuchten kortikalen Regionen lag bei $\approx 134,2 \pm 62,9 \%$ über Grundlinie. 


\section{Diskussion}

Die hier vorliegende Arbeit sollte einen Beitrag zum besseren Verständnis der subzellulären Organisation des präsynaptischen Proteoms im Vergleich verschiedener Hirnregionen leisten. Abweichende subzelluläre Proteinorganisationen, im Vergleich unterschiedlich lokalisierter Präsynapsen, könnten sich an der Ausbildung der variierenden synaptischen Aktivität und damit der Ausbildung hochkomplexer neuronaler Kreisläufe beteiligen. Ausgehend von Epifluoreszenzbildern expansionsmikroskopisch präparierter Rattenhirnschnitte wurden durchschnittliche Fluoreszenzbilder präsynaptischer Proteine aus verschiedenen Hirnregionen erstellt. Diese Erstellung, akkumulierter, hochauflösender Fluoreszenzbilder, zur Untersuchung subzellulärer Strukturen, ermöglichte die Darstellung durchschnittlicher Signalverteilungen, bei gleichzeitig reduzierter Fehlerwahrscheinlichkeit durch mögliche Effizienzschwankungen der Antikörpermarkierung (vgl. Löschberger et al. 2012) und wurde beispielsweise bereits angewandt, um das durchschnittliche, dreidimensionale Modell einer zentralen Präsynapse zu erstellen (vgl. Wilhelm et al. 2014). Die detektierten Fluoreszenzsignale der antikörpermarkierten Testproteine Synaptophysin, Bassoon, SNAP-25, VGLUT 1/2 und Amphiphysin, in den durchschnittlichen Präsynapsen, wurden hinsichtlich ihrer Halbwertsbreiten und Signalintensitäten untersucht. Der experimentelle Fokus dieser Arbeit lag hierbei auf den gehäuft vorkommenden präsynaptischen Proteinen Synaptophysin und Bassoon. Hierdurch konnten Rückschlüsse auf mögliche Unterschiede hinsichtlich subzellulärer Verteilung und Menge dieser Proteine im Vergleich hippocampaler und kortikaler Regionen gezogen werden. Diese Art der Analyse, fluoreszenzmikroskopischer Aufnahmen, ermöglichte keine exakte subzelluläre Lokalisation der Testproteine in einzelnen Präsynapsen, sondern diente der Untersuchung hinsichtlich genereller Unterschiede bezüglich des subzellulären Verteilungsmusters der Testproteine in verschiedenen Hirnregionen. Hierdurch sollten Grundlagen für zukünftige Studien gebildet werden, die mögliche Unterschiede detaillierter Untersuchen könnten. 
Die Expansionsmikroskopie stellte zum Zeitpunkt der Datenerhebung ein erst kürzlich zuvor publiziertes, hochauflösendes Mikroskopieverfahren dar und ermöglichte erstmals die breitgefächerte, subzelluläre Untersuchung mehrerer Proteine in verschiedenen Neuronen- und Synapsentypen sowie in mehreren Hirnregionen gleichzeitig mit geringerem Aufwand als alternative hochauflösende Mikroskopieverfahren (siehe Abschnitt 1.5.2). Die erhobenen Daten werden im Folgenden, im wissenschaftlichen Kontext und hinsichtlich ihrer Bedeutung für präsynaptische Funktionen diskutiert.

\subsection{Subzelluläre Organisation der Testproteine}

\subsubsection{Bassoon}

Bassoon beteiligt sich maßgeblich an der Strukturerhaltung der aktiven Zone (Wang et al. 2009), sodass die erhobenen Daten in ihrer Gesamtheit Rückschlüsse auf die subzelluläre Organisation der aktiven Zonen erlaubten. Die Untersuchung hinsichtlich der Halbwertsbreiten detektierter Bassoon-Fluoreszenzsignale stellte sich, bei vereinzelt festgestellten signifikanten Unterschieden, in den untersuchten Hirnregionen größtenteils ähnlich dar (siehe Abschnitt 3.3.1). Signifikante Unterschiede ergaben sich im Vergleich der Hirnregion PoDG mit den Hirnregionen GrDG, MoDG, PyCA1 und RadCA1. Die molekulare Organisation der aktiven Zonen der hippocampalen Region PoDG unterschied sich somit durchschnittlich im Vergleich zu vier der insgesamt zwölf untersuchten hippocampalen Regionen. Im Vergleich hippocampaler und kortikaler Präsynapsen ergab sich lediglich im Vergleich der Regionen PyCA1 und S1VI ein statistisch signifikanter Unterschied. Unterschiedliche molekulare Organisationen der aktiven Zonen könnten ursächlich für funktionelle Unterschiede der Präsynapsen dieser Hirnregionen sein.

Die durchschnittlichen Halbwertsbreiten der Bassoon-Fluoreszenzsignale in hippocampalen $(\approx 103,3 \pm 2,8 \mathrm{~nm})$ und kortikalen Präsynapsen $(\approx 106,2 \pm 2,7 \mathrm{~nm})$ stellten sich nahezu identisch dar. Im Vergleich zwischen den Regionen des somatosensorischen und motorischen Kortex ergaben sich keine statistisch signifikanten Unterschiede. Somit lässt sich vermuten, dass sich die subzelluläre Organisation des Bassoons in den aktiven Zonen des Hippocampus und den untersuchten Regionen des somatosensorischen und motorischen Kortex nicht grundlegend voneinander unterscheidet. 
Die durchschnittliche Halbwertsbreite aller detektierten Bassoon-Fluoreszenzsignale $\quad(\approx$ $104,5 \pm 2,8 \mathrm{~nm}$ ) fiel deutlich kleiner aus als die durchschnittlichen Halbwertsbreite der Fluoreszenzsignale der Testproteine Synaptophysin $(\approx 203,7 \pm 15,9 \mathrm{~nm})$ und SNAP-25 $(\approx 170,1 \pm 23,2 \mathrm{~nm})$. Bassoon verteilt sich dementsprechend in einem kleineren Raum als die beiden Vergleichsproteine. Diese Daten gehen mit den Beobachtungen verschiedener elektronenmikroskopischer Untersuchungen einher, dass die Aktive Zone, im Vergleich zur Gesamtheit aller synaptischen Vesikel, einen kleineren Bereich zentraler Präsynapsen einnimmt (Südhof 2012b) sowie der Erkenntnis, dass SNAP-25, im Gegensatz zum Bassoon, kaum im Bereich der aktiven Zone, sondern vor allem im restlichen Bereich der präsynaptischen Plasmamembran bis hin zur axonalen Membran (Tao-Cheng et al. 2000), den postsynaptischen Dornenfortsätzen (Hussain et al. 2019) sowie umgebenden, extrasynaptischen Bereichen nachweisbar ist (Maidorn et al. 2018).

Die Untersuchung hinsichtlich des Bassoon-Fluoreszenzpeaks ließ in einzelnen Hirnregionen Tendenzen zu höheren oder niedrigeren Fluoreszenzpeaks erkennen, ergab im Vergleich der untersuchten Hirnregionen jedoch keine statistisch signifikanten Unterschiede (siehe Abschnitt 3.4.1). Dementsprechend stellten sich die durchschnittlichen Fluoreszenzpeaks aller untersuchten hippocampalen $(\approx 669,3 \pm 77,3 \%$ über Grundlinie) und kortikalen Regionen ( $\approx 666,1 \pm 65,8 \%$ über Grundlinie) nahezu identisch dar. Die Menge des Bassoons in den aktiven Zonen der untersuchten Regionen des Hippocampus und der somatosensorischen und motorischen kortikalen Regionen unterschied sich somit im Durchschnitt nicht grundlegend voneinander.

Der, über alle untersuchten Hirnregionen, gemittelte Fluoreszenpeak des Bassoons (667,9 $\pm 72,4 \%$ über Grundlinie) lag deutlich höher als die durchschnittlichen Fluoreszenzpeaks des Synaptophysins $(87,9 \pm 23,0 \%$ über Grundlinie) und des SNAP-25 (158,4 \pm 37,9 \% über Grundlinie). Bassoon ist somit deutlich stärker in seinem subsynaptischen Verteilungsbereich angereichert als die beiden Vergleichsproteine in ihren jeweiligen Verteilungsbereichen. Dieses Ergebnis korrespondiert mit dem Wissen, dass Bassoon, im Gegensatz zu den beiden Vergleichsproteinen, nahezu ausschließlich in der aktiven Zone (Dieck et al. 1998), also in einem kleinen Areal der präsynaptischen Membran vorliegt als das Synaptophysin als Bestandteil synaptischer Vesikel (Takamori et al. 2006) und SNAP-25 als gehäuft vorkommendes Protein der synaptischen Plasmamembran (Wilhelm et al. 2014; siehe Ausführungen oben bezüglich des Vergleichs der Halbwertsbreiten dieser Proteine). 
Zusammengefasst unterschied sich Bassoon hinsichtlich seiner subzellulären Verteilung und Menge im Vergleich der aktiven Zonen der untersuchten Hirnregionen miteinander lediglich geringfügig. Die hier erzielten Ergebnisse gehen in ihrer Gesamtheit mit den Ergebnissen von Wilhelm und Kollegen einher, die zeigten, dass Bassoon in durchschnittlichen zentralen Präsynapsen, im Vergleich mit Proteinen wie beispielsweise Synaptophysin, in geringer Menge vorkommt, sich aber im Gegensatz zu den meisten präsynaptischen Proteinen sehr stark auf einen kleinen Teilbereich der Synapse, die aktive Zone, konzentriert (vgl. Wilhelm et al. 2014).

\subsubsection{Synaptophysin}

Synaptophysin kommt gehäuft auf der Oberfläche synaptischer Vesikel vor (Takamori et al. 2006), sodass die erhobenen Daten in ihrer Gesamtheit Rückschlüsse auf die subzelluläre Organisation des gesamten Vesikelclusters erlaubten. Die Halbwertsbreiten detektierter Synaptophysin-Fluoreszenzsignale stellten sich in den untersuchten Hirnregionen größtenteils ähnlich dar (siehe Abschnitt 3.3.2). Statistisch signifikante Unterschiede ergaben sich im Vergleich der Halbwertsbreiten der beiden hippocampalen Regionen PyCA1 und PyCA2 mit der kortikalen Region S1I. Die subzelluläre Verteilung des Synaptophysins wich somit im Vergleich dieser Hirnregionen voneinander ab und könnte ursächlich für funktionelle Unterschiede der entsprechend lokalisierten Präsynapsen sein. Ursächlich für eine variierende, subzelluläre Organisation des Synaptophysins könnten hierbei Verhältnissunterschiede hinsichtlich der Dichte aller synaptischen Vesikel und der an den aktiven Zonen angedockten Vesikeln sein (Schikorski und Stevens 1999). Frühere Studien konnten entsprechend dieser Hypothese nachweisen, dass hippocampale CA1-Synapsen sowohl hinsichtlich Anzahl enthaltener präsynaptischer Vesikel (Harris und Sultan 1995) als auch dem Verhältnis zwischen der Anzahl der an die aktive Zone angedockter Vesikel und der Anzahl nicht angedockter Vesikel variieren (Schikorski und Stevens 1997). In der hier vorliegenden Arbeit wichen die Halbwertsbreiten des Synaptophysins im Vergleich der CA1-Synapsen (OrCA1, PyCA1, RadCA1) dementsprechend tendenziell voneinander ab. Trotz fehlender statistischer Signifikanz könnte sich die subzelluläre Verteilung der synaptischen Vesikel, im Vergleich dieser Subregionen des Hippocampus, voneinander unterscheiden. Neher und Brose zeigten weiterführend, dass auch im Vergleich aller angedockten Vesikel Unterschiede hinsichtlich ihrer Exozytosewahrscheinlichkeit vorliegen (Neher und Brose 2018; siehe Ausführungen in Abschnitt 4.2). 
In Anbetracht der erhobenen Daten könnten dementsprechend nicht generalisiert unterschiedliche subzelluläre Verteilungsmuster der synaptischen Vesikel unterschiedliche präsynaptische Funktionen bedingen, sondern minimale Unterschiede bezüglich der subzellulären Organisation des Vesikelclusters beziehungsweise Unterschiede im funktionellen Status einzelner synaptischer Vesikel zu bestimmten Zeitpunkten. Diese feinen Unterschiede konnten mit dem gewählten Analyseverfahren jedoch nicht untersucht werden und sollten durch zukünftige Studien detailliert betrachtet werden.

Die durchschnittliche Halbwertsbreite der Synaptophysin-Fluoreszenzsignale aller untersuchten hippocampalen Präsynapsen $(\approx 193,9 \pm 16,5 \mathrm{~nm})$ lag tendenziell unter der, der kortikalen Präsynapsen $(\approx 216,7 \pm 15,1 \mathrm{~nm})$. Da das Vesikelcluster sich auf einen Großteil des präsynaptischen Volumens verteilt (Wilhelm et al. 2014) und elektronenmikroskopische Untersuchungen zeigten, dass das Präsynaptische Volumen in linearer Beziehung zur Größe der aktiven Zone und Zahl der präsynaptischen Vesikel steht (Yeow und Peterson 1991) ließ sich somit vermuten, dass hippocampale Präynapsen durchschnittlich kleiner waren als die, der untersuchten Regionen des somatosensorischen und motorischen Kortex. Dies geht mit den Ergebnissen von Schikorski und Stevens einher, die zeigten, dass exzitatorische Synapsen des Hippocampus in Relation zu vergleichbaren kortikalen Synapsen kleiner sind. Die Autoren konnten weiterhin anhand hippocampaler CA1-Synapsen und Synapsen des olfaktorischen Kortex zeigen, dass eine lineare Beziehung zwischen dem Volumen präsynaptischer Endigungen, der Anzahl synaptischer Vesikel und der Größe ihrer aktiven Zone besteht (Schikorski und Stevens 1997; Schikorski und Stevens 1999). Korrelationen zwischen der Vesikelanzahl, der Größe der aktiven Zone sowie dem präsynaptischen Volumen konnten auch in neueren Studien nachgewiesen werden (Reshetniak et al. 2020). Diese Zusammenhänge lassen sich im Vergleich der gemessenen Halbwertsbreiten der Fluoreszenzsignale des Synaptophysins und des Bassoons ebenfalls erkennen. Geringere, beziehungsweise ausgeprägtere Halbwertsbreiten im Vergleich der Hirnregionen konnten gehäuft bezüglich beider Proteine festgestellt werden (siehe Ausführungen oben bezüglich der Halbwertsbreiten der Testproteine; vgl. Abbildungen 3.3.1 und 3.3.2).

Die Untersuchung hinsichtlich des Synaptophysin-Fluoreszenzpeaks ließ in einzelnen Hirnregionen Tendenzen zu höheren oder niedrigeren Fluoreszenzpeaks erkennen, ergab im Vergleich der untersuchten Hirnregionen jedoch keine statistisch signifikanten Unterschiede (siehe Abschnitt 3.4.2). 
Durchschnittliche Fluoreszenzpeaks hippocampaler Regionen $(\approx 80,1 \pm 25,5 \%$ über Grundlinie) und kortikaler Regionen $(\approx 98,4 \pm 19,8 \%$ über Grundlinie) stellten sich ähnlich dar. Die Menge an Synaptophysin könnte in hippocampalen Präsynapsen tendenziell geringer sein (siehe Ausführungen oben bezüglich der Fluoreszenzpeaks der Testproteine in hippocampalen und kortikalen Hirnregionen). In Anbetracht der fehlenden statistischen Signifikanz lässt sich jedoch schlussfolgern, dass die Menge an Synaptophysin in hippocampalen Präsynapsen und Präsynapsen des somatosensorischen Kortex und des motorischen Kortex vergleichbar ist.

Zusammengefasst stellten sich die Verteilung und Menge des Synaptophysins und damit der synaptischen Vesikel innerhalb der untersuchten Präsynapsen des Hippocampus und der Regionen des somatosensorischen und motorischen Kortex ähnlich dar. Die, durch Wilhelm und Kollegen publizierte, Organisation des Vesikelclusters einer durchschnittlichen zentralen Präsynapse (Wilhelm et al. 2014) gilt anscheinend für Präsynapsen verschiedener Hirnregionen.

\subsubsection{SNAP-25}

SNAP-25 lokalisiert sich in großer Menge, mit wenigen Ausnahmen, vor allem im Bereich der präsynaptischen Plasmamembran bis hin zum Axon (Tao-Cheng et al. 2000; Wilhelm et al. 2014; Maidorn et al. 2018). SNAP-25 kann somit als Markierung der präsynaptischen Plasmamebran angesehen werden. Die äußere Plasmamembran definiert das präsynaptische Volumen und umschließt das Vesikelcluster und lösliche präsynaptische Proteine räumlich. Die erhobenen Daten ermöglichten somit Rückschlüsse auf die molekulare Organisation der präsynaptischen Plasmamembran.

Die Untersuchung hinsichtlich der Halbwertsbreiten detektierter SNAP-25-Fluoreszenzsignale ergab, im Vergleich der untersuchten Hirnregionen, keine statistisch signifikanten Unterschiede (siehe Abschnitt 3.3.3). Die subzelluläre Verteilung des SNAP-25 ist demnach in den untersuchten Hirnregionen vergleichbar. Die durchschnittlichen Halbwertsbreiten hippocampaler und kortikaler Fluoreszenzsignale des SNAP $25(\approx 167,8 \pm 23,9$ $\mathrm{nm}$ vs. $\approx 173,2 \pm 22,2 \mathrm{~nm}$ ) ließen eine leichte Tendenz zu geringeren Halbwertsbreiten in hippocampalen Präsynapsen erkennen. Diese Tendenz korrespondierte mit den Halbwertsbreiten des Synaptophysins, den VGLUT 1/2 und des Amphiphysins, im jeweiligen Vergleich, hippocampaler und kortikaler Präsynapsen. 
Hierdurch wird die Vermutung, dass hippocampale Präsynapsen kleiner als kortikale Präsynapsen sind, gestützt (siehe Ausführungen und Literaturvergleich in Abschnitt 4.1.2). Die, über alle untersuchten Hirnregionen gemittelte, Halbwertsbreite der SNAP-25-Fluoreszenzsignale $(\approx 170,1 \pm 23,2 \mathrm{~nm})$ war ebenfalls vergleichbar zu den durchschnittlichen Halbwertsbreiten des Amphiphysins $(\approx 180,6 \pm 16,1 \mathrm{~nm})$, den VGLUT 1/2 $(\approx 190,0 \pm$ $15,0 \mathrm{~nm}$ ) und des Synaptophysins $(\approx 203,7 \pm 15,9 \mathrm{~nm})$. Auch im Vergleich zur deutlich geringeren durchschnittlichen Halbwertsbreite des Bassoons $(\approx 104,5 \pm 2,8 \mathrm{~nm})$ verhielt sich SNAP-25 somit analog zu allen Testproteinen. Ein unmittelbarer Vergleich der Halbwertsbreiten des membranständigen SNAP-25, mit den Halbwertsbreiten der löslichen, beziehungsweise vesikulären Proteine Synaptophysin, VGLUT 1/2 und Amphiphysin ist aufgrund der voneinander abweichenden Ausgangsdatenmenge sowie den unterschiedlichen synaptischen Lokalisationen dieser Proteine erschwert. Der Vergleich mit dem Bassoon steht allerdings im Einklang mit dem Wissen, dass sich Bassoon, im Gegensatz zum SNAP-25, nur in einem kleinen Teilbereich der präsynaptischen Membran, der aktiven Zone, lokalisiert (Südhof 2012b, siehe Ausführungen und Literaturvergleich in Abschnitt 4.1.1).

Die Untersuchung hinsichtlich des SNAP-25-Fluoreszenzpeaks verblieb ebenfalls ohne statistische Signifikanz. Der Vergleich des durchschnittlichen Fluoreszenzpeaks des SNAP-25 der hippocampalen Präsynapsen $(\approx 158,7 \pm 49,8 \%$ über Grundlinie $)$, mit dem, der kortikalen Präynapsen $(\approx 157,9 \pm 22,2 \%$ über Grundlinie) entsprach der fehlenden statistischen Signifikanz. Die Menge an SNAP-25, in den Präsynapsen der untersuchten Hirnregionen, ähnelte sich somit.

Der, über alle untersuchten Hirnregionen, gemittelte Fluoreszenzpeak des SNAP-25 $(\approx$ $158,4 \pm 37,9 \%$ über Grundlinie) war im Vergleich zum Synaptophysin $87,9 \pm 23,0 \%$ über Grundlinie), Amphiphysin ( $\approx 115,4 \pm 31,4 \%$ über Grundlinie) und den VGLUT $1 / 2(\approx 136,4 \pm 24,1 \%$ über Grundlinie $)$ höher. Da sich SNAP-25, in großer Menge (Wilhelm et al. 2014), auf einen ausgedehnten Bereich der synaptischen Plasmamembran und angrenzende Strukturen verteilt (Tao-Cheng et al. 2000; Maidorn et al. 2018; Hussain et al. 2019), eine hohe Effizienz der immunologischen Markierung des SNAP-25 wahrscheinlich ist (siehe Ausführungen unten) und der Vergleich zum durchschnittlichen Fluoreszenpeak des Bassoons ( $\approx 667,9 \pm 72,4 \%$ über Grundlinie) zusätzlich verdeutlicht, dass sich Bassoon im Gegensatz zum SNAP-25 stark auf einen kleinen Bereich, die aktive Zone, der präsynaptischen Membran konzentriert (Dieck et al. 1998), sind die erzielten Ergebnisse als plausibel einzustufen. 
Die in dieser Arbeit erkennbaren leichten Schwankungen der Halbwertsbreiten und Fluoreszenzpeaks des SNAP-25 könnten, bei gegenüber den Testproteinen Bassoon und Synaptophysin reduzierter Datenmenge, trotzdem auf Einschränkungen bezüglich der immunologischen Markierung zurückzuführen sein (siehe Abschnitt 4.3). Aufgrund des gehäuften Vorkommens des SNAP-25 sowie der guten Zugänglichkeit für Fluoreszenzantikörper, im Bereich der Plasmamebran, ist jedoch eine hohe Effizienz der Fluoreszenzmarkierung anzunehmen. Durch zusätzliche Summation aller SNAP-25 Fluoreszenzsignale, wurde die Wahrscheinlichkeit von Fehlinterpretationen nicht-präsynaptischer Signale zusätzlich reduziert (Siehe Abschnitt 4.3).

Zusammengefasst unterschied sich die subzelluläre Verteilung und Menge des SNAP-25, im Vergleich unterschiedlich lokalisierter Präsynapsen des Hippocampus sowie des somatosensorischen und motorischen Kortex, nicht grundlegend voneinander.

\subsubsection{VGLUT 1/2 und Amphiphysin}

Die Untersuchungen hinsichtlich der durchschnittlichen Halbwertsbreiten detektierter Fluoreszenzsignale der Testproteine VGLUT 1/2 und Amphiphysin ergaben, im Vergleich der jeweils untersuchten Hirnregionen, keine statistisch signifikanten Unterschiede (siehe Abschnitt 3.3.4 und 3.3.5).

Die durchschnittlichen Halbwertsbreiten hippocampaler und kortikaler Fluoreszenzsignale der VGLUT $1 / 2(\approx 177,8 \pm 9,8 \mathrm{~nm}$ vs. $\approx 206,4 \pm 21,9 \mathrm{~nm})$ und des Amphiphysins $(\approx 175,9 \mathrm{~nm}$ vs. $\approx 185,3 \pm 32,2 \mathrm{~nm})$ ließen, in beiden Testgruppen, eine leichte Tendenz zu geringeren Halbwertsbreiten in hippocampalen Präsynapsen erkennen. Weiterhin verhielten sich die, über alle Hirnregionen gemittelten, Halbwertsbreiten des Amphiphysins $(\approx 180,6 \pm 16,1 \mathrm{~nm})$ und der VGLUT $1 / 2(\approx 190,0 \pm 15,0 \mathrm{~nm})$ ähnlich. Auch im Vergleich zum Synaptophysin $(\approx 203,7 \pm 15,9 \mathrm{~nm})$ und dem Bassoon $(\approx 104,5 \pm 2,8 \mathrm{~nm})$ verhielten sich beide Testproteine somit vergleichbar. Die subzellulären Verteilungen der VGLUT 1/2 und des Amphiphysins waren demnach, im Vergleich der jeweils untersuchten Hirnregionen, ähnlich und zeigten ein, zum Synaptophysin vergleichbares subzelluläres Verteilungsmuster (siehe Ausführungen und Literaturvergleich in Abschnitt 4.1.2). 
Im Literaturvergleich wird dementsprechend eine vergleichbare subzelluläre Verteilung dieser Proteine angenommen. VGLUT 1/2 und Synaptophysin sind beide Bestandteil vesikulärer Membranen (Bellocchio et al. 2000; Takamori et al. 2000; Takamori et al. 2006) und kommen den Untersuchungen von Wilhelm und Kollegen zu Folge, in durchschnittlichen Präsynapsen, in vergleichbarer Menge vor (Wilhelm et al. 2014). Ein vergleichbares subzelluläres Verteilungsmuster ist somit wahrscheinlich. Amphiphysin verteilt sich, bei geringer Gesamtmenge, zudem ebenfalls im gesamten präsynaptischen Volumen (Wilhelm et al. 2014) und besitzt eine Tendenz zum Erkennen und binden gekrümmter Plasmamembranen (Peter et al. 2004; Sorre et al. 2012). Lichte und Kollegen konnten dementsprechend licht- und elektronenmikroskopisch ein ähnliches Verteilungsmuster des Amphiphysins und des Synaptophysins nachweisen. Amphiphysin assoziiert demnach als peripheres Vesikelprotein mit dem präsynaptischen Vesikelcluster (Lichte et al. 1992). Weiterführend konnten Denker und Kollegen auch mittels hochauflösender Mikroskopie visualisieren, dass Amphiphysin mit dem, in größerer Menge vorkommenden, Synaptophysin innerhalb des Vesikelclusters kolokalisiert. Analog zu einer Vielzahl präsynaptischer Proteine wird Amphiphysin durch das Vesikelcluster abgepuffert und liegt somit in Assoziation zu den synaptischen Vesikeln vor (Denker et al. 2011b). Ein vergleichbares subzelluläres Verteilungsmuster des Amphiphysins, im Vergleich zu den vesikulären Proteinen Synaptophysin und VGLUT 1/2 ist somit wahrscheinlich.

Die, in dieser Arbeit, im Vergleich der untersuchten Hirnregionen, erkennbaren Schwankungen der Halbwertsbreiten des Amphiphysins, könnten in Anbetracht der Studien von Bauerfeind und Kollegen auf unterschiedliche Verhältnisse zwischen dem, mit dem Vesikelcluster assoziierten Amphiphysin und dem, mit in Endozytose befindlichen Vesikeln assoziiertem Amphiphysin, zurückzuführen sein (Bauerfeind et al. 1997). Mögliche Einschränkungen bezüglich der immunologischen Markierung der Testproteine VGLUT 1/2 und Amphiphysin können jedoch nicht ausgeschlossen werden (siehe Abschnitt 4.3).

Die Untersuchungen hinsichtlich des Fluoreszenzpeaks des Amphiphysins und der VGLUT 1/2 blieben, im Vergleich der jeweils untersuchten Hirnregionen, ebenfalls ohne statistische Signifikanz. Der Vergleich des durchschnittlichen Fluoreszenzpeaks des Amphiphysins hippocampaler Präsynapsen $(\approx 96,5 \%$ über Grundlinie), mit dem, der kortikalen Präsynapsen ( $\approx 134,2 \pm 62,9 \%$ über Grundlinie) lässt vermuten, dass die Amphiphysinmenge in hippocampalen Präsynapsen geringer ist als in kortikalen Präsynapsen. Der durchschnittliche VGLUT-Fluoreszenzpeak der untersuchten hippocampalen Präsynapsen $(\approx 130,8 \pm 17,0 \%$ über Grundlinie) fiel ebenfalls geringer aus als der 
durchschnittliche Fluoreszenzpeak der untersuchten kortikalen Präsynapsen $144,0 \pm 33,6 \%$ über Grundlinie). Die Menge an VGLUT 1/2 in hippocampalen Präsynapsen könnte somit ebenfalls geringer sein als in den Präsynapsen der untersuchten Regionen des somatosensorischen und motorischen Kortex. Bei fehlender statistischer Signifikanz könnte diese Tendenz auf geringfügig voneinander abweichende Mengen der VGLUT 1/2 in Präsynapsen unterschiedlicher Hirnregionen hindeuten. VGLUT kommen insbesondere in exzitatorischen Synapsen vor (El Mestikawy et al. 2011). Unterschiedliche Verhältnisse zwischen exzitatorischen und inhibitorischen synaptischen Kontakten könnten im Vergleich der untersuchten Hirnregionen vorliegen und funktionelle Unterschiede bedingen. Dementsprechend konnte beispielsweise gezeigt werden, dass die Dichte exzitatorischer Synapsen im akzessorischen Riechkolben geringer ist, als im Kortex (Dani et al. 2010). Neben grundsätzlich voneinander abweichenden subzellulären Verteilungen und Mengen der VGLUT in exzitatorischen Synapsen könnten auch Unterschiede hinsichtlich der Verteilung der Isoformen des Proteins ursächlich für funktionelle Unterschiede verschiedener Präsynapsen sein. Die Isoformen VGLUT1 und VGLUT2 verteilen sich größtenteils komplementär in verschiedenen Hirnregionen (Kaneko und Fujiyama 2002; Herzog et al. 2006) und konnten von Graziano und Kollegen in Präsynapsen einzelner kortikaler Schichten kolokalisiert nachgewiesen werden. Dadurch, dass sie möglicherweise in unterschiedlichen Vesikelpopulationen vorkommen, könnten sie zur Ausbildung unterschiedlicher neuronaler Projektionssysteme beitragen (Graziano et al. 2008). Fremeau und Kollegen zeigten, dass sich VGLUT1 gehäuft in Nervendigungen mit geringer Exozytosewahrscheinlichkeit nachweisen lässt, wohingegen VGLUT2 gehäuft in Nervendigungen mit höherer Exozytosewahrscheinlichkeit vorkommt. Dieses Verteilungsmuster könnte direkten Einfluss auf die Aktivität neuronaler Netzwerke haben (Fremeau et al. 2004).

Unterschiedliche Expression der Isoformen des VGLUT führen zu morphologischen und funktionellen Veränderungen innerhalb des Gehirns, sodass VGLUT Einfluss auf die verfügbare Menge an Glutamat nehmen und damit die neuronale Übertragung modulieren könnten (Pietrancosta et al. 2020). Eine Differenzierung der Isoformen 1 und 2 des VGLUT konnte mit der in dieser Arbeit angewandten Methodik jedoch nicht erfolgen. 
Zusammenfassend unterschied sich die subzelluläre Verteilung und Menge der VGLUT 1/2 und des Amphiphysins im Vergleich der jeweils untersuchten unterschiedlich lokalisierten, Präsynapsen des Hippocampus sowie des somatosensorischen und motorischen Kortex, nicht grundlegend voneinander. VGLUT 1/2 und Amphiphysin zeigten zudem ein vergleichbares subzelluläres Verteilungsmuster zum Synaptophysin.

\subsubsection{Fazit}

Die untersuchten Testproteine repräsentierten essenzielle Bestandteile des präsynaptischen Mechanismus zur Steuerung des Vesikelrecyclings. Die Untersuchungen hinsichtlich ihrer subzellulären Verteilungen und relativen Mengen ergaben lediglich vereinzelt statistisch signifikante Unterschiede. Der Fokus dieser Arbeit lag auf den beiden gehäuft vorkommenden präsynaptischen Proteinen Synaptophysin und Bassoon (siehe Tabelle Abschnitt 7.1 bezüglich Anzahl der untersuchten Fluoreszenzsignale). Gemäß den, bezüglich dieser beiden Proteine, erhobenen Daten unterschieden sich die molekularen Organisationen der aktiven Zonen und Vesikelcluster unterschiedlich lokalisierter Präsynapsen lediglich geringfügig voneinander. Die ergänzend durchgeführten Untersuchungen, bezüglich der Testproteine SNAP-25, VGLUT 1/2 und Amphiphysin, entsprachen in ihren Tendenzen diesen Ergebnissen. Die erhobenen Daten führten zu der Hypothese, dass sich Präsynapsen in unterschiedlichen Hirnregionen hinsichtlich der subzellulären Verteilung und Menge der enthaltenen Proteine lediglich geringfügig voneinander unterscheiden. Das synaptische Proteom besteht aus 2000 bis 3000 Proteinen (Grant 2018) von denen bis zu 1124 verschiedene Proteine das postsynaptische Proteom exzitatorischer Synapsen bilden (Collins et al. 2006). In Anbetracht der Komplexität des synaptischen Proteoms liegt somit die Vermutung nahe, dass entgegen der Interpretation der hier erhobenen Daten, Unterschiede hinsichtlich der subzellulären Organisation des präsynaptischen Proteoms unterschiedlich lokalisierter Präsynapsen eine Rolle bei der Ausprägung funktioneller Unterschiede spielen.

Anderson und Grant entwickelten dementsprechend ein Modell, in dem der Proteinspiegel einiger Kernproteine glutamaterger Synapsen, in Abhängigkeit der Funktion und Lokalisation der Synapsen im Gehirn, variiert. Somit könnten regionale Unterschiede in der Zusammensetzung des Proteoms einzelner Synapsen zu unterschiedlichen synaptischen Funktionsmustern führen (Anderson und Grant 2006). Grant und Kollegen vermuteten ebenfalls, dass die Organisation des synaptischen Proteoms molekulare Mechanismen und damit die synaptische Funktion steuert. Die Autoren vermuteten, dass Prozesse wie 
beispielsweise das Lernen durch Modifizierung des postsynaptischen Proteoms bedingt sein könnten (Grant 2018). Die, gemäß den Ausführungen von Anderson und Grant, nachweisbar unterschiedliche Genexpression in Neuronen verschiedener Hirnregionen und Subregionen des Hippocampus stützt diese Hypothesen. Studien hinsichtlich der Genexpression geben jedoch keine Information über die subzelluläre Verteilung der entsprechenden Proteine (Anderson und Grant 2006).

Der Großteil der Studien, die das synaptische Proteom bisher untersuchten, bezog sich zudem auf das gesamte Gehirn. Die Frage, ob hierbei zwischen verschiedenen Hirnregionen, Subregionen und einzelnen Kompartimenten zentraler Neurone wie beispielsweise den Präsynapsen Heterogenität hinsichtlich der subzellulären Organisation einzelner synaptischer Proteine besteht konnte somit bisher nicht eindeutig geklärt werden. Aussagekräftige Daten bezüglich subzellulärer Proteinorganisationen können nur durch unterstützende Anwendung hochauflösender Mikroskopieverfahren erhoben werden. Dani und Kollegen konnten dementsprechend, unter Anwendung von STORM, synaptische Proteine im direkten Vergleich verschiedener Hirnregionen der Maus untersuchen. Die laterale Organisation postsynaptischer Rezeptoren variierte hierbei im Vergleich einzelner Synapsen deutlich (Dani et al. 2010). Unterschiedliche subzelluläre Organisationen einzelner synaptischer Proteine sind somit wahrscheinlich. Zhu und Kollegen untersuchten weiterführend und methodisch in Teilen zur hier vorgelegten Arbeit vergleichbar, zwei gehäuft vorkommende postsynaptische Proteine (PSD95 und SAP102) zum besseren Verständnis der Zusammensetzung des synaptischen Proteoms in verschiedenen Hirnregionen der Maus. Unter Anwendung von STED konnten Zhu und Kollegen anhand der zwei, mittels Green Fluorescent Protein (GFP), genetisch markierten postsynaptischen Proteine exzitatorischer Synapsen insgesamt 37 synaptische Subtypen klassifizieren, die sich zusätzlich in zahlreiche weitere Subtypen einteilen ließen. Diese synaptischen Subtypen ließen sich in unterschiedlicher Verteilung, in verschiedenen Hirnregionen nachweisen.

Hirnregionen konnten so, durch Zhu und Kollegen, anhand spezifischer Verteilungsmuster synaptischer Subtypen charakterisiert werden. Einige synaptische Subtypen ließen sich im gesamten Gehirn nachweisen, wohingegen andere Subtypen nur in bestimmten Regionen des Mausgehirns gehäuft vorkamen. Weiterhin unterschied sich in der Arbeit von Zhu und Kollegen die subzelluläre Organisation des postsynaptischen Proteoms hinsichtlich der beiden Testproteine sowohl im Vergleich verschiedener Hirnregionen wie beispielsweise im Vergleich des Hippocampus mit dem somatosensorischen Kortex als auch im Vergleich einzelner Subregionen des Hippocampus sowie zwischen einzelnen 
Schichten kortikaler Regionen. Hirnregionen, die höheren kognitiven Funktionen dienen, wie beispielsweise der Hippocampus und Regionen des Neokortex, wiesen in dieser Studie die höchste postsynaptische Diversität auf, wohingegen der Hirnstamm durch eine geringe postsynaptische Diversität charakterisiert wurde. Zhu und Kollegen schlussfolgerten, dass die hohe Diversität des synaptischen Proteoms nicht nur für diese zwei postsynaptischen Proteine exzitatorischer Synapsen gilt, sondern für das gesamte postsynaptische und präsynaptische Proteom in exzitatorischen und inhibitorischen Synapsen. Die hieraus resultierende hohe Vielfalt unterschiedlicher Synapsentypen könnte die Grundlage zur Ausbildung hochkomplexer neuronaler Kreisläufe bilden. Bedingt durch Unterschiede hinsichtlich der Organisation des synaptischen Proteoms könnten verschiedene synaptische Subtypen unterschiedlich auf neuronale Aktivitätsmuster reagieren und damit die funktionelle Diversität verschiedener Hirnregionen bedingen (Zhu et al. 2018).

Eine Kombination der von Zhu und Kollegen festgestellten hohen Diversität der subzellulären Organisation des postsynaptischen Proteoms und der, den Daten der hier vorgelegten Arbeit zugrunde liegenden Vermutung, dass sich die subzelluläre Organisation des präsynaptischen Proteoms in verschiedenen Hirnregionen geringfügig unterscheidet, sollte in Erwägung gezogen werden. Hieraus ergibt sich die Hypothese, dass das synaptische Proteom einerseits hinsichtlich bestimmter Proteine unabhängig der synaptischen Lokalisation im Gehirn lediglich geringfügig variiert und andererseits hinsichtlich anderer Proteine, in Abhängigkeit der synaptischen Lokalisation im Gehirn deutlich variiert. Synapsen könnten unabhängig von ihrer Lokalisation einen konstante Grundzusammensetzung ihres Proteoms vorweisen, die in unterschiedlichen Bereichen des Gehirns hinsichtlich spezifischer Proteine modifiziert wird.

Weiterhin erscheint auch eine ausgeprägte Diversität der Organisation des postsynaptischen Proteoms, bei gleichzeitig schwach ausgeprägter Diversität der Organisation des präsynaptischen Proteoms möglich. Hierdurch würde die, lediglich in Teilen vorliegende, makroskopische Heterogenität unterschiedlich lokalisierter Präsynapsen (Schikorski und Stevens 1999) auch auf subzellulärer Ebene vorliegen.

Die, in dieser Arbeit, durchgeführte Form der Auswertung knüpfte methodisch unmittelbar an die Untersuchungen von Wilhelm und Kollegen an. Die Autoren konnten durch Kombination elektronenmikroskopischer Aufnahmen, der Massenspektrometrie und hochauflösender Mikroskopie (STED) anhand isolierter Synaptosomen verschiedener Hirnregionen ein Modell einer durchschnittlichen Präsynapse, einschließlich des dicht 
gepackten präsynaptischen Proteoms erstellen. Bei der Auswertung der Fluoreszenzsignale der antikörpermarkierten Testproteine gingen die Autoren entsprechend der, in der vorliegenden Arbeit durchgeführten Analyse vor. Präsynaptische Fluoreszenzsignale wurden anhand ihrer aktiven Zonen korrekt zueinander ausgerichtet und zu durchschnittlichen Fluoreszenzbildern der Präsynapsen zusammengefasst. Fluoreszenzsignale des Vesikelclusters und zusätzlich markierter Proteine konnten so korrekt zueinander ausgerichtet und summiert werden. Hierdurch konnten Rückschlüsse auf die durchschnittliche räumliche Verteilung der Testproteine innerhalb der Präsynapsen gezogen werden. Entsprechend der hier erzielten Ergebnisse stellte sich auch in dieser Studie die subzelluläre Verteilung der meisten Proteine innerhalb der Präsynapsen ähnlich dar. Proteine der aktiven Zone, wie hier anhand des Bassoons gezeigt, konzentrierten sich ebenfalls insbesondere auf die aktiven Zone, wohingegen der Großteil präsynaptischer Proteine, in schwankender Konzentration in unterschiedlichen Bereichen, im gesamten Bereich der Präsynapse vorlagen. Die Autoren schlussfolgerten ebenfalls, dass für den Großteil präsynaptischer Proteine die Lokalisation geringe absolute Konzentrationen wahrscheinlich nicht ausgleicht (Wilhelm et al. 2014).

Zusammenfassend lässt sich anhand der Ergebnisse von Wilhelm und Kollegen, sowie den in dieser Arbeit erzielten Ergebnissen vermuten, dass die subzellulären Lokalisationen präsynaptischer Proteine nicht primär ursächlich für funktionelle Unterschiede verschiedener Präynapsen sind. Möglicherweise resultieren unterschiedliche Funktionen einzelner Präsynapsen aus dem nachweisbar variablem, postsynaptischem Proteom unterschiedlich lokalisierter Postsynapsen (Zhu et al. 2018). 
Postsynapsen könnten hierdurch unterschiedlich auf eintreffende neuronale Stimulation reagieren, wodurch auch die in den Präsynapsen, der entsprechenden Neuronen, eintreffenden Signale variieren würden. Hierdurch wären auch bei durchschnittlich ähnlichem, präsynaptischem Proteom (siehe Abbildung 40; Modell einer durchschnittlichen Präsynapse einschließlich des präsynaptischen Proteins) unterschiedliche präsynaptische Funktionen denkbar. Nicht die Zusammensetzung des präsynaptischen Proteoms würde somit über präsynaptische Funktionen entscheiden, sondern die eintreffenden Signale, die durch die Organisation des vorgeschalteten, postsynaptischen Proteoms unterschiedlich beeinflusst werden. Weitere denkbare Ursachen variierender präsynaptischer Funktionen werden im Abschnitt 4.2 diskutiert.

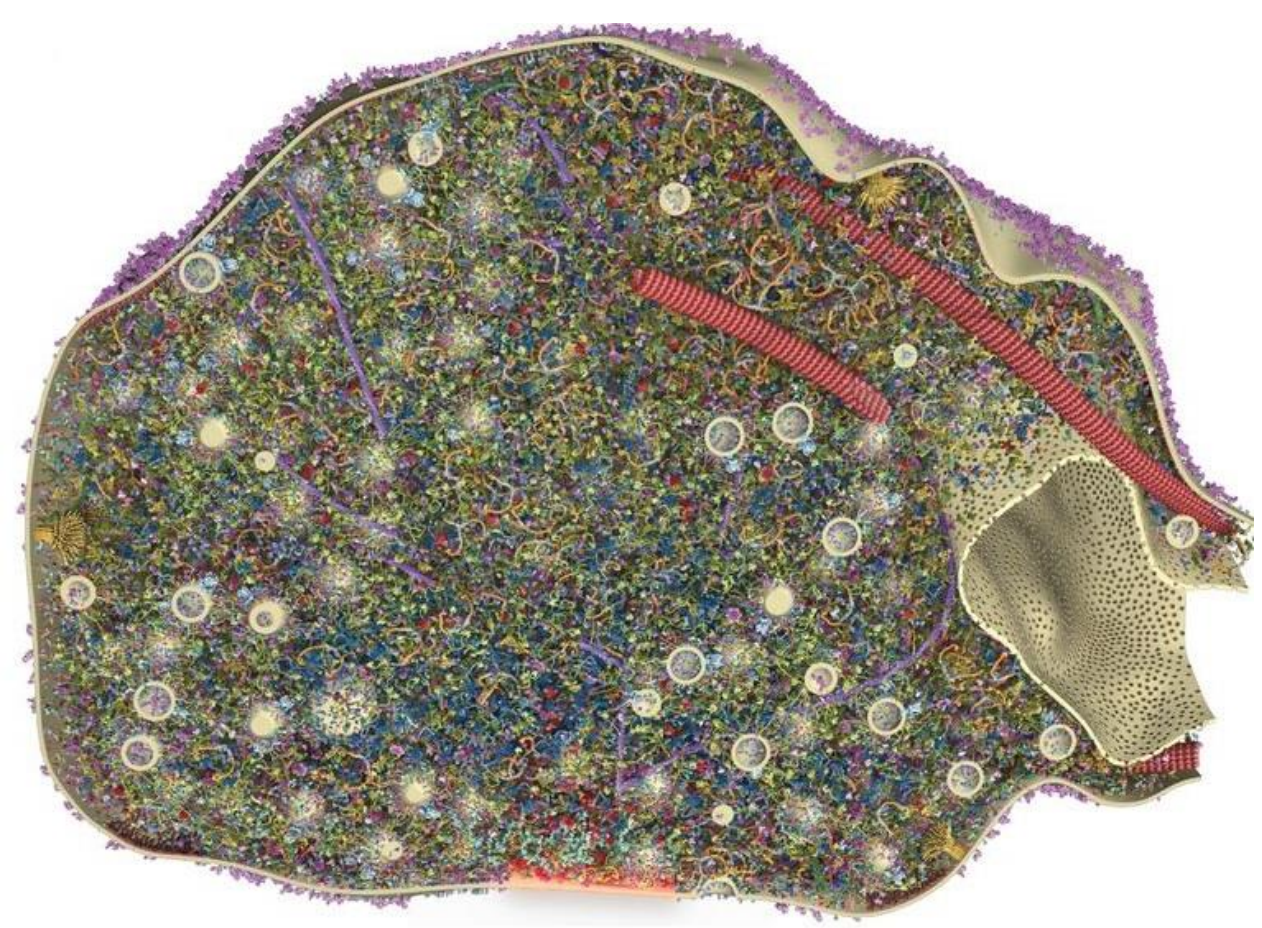

Abbildung 40: Dreidimensionales Modell der präsynaptischen Architektur.

Durchschnittliches Modell der präsynaptischen Proteinorganisation sowie der subzellulären Verteilung synaptischer Vesikel (beige runde Strukturen) und 60 präsynaptischer Proteine. Eine Dreidimensionale Modelldarstellung verschiedener Präsynapsen aus unterschiedlichen Hirnregionen könnte in Zukunft einen großen Beitrag zum Verständnis des zentralen Nervensystems leisten (entnommen und modifiziert nach Wilhelm et al. 2014). Die Verwendung erfolgt mit freundlicher Genehmigung von The American Association for the Advancement of Science. 


\subsection{Mögliche Ursachen variierender synaptischer Aktivität}

Die synaptische Aktivität wird durch das hochkomplexe Zusammenspiel aus neuronaler Diversifikation, der Verschaltung exzitatorischer und inhibitorischer Synapsen (Lodato und Arlotta 2015), der anhand unterschiedlicher Transkritpome feststellbaren hohen Anzahl verschiedener Klassen und Unterklassen von Neuronen und Gliazellen (Zeisel et al. 2015), unterschiedlicher elektrischer Aktivitätsmuster (Mizuseki et al. 2012; Mizuseki und Buzsáki 2013), funktioneller Unterschiede einzelner Isoformen synaptischer Proteine (De Gois et al. 2006; Voglmaier et al. 2006; O'Rourke et al. 2012) und postsynaptischer Rezeptoren (Hull et al. 2009), der Regulation synaptischer Aktivität durch Calcium (Maus et al. 2020) sowie der subzellulären Regulation synaptischer Mechanismen (Rizzoli 2014) gesteuert. Den Ergebnissen der vorliegenden Arbeit zufolge unterscheiden sich die subzellulären Organisationen verschiedener präsynaptischer Proteine, in hippocampalen und kortikalen Hirnregionen lediglich geringfügig voneinander. Sofern die subzelluläre Organisation des präsynaptischen Proteoms auch in vivo unabhängig von der synaptischen Lokalisation im Gehirn geringfügig variiert, stellt sich somit weiterhin die Frage, wodurch funktionelle Unterschiede verschiedener Präsynapsen auf subzellulärer Ebene bedingt sein könnten.

Bei hoher synaptischer Aktivität werden lediglich maximal $5 \%$ aller synaptischen Vesikel aktiv recycelt (Denker et al. 2011a). Ein Großteil der präsynaptischen Vesikel und Proteine würde demnach eine Sicherheitsreserve darstellen, die nicht aktiv genutzt wird. Mögliche unterschiedliche subzelluläre Organisationen einzelner präsynaptischer Proteine hätten somit geringen Einfluss auf Vorgänge des Vesikelzyklus.

Die Ausprägung lokaler präsynaptischer Aktivitäten könnte in Abhängigkeit unterschiedlicher Proteinregulation, der im Überschuss verfügbaren präsynaptischen Proteine, erfolgen. Frühere Studien vermuteten eine Regulierung des Vesikelzyklus durch spezifische Kontrollproteine, die zu bestimmten Zeitpunkten in spezifischen Lokalisationen aktiv werden. Insbesondere durch Einführung hochauflösender Mikroskopieverfahren wurde deutlich, dass solche Erklärungen synaptischer Reaktionen und deren Steuerung hinsichtlich ihrer Komplexität nicht ausreichend sind (Saka und Rizzoli 2012). Wahrscheinlich werden Reaktionen des Vesikelzyklus durch Konzentrationsverhältnisse, Positionen, Anzahl und reaktiven Zustand der beteiligten, bekannten, Komponenten gesteuert (Rizzoli 2014). 
Gemäß den Untersuchungen von Denker und Kollegen werden die, zur synaptischen Übertragung benötigten, löslichen Proteine durch die präsynaptischen Reservevesikel in der Präsynapse gehalten. Benötigte Proteine können so in Abhängigkeit der synaptischen Aktivität durch den Einfluss von Calciumionen bereitgestellt werden (Denker et al. 2011b). Amphiphysin wird dementsprechend beispielsweise in Abhängigkeit der intrazellulären Calciumkonzentration aktiviert (Bauerfeind et al. 1997; Cousin und Robinson 2001; Wu et al. 2009). Die Bereitstellung benötigter Faktoren der synaptischen Übertragung sowie des Vesikelrecyclings könnte so insgesamt garantiert und reguliert werden (Rizzoli 2014). Vesikel des reserve pool könnten somit die synaptische Übertragung beeinflussen, indem die Verfügbarkeit bestimmter Proteine beeinflusst wird.

Das gehäuft vorkommende Synaptophysin beteiligt sich wahrscheinlich an der Ausbildung einer Vielzahl synaptischer Eigenschaften, wie beispielsweise der aktivitätsabhängigen Formation synaptischer Kontakte (Tarsa und Goda 2002; siehe Abschnitt 1.4.3). Synaptophysin könnte, aufgrund seiner zahlreichen Proteininteraktionen, einen wichtigen Regulator verschiedener Schritte des Vesikelrecyclings darstellen (Felkl und Leube 2008). Die erhobenen Daten ergaben im Vergleich der Hirnregionen jedoch kaum statistisch signifikante Unterschiede bezüglich der subzellulären Verteilung des Synaptophysins und keine statistisch signifikanten Unterschiede hinsichtlich der Proteinmenge. Diese Ergebnisse stützen die Hypothese, dass nicht die Menge beziehungsweise Proteinkonzentration in bestimmten präsynaptischen Bereichen entscheidend für die Regulation der synaptischen Aktivität ist, sondern die variierende Aktivitätsregulierung einzelner Proteine zu unterschiedlichen Zeitpunkten des Vesikelzyklus. Kwon und Chapman konnten in Einklang mit dieser Vermutung zeigen, dass Synaptophysin mit unterschiedlichen Strukturelementen, zu verschiedenen Zeitpunkten der Vesikelendozytose aktiv wird. Während und nach neuronaler Stimulation fördert es vermutlich die Rekrutierung und Ansammlung endozytotischer Faktoren. Bei fehlendem Synaptophysin beziehungsweise fehlender Aktivität könnte die Vesikelendozytose durch den langsameren Ablauf endozytotischer Prozesse oder durch verringerte Anzahl gleichzeitig aufnehmbarer Vesikel beeinträchtigt werden (Kwon und Chapman 2011). Anhand der erhobenen Daten lässt sich auch bezüglich des SNAP-25 vermuten, dass nicht die Anzahl und Lokalisation des gehäuft vorkommenden SNAP-25 entscheidend ist, sondern dessen Aktivität zu bestimmten Zeitpunkten. Seine Aktivität könnte unmittelbaren Einfluss auf die präsynaptischen Calciumdynamik (Verderio et al. 2004) sowie auf die Ausbalancierung zwischen Vesikelexozytose und Endozytose nehmen (Zhang et al. 2013). 
Weiterhin könnten Unterschiede in der Aktivitätsregulation präsynaptischer Proteine verschiedener Präsynapsen Einfluss auf den überwiegend stattfindenden Endozytosemechanismus nehmen, wodurch die Effizienz der synaptischen Übertragung beeinflusst werden könnte. Delvendahl und Kollegen vermuteten dementsprechend, dass Synapsen aktivitätsabhängig zwischen verschiedenen Endozytoseformen wechseln (Delvendahl et al. 2016). Durch einen einzelnen eintreffenden Reiz wird beispielsweise ultraschnelle, clathrinunabhängige, Endozytose im Bereich von periaktiven Zonen ausgelöst (Watanabe et al. 2013b; Delvendahl et al. 2016), wohingegen bei steigender synaptischer Aktivität zusätzlich clathrinabhängigen Endozytose stattfindet (Delvendahl et al. 2016). Bei starker Steigerung der synaptischen Aktivität kommt es letztendlich zur Aktivierung von „, Bulk“Endozytosemechanismen (Clayton und Cousin 2009).

Gemäß den erhobenen Daten bezüglich des Bassoons ähnelt sich die molekulare Organisation der aktiven Zonen in unterschiedlichen Hirnregionen ebenfalls. Vermutlich entscheidet nicht die Organisation der aktiven Zonen direkt über die Exozytosewahrscheinlichkeit synaptischer Vesikel, sondern Unterschiede hinsichtlich der Eigenschaften synaptischer Vesikel. Sie stellen vermutlich einen weiteren wichtigen Faktor bei der variierenden Regulation der synaptischen Aktivität dar. Dementsprechend konnten Schikorski und Stevens zeigen, dass, im Vergleich unterschiedlicher Schichten des lateralen Riechstreifens, sowohl die absolute Vesikeldichte als auch die Dichte angedockter Vesikel im Bereich der aktiven Zone variiert (Schikorski und Stevens 1999). Eine erhöhte Anzahl angedockter Vesikel geht hierbei mit erhöhter Exozytosewahrscheinlichkeit einher (Dobrunz und Stevens 1997; Murthy et al. 1997). Weiterhin besteht anscheinend auch innerhalb der, an die aktiven Zonen, angedockten Vesikelpopulation funktionelle Heterogenität. Neher und Brose vermuteten, dass sich phasische und tonische Synapsen durch die Besetzung ihrer aktiven Zonen mit fest und locker gebundenen Vesikeln unterscheiden. Vesikel könnten hierbei calciumabhängig, vermittelt durch unterschiedliche Aktivität der SNARE-Proteine, dynamisch zwischen einem locker angedockten Zustand und einem enger angedockten Zustand wechseln. Unterschiede im Verhältnis dieser Vesikel könnten die synaptische Übertragung beeinflussen (Neher und Brose 2018). Maus und Kollegen konnten weiterführend zeigen, dass eine geringere präsynaptische Exozytosewahrscheinlichkeit mit einer geringeren Anzahl angedockter Vesikel einhergeht. Bei vergleichbarer absoluter Menge an synaptischen Vesikeln in unterschiedlichen Synapsen variierte das Verhältnis zwischen fest an die aktive Zone angedockten Vesikeln und locker, in der Nähe der aktiven Zone gebundenen synaptischen Vesikeln. Die unterschiedliche 
Verteilung der synaptischen Vesikel im Bereich der aktiven zone beteiligt sich anscheinend an der Ausbildung der funktionellen Heterogenität verschiedener Synapsen (Maus et al. 2020). Bei ähnlicher molekularer Zusammensetzung synaptischer Vesikel besteht somit ausgeprägte funktionelle Heterogenität. Diese feinen Unterschiede innerhalb der Vesikelpopulation konnten durch die, in dieser Arbeit durchgeführte Analyse, nicht erfasst werden und stellen mögliche Erklärungen dar, wodurch funktionelle Heterogenität bezüglich synaptischer Vesikel, bei vergleichbarer subzellulärer Organisation der untersuchten Proteine bedingt sein könnten.

Einen weiteren Faktoren, der die Ausbildung komplexer neuronaler Netzwerke auf subzellulärer Ebene beeinflussen könnten, stellt das metabolische Alter der aktiv recycelnden Vesikel einzelner Präsynapsen dar. Truckenbrodt und Kollegen konnten nachweisen, dass aktiv recycelnde Vesikel metabolisch jünger sind, als Vesikel, die dem reserve pool zuzuordnen sind. Synaptische Vesikel werden nach einer begrenzten Anzahl an Exozytosevorgänge, durch weitestgehend unbekannte molekulare Mechanismen, inaktiviert und stehen der synaptischen Übertragung unter physiologischen Bedingungen nicht mehr zur Verfügung (Truckenbrodt et al. 2018a). Synapsen, in denen die Anzahl neu synthetisierter Vesikel und/oder die Austauschrate alter Vesikel erhöht ist könnten somit effizienter arbeiten. Hierdurch könnte die funktionelle Heterogenität verschiedener Präsynapsen bedingt sein.

Zusammenfassend lässt sich schlussfolgern, dass die Verknüpfung variierender synaptischer Funktionen und Eigenschaften mit spezifischen physiologischen und ultrastrukturellen Eigenschaften (vgl. O’Rourke et al. 2012; Maus et al. 2020), sowie das Komplexe Zusammenspiel der zahlreichen, an der synaptischen Übertragung beteiligten, Faktoren und insbesondere deren unterschiedliche Regulation im Vergleich unterschiedlich lokalisierter Präsynapsen Gegenstand der Forschung verbleiben. Die Vermutung, dass Unterschiede bezüglich der subzellulären Organisation einzelner präsynaptischer Proteine in Präsynapsen verschiedener Hirnregionen einen Einfluss auf die Ausbildung unterschiedlicher präsynaptischer Eigenschaften nehmen, erscheint in Anbetracht der vorliegenden Arbeit unwahrscheinlich. In Anbetracht der aktuellen Literatur erscheint die Ausbildung unterschiedlicher synaptischer Aktivitäten in Abhängigkeit der Regulation, der häufig in vergleichbarer Zusammensetzung vorhandenen, präsynaptischen Proteine zu erfolgen. 


\subsection{Limitationen der vorliegenden Arbeit}

Die durchgeführte Analyse erfolgte anhand fixierter Schnittpräparate von Rattenhirnen. In Anbetracht der Mobilität subzellulärer präsynaptischer Strukturen stellen die festgestellten Proteinverteilungen die in vivo vorhandene Situation nicht exakt dar. Der Großteil der synaptischen Vesikel ist jedoch dem vorwiegend immobilen reserve pool zuzuordnen (Denker und Rizzoli 2010), nur 1 - 5 \% aller synaptischen Vesikel recyclen aktiv, der Austausch zwischen mobilen und immobilen Vesikeln erfolgt langsam (Denker et al. 2011a) und lösliche Proteine werden durch den reserve pool abgepuffert (Denker et al. 2011b; Denker et al. 2011a). Insgesamt ist die Mobilität löslicher und membranständiger präsynaptischer Proteine somit gering (Reshetniak et al. 2020) und die erhobenen Daten annährungsweise als korrekt einzustufen.

Die immunologische Markierung der Testproteine, mittels spezifischer primärer und fluoreszierender sekundärer Antikörper muss als weitere Fehlerquelle angesehen werden. Aufgrund unterschiedlicher präsynaptischer Testproteinmengen schwankt die Qualität der Antikörpermarkierung. Proteine, die in großen Mengen vorkommen (Bassoon, Synaptophysin, SNAP-25, VGLUT), konnten im Vergleich zu Proteinen, die in geringer Menge vorkommen (Amphiphysin) (vgl. Wilhelm et al. 2014) deutlich besser immunologisch markiert werden. Hierdurch wurde die auswertbare Datenmenge einzelner Testproteine deutlich reduziert (siehe Abschnitt 7.1 im Anhang). Bei gleichzeitiger Markierung mehrerer Testproteine können zudem Kreuzreaktionen der unterschiedlichen Antikörper auftreten (Marx 2013; Durisic et al. 2014). Weiterhin schwanken die Qualität und Spezifität von Antikörpern. Hierdurch wird die Reproduzierbarkeit der erhobenen Daten eingeschränkt (Baker 2015; Bradbury und Plückthun 2015). Es erfolgte zwar eine manuelle Auswahl wahrscheinlich präsynaptischer Fluoreszenzsignale, dennoch besteht die Möglichkeit, dass es, bei vorwiegender Anwendung polyklonaler, primärer Antikörper (siehe Tabelle 4) zu Anhäufungen von Antikörpern kam, die Fehlinterpretationen nicht synaptischer Signale bedingten (Durisic et al. 2014; Maidorn et al. 2016). Die Größe von 12-15 nm einzelner Antikörper führt dazu, dass das Fluorophor ca. 20-25 nm von der Zielstruktur entfernt abgebildet wird (Maidorn et al. 2016). Das Volumen des Antikörperkomplexes beeinträchtigt so die exakte Lokalisation der Testproteine (Mikhaylova et al. 2015) und könnte sterische Blockaden, die die Anzahl markierbarer Epitope einschränkt bedingen (Kent et al. 1978). Die resultierende reduzierte Markierungsdichte beeinflusst die Genauigkeit von Untersuchungen mittels hochauflösender Mikroskopieverfahren (Huang et al. 2009; Sauer 2013). 
Eine insuffiziente Bindung von Antikörpern, an den dicht gepackten Epitopen, auf der Oberfläche synaptischer Vesikel (Bei gleichzeitiger Markierung von Synaptophysin und VGLUT 1/2) ist somit nicht auszuschließen (Fornasiero und Opazo 2015). Aufgrund inhomogener Signalverstärkungen, durch mögliche Bindung mehrerer sekundärer Antikörper an einem primären Antikörper (Durisic et al. 2014) sowie schwankenden Anzahlen fluoreszierender Einheiten, pro sekundärem Antikörper, waren zudem nur relative Quantifizierungen (bezüglich des Fluoreszenzpeaks einzelner Testproteine in verschiedenen Hirnregionen), im Vergleich verschiedener Testgruppen möglich (Fornasiero und Opazo 2015).

Bei der expansionsmikroskopischen Hirnschnittpräparation könnten analog zur Probenpräparation für die Licht- und Elektronenmikroskope Verzerrungen und Risse der Proben aufgetreten sein. Insbesondere Veränderung der präsynaptischen Mikro- und Nanoarchitektur nach Präparation und Expansion sind somit nicht auszuschließen (Truckenbrodt 2019). Die Chemische Fixierung der Hirnschnitte könnte zudem Einfluss auf die Anzahl der, an die aktiven Zonen, angedockten Vesikel genommen haben (Maus et al. 2020) und damit Fehlinterpretationen der Fluoreszenzsignale vesikulärer Proteine bedingt haben. Weiterhin kann die Dickenzunahme eingebetteter Hirnschnitte bei Expansion zu Problemen mit der Abbildungstiefe führen und so zu optischen Aberrationen, reduzierten Signalintensitäten in tieferen Schichten und insgesamt verringerter lateraler Auflösung führen (Hell et al. 1993; Gao et al. 2018).

Hauptprobleme der Expansionsmikroskopie stellen das Ausbleichen fluoreszierender Verbindungen während der Gelpolymerisation (Chen F et al. 2015; Chozinski et al. 2016; Tillberg et al. 2016), die durch Separation der Fluorophore voneinander bedingte reduzierte Helligkeit der Fluoreszenzsignale nach Expansion (Truckenbrodt et al. 2019) sowie die notwendige, ausgeprägte Penetration der Antikörper in hoher Dichte, durch das zu untersuchende Gewebe dar (Maidorn et al. 2016). Weiterhin könnte die Bildqualität durch Verlust an Fluorophoren während der proteolytischen Verdauung sowie insuffiziente Verankerung der Zielstrukturen am Polyelektrolytgel und damit einhergehenden vollständigen Verlust von Fluoreszenzsignalen beeinträchtigt worden sein (Truckenbrodt 2019). Die, zur immunologischen Markierung der Testproteine verwendeten, Fluorophore CF633, Alexa 488 und Alexa 546 zeigten, in Untersuchungen anderer Arbeitsgruppen, jedoch keine ausgeprägten Verluste an Fluoreszenzsignalen im Zuge expansionsmikroskopischer Probenpräparationen (Chozinski et al. 2016; Cho et al. 2018; Truckenbrodt et al. 2018b). 
Ein übermäßiger Verlust an Fluoreszenzsignalen, im Zuge der Probenpräparation, ist somit als unwahrscheinlich einzustufen. Durch Auswertung anhand durchschnittlicher Präsynapsen (durch Summation aller Fluoreszenzsignale) und manuelle Vorauswahl zu analysierender Fluoreszenzsignale wurde die Wahrscheinlichkeit möglicher Fehlinterpretationen von Fehlsignalen aufgrund der oben ausgeführten Einschränkungen der Hirnschnittpräparation und immunologischen Markierung zwar reduziert und die unterschiedliche Ausrichtung angeschnittener Präsynapsen kompensiert (vgl. Methodik in Löschberger et al. 2012 und Wilhelm et al. 2014), ein Einfluss auf die Präzision der erhobenen Daten ist dennoch nicht auszuschließen. Diese Art der Auswertung anhand zweidimensionaler, durchschnittlicher Präsynapsen ermöglichte zudem lediglich die Analyse durchschnittlicher Verteilungsmuster der Testproteine im Vergleich verschiedener Hirnregionen. Denkbare Unterschiede im Vergleich einzelner Präsynapsen innerhalb von Hirnregionen und deren Subregionen konnten so nicht analysiert werden.

\subsection{Ausblick für zukünftige Forschungsarbeiten}

Die, in der vorliegenden Arbeit, angewandte Methodik zur Analyse präsynaptischer Fluoreszenzsignale unterschiedlicher Testproteine wurde in dieser Art und Weise zuvor nicht in Kombination mit der Expansionsmikroskopie genutzt. Die erhobenen Daten, bezüglich der subzellulären, präsynaptischen Proteinorganisation der Testproteine, standen hierbei im Einklang mit der vorhandenen Literatur und verdeutlichten, dass die angewandte Methodik belastbare Daten zur Erforschung subzellulärer Strukturen, im gleichzeitigem Vergleich unterschiedlicher Hirnregionen, liefert. Die Expansionsmikroskopie stellte zum Zeitpunkt der Datenerhebung ein erst kürzlich publiziertes Verfahren zur Durchführung hochauflösender Mikroskopie dar. Dementsprechend bildeten Rattenhirnschnitte, die gemäß des damaligen Entwicklungstandes des Verfahrens um den Faktor $\sim 4$ vergrößert wurden, die Grundlage dieser Arbeit. Das Verfahren wird jedoch fortlaufend weiterentwickelt und optimiert (Truckenbrodt et al. 2018b; Truckenbrodt et al. 2019; Hu et al. 2020; siehe Ausführungen unten). Das Anwendungsspektrum der Expansionsmikroskopie erweitert sich stetig (Cahoon et al. 2017; Freifeld et al. 2017) und findet mittlerweile auch klinisch, bei verschiedenen pathologischen Untersuchungen, Anwendung (Zhao et al. 2017; Bucur et al. 2020). 
Zur Verbesserung des optischen Auflösungsvermögens und der dreidimensionalen Bildgebung wäre eine Kombination der EXM mit anderen hochauflösenden Mikroskopieverfahren denkbar. Die Funktionalität solcher Kombinationen konnte anhand von STED (Gao et al. 2018) und STORM (Xu et al. 2019; Zwettler et al. 2020) bereits nachgewiesen werden. Aufgrund der erhöhten Bildgebungsdauer bei Kombination der EXM mit zusätzlichen Mikroskopieverfahren wie beispielsweise STED, im Vergleich zur alleinigen Anwendung der EXM (Gao et al. 2018), sind diese Verfahren jedoch nicht optimal für großvolumige Untersuchungen geeignet.

Zukünftige Studien könnten jedoch auch durch alleinige Anwendung optimierter Protokolle der EXM das erreichbare Auflösungsvermögen steigern. Die Iterative Expansionsmikroskopie (IEXM) ermöglicht die Vergrößerung einer Probe um das 16 bis 22-fache. Nach erfolger erster Expansion, um das 4,5-fache, erfolgt durch Einbau eines zweiten Polymernetzwerkes und erneute Wasserzugabe eine erneute Expansion der Probe. Hierdurch erreicht die EXM ein vollständig mit aufwendigeren, hochauflösenden Mikroskopieverfahren (z.B. STED und STORM), vergleichbares laterales Auflösungsvermögen von bis zu $25 \mathrm{~nm}$ (Chang et al. 2017). IEXM ist durch die zwei Expansionsschritte und die Notwendigkeit zur Verwendung synthetisierter Oligonukleotidmarker zeitaufwendig und teurer als andere, vereinfachte EXM-Verfahren (Truckenbrodt et al. 2019).

Truckenbrodt und Kollegen haben das IEXM-Protokoll zur Verwendung mit Hirnschnitten weiter vereinfacht und optimiert. Durch Modifikation des Polyelektrolytgels und Optimierung des Laborprotokolls können mit lediglich einem Expansionsschritt Proben, unter Verwendung von Standardfluorophoren, um den Faktor 10 expandiert werden. So können, unter Anwendung von Epifluoreszenzmikroskopen, laterale Auflösungen von 25-30 nm erreicht werden. Das X10-Mikroskopie genannte Verfahren erzielt diese Auflösungen hierbei deutlich leichter, schneller und verlässlicher als IEXM. X10-Mikroskopie stellt eine günstige und einfache Möglichkeit zur Durchführung hochauflösender Mikroskopie dar. Das Verfahren ermöglicht mehrfarbige Untersuchungen, deren Qualität vergleichbar und teilweise höher ist als die, der aufwendigeren Verfahren STED, STORM und IEXM (Truckenbrodt et al. 2018b). Abbildung 41 verdeutlicht die erreichbare Auflösungsverbesserung durch X10Mikroskopie. 
Zukünftige Studien, die die Erforschung der subzellulären Organisation des präsynaptischen Proteoms fortführen, sollten sich diese Entwicklungen zu Nutze machen. Die weitere Steigerung des Auflösungsvermögens expansionsmikroskopischer Verfahren bietet hierbei die Möglichkeit zur großvolumigen Bildgebung bei Präzision auf Nanoebene und könnte die Darstellung neuronaler Schaltkreise, Hirnregionen oder auch ganzer Gehirne ermöglichen (Chang et al. 2017).
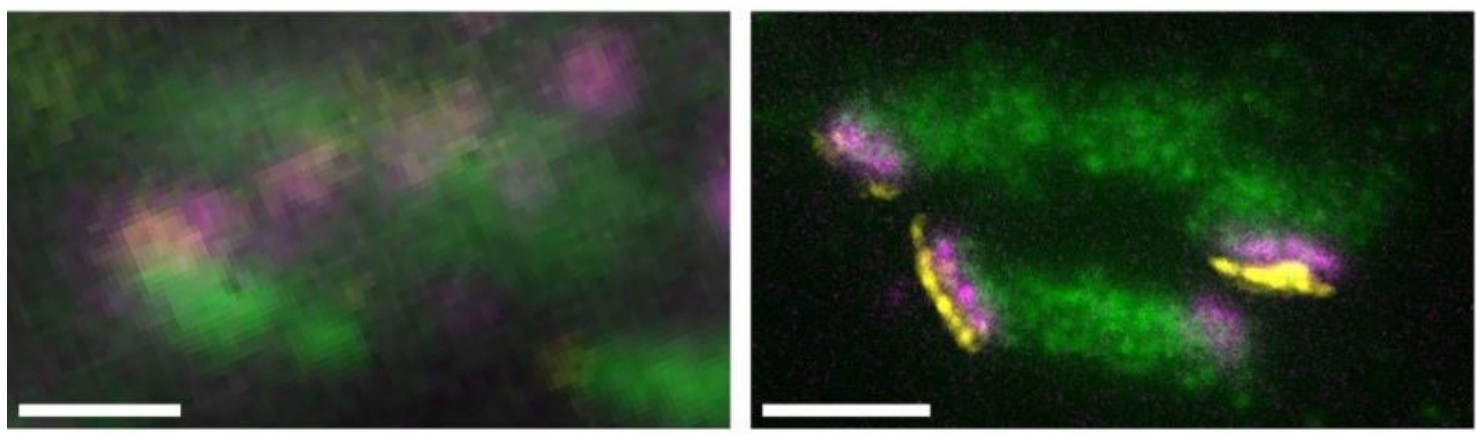

\section{Abbildung 41: Darstellung der durch X10-Mikroskopie erreichbaren Auflösungs- verbesserung eines Weitfeldmikroskops.}

Individuelle Synapsen vor (links) und nach Expansion um den Faktor 10 (rechts). Die Signale von Bassoon (Magenta), Synaptophysin (Grün) und Homer 1 (Gelb) werden nach Expansion deutlich voneinander separiert dargestellt. Maßstabsleiste $=1 \mu \mathrm{m}$ (entnommen und modifiziert nach Truckenbrodt et al. 2019). Die Verwendung erfolgt mit freundlicher Genehmigung des Springer Nature Verlages.

Die molekulare Markierung der Testproteine mittels primärer und sekundärer Antikörper geht mit spezifischen Nachteilen einher (siehe Abschnitt 4.3). In Zukunft wäre bei der Anwendung hochauflösender Mikroskopieverfahren, zur präziseren Untersuchung der präsynaptischen Proteinorganisation, die Intensivere Markierung zahlreicher Epitope eines Proteins (Gao et al. 2018), die immunologische Markierung von Zielstrukturen nach erfolgter Expansion (Zwettler et al. 2020) oder die ursprünglich in der EXM angewandte, aufwendige, Verwendung DNS-basierter, proteasestabiler, molekularer Marker (Chen F et al. 2015) in Erwägung zu ziehen. Optimierte labortechnische EXM-Protokolle ermöglichen es bereits heute, den Verlust an Fluorophoren im Zuge der Gelexpansion sowie Kreuzreaktionen verwendeter Antikörper weiter zu reduzieren (Gambarotto et al. 2019). Die oben genannten weiterentwickelten EXM-Protokolle wurden dementsprechend auch hinsichtlich der immunologischen Markierung optimiert. 
Weiterhin wäre jedoch insbesondere die Anwendung verschiedener Typen sehr kleiner, hochspezifischer, molekularer Marker anzustreben (Ries et al. 2012; Maidorn et al. 2016; Pleiner et al. 2018). Die Durchsetzung biologischer Gewebe mit diesen, im Vergleich zu Antikörpern deutlich kleineren, hochspezifischen Markern ist verbessert (Ries et al. 2012; Škrlec et al. 2015) und birgt großes Potenzial die Bildgebung auf Nanoebene zu optimieren und somit präzisere quantitative Untersuchungen zu erlauben (Ries et al. 2012). Die erreichbare Auflösung, die Markierungsdichte, die Penetration durch biologische Gewebe, der Zugang zu tiefliegenden Zielepitopen sowie die korrekte Lokalisierung von Zielstrukturen könnte so verbessert werden (Ries et al. 2012; Maidorn et al. 2016). Die standardisierte Anwendung verschiedener Typen dieser molekularen Marker bedarf aktuell jedoch weiterer Forschung, der Entwicklung passender Marker für eine Großzahl an Zielstrukturen und stärkerer kommerzieller Verbreitung (Maidorn et al. 2016; SograteIdrissi et al. 2020). Die zunehmend erfolgreich in Kombination mit verschiedenen hochauflösenden Mikroskopieverfahren angewandten kleinen molekularen Marker (Maidorn et al. 2018; Seitz und Rizzoli 2019; Gerdes et al. 2020; Sograte-Idrissi et al. 2020) könnten die, durch Separation der Fluoreszenzsignale bedingte, reduzierte Helligkeit expansionsmikroskopischer Bilder in dicht organisierten Kompartimenten wie den Synapsen ausgleichen und nachteilige Effekte klassischer Antikörpermarkierungen umgehen. In bisherigen Versuchen, führte die Anwendung dieser Nanokörper in Kombination mit der EXM jedoch zu deutlichen Fluoreszenzsignalverlusten, da sie wahrscheinlich während der Präparation degradiert und/oder nicht am Polyelektrolytgel verankert werden (Gao et al. 2018).

Zukünftige Studien, sollten zur Verifizierung der hier erhobenen Daten eine Wiederholung der durchgeführten Analyse anhand neuer Schnittpräparate anstreben. Hierbei wäre insbesondere bezüglich der Testproteine SNAP-25, VGLUT 1/2 und Amphiphysin, zur Reduzierung der Fehlerwahrscheinlichkeit, eine erhöhte Experimentanzahl wünschenswert. Bei insgesamt erhöhter Datenmenge wären aussagekräftigere Vergleiche zwischen allen Testproteinen möglich. In Teilen festgestellte Tendenzen bezüglich möglicherweise vorliegender Unterschiede hinsichtlich subzellulärer Verteilung und Menge dieser drei Proteine könnten so hinsichtlich Reproduzierbarkeit der erhobenen Daten beziehungsweise möglicherweise dennoch vorliegender statistisch signifikanter Unterschiede überprüft werden. 
Weiterhin wäre eine Untersuchung zahlreicher weiterer präsynaptischer Proteine wie beispielsweise Piccolo und Bruchpilot denkbar. Eine Anwendung der oben genannten Weiterentwicklungen hinsichtlich der EXM sowie der molekularen Markierung von Zielstrukturen sollten hierbei Anwendung finden. Die zusätzliche Anwendung alternativer hochauflösender Mikroskopieverfahren wie beispielsweise STORM zur Untersuchung ganzer Hirnschnitte und STED zur detaillierten Untersuchung einzelner Präsynapsen (vgl. Dani et al. 2010) in Kombination mit weiteren Analysemethoden sollte zur detaillierteren Betrachtung der, in dieser Arbeit vereinzelt festgestellten, signifikanten Unterschiede hinsichtlich der Proteine Synaptophysin und Bassoon verwendet werden und letztendlich die Erforschung der exakten molekularen Zusammensetzung und subzellulären Organisation des gesamten synaptischen Proteoms im Vergleich verschiedener Hirnregionen vorantreiben. 


\section{$5 \quad$ Zusammenfassung}

Grundlage und Antrieb zur Durchführung der vorliegenden Arbeit war der Wunsch nach einem präziseren Verständnis bezüglich der subzellulären Verteilung und Menge präsynaptischer Proteine in Präsynapsen verschiedener Hirnregionen. Diese Informationen stellen bisher weitestgehend unbekannte Grundlagen zum Verständnis der Organisation neuronaler Kreisläufe, der Entstehung komplexer zentralnervöser Vorgänge, wie beispielsweise der Gedächtnisbildung und der Entstehung neurologischer Erkrankungen dar. Diesbezüglich wurde vor Beginn der Arbeit die Hypothese aufgestellt, dass unterschiedliche subzelluläre Proteinorganisationen zur Ausbildung variierender präsynaptischer Eigenschaften beitragen. Präsynapsen konnten lange Zeit nur durch technisch hochkomplexe und kostenintensive, hochauflösende, bildgebende Verfahren dargestellt werden. Die Grundlage zur Durchführung der vorliegenden Arbeit bildete deswegen das im Jahr 2015 publizierte Verfahren der Expansionsmikroskopie. Sie erzielt, bei vergleichbar geringem Aufwand, eine laterale Auflösung von 60-70 nm unter Anwendung eines Epifluoreszenzmikroskops. Durch physische Vergrößerung von Rattenhirnschnitten wurde so die breitgefächerte, gleichzeitige, subzelluläre Untersuchung mehrerer fluoreszenzmarkierter präsynaptischer Proteine in Präsynapsen unterschiedlicher Neuronentypen verschiedener Gehirnregionen ermöglicht. Unter Anwendung spezifischer MATLAB-Routinen wurden die Fluoreszenzsignale der Testproteine Synaptophysin, Bassoon, SNAP25, VGLUT 1/2 und Amphiphysin summiert. Die so erstellen durchschnittlichen Fluoreszenzbilder der untersuchten Präsynapsen aus verschiedenen Hirnregionen des Hippocampus, des somatosensorischen Kortex und des motorischen Kortex wurden anschließend hinsichtlich Halbwertsbreiten und Signalintensitäten der detektierten Fluoreszenzsignale vergleichend analysiert. Der experimentelle Fokus lag hierbei auf den Testproteinen Bassoon (aktive Zone) und Synaptophysin (Vesikelcluster). Die erhaltenen Daten konnten unter Anwendung der Software SigmaPlot 10 statistisch ausgewertet werden und ermöglichten es, Rückschlüsse hinsichtlich der subzellulären Verteilung und relativen Menge der Testproteine in hippocampalen und kortikalen Präsynapsen aus verschiedenen Regionen des Rattengehirns zu ziehen.

Diese Form der Auswertung subzellulärer Fluoreszenzsignale verschiedener Proteine gab zwar keine Auskünfte über exakte Positionen und Mengen einzelner Proteine, innerhalb der unterschiedlich lokalisierten Präsynapsen, ermöglichte jedoch, grobe Schätzungen hinsichtlich möglicherweise vorliegender, generalisiert voneinander abweichender subzellulärer Proteinorganisationen. Die untersuchten Proteine wiesen im Vergleich der 
untersuchten Hirnregionen lediglich vereinzelt signifikante Unterschiede hinsichtlich ihrer subzellulären Verteilung und Menge auf. Präsynapsen in unterschiedlichen Bereichen des Gehirns unterscheiden sich anscheinend hinsichtlich der subzellulären Organisation der Testproteine geringfügig voneinander. Hieran ließ sich vermuten, dass sich die subzelluläre Organisation des präsynaptischen Proteoms unterschiedlich lokalisierter Präsynapsen generell ähnelt. Der Regulation der Proteinaktivitäten kommt somit möglicherweise eine bedeutendere Rolle, bei der Ausprägung der präsynaptischen Aktivität zu als der subzellulären Verteilung und Menge der Proteine im Vergleich unterschiedlicher Präsynapsen. Weiterhin erscheint ein Zusammenspiel des nachweisbar variierenden postsynaptischen Proteoms mit dem, gemäß der in dieser Arbeit erzielten Ergebnisse, durchschnittlich ähnlichem präsynaptischen Proteom verschiedener Hirnregionen, im Zuge der Ausbildung variierender synaptischer Aktivitäten möglich. Ergänzend zeigt die vorgelegte Arbeit, dass mit Hilfe der Expansionsmikroskopie und anschließender Auswertung summierter, durchschnittlicher Fluoreszenzsignale, hochauflösende Mikroskopie mit geringem finanziellen und instrumentellen Aufwand betrieben werden kann. Die angewandte Methodik ermöglicht die gleichzeitige Untersuchung mehrerer Proteine in verschieden Hirnregionen. Die Expansionsmikroskopie könnte zukünftig, in Kombination mit weiteren Untersuchungsverfahren wie beispielsweise der Elektronenmikroskopie und Massenspektrometrie die Erstellung durchschnittlicher Präsynapsen einer Vielzahl verschiedener Hirnregionen bei kleinerem Aufwand als unter Anwendung alternativer, hochauflösender Mikroskopieverfahren wie beispielsweise STED ermöglichen und so einen großen Beitrag zur Kartierung der hochkomplexen neuronalen Verschaltung des Gehirns und der Erforschung der molekularen Organisation synaptischer Strukturen leisten. 


\section{Anhang}

\subsection{Anzahl untersuchter Fluoreszenzspots pro Testprotein pro Hirnregion}

Einzelne Fluoreszenzspots entsprachen wahrscheinlich präsynaptischen Signalen (siehe Abschnitt 2.4).

\subsubsection{Synaptophysin und Bassoon}

Tabelle A.1: Anzahl untersuchter Fluoreszenzspots der Testproteine Synaptophysin und Bassoon in den untersuchten Hirnregionen.

\begin{tabular}{|c|c|c|}
\hline Hirnregion & $\begin{array}{l}\text { Anzahl Fluoreszenzspots } \\
\text { Analyse } 1\end{array}$ & $\begin{array}{l}\text { Anzahl Fluoreszenzspots } \\
\text { Analyse } 2\end{array}$ \\
\hline GrDG & 407 & 245 \\
\hline M1I & 618 & 319 \\
\hline M1II & 524 & 397 \\
\hline M1IV & 516 & 399 \\
\hline M1V & 369 & 320 \\
\hline M1VI & 521 & 306 \\
\hline MoDG & 376 & 376 \\
\hline OrCA1 & 214 & 215 \\
\hline OrCA2 & 388 & 244 \\
\hline OrCA3 & 519 & 210 \\
\hline PoDG & 452 & 226 \\
\hline PyCA1 & 209 & 161 \\
\hline PyCA2 & 179 & 126 \\
\hline PyCA3 & 384 & 140 \\
\hline RadCA1 & 274 & 215 \\
\hline RadCA2 & 408 & 257 \\
\hline RadCA3 & 500 & 125 \\
\hline S1I & 653 & 417 \\
\hline S1II & 379 & 318 \\
\hline S1V & 493 & 312 \\
\hline S1VI & 513 & 290 \\
\hline Summe / Analyse & 8896 & 5618 \\
\hline Gesamtsumme & 14514 & \\
\hline
\end{tabular}




\subsubsection{SNAP-25}

Tabelle A.2: Anzahl untersuchter Fluoreszenzspots des Testproteins SNAP-25 in den untersuchten Hirnregionen.

\begin{tabular}{|c|c|c|}
\hline Hirnregion & $\begin{array}{l}\text { Anzahl Fluoreszenzspots } \\
\text { Analyse } 1\end{array}$ & $\begin{array}{l}\text { Anzahl Fluoreszenzspots } \\
\text { Analyse } 2\end{array}$ \\
\hline GrDG & 79 & 94 \\
\hline M1I & 85 & 116 \\
\hline M1II & 93 & 109 \\
\hline M1IV & 69 & 171 \\
\hline M1V & 98 & 109 \\
\hline M1VI & 155 & 150 \\
\hline MoDG & 97 & 124 \\
\hline OrCA1 & 63 & 85 \\
\hline OrCA2 & 168 & 184 \\
\hline OrCA3 & 169 & 100 \\
\hline PoDG & 130 & 105 \\
\hline PyCA1 & 68 & 74 \\
\hline PyCA2 & 67 & 83 \\
\hline PyCA3 & 125 & 70 \\
\hline RadCA1 & 101 & 122 \\
\hline RadCA2 & 121 & 198 \\
\hline RadCA3 & 108 & 106 \\
\hline S1I & 197 & 106 \\
\hline S1II & 100 & 84 \\
\hline S1V & 88 & 98 \\
\hline S1VI & 132 & 82 \\
\hline Summe / Analyse & 2313 & 2370 \\
\hline Gesamtsumme & 4683 & \\
\hline
\end{tabular}




\subsubsection{VGLUT 1/2}

Tabelle A.3: Anzahl untersuchter Fluoreszenzspots der Testproteine VGLUT 1/2 in den untersuchten Hirnregionen.

\begin{tabular}{|c|c|c|}
\hline Hirnregion & $\begin{array}{l}\text { Anzahl Fluoreszenzspots } \\
\text { Analyse } 1\end{array}$ & $\begin{array}{l}\text { Anzahl Fluoreszenzspots } \\
\text { Analyse } 2\end{array}$ \\
\hline GrDG & 60 & 78 \\
\hline M1I & 105 & \\
\hline M1II & 96 & 131 \\
\hline M1IV & 106 & 121 \\
\hline M1V & 76 & 148 \\
\hline M1VI & 131 & 61 \\
\hline MoDG & 75 & 131 \\
\hline OrCA1 & 88 & \\
\hline OrCA2 & 139 & \\
\hline OrCA3 & 119 & \\
\hline PoDG & 116 & 66 \\
\hline PyCA1 & 49 & \\
\hline PyCA2 & 76 & \\
\hline PyCA3 & 108 & \\
\hline RadCA1 & 97 & \\
\hline RadCA2 & 193 & \\
\hline RadCA3 & 146 & \\
\hline S1I & 215 & 113 \\
\hline S1II & 125 & 71 \\
\hline S1V & 102 & $68^{*}$ \\
\hline S1VI & 113 & $72 *$ \\
\hline Summe / Analyse & 2335 & 1060 \\
\hline Gesamtsumme & 3395 & \\
\hline
\end{tabular}

*Bei Auswertung hinsichtlich des Fluoreszenzpeaks exkludiert. 


\subsubsection{Amphiphysin}

Tabelle A.4: Anzahl untersuchter Fluoreszenzspots des Testproteins Amphiphysin in den untersuchten Hirnregionen.

\begin{tabular}{|c|c|c|}
\hline Hirnregion & $\begin{array}{l}\text { Anzahl Fluoreszenzspots } \\
\text { Analyse } 1\end{array}$ & $\begin{array}{l}\text { Anzahl Fluoreszenzspots } \\
\text { Analyse } 2\end{array}$ \\
\hline GrDG & 78 & \\
\hline M1I & 150 & 111 \\
\hline M1II & 109 & 92 \\
\hline M1IV & 157 & 28 \\
\hline M1V & 128 & 28 \\
\hline M1VI & 184 & 48 \\
\hline MoDG & 106 & \\
\hline OrCA1 & & 81 \\
\hline OrCA3 & 156 & \\
\hline PoDG & 152 & \\
\hline PyCA1 & & 63 \\
\hline $\mathrm{PyCA} 3$ & 109 & \\
\hline RadCA1 & & 49 \\
\hline RadCA3 & 165 & \\
\hline S1I & 197 & 128 \\
\hline S1II & 72 & 116 \\
\hline S1V & 177 & 98 \\
\hline S1VI & 184 & 100 \\
\hline Summe / Analyse & 2124 & 942 \\
\hline Gesamtsumme & 3066 & \\
\hline
\end{tabular}




\subsection{Halbwertsbreiten}

Die Halbwertsbreiten werden in Pixeln, mit einer Kantenlänge von 12,2 nm, nach Gaußscher Kurvenanpassung der graphischen Darstellung detektierter Fluoreszenzsignale angegeben.

\subsubsection{Synaptophysin}

Tabelle 5.A: Halbwertsbreiten und Standardfehler der detektierten SynaptophysinFluoreszenzsignale in den untersuchten Hirnregionen mit Angabe der Anzahl untersuchter Rattenhirnschnitte.

\begin{tabular}{|c|c|c|c|}
\hline Hirnregion & $\begin{array}{l}\text { Halbwertsbreite in Pi- } \\
\text { xeln }\end{array}$ & $\begin{array}{l}\text { Standardfehler in } \\
\text { Pixeln }\end{array}$ & $\begin{array}{l}\text { Untersuchte Ratten- } \\
\text { hirnschnitte }\end{array}$ \\
\hline GrDG & 15,6130 & 1,1977 & 7 \\
\hline M1I & 18,5870 & 0,9641 & 7 \\
\hline M1II & 17,1890 & 1,2234 & 8 \\
\hline M1IV & 18,3030 & 1,5637 & 8 \\
\hline M1V & 16,5460 & 1,2380 & 7 \\
\hline M1VI & 16,3610 & 1,2923 & 8 \\
\hline MoDG & 16,3140 & 0,6099 & 7 \\
\hline OrCA1 & 17,2650 & 2,0406 & 6 \\
\hline OrCA2 & 17,4100 & 2,3041 & 5 \\
\hline OrCA3 & 16,8210 & 1,1783 & 6 \\
\hline PoDG & 15,8580 & 1,0826 & 6 \\
\hline PyCA1 & 12,7300 & 1,0070 & 6 \\
\hline PyCA2 & 11,1940 & 0,6963 & 4 \\
\hline PyCA3 & 19,2080 & 0,8770 & 5 \\
\hline RadCA1 & 15,5470 & 1,9193 & 5 \\
\hline RadCA2 & 17,4190 & 1,8062 & 5 \\
\hline RadCA3 & 15,3610 & 1,4932 & 6 \\
\hline S1I & 20,6310 & 1,2580 & 8 \\
\hline S1II & 18,6450 & 1,1889 & 8 \\
\hline S1V & 16,5680 & 1,0894 & 8 \\
\hline S1VI & 16,9940 & 1,3563 & 8 \\
\hline
\end{tabular}




\subsubsection{Bassoon}

Tabelle 6.A: Halbwertsbreiten und Standardfehler der detektierten Bassoon-Fluoreszenzsignale in den untersuchten Hirnregionen mit Angabe der Anzahl untersuchter Rattenhirnschnitte.

\begin{tabular}{l|r|r|r}
\hline Hirnregion & \multicolumn{2}{|l|}{$\begin{array}{l}\text { Halbwertsbreite in } \\
\text { Pixeln }\end{array}$} & \multicolumn{2}{l}{$\begin{array}{l}\text { Standardfehler in } \\
\text { Pixeln }\end{array}$} & & \multicolumn{2}{l}{ Untersuchte Ratten- } \\
\hline GrDG & 7,9823 & 0,2424 & 5 \\
\hline M1I & 8,6868 & 0,1695 & 7 \\
\hline M1II & 8,6979 & 0,2192 & 8 \\
\hline M1IV & 8,6466 & 0,1322 & 7 \\
\hline M1V & 8,5951 & 0,2492 & 8 \\
\hline M1VI & 8,3638 & 0,2824 & 7 \\
\hline MoDG & 8,0299 & 0,1285 & 7 \\
\hline OrCA1 & 8,1829 & 0,3152 & 6 \\
\hline OrCA2 & 8,6752 & 0,3262 & 5 \\
\hline OrCA3 & 8,7537 & 0,2148 & 6 \\
\hline PoDG & 9,3165 & 0,1823 & 7 \\
\hline PyCA1 & 7,7569 & 0,1789 & 6 \\
\hline PyCA2 & 8,7439 & 0,3399 & 4 \\
\hline PyCA3 & 8,6505 & 0,2159 & 6 \\
\hline RadCA1 & 7,9650 & 0,0718 & 6 \\
\hline RadCA2 & 8,8364 & 0,3527 & 5 \\
\hline RadCA3 & 8,6686 & 0,2172 & 6 \\
\hline S1I & 8,8101 & 0,2201 & 6 \\
\hline S1II & 8,8020 & 0,2403 & 7 \\
\hline S1V & 8,7012 & 0,2039 & 7 \\
\hline S1VI & 9,0117 & 0,2578 & 7 \\
\hline
\end{tabular}




\subsubsection{SNAP-25}

Tabelle 7.A: Halbwertsbreiten und Standardfehler der detektierten SNAP-25-Fluoreszenzsignale in den untersuchten Hirnregionen mit Angabe der Anzahl untersuchter Rattenhirnschnitte.

\begin{tabular}{l|r|r|r}
\hline Hirnregion & \multicolumn{2}{|l|}{$\begin{array}{l}\text { Halbwertsbreite in } \\
\text { Pixeln }\end{array}$} & \multicolumn{2}{l}{$\begin{array}{l}\text { Standardfehler in } \\
\text { Pixeln }\end{array}$} & $\begin{array}{l}\text { Untersuchte Ratten- } \\
\text { hirnschnitte }\end{array}$ \\
\hline GrDG & 11,8250 & 2,6014 & 2 \\
\hline M1I & 13,6090 & 2,2050 & 2 \\
\hline M1II & 12,9440 & 2,7825 & 2 \\
\hline M1IV & 14,9670 & 3,8505 & 2 \\
\hline M1V & 15,3890 & 0,0270 & 2 \\
\hline M1VI & 16,2810 & 1,7705 & 2 \\
\hline MoDG & 11,0850 & 2,8143 & 2 \\
\hline OrCA1 & 9,3191 & 2,2759 & 2 \\
\hline OrCA2 & 14,2760 & 2,8080 & 2 \\
\hline OrCA3 & 16,0000 & 0,0985 & 2 \\
\hline PoDG & 15,5510 & 1,9125 & 2 \\
\hline PyCA1 & 17,0500 & 0,5080 & 2 \\
\hline PyCA2 & 14,0650 & 0,5885 & 2 \\
\hline PyCA3 & 10,5670 & 2,1760 & 2 \\
\hline RadCA1 & 13,4270 & 4,8335 & 2 \\
\hline RadCA2 & 17,2490 & 0,8625 & 2 \\
\hline RadCA3 & 14,6210 & 2,0115 & 1 \\
\hline S1I & 16,9410 & 2,0395 & 2 \\
\hline S1II & 12,3370 & & 2 \\
\hline S1V & 11,7940 & 1,7765 & 2 \\
\hline S1VI & 13,5170 & 1,9425 & 2 \\
\hline
\end{tabular}




\subsubsection{VGLUT 1/2}

Tabelle 8.A: Halbwertsbreiten und Standardfehler der detektierten VGLUT 1/2Fluoreszenzsignale in den untersuchten Hirnregionen mit Angabe der Anzahl untersuchter Rattenhirnschnitte.

\begin{tabular}{|c|c|c|c|}
\hline Hirnregion & $\begin{array}{l}\text { Halbwertsbreite } \\
\text { in Pixeln }\end{array}$ & $\begin{array}{l}\text { Standardfehler } \\
\text { in Pixeln }\end{array}$ & $\begin{array}{l}\text { Untersuchte Ratten- } \\
\text { hirnschnitte }\end{array}$ \\
\hline GrDG & 16,6440 & 6,5515 & 2 \\
\hline M1I & 13,0620 & & 1 \\
\hline M1II & 13,7060 & 1,0535 & 2 \\
\hline M1IV & 23,0170 & 0,4195 & 2 \\
\hline M1V & 12,5120 & 2,5202 & 2 \\
\hline M1VI & 19,0280 & 4,7635 & 2 \\
\hline MoDG & 18,4800 & 0,4175 & 2 \\
\hline OrCA1 & 25,2230 & & 1 \\
\hline OrCA2 & 11,2740 & & 1 \\
\hline OrCA3 & 10,0690 & & 1 \\
\hline PoDG & 19,8410 & 2,6730 & 2 \\
\hline PyCA1 & 9,7146 & & 1 \\
\hline PyCA2 & 13,2050 & & 1 \\
\hline PyCA3 & 12,4930 & & 1 \\
\hline RadCA1 & 10,1350 & & 1 \\
\hline RadCA2 & 15,9150 & & 1 \\
\hline RadCA3 & 11,8500 & & 1 \\
\hline S1I & 17,6830 & 5,8190 & 2 \\
\hline S1II & 21,3870 & 0,2780 & 2 \\
\hline S1V & 15,8160 & 0,0230 & 2 \\
\hline S1VI & 16,0690 & 1,3005 & 2 \\
\hline
\end{tabular}




\subsubsection{Amphiphysin}

Tabelle 9.A: Halbwertsbreiten und Standardfehler der detektierten AmphiphysinFluoreszenzsignale in den untersuchten Hirnregionen mit Angabe der Anzahl untersuchter Rattenhirnschnitte.

\begin{tabular}{|c|c|c|c|}
\hline Hirnregion & $\begin{array}{l}\text { Halbwertsbreite in } \\
\text { Pixeln }\end{array}$ & $\begin{array}{l}\text { Standardfehler in } \\
\text { Pixeln }\end{array}$ & $\begin{array}{l}\text { Untersuchte Ratten- } \\
\text { hirnschnitte }\end{array}$ \\
\hline GrDG & 11,5700 & & 1 \\
\hline M1I & 17,0030 & 3,3430 & 2 \\
\hline M1II & 14,3620 & 5,1904 & 2 \\
\hline M1IV & 14,9480 & 4,4885 & 2 \\
\hline M1V & 15,2510 & 1,5965 & 2 \\
\hline M1VI & 13,0830 & 0,5110 & 2 \\
\hline MoDG & 21,7560 & & 1 \\
\hline OrCA1 & 17,0130 & & 1 \\
\hline OrCA3 & 12,1970 & & 1 \\
\hline PoDG & 15,7190 & & 1 \\
\hline PyCA1 & 20,6710 & & 1 \\
\hline PyCA3 & 6,6281 & & 1 \\
\hline RadCA1 & 9,7250 & & 1 \\
\hline RadCA3 & 14,5180 & & 1 \\
\hline S1I & 20,8040 & 2,2285 & 2 \\
\hline S1II & 13,5270 & 4,9606 & 2 \\
\hline S1V & 13,0830 & 1,4710 & 2 \\
\hline S1VI & 14,6170 & & 1 \\
\hline
\end{tabular}




\subsection{Fluoreszenzspeaks}

Die Fluoreszenzpeaks werden in Prozent über der Grundlinie nach Gaußscher Kurvenanpassung der graphischen Darstellung detektierter Fluoreszenzsignale angegeben.

\subsubsection{Synaptophysin}

Tabelle 10.A: Fluoreszenzpeaks und Standardfehler der detektierten Synaptophysin-Fluoreszenzsignale in den untersuchten Hirnregionen mit Angabe der Anzahl untersuchter Rattenhirnschnitte.

\begin{tabular}{l|r|r|r}
\hline Hirnregion & $\begin{array}{l}\text { Fluoreszenzpeak in } \\
\text { Prozent über der } \\
\text { Grundlinie }\end{array}$ & $\begin{array}{l}\text { Standardfehler in } \\
\text { Prozent über der } \\
\text { Grundlinie }\end{array}$ & $\begin{array}{l}\text { Untersuchte Ratten- } \\
\text { hirnschnitte }\end{array}$ \\
\hline GrDG & 44,6450 & 20,5800 & 6 \\
\hline M1I & 118,8900 & 21,6100 & 7 \\
\hline M1II & 114,6500 & 33,0350 & 8 \\
\hline M1IV & 97,4440 & 19,1000 & 8 \\
\hline M1V & 83,0080 & 14,6300 & 8 \\
\hline M1VI & 88,6910 & 15,8990 & 7 \\
\hline MoDG & 68,1900 & 13,5610 & 6 \\
\hline OrCA1 & 50,9660 & 13,3750 & 6 \\
\hline OrCA2 & 109,4600 & 39,7460 & 5 \\
\hline OrCA3 & 83,2310 & 18,3240 & 6 \\
\hline PoDG & 92,5520 & 24,6970 & 7 \\
\hline PyCA1 & 55,3330 & 14,0480 & 5 \\
\hline PyCA2 & 125,9900 & 46,4510 & 5 \\
\hline PyCA3 & 69,8440 & 24,4860 & 6 \\
\hline RadCA1 & 45,8650 & 15,0570 & 6 \\
\hline RadCA2 & 95,1980 & 32,1090 & 5 \\
\hline RadCA3 & 119,4100 & 43,3990 & 6 \\
\hline S1I & 77,5470 & 17,6960 & 8 \\
\hline S1II & 93,4040 & 15,5860 & 7 \\
\hline S1V & 107,8000 & 16,5690 & 7 \\
\hline S1VI & 104,2500 & 24,0880 & \\
\hline & & & 7 \\
\hline
\end{tabular}




\subsubsection{Bassoon}

Tabelle 11.A: Fluoreszenzpeaks und Standardfehler der detektierten Bassoon-Fluoreszenzsignale in den untersuchten Hirnregionen mit Angabe der Anzahl untersuchter Rattenhirnschnitte.

\begin{tabular}{l|r|r|r}
\hline Hirnregion & $\begin{array}{l}\text { Fluoreszenzpeak in } \\
\text { Prozent über der } \\
\text { Grundlinie }\end{array}$ & $\begin{array}{l}\text { Standardfehler in } \\
\text { Prozent über der } \\
\text { Grundlinie }\end{array}$ & $\begin{array}{l}\text { Untersuchte Ratten- } \\
\text { hirnschnitte }\end{array}$ \\
\hline GrDG & 708,4400 & 106,9900 & 7 \\
\hline M1I & 760,2700 & 100,2300 & 7 \\
\hline M1II & 641,2200 & 96,5960 & 8 \\
\hline M1IV & 659,8200 & 49,9760 & 8 \\
\hline M1V & 716,3300 & 56,2860 & 8 \\
\hline M1VI & 681,5200 & 39,2030 & 6 \\
\hline MoDG & 665,6700 & 58,5220 & 7 \\
\hline OrCA1 & 711,1500 & 91,5790 & 6 \\
\hline OrCA2 & 666,7900 & 74,2180 & 4 \\
\hline OrCA3 & 629,8500 & 81,3880 & 6 \\
\hline PoDG & 654,1300 & 71,4540 & 6 \\
\hline PyCA1 & 727,0300 & 61,5890 & 5 \\
\hline PyCA2 & 731,4000 & 94,8190 & 5 \\
\hline PyCA3 & 717,8900 & 100,0300 & 6 \\
\hline RadCA1 & 524,4800 & 30,9000 & 6 \\
\hline RadCA2 & 731,4000 & 91,3510 & 5 \\
\hline RadCA3 & 562,9900 & 64,9330 & 6 \\
\hline S1I & 616,1100 & 58,7590 & 8 \\
\hline S1II & 545,0900 & 42,1940 & 8 \\
\hline S1V & 749,3300 & 95,3230 & 8 \\
\hline S1VI & 625,3000 & 53,6940 & 8 \\
\hline & & & \\
\hline
\end{tabular}




\subsubsection{SNAP-25}

Tabelle 12.A: Fluoreszenzpeaks und Standardfehler der detektierten SNAP-25-Fluoreszenzsignale in den untersuchten Hirnregionen mit Angabe der Anzahl untersuchter Rattenhirnschnitte.

\begin{tabular}{l|r|r|r}
\hline Hirnregion & $\begin{array}{l}\text { Fluoreszenzpeak in } \\
\text { Prozent über der } \\
\text { Grundlinie }\end{array}$ & $\begin{array}{l}\text { Standardfehler in } \\
\text { Prozent über der } \\
\text { Grundlinie }\end{array}$ & $\begin{array}{l}\text { Untersuchte Ratten- } \\
\text { hirnschnitte }\end{array}$ \\
\hline GrDG & 131,3400 & 77,0790 & 2 \\
\hline M1I & 170,3200 & & 1 \\
\hline M1II & 143,3200 & & 1 \\
\hline M1IV & 163,9100 & 34,7250 & 2 \\
\hline M1V & 110,5800 & 33,9010 & 2 \\
\hline M1VI & 122,6900 & 13,9800 & 2 \\
\hline MoDG & 160,8900 & 37,1750 & 2 \\
\hline OrCA1 & 87,6400 & 11,2220 & 2 \\
\hline OrCA2 & 115,7800 & 43,5840 & 2 \\
\hline OrCA3 & 181,0600 & 36,9950 & 2 \\
\hline PoDG & 165,9000 & 74,8650 & 2 \\
\hline PyCA1 & 230,6100 & 22,1500 & 2 \\
\hline PyCA2 & 202,4100 & 101,9400 & 2 \\
\hline PyCA3 & 167,5500 & 75,5600 & 2 \\
\hline RadCA1 & 89,6260 & 7,9365 & 2 \\
\hline RadCA2 & 176,7600 & 45,7250 & 2 \\
\hline RadCA3 & 195,3000 & 62,8250 & 1 \\
\hline S1I & 107,4200 & & 2 \\
\hline S1II & 202,6400 & 47,5800 & 2 \\
\hline S1V & 194,9100 & 45,9700 & 2 \\
\hline S1VI & 204,8900 & 23,6650 & 2 \\
\hline & & & 2 \\
\hline
\end{tabular}




\subsubsection{VGLUT 1/2}

Tabelle 13.A: Fluoreszenzpeaks und Standardfehler der detektierten VGLUT 1/2Fluoreszenzsignale in den untersuchten Hirnregionen mit Angabe der Anzahl untersuchter Rattenhirnschnitte.

\begin{tabular}{|c|c|c|c|}
\hline Hirnregion & $\begin{array}{l}\text { Fluoreszenzpeak in } \\
\text { Prozent über der } \\
\text { Grundlinie } \\
\end{array}$ & $\begin{array}{l}\text { Standardfehler in } \\
\text { Prozent über der } \\
\text { Grundlinie } \\
\end{array}$ & $\begin{array}{l}\text { Untersuchte Ratten- } \\
\text { hirnschnitte }\end{array}$ \\
\hline GrDG & 115,5700 & 5,0350 & 2 \\
\hline M1I & 178,9600 & & 1 \\
\hline M1II & 221,7900 & 79,8450 & 2 \\
\hline M1IV & 99,3100 & 30,6400 & 2 \\
\hline M1V & 105,7800 & 5,3500 & 2 \\
\hline M1VI & 179,2500 & 100,6500 & 2 \\
\hline MoDG & 164,5800 & 55,8700 & 2 \\
\hline OrCA1 & 73,5720 & & 1 \\
\hline OrCA2 & 106,4900 & & 1 \\
\hline OrCA3 & 108,9500 & & 1 \\
\hline PoDG & 256,8000 & 142,8400 & 2 \\
\hline PyCA1 & 168,3300 & & 1 \\
\hline PyCA2 & 175,4100 & & 1 \\
\hline PyCA3 & 75,2300 & & 1 \\
\hline RadCA1 & 171,7600 & & 1 \\
\hline RadCA2 & 57,2640 & & 1 \\
\hline RadCA3 & 95,1590 & & 1 \\
\hline S1I & 137,3600 & 22,9250 & 2 \\
\hline S1II & 145,3500 & 62,5610 & 2 \\
\hline S1V & 103,2600 & & 1 \\
\hline S1VI & 125,2300 & & 1 \\
\hline
\end{tabular}




\subsubsection{Amphiphysin}

Tabelle 14.A: Fluoreszenzpeaks und Standardfehler der detektierten AmphiphysinFluoreszenzsignale in den untersuchten Hirnregionen mit Angabe der Anzahl untersuchter Rattenhirnschnitte.

\begin{tabular}{|c|c|c|c|}
\hline Hirnregion & $\begin{array}{l}\text { Fluoreszenzpeak in } \\
\text { Prozent über der } \\
\text { Grundlinie } \\
\end{array}$ & $\begin{array}{l}\text { Standardfehler in } \\
\text { Prozent über der } \\
\text { Grundlinie } \\
\end{array}$ & $\begin{array}{l}\text { Untersuchte Ratten- } \\
\text { hirnschnitte }\end{array}$ \\
\hline GrDG & 69,7810 & & 1 \\
\hline M1I & 102,4800 & 43,5890 & 2 \\
\hline M1II & 58,1680 & 10,9960 & 2 \\
\hline M1IV & 195,0700 & 67,9850 & 2 \\
\hline M1V & 55,9650 & & 1 \\
\hline M1VI & 92,5530 & & 1 \\
\hline MoDG & 78,9870 & & 1 \\
\hline OrCA1 & 176,2800 & & 1 \\
\hline OrCA3 & 46,4510 & & 1 \\
\hline PoDG & 99,2720 & & 1 \\
\hline PyCA1 & 305,9000 & & 1 \\
\hline PyCA3 & 25,9390 & & 1 \\
\hline RadCA1 & 34,2280 & & 1 \\
\hline RadCA3 & 31,8930 & & 1 \\
\hline S1I & 135,3300 & 45,6690 & 2 \\
\hline S1II & 160,9400 & 93,7740 & 2 \\
\hline S1V & 234,0100 & 145,3000 & 2 \\
\hline S1VI & 173,1300 & 158,4700 & 2 \\
\hline
\end{tabular}




\section{Literaturverzeichnis}

Abbe E (1873): Beiträge zur Theorie des Mikroskops und der mikroskopischen Wahrnehmung. Archiv f mikrosk Anatomie 9, 413-468

Adams DJ, Arthur CP, Stowell MHB (2015): Architecture of the synaptophysin/synaptobrevin complex: structural evidence for an entropic clustering function at the synapse. Sci Rep $\underline{5}, 13659$

Adrian ED (1914): The all-or-none principle in nerve. J Physiol 47, 460-474

Ahmari SE, Buchanan J, Smith SJ (2000): Assembly of presynaptic active zones from cytoplasmic transport packets. Nat Neurosci $\underline{3}, 445-451$

Alabi AA, Tsien RW (2012): Synaptic vesicle pools and dynamics. Cold Spring Harb Perspect Biol 4, a013680

Alabi AA, Tsien RW (2013): Perspectives on kiss-and-run: role in exocytosis, endocytosis, and neurotransmission. Annu Rev Physiol 75, 393-422

Alder J, Xie ZP, Valtorta F, Greengard P, Poo M (1992a): Antibodies to synaptophysin interfere with transmitter secretion at neuromuscular synapses. Neuron $\underline{9}, 759-768$

Alder J, Lu B, Valtorta F, Greengard P, Poo M (1992b): Calcium-dependent transmitter secretion reconstituted in xenopus oocytes: requirement for synaptophysin. Science 257, $657-661$

Alder J, Kanki H, Valtorta F, Greengard P, Poo M (1995): Overexpression of synaptophysin enhances neurotransmitter secretion at xenopus neuromuscular synapses. J Neurosci $\underline{15}$, $511-519$

Amunts K, Zilles K (2015): Architectonic mapping of the human brain beyond Brodmann. Neuron $\underline{88}, 1086-1107$

Anderson CNG, Grant SGN (2006): High throughput protein expression screening in the nervous system - needs and limitations. J Physiol 575, 367-372

Antonucci F, Corradini I, Fossati G, Tomasoni R, Menna E, Matteoli M (2016): SNAP-25, a known presynaptic protein with emerging postsynaptic functions. Front Synaptic Neurosci $\underline{8}, 7$

Aravamudan B, Fergestad T, Davis WS, Rodesch CK, Broadie K (1999): Drosophila Unc-13 is essential for synaptic transmission. Nat Neurosci $\underline{2}, 965-971$

Asano SM, Gao R, Wassie AT, Tillberg P, Chen F, Boyden ES (2018): Expansion microscopy: protocols for imaging proteins and RNA in cells and tissues. Curr Protoc Cell Biol $\underline{80}$, e56

Azevedo FAC, Carvalho LRB, Grinberg LT, Farfel JM, Ferretti REL, Leite REP, Jacob Filho W, Lent R, Herculano-Houzel S (2009): Equal numbers of neuronal and nonneuronal cells make the human brain an isometrically scaled-up primate brain. J Comp Neurol $\underline{513}, 532-541$

Bai L, Xu H, Collins JF, Ghishan FK (2001): Molecular and functional analysis of a novel neuronal vesicular glutamate transporter. J Biol Chem 276, 36764-36769

Baker M (2015): Reproducibility crisis: Blame it on the antibodies. Nature 521, 274-276 
Barnett MW, Larkman PM (2007): The action potential. Pract Neurol 7, 192-197

Barr CL, Feng Y, Wigg K, Bloom S, Roberts W, Malone M, Schachar R, Tannock R, Kennedy JL (2000): Identification of DNA variants in the SNAP-25 gene and linkage study of these polymorphisms and attention-deficit hyperactivity disorder. Mol Psychiatry $\underline{5}$, 405-409

Bauerfeind R, Takei K, Camilli PD (1997): Amphiphysin I is associated with coated endocytic intermediates and undergoes stimulation-dependent dephosphorylation in nerve terminals. J Biol Chem 272, 30984-30992

Becher A, Drenckhahn A, Pahner I, Margittai M, Jahn R, Ahnert-Hilger G (1999): The synaptophysin-synaptobrevin complex: A hallmark of synaptic vesicle maturation. J Neurosci 19, 1922-1931

Bellocchio EE, Reimer RJ, Fremeau RT, Edwards RH (2000): Uptake of glutamate into synaptic vesicles by an inorganic phosphate transporter. Science 289, 957-960

Betzig E, Patterson GH, Sougrat R, Lindwasser OW, Olenych S, Bonifacino JS, Davidson MW, Lippincott-Schwartz J, Hess HF (2006): Imaging intracellular fluorescent proteins at nanometer resolution. Science 313, 1642-1645

Bitsikas V, Corrêa IR, Nichols BJ (2014): Clathrin-independent pathways do not contribute significantly to endocytic flux. eLife $\underline{3}$, e03970

Bliss TVP, Lømo T (1973): Long-lasting potentiation of synaptic transmission in the dentate area of the anaesthetized rabbit following stimulation of the perforant path. J Physiol $\underline{232}, 331-356$

Bloom O, Evergren E, Tomilin N, Kjaerulff O, Löw P, Brodin L, Pieribone VA, Greengard P, Shupliakov O (2003): Colocalization of synapsin and actin during synaptic vesicle recycling. J Cell Biol 161, 737-747

Boulland JL, Jenstad M, Boekel AJ, Wouterlood FG, Edwards RH, Storm-Mathisen J, Chaudhry FA (2009): Vesicular glutamate and GABA transporters sort to distinct sets of vesicles in a population of presynaptic terminals. Cereb Cortex $\underline{19}, 241-248$

Bradbury A, Plückthun A (2015): Reproducibility: Standardize antibodies used in research. Nature $\underline{518}, 27-29$

Bucur O, Fu F, Calderon M, Mylvaganam GH, Ly NL, Day J, Watkin S, Walker BD, Boyden ES, Zhao Y (2020): Nanoscale imaging of clinical specimens using conventional and rapid-expansion pathology. Nat Protoc $\underline{15}, 1649-1672$

Burgalossi A, Jung S, Meyer G, Jockusch WJ, Jahn O, Taschenberger H, O'Connor VM, Nishiki T, Takahashi M, Brose $\mathrm{N}$ et al. (2010): SNARE protein recycling by $\alpha$ SNAP and $\beta$ SNAP supports synaptic vesicle priming. Neuron $\underline{68}, 473-487$

Burkhardt P, Hattendorf DA, Weis WI, Fasshauer D (2008): Munc18a controls SNARE assembly through its interaction with the syntaxin N-peptide. EMBO J 27, 923-933

Cahoon CK, Yu Z, Wang Y, Guo F, Unruh JR, Slaughter BD, Hawley RS (2017): Superresolution expansion microscopy reveals the three-dimensional organization of the Drosophila synaptonemal complex. Proc Natl Acad Sci USA 114, E6857-E6866

Calakos N, Scheller RH (1994): Vesicle-associated membrane protein and synaptophysin are associated on the synaptic vesicle. J Biol Chem 269, 24534-24537 
Cano R, Tabares L (2016): The active and periactive zone organization and the functional properties of small and large synapses. Front Synaptic Neurosci $\underline{8}, 12$

Chang JB, Chen F, Yoon YG, Jung EE, Babcock H, Kang JS, Asano S, Suk HJ, Pak N, Tillberg PW (2017): Iterative expansion microscopy. Nat Methods 14, 593-599

Chapman ER (2008): How does synaptotagmin trigger neurotransmitter release? Annu Rev Biochem $\underline{77}, 615-641$

Chen F, Tillberg PW, Boyden ES (2015): Optical imaging. Expansion microscopy. Science 347, 543-548

Chen F, Wassie AT, Cote AJ, Sinha A, Alon S, Asano S, Daugharthy ER, Chang JB, Marblestone A, Church GM et al. (2016): Nanoscale imaging of RNA with expansion microscopy. Nat Methods $\underline{13}, 679-684$

Chen X, Levy JM, Hou A, Winters C, Azzam R, Sousa AA, Leapman RD, Nicoll RA, Reese TS (2015): PSD-95 family MAGUKs are essential for anchoring AMPA and NMDA receptor complexes at the postsynaptic density. Proc Natl Acad Sci USA 112, E6983-E6992

Cho I, Seo JY, Chang J (2018): Expansion microscopy. J Microsc 271, 123-128

Choi BJ, Imlach WL, Jiao W, Wolfram V, Wu Y, Grbic M, Cela C, Baines RA, Nitabach MN, McCabe BD (2014): Miniature neurotransmission regulates drosophila synaptic structural maturation. Neuron $\underline{82}, 618-634$

Chozinski TJ, Halpern AR, Okawa H, Kim HJ, Tremel GJ, Wong ROL, Vaughan JC (2016): Expansion microscopy with conventional antibodies and fluorescent proteins. Nat Methods $\underline{13}, 485-488$

Citri A, Malenka RC (2008): Synaptic Plasticity: Multiple Forms, functions, and mechanisms. Neuropsychopharmacology $\underline{33}, 18-41$

Clayton EL, Cousin MA (2009): The molecular physiology of activity-dependent bulk endocytosis of synaptic vesicles. J Neurochem $\underline{111}, 901-914$

Clayton EL, Evans GJO, Cousin MA (2007): Activity-dependent control of bulk endocytosis by protein dephosphorylation in central nerve terminals. J Physiol 585, 687-691

Collins MO, Husi H, Yu L, Brandon JM, Anderson CNG, Blackstock WP, Choudhary JS, Grant SGN (2006): Molecular characterization and comparison of the components and multiprotein complexes in the postsynaptic proteome. J Neurochem 97, 16-23

Cousin MA, Robinson PJ (2001): The dephosphins: dephosphorylation by calcineurin triggers synaptic vesicle endocytosis. Trends Neurosci 24, 659-665

Cremona O, Di Paolo G, Wenk MR, Lüthi A, Kim WT, Takei K, Daniell L, Nemoto Y, Shears SB, Flavell RA et al. (1999): Essential role of phosphoinositide metabolism in synaptic vesicle recycling. Cell $\underline{99}, 179-188$

Daly C, Ziff EB (2002): Ca2+-dependent formation of a dynamin-synaptophysin complex: potential role in synaptic vesicle endocytosis. J Biol Chem $\underline{277}$, 9010-9015

Dani A, Huang B, Bergan J, Dulac C, Zhuang X (2010): Super-resolution imaging of chemical synapses in the brain. Neuron $\underline{68}, 843-856$ 
Daniels RW, Collins CA, Chen K, Gelfand MV, Featherstone DE, DiAntonio A (2006): A single vesicular glutamate transporter is sufficient to fill a synaptic vesicle. Neuron $\underline{49}, 11-$ 16

Darcy KJ, Staras K, Collinson LM, Goda Y (2006): Constitutive sharing of recycling synaptic vesicles between presynaptic boutons. Nat Neurosci $\underline{9}, 315-321$

David C, Solimena M, Camilli PD (1994): Autoimmunity in stiff-man syndrome with breast cancer is targeted to the C-terminal region of human amphiphysin, a protein similar to the yeast proteins, Rvs167 and Rvs161. FEBS Lett $\underline{351}$, 73-79

Davydova D, Marini C, King C, Klueva J, Bischof F, Romorini S, Montenegro-Venegas C, Heine M, Schneider R, Schröder MS (2014): Bassoon specifically controls presynaptic P/Q-type Ca2+ channels via RIM-binding protein. Neuron 2, 181-194

De Gois S, Jeanclos E, Morris M, Grewal S, Varoqui H, Erickson JD (2006): Identification of endophilins 1 and 3 as selective binding partners for VGLUT1 and their co-localization in neocortical glutamatergic synapses: Implications for vesicular glutamate transporter trafficking and excitatory vesicle formation. Cell Mol Neurobiol 26, 677-691

Dejanovic B, Semtner M, Ebert S, Lamkemeyer T, Neuser F, Lüscher B, Meier JC, Schwarz G (2014): Palmitoylation of gephyrin controls receptor clustering and plasticity of GABAergic synapses. PLoS Biol 12, e1001908

del Castillo J, Katz B (1954): Quantal components of the end-plate potential. J Physiol $\underline{124}$, $560-573$

Delvendahl I, Vyleta NP, von Gersdorff H, Hallermann S (2016): Fast, temperature-sensitive and clathrin-independent endocytosis at central synapses. Neuron $\underline{90}, 492-498$

Denker A, Rizzoli SO (2010): Synaptic vesicle pools: An update. Front Synaptic Neurosci 2 , 135

Denker A, Bethani I, Kröhnert K, Körber C, Horstmann H, Wilhelm BG, Barysch SV, Kuner T, Neher E, Rizzoli SO (2011a): A small pool of vesicles maintains synaptic activity in vivo. Proc Natl Acad Sci USA $\underline{108}$, 17177-17182

Denker A, Kröhnert K, Bückers J, Neher E, Rizzoli SO (2011b): The reserve pool of synaptic vesicles acts as a buffer for proteins involved in synaptic vesicle recycling. Proc Natl Acad Sci USA $\underline{108}, 17183-17188$

Di Giovanni J, Boudkkazi S, Mochida S, Bialowas A, Samari N, Lévêque C, Youssouf F, Brechet A, Iborra C, Maulet Y (2010): V-ATPase membrane sector associates with synaptobrevin to modulate neurotransmitter release. Neuron $\underline{67}, 268-279$

Di Paolo G, Sankaranarayanan S, Wenk MR, Daniell L, Perucco E, Caldarone BJ, Flavell R, Picciotto MR, Ryan TA, Cremona O, De Camilli P (2002): Decreased synaptic vesicle recycling efficiency and cognitive deficits in amphiphysin 1 knockout mice. Neuron $\underline{33}$, 789-804

Dieck S, Sanmartí-Vila L, Langnaese K, Richter K, Kindler S, Soyke A, Wex H, Smalla KH, Kämpf U, Fränzer J-T (1998): Bassoon, a novel zinc-finger CAG/glutamine-repeat protein selectively localized at the active zone of presynaptic nerve terminals. J Cell Biol $\underline{142}, 499-509$

Disbrow JK, Gershten MJ, Ruth JA (1982): Uptake of L-[3H] glutamic acid by crude and purified synaptic vesicles from rat brain. Biochem Biophys Res Commun 108, 1221-1227 
Dittman J, Ryan TA (2009): Molecular circuitry of endocytosis at nerve terminals. Annu Rev Cell Dev Biol 25, 133-160

Dobrunz LE, Stevens CF (1997): Heterogeneity of release probability, facilitation, and depletion at central synapses. Neuron $\underline{18}, 995-1008$

Dong H, O’Brien RJ, Fung ET, Lanahan AA, Worley PF, Huganir RL (1997): GRIP: a synaptic PDZ domain-containing protein that interacts with AMPA receptors. Nature 386, 279284

Durisic N, Cuervo LL, Lakadamyali M (2014): Quantitative super-resolution microscopy: pitfalls and strategies for image analysis. Curr Opin Chem Biol 20, 22-28

Edwards RH (2007): The neurotransmitter cycle and quantal size. Neuron 55, 835-858

Ehrlich M, Boll W, van Oijen A, Hariharan R, Chandran K, Nibert ML, Kirchhausen T (2004): Endocytosis by random initiation and stabilization of clathrin-coated pits. Cell $\underline{118}$, 591-605

El Mestikawy S, Wallén-Mackenzie Å, Fortin GM, Descarries L, Trudeau LE (2011): From glutamate co-release to vesicular synergy: vesicular glutamate transporters. Nat Rev Neu$\operatorname{rosci} \underline{12}, 204-216$

Faelber K, Held M, Gao S, Posor Y, Haucke V, Noé F, Daumke O (2012): Structural insights into dynamin-mediated membrane fission. Structure 20, 1621-1628

Fatemi S, Earle J, Stary J, Lee S, Sedgewick J (2001): Altered levels of the synaptosomal associated protein SNAP-25 in hippocampus of subjects with mood disorders and schizophrenia. Neuroreport $\underline{12}, 3257-3262$

Fatt P, Katz B (1952): Spontaneous subthreshold activity at motor nerve endings. J Physiol $\underline{117}$, $109-128$

Fejtova A, Davydova D, Bischof, F, Lazarevic V, Altrock WD, Romorini S, Schöne C, Zuschratter W, Kreutz MR, Garner CC (2009): Dynein light chain regulates axonal trafficking and synaptic levels of Bassoon. J Cell Biol 185, 341-355

Felkl M, Leube RE (2008): Interaction assays in yeast and cultured cells confirm known and identify novel partners of the synaptic vesicle protein synaptophysin. Neuroscience $\underline{156}$, $344-352$

Fenster SD, Chung WJ, Zhai R, Cases-Langhoff C, Voss B, Garner AM, Kaempf U, Kindler S, Gundelfinger ED, Garner CC (2000): Piccolo, a presynaptic zinc finger protein structurally related to bassoon. Neuron $\underline{25}, 203-214$

Ferguson SM, Raimondi A, Paradise S, Shen H, Mesaki K, Ferguson A, Destaing O, Ko G, Takasaki J, Cremona O (2009): Coordinated actions of actin and BAR proteins upstream of dynamin at endocytic clathrin-coated pits. Dev Cell 17, 811-822

Fernandez-Alfonso T, Ryan TA (2008): A heterogeneous "resting" pool of synaptic vesicles that is dynamically interchanged across boutons in mammalian CNS synapses. Brain Cell Biol $\underline{36}, 87-100$

Fesce R, Grohovaz F, Valtorta F, Meldolesi J (1994): Neurotransmitter release: fusion or 'kissand-run'? Trends Cell Biol $\underline{4}, 1-4$ 
Fornasiero EF, Rizzoli SO: Super-resolution microscopy techniques in the Neurosciences. Neuromethods 86; Springer, New York 2014

Fornasiero EF, Opazo F (2015): Super-resolution imaging for cell biologists. Bioessays $\underline{37}$, $436-451$

Freifeld L, Odstrcil I, Förster D, Ramirez A, Gagnon JA, Randlett O, Costa EK, Asano S, Celiker OT, Gao R (2017): Expansion microscopy of zebrafish for neuroscience and developmental biology studies. Proc Natl Acad Sci USA 114, E10799-E10808

Fremeau RT, Burman J, Qureshi T, Tran CH, Proctor J, Johnson J, Zhang H, Sulzer D, Copenhagen DR, Storm-Mathisen J (2002): The identification of vesicular glutamate transporter 3 suggests novel modes of signaling by glutamate. Proc Natl Acad Sci USA $\underline{99}$, $14488-14493$

Fremeau RT, Kam K, Qureshi T, Johnson J, Copenhagen DR, Storm-Mathisen J, Chaudhry FA, Nicoll RA, Edwards RH (2004): Vesicular glutamate transporters 1 and 2 target to functionally distinct synaptic release sites. Science $\underline{304}, 1815-1819$

Galic M, Jeong S, Tsai FC, Joubert LM, Wu YI, Hahn KM, Cui Y, Meyer T (2012): External push and internal pull forces recruit curvature sensing N-BAR domain proteins to the plasma membrane. Nat Cell Biol 14, 874-881

Galli T, McPherson PS, Camilli PD (1996): The v Sector of the V-ATPase, synaptobrevin, and synaptophysin are associated on synaptic vesicles in a triton X-100-resistant, freezethawing sensitive, complex. J Biol Chem 271, 2193-2198

Gambarotto D, Zwettler FU, Le Guennec M, Schmidt-Cernohorska M, Fortun D, Borgers S, Heine J, Schloetel JG, Reuss M, Unser M (2019): Imaging cellular ultrastructures using expansion microscopy (U-ExM). Nat Methods $\underline{16}, 71-74$

Gan Q, Watanabe S (2018): Synaptic vesicle endocytosis in different model systems. Front Cell Neurosci $\underline{12}, 171$

Gandhi SP, Stevens CF (2003): Three modes of synaptic vesicular recycling revealed by singlevesicle imaging. Nature $\underline{423}, 607-613$

Gao M, Maraspini R, Beutel O, Zehtabian A, Eickholt B, Honigmann A, Ewers H (2018): Expansion stimulated emission depletion microscopy (ExSTED). ACS Nano $\underline{12}, 4178-$ 4185

Gerdes C, Waal N, Offner T, Fornasiero EF, Wender N, Verbarg H, Manzini I, Trenkwalder C, Mollenhauer B, Strohäker T (2020): A nanobody-based fluorescent reporter reveals human $\alpha$-synuclein in the cell cytosol. Nat Commun $\underline{11}, 2729$

Goda Y (1997): SNAREs and regulated vesicle exocytosis. Proc Natl Acad Sci USA $\underline{94}, 769$ 772

Gordon SL, Leube RE, Cousin MA (2011): Synaptophysin is required for synaptobrevin retrieval during synaptic vesicle endocytosis. J Neurosci 31, 14032-14036

Gordon SL, Cousin MA (2014): The sybtraps: control of synaptobrevin traffic by synaptophysin, $\alpha$-synuclein and AP-180. Traffic 15, 245-254

Granseth B, Lagnado L (2008): The role of endocytosis in regulating the strength of hippocampal synapses. J Physiol 586, 5969-5982 
Granseth B, Odermatt B, Royle SJ, Lagnado L (2006): Clathrin-mediated endocytosis is the dominant mechanism of vesicle retrieval at hippocampal synapses. Neuron $\underline{51}, 773-786$

Granseth B, Odermatt B, Royle SJ, Lagnado L (2009): Comment on "The dynamic control of kiss-and-run and vesicular reuse probed with single nanoparticles". Science 325, 1499

Grant SGN (2018): Synapse molecular complexity and the plasticity behaviour problem. Brain Neurosci Adv 2, 2398212818810685

Gras C, Herzog E, Bellenchi GC, Bernard V, Ravassard P, Pohl M, Gasnier B, Giros B, Mestikawy SE (2002): A third vesicular glutamate transporter expressed by cholinergic and serotoninergic neurons. J Neurosci 22, 5442-5451

Graziano A, Liu XB, Murray KD, Jones EG (2008): Vesicular glutamate transporters define two sets of glutamatergic afferents to the somatosensory thalamus and two thalamocortical projections in the mouse. J Comp Neurol $\underline{507}, 1258-1276$

Gundelfinger ED, Kessels MM, Qualmann B (2003): Temporal and spatial coordination of exocytosis and endocytosis. Nat Rev Mol Cell Biol 4, 127-139

Gundelfinger ED, Reissner C, Garner CC (2016): Role of bassoon and piccolo in assembly and molecular organization of the active zone. Front Synaptic Neurosci $\underline{7}, 19$

Gustafsson MGL (2000): Surpassing the lateral resolution limit by a factor of two using structured illumination microscopy. J Microsc 198, 82-87

Hallermann S, Fejtova A, Schmidt H, Weyhersmüller A, Silver RA, Gundelfinger ED, Eilers J (2010): Bassoon speeds vesicle reloading at a central excitatory synapse. Neuron $\underline{68}$, $710-723$

Hanson PI, Heuser JE, Jahn R (1997): Neurotransmitter release - four years of SNARE complexes. Curr Opin Neurobiol 7, 310-315

Harata NC, Choi S, Pyle JL, Aravanis AM, Tsien RW (2006): Frequency-dependent kinetics and prevalence of kiss-and-run and reuse at hippocampal synapses studied with novel quenching methods. Neuron $\underline{49}, 243-256$

Harlow ML, Ress D, Stoschek A, Marshall RM, McMahan UJ (2001): The architecture of active zone material at the frog's neuromuscular junction. Nature $\underline{409}, 479-484$

Harris KD, Hirase H, Leinekugel X, Henze DA, Buzsáki G (2001): Temporal interaction between single spikes and complex spike bursts in hippocampal pyramidal cells. Neuron $\underline{32}, 141-149$

Harris KM, Sultan P (1995): Variation in the number, location and size of synaptic vesicles provides an anatomical basis for the nonuniform probability of release at hippocampal CA1 synapses. Neuropharmacology $\underline{34}, 1387-1395$

Harris KM, Weinberg RJ (2012): Ultrastructure of synapses in the mammalian brain. Cold Spring Harb Perspect Biol 4, a005587

Haucke V, Neher E, Sigrist SJ (2011): Protein scaffolds in the coupling of synaptic exocytosis and endocytosis. Nat Rev Neurosci 12, 127-138 
He L, Wu LG (2007): The debate on the kiss-and-run fusion at synapses. Trends Neurosci $\underline{30}$, $447-455$

Hell SW, Reiner G, Cremer C, Stelzer EHK (1993): Aberrations in confocal fluorescence microscopy induced by mismatches in refractive index. J Microsc 169, 391-405

Hell SW, Wichmann J (1994): Breaking the diffraction resolution limit by stimulated emission: stimulated-emission-depletion fluorescence microscopy. Opt lett 19, 780-782

Herzog E, Bellenchi GC, Gras C, Bernard V, Ravassard P, Bedet C, Gasnier B, Giros B, El Mestikawy S (2001): The existence of a second vesicular glutamate transporter specifies subpopulations of glutamatergic neurons. J Neurosci 21, RC181

Herzog E, Takamori S, Jahn R, Brose N, Wojcik SM (2006): Synaptic and vesicular co-localization of the glutamate transporters VGLUT1 and VGLUT2 in the mouse hippocampus. J Neurochem 99, 1011-1018

Herzog E, Nadrigny F, Silm K, Biesemann C, Helling I, Bersot T, Steffens H, Schwartzmann R, Nägerl UV, El Mestikawy S (2011): In vivo imaging of intersynaptic vesicle exchange using VGLUT1Venus knock-in mice. J Neurosci 31, 15544-15559

Heuser J (1989): The role of coated vesicles in recycling of synaptic vesicle membrane. Cell Biol Int Rep 수, $1063-1076$

Heuser JE, Reese TS (1973): Evidence for recycling of synaptic vesicle membrane during transmitter release at the frog neuromuscular junction. J Cell Biol 57, 315-344

Heuser J, Reese T (1981): Structural changes after transmitter release at the frog neuromuscular junction. J Cell Biol $\underline{88}, 564-80$

Heuser JE, Reese TS, Dennis MJ, Jan Y, Jan L, Evans L (1979): Synaptic vesicle exocytosis captured by quick freezing and correlated with quantal transmitter release. J Cell Biol $\underline{81}, 275-300$

Hille B: Ionic channels of excitable membranes. 2. Auflage; Sinauer, Associates INC., Sunderland, Massachusetts 1992

Hnasko TS, Edwards RH (2012): Neurotransmitter co-release: Mechanism and physiological role. Annu Rev Physiol 74, 225-243

Hodgkin AL (1937): Evidence for electrical transmission in nerve. J Physiol 90, 211-232

Hoopmann P, Punge A, Barysch SV, Westphal V, Bückers J, Opazo F, Bethani I, Lauterbach MA, Hell SW, Rizzoli SO (2010): Endosomal sorting of readily releasable synaptic vesicles. Proc Natl Acad Sci USA 107, 19055-19060

Horikawa HPM, Kneussel M, El Far O, Betz H (2002): Interaction of synaptophysin with the AP-1 adaptor protein $\gamma$-adaptin. Mol Cell Neurosci 21, 454-462

Hu Y, Chu X, Chen T, Pan Q, Liu C, Yi J, Chu Xi (2020): Improving resolving ability of expansion microscopy by varying crosslinker concentration. Chem Commun $\underline{56}, 4176-4179$

Huang B, Bates M, Zhuang X (2009): Super resolution fluorescence microscopy. Annu Rev Biochem $\underline{78}, 993-1016$

Hull C, Isaacson JS, Scanziani M (2009): Postsynaptic mechanisms govern the differential excitation of cortical neurons by thalamic inputs. J Neurosci $\underline{29}, 9127-9136$ 
Hussain S, Ringsevjen H, Schupp M, Hvalby Ø, Sørensen JB, Jensen V, Davanger S (2019): A possible postsynaptic role for SNAP-25 in hippocampal synapses. Brain Struct Funct $\underline{224}, 521-532$

Imig C, Min SW, Krinner S, Arancillo M, Rosenmund C, Südhof TC, Rhee J, Brose N, Cooper BH (2014): The morphological and molecular nature of synaptic vesicle priming at presynaptic active zones. Neuron $\underline{84}, 416-431$

Ivanova D, Dirks A, Fejtova A (2016): Bassoon and piccolo regulate ubiquitination and link presynaptic molecular dynamics with activity-regulated gene expression. J Physiol 594, $5441-5448$

Jahn R, Schiebler W, Ouimet C, Greengard P (1985): A 38,000-dalton membrane protein (p38)

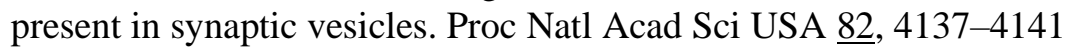

Jahn R, Südhof TC (1994): Synaptic vesicles and exocytosis. Annu Rev Neurosci 17, 219-246

Jahn R, Scheller RH (2006): SNAREs - engines for membrane fusion. Nat Rev Mol Cell Biol 7 , 631-643

Jahn R, Fasshauer D (2012): Molecular machines governing exocytosis of synaptic vesicles. Nature $490,201-207$

Janz R, Südhof TC, Hammer RE, Unni V, Siegelbaum SA, Bolshakov VY (1999): Essential roles in synaptic plasticity for synaptogyrin I and synaptophysin I. Neuron $\underline{24}, 687-700$

Johnston PA, Südhof TC (1990): The multisubunit structure of synaptophysin. Relationship between disulfide bonding and homo-oligomerization. J Biol Chem 265, 8869-8873

Jurado S, Goswami D, Zhang Y, Molina AJM, Südhof TC, Malenka RC (2013): LTP requires a unique postsynaptic SNARE fusion machinery. Neuron $77,542-558$

Kamin D, Lauterbach MA, Westphal V, Keller J, Schönle A, Hell SW, Rizzoli SO (2010): High- and low-mobility stages in the synaptic vesicle cycle. Biophys J $\underline{99}, 675-684$

Kaneko T, Fujiyama F (2002): Complementary distribution of vesicular glutamate transporters in the central nervous system. Neurosci Res $\underline{42}, 243-250$

Katz B, Miledi R (1969): Spontaneous and evoked activity of motor nerve endings in calcium Ringer. J Physiol 203, 689-706

Kent SP, Ryan KH, Siegel AL (1978): Steric hindrance as a factor in the reaction of labeled antibody with cell surface antigenic determinants. J Histochem Cytochem 26, 618-621

Kim SH, Ryan TA (2009): Synaptic vesicle recycling at CNS synapses without AP-2. J Neurosci $\underline{29}, 3865-3874$

Kirchhausen T, Harrison SC (1981): Protein organization in clathrin trimers. Cell 23, 755-761

Kononenko NL, Puchkov D, Classen GA, Walter AM, Pechstein A, Sawade L, Kaempf N, Trimbuch T, Lorenz D, Rosenmund C (2014): Clathrin/AP-2 mediate synaptic vesicle reformation from endosome-like vacuoles but Are not essential for membrane retrieval at central synapses. Neuron $\underline{82}, 981-988$

Krueger SR, Kolar A, Fitzsimonds RM (2003): The presynaptic release apparatus is functional in the absence of dendritic contact and highly mobile within isolated axons. Neuron $\underline{40}$, 945-957 
Kustanovich V, Merriman B, McGough J, McCracken JT, Smalley SL, Nelson SF (2003): Biased paternal transmission of SNAP-25 risk alleles in attention-deficit hyperactivity disorder. Mol Psychiatry $\underline{8}, 309-315$

Kwon SE, Chapman ER (2011): Synaptophysin regulates the kinetics of synaptic vesicle endocytosis in central neurons. Neuron $\underline{70}, 847-854$

Lang T, Bruns D, Wenzel D, Riedel D, Holroyd P, Thiele C, Jahn R (2001): SNAREs are concentrated in cholesterol-dependent clusters that define docking and fusion sites for exocytosis. EMBO J 20, 2202-2213

Lau CG, Takayasu Y, Rodenas-Ruano A, Paternain AV, Lerma J, Bennett MVL, Zukin RS (2010): SNAP-25 is a target of protein kinase C phosphorylation critical to NMDA receptor trafficking. J Neurosci $\underline{30}, 242-254$

Lavenex P, Suzuki WA, Amaral DG (2002): Perirhinal and parahippocampal cortices of the macaque monkey: Projections to the neocortex. J Comp Neurol 447, 394-420

Lee JS, Ho WK, Lee SH (2012): Actin-dependent rapid recruitment of reluctant synaptic vesicles into a fast-releasing vesicle pool. Proc Natl Acad Sci USA 109, E765-E774

Li JY, Dahlström A (1997): Axonal transport of synaptic vesicle proteins in the rat optic nerve. J Neurobiol $\underline{32}, 237-250$

Lichte B, Veh RW, Meyer HE, Kilimann MW (1992): Amphiphysin, a novel protein associated with synaptic vesicles. EMBO J 11 , 2521-2530

Lim L, Mi D, Llorca A, Marín O (2018): Development and functional diversification of cortical interneurons. Neuron $\underline{100}, 294-313$

Liu KSY, Siebert M, Mertel S, Knoche E, Wegener S, Wichmann C, Matkovic T, Muhammad K, Depner H, Mettke C (2011): RIM-binding protein, a central part of the active zone, is essential for neurotransmitter release. Science $\underline{334}, 1565-1569$

Lodato S, Arlotta P (2015): Generating neuronal diversity in the mammalian cerebral cortex. Annu Rev Cell Dev Biol 31, 699-720

Löschberger A, van de Linde S, Dabauvalle MC, Rieger B, Heilemann M, Krohne G, Sauer M (2012): Super-resolution imaging visualizes the eightfold symmetry of gp210 proteins around the nuclear pore complex and resolves the central channel with nanometer resolution. J Cell Sci $\underline{125}$, 570-575

Lou X (2018): Sensing exocytosis and triggering endocytosis at synapses: Synaptic vesicle exocytosis-endocytosis coupling. Front Cell Neurosci 12, 66

Lou X, Shin YK (2016): SNARE zippering. Biosci Rep 36, e00327

Ma C, Su L, Seven AB, Xu Y, Rizo J (2013): Reconstitution of the vital functions of munc18 and munc13 in neurotransmitter release. Science $\underline{339}, 421-425$

Maidorn M, Rizzoli SO, Opazo F (2016): Tools and limitations to study the molecular composition of synapses by fluorescence microscopy. Biochem J 473, 3385-3399

Maidorn M, Olichon A, Rizzoli SO, Opazo F (2018): Nanobodies reveal an extra-synaptic population of SNAP-25 and syntaxin 1A in hippocampal neurons. MAbs $\underline{11}, 305-321$ 
Martens S, Kozlov MM, McMahon HT (2007): How synaptotagmin promotes membrane fusion. Science $\underline{316}, 1205-1208$

Martin SJ, Grimwood PD, Morris RGM (2000): Synaptic plasticity and memory: An evaluation of the hypothesis. Annu Rev Neurosci 23, 649-711

Marx V (2013): Finding the right antibody for the job. Nat Methods $\underline{10}, 703-707$

Maus L, Lee C, Altas B, Sertel SM, Weyand K, Rizzoli SO, Rhee J, Brose N, Imig C, Cooper BH (2020): Ultrastructural correlates of presynaptic functional heterogeneity in hippocampal synapses. Cell Rep 30, 3632-3643.e8

McClelland JL, Goddard NH (1996): Considerations arising from a complementary learning systems perspective on hippocampus and neocortex. Hippocampus $\underline{6}, 654-665$

McKinney RA, Capogna M, Dürr R, Gähwiler BH, Thompson SM (1999): Miniature synaptic events maintain dendritic spines via AMPA receptor activation. Nat Neurosci $\underline{2}, 44-49$

McMahon HT, Boucrot E (2011): Molecular mechanism and physiological functions of clathrin-mediated endocytosis. Nat Rev Mol Cell Biol 12, 517-533

McMahon HT, Gallop JL (2005): Membrane curvature and mechanisms of dynamic cell membrane remodelling. Nature $\underline{438}, 590-596$

McMahon HT, Bolshakov VY, Janz R, Hammer RE, Siegelbaum SA, Südhof TC (1996): Synaptophysin, a major synaptic vesicle protein, is not essential for neurotransmitter release. Proc Natl Acad Sci USA 93, 4760-4764

McMahon HT, Wigge P, Smith C (1997): Clathrin interacts specifically with amphiphysin and is displaced by dynamin 1 . FEBS Lett $\underline{413}, 319-322$

Megías M, Emri Z, Freund TF, Gulyás AI (2001): Total number and distribution of inhibitory and excitatory synapses on hippocampal CA1 pyramidal cells. Neuroscience $\underline{102}, 527-$ 540

Merrifield CJ, Moss SE, Ballestrem C, Imhof BA, Giese G, Wunderlich I, Almers W (1999): Endocytic vesicles move at the tips of actin tails in cultured mast cells. Nat Cell Biol $\underline{1}$, $72-74$

Micheva KD, Smith SJ (2007): Array tomography. Neuron 포, 25-36

Mikhaylova M, Cloin BMC, Finan K, van den Berg R, Teeuw J, Kijanka MM, Sokolowski M, Katrukha EA, Maidorn M, Opazo F (2015): Resolving bundled microtubules using antitubulin nanobodies. Nat Commun $\underline{6}, 7933$

Miller TM, Heuser JE (1984): Endocytosis of synaptic vesicle membrane at the frog neuromuscular junction. J Cell Biol $\underline{98}, 685-698$

Milosevic I, Giovedi S, Lou X, Raimondi A, Collesi C, Shen H, Paradise S, O’Toole E, Ferguson S, Cremona O et al. (2011): Recruitment of endophilin to clathrin-coated pit necks is required for efficient vesicle uncoating after fission. Neuron $\underline{72}, 587-601$

Mittelstaedt T, Alvarez-Baron E (2008): Die Cytomatrix der präsynaptischen Aktiven Zone: molekulare Organisation und Funktion. Neuroforum $\underline{08}, 7$

Mizuseki K, Buzsáki G (2013): Preconfigured, skewed distribution of firing rates in the hippocampus and entorhinal cortex. Cell Rep $\underline{4}, 1010-1021$ 
Mizuseki K, Royer S, Diba K, Buzsáki G (2012): Activity dynamics and behavioral correlates of CA3 and CA1 hippocampal pyramidal neurons. Hippocampus 22, 1659-1680

Mohrmann R, de Wit H, Connell E, Pinheiro PS, Leese C, Bruns D, Davletov B, Verhage M, Sørensen JB (2013): Synaptotagmin interaction with SNAP-25 governs vesicle docking, priming, and fusion triggering. J Neurosci $\underline{33}, 14417-14430$

Mooren OL, Galletta BJ, Cooper JA (2012): Roles for actin assembly in endocytosis. Annu Rev Biochem $\underline{81}, 661-686$

Morel N (2003): Neurotransmitter release: the dark side of the vacuolar-H+ATPase. Biol Cell 95, 453-457

Moriyama Y, Maeda M, Futai M (1992): The role of V-ATPase in neuronal and endocrine systems. J Exp Biol 172, 171-178

Mukherjee K, Yang X, Gerber SH, Kwon HB, Ho A, Castillo PE, Liu X, Südhof TC (2010): Piccolo and bassoon maintain synaptic vesicle clustering without directly participating in vesicle exocytosis. Proc Natl Acad Sci USA 107, 6504-6509

Mundigl O, Ochoa GC, David C, Slepnev VI, Kabanov A, De Camilli P (1998): Amphiphysin I antisense oligonucleotides inhibit neurite outgrowth in cultured hippocampal neurons. J Neurosci $\underline{18}, 93-103$

Murthy VN, Stevens CF (1999): Reversal of synaptic vesicle docking at central synapses. Nat Neurosci 2, 503-507

Murthy VN, Sejnowski TJ, Stevens CF (1997): Heterogeneous release properties of visualized individual hippocampal synapses. Neuron $\underline{18}, 599-612$

Nagwaney S, Harlow ML, Jung JH, Szule JA, Ress D, Xu J, Marshall RM, McMahan UJ (2009): Macromolecular connections of active zone material to docked synaptic vesicles and presynaptic membrane at neuromuscular junctions of mouse. J Comp Neurol $\underline{513}$, $457-468$

Naito S, Ueda T (1985): Characterization of glutamate uptake into synaptic vesicles. J Neurochem $44,99-109$

Neher E (2010): What is rate-limiting during sustained synaptic activity: Vesicle supply or the availability of release sites. Front Synaptic Neurosci 2, 144

Neher E, Brose N (2018): Dynamically primed synaptic vesicle states: Key to understand synaptic short-term plasticity. Neuron $\underline{100}, 1283-1291$

Neher E, Sakaba T (2008): Multiple roles of calcium ions in the regulation of neurotransmitter release. Neuron $\underline{59}, 861-872$

Newman GR, Jasani B, Williams ED (1983): A simple post-embedding system for the rapid demonstration of tissue antigens under the electron microscope. Histochem J $\underline{15}, 543-$ 555

Newton AJ, Kirchhausen T, Murthy VN (2006): Inhibition of dynamin completely blocks compensatory synaptic vesicle endocytosis. Proc Natl Acad Sci USA 103, 17955-17960

Ni B, Wu X, Yan G, Wang J, Paul S (1995): Regional expression and cellular localization of the $\mathrm{Na}(+)$-dependent inorganic phosphate cotransporter of rat brain. J Neurosci $\underline{15}, 5789$ 5799 
Opazo F, Rizzoli SO (2010): The fate of synaptic vesicle components upon fusion. Commun Integr Biol $\underline{3}, 427-429$

O'Rourke NA, Weiler NC, Micheva KD, Smith SJ (2012): Deep molecular diversity of mammalian synapses: why it matters and how to measure it. Nat Rev Neurosci 13, 365-379

Paillart C, Li J, Matthews G, Sterling P (2003): Endocytosis and vesicle recycling at a ribbon synapse. J Neurosci 23, 4092-4099

Pan PY, Tian JH, Sheng ZH (2009): Snapin facilitates the synchronization of synaptic vesicle fusion. Neuron $\underline{61}, 412-424$

Parnavelas JG (2002): The origin of cortical neurons. Braz J Med Biol Res $\underline{35}, 1423-1429$

Pearse BMF (1975): Coated vesicles from pig brain: Purification and biochemical characterization. J Mol Biol 97, 93-98

Pennuto M, Dunlap D, Contestabile A, Benfenati F, Valtorta F (2002): Fluorescence resonance energy transfer detection of synaptophysin I and vesicle-associated membrane protein 2 interactions during exocytosis from single live synapses. Mol Biol Cell $\underline{13}$, 2706-2717

Pennuto M, Bonanomi D, Benfenati F, Valtorta F (2003): Synaptophysin I controls the targeting of VAMP2/Synaptobrevin II to synaptic vesicles. Mol Biol Cell $\underline{14}$, 4909-4919

Penzes P, Cahill ME, Jones KA, van Leeuwen JE, Woolfrey KM (2011): Dendritic spine pathology in neuropsychiatric disorders. Nat Neurosci 14, 285-293

Peter BJ, Kent HM, Mills IG, Vallis Y, Butler PJG, Evans PR, McMahon HT (2004): BAR domains as sensors of membrane curvature: The amphiphysin BAR structure. Science $\underline{303}, 495-499$

Pieribone VA, Shupliakov O, Brodin L, Hilfiker-Rothenfluh S, Czernik AJ, Greengard P (1995): Distinct pools of synaptic vesicles in neurotransmitter release. Nature $\underline{375}, 493-$ 497

Pietrancosta N, Djibo M, Daumas S, El Mestikawy S, Erickson JD (2020): Molecular, structural, functional, and pharmacological sites for vesicular glutamate transporter regulation. Mol Neurobiol 57, 3118-3142

Pleiner T, Bates M, Görlich D (2018): A toolbox of anti-mouse and anti-rabbit IgG secondary nanobodies. J Cell Biol 217, 1143-1154

Pozzi D, Condliffe S, Bozzi Y, Chikhladze M, Grumelli C, Proux-Gillardeaux V, Takahashi M, Franceschetti S, Verderio C, Matteoli M (2008): Activity-dependent phosphorylation of Ser187 is required for SNAP-25-negative modulation of neuronal voltage-gated calcium channels. Proc Natl Acad Sci USA 105, 323-328

Prekeris R, Terrian DM (1997): Brain myosin V is a synaptic vesicle-associated motor protein: evidence for a $\mathrm{Ca} 2+-d e p e n d e n t$ interaction with the synaptobrevin-synaptophysin complex. J Cell Biol 137, 1589-1601

Raja MK, Preobraschenski J, Del Olmo-Cabrera S, Martinez-Turrillas R, Jahn R, Perez-Otano I, Wesseling JF (2019): Elevated synaptic vesicle release probability in synaptophysin/gyrin family quadruple knockouts. eLife $\underline{8}$, e40744 
Rajappa R, Gauthier-Kemper A, Böning D, Hüve J, Klingauf J (2016): Synaptophysin 1 clears synaptobrevin 2 from the presynaptic active zone to prevent short-term depression. Cell Rep 14, 1369-1381

Rao Y, Haucke V (2011): Membrane shaping by the bin/amphiphysin/Rvs (BAR) domain protein superfamily. Cell Mol Life Sci $\underline{68}$, 3983-3993

Raviola E, Gilula NB (1973): Gap junctions between photoreceptor cells in the vertebrate retina. Proc Natl Acad Sci USA 무, 1677-1681

Renden R, von Gersdorff H (2007): Synaptic vesicle endocytosis at a CNS nerve terminal: Faster kinetics at physiological temperatures and increased endocytotic capacity during maturation. J Neurophysiol 98, 3349-3359

Reshetniak S, Ußling JE, Perego E, Rammner B, Schikorski T, Fornasiero EF, Truckenbrodt S, Köster S, Rizzoli SO (2020): A comparative analysis of the mobility of 45 proteins in the synaptic bouton. EMBO J $\underline{39}$, e104596

Richards DA, Guatimosim C, Betz WJ (2000): Two endocytic recycling routes selectively fill two vesicle pools in frog motor nerve terminals. Neuron $\underline{27}, 551-559$

Richards DA, Guatimosim C, Rizzoli SO, Betz WJ (2003): Synaptic vesicle pools at the frog neuromuscular junction. Neuron $\underline{39}, 529-541$

Richmond JE, Davis WS, Jorgensen EM (1999): UNC-13 is required for synaptic vesicle fusion in C. elegans. Nat Neurosci 2, 959-964

Ries J, Kaplan C, Platonova E, Eghlidi H, Ewers H (2012): A simple, versatile method for GFPbased super-resolution microscopy via nanobodies. Nat Methods $\underline{9}, 582-584$

Risselada HJ, Grubmüller H (2012): How SNARE molecules mediate membrane fusion: Recent insights from molecular simulations. Curr Opin Struct Biol 22, 187-196

Rizzoli SO (2014): Synaptic vesicle recycling: steps and principles. EMBO J $\underline{33}$, 788-822

Rizzoli SO, Betz WJ (2004): The structural organization of the readily releasable pool of synaptic vesicles. Science 303, 2037-2039

Rizzoli SO, Betz WJ (2005): Synaptic vesicle pools. Nat Rev Neurosci $\underline{6}$, 57-69

Rizzoli SO, Tabares L (2016): Editorial: Molecular nanomachines of the presynaptic terminal. Front Synaptic Neurosci $\underline{8}, 27$

Rollenhagen A, Lübke JHR (2010): The mossy fiber bouton: the "common" or the "unique" synapse? Front Synaptic Neurosci $\underline{2}, 2$

Roux A, Uyhazi K, Frost A, De Camilli P (2006): GTP-dependent twisting of dynamin implicates constriction and tension in membrane fission. Nature $\underline{441}, 528-531$

Rust MJ, Bates M, Zhuang X (2006): Stochastic optical reconstruction microscopy (STORM) provides sub-diffraction-limit image resolution. Nat Methods $\underline{3}, 793-795$

Saheki Y, De Camilli P (2012): Synaptic vesicle endocytosis. Cold Spring Harb Perspect Biol $\underline{4}$, a005645 
Saitoe M, Schwarz TL, Umbach JA, Gundersen CB, Kidokoro Y (2001): Absence of junctional glutamate receptor clusters in drosophila mutants lacking spontaneous transmitter release. Science $\underline{293}, 514-517$

Saka S, Rizzoli SO (2012): Super-resolution imaging prompts re-thinking of cell biology mechanisms. Bioessays $\underline{34}, 386-395$

Sakaba T, Neher E (2003): Involvement of actin polymerization in vesicle recruitment at the calyx of held synapse. J Neurosci $\underline{23}, 837-846$

Sankaranarayanan S, Atluri PP, Ryan TA (2003): Actin has a molecular scaffolding, not propulsive, role in presynaptic function. Nat Neurosci $\underline{6}, 127-135$

Saroussi S, Nelson N (2009): The little we know on the structure and machinery of V-ATPase. J Exp Biol 212, 1604-1610

Sauer M (2013): Localization microscopy coming of age: from concepts to biological impact. J Cell Sci $\underline{126}, 3505-3513$

Schäfer MKH, Varoqui H, Defamie N, Weihe E, Erickson JD (2002): Molecular cloning and functional identification of mouse vesicular glutamate transporter 3 and its expression in subsets of novel excitatory neurons. J Biol Chem $\underline{277}$, 50734-50748

Schermelleh L, Carlton PM, Haase S, Shao L, Winoto L, Kner P, Burke B, Cardoso MC, Agard DA, Gustafsson MGL (2008): Subdiffraction multicolor imaging of the nuclear periphery with 3D structured illumination microscopy. Science 320, 1332-1336

Schermelleh L, Heintzmann R, Leonhardt H (2010): A guide to super-resolution fluorescence microscopy. J Cell Biol 190, 165-175

Schikorski T, Stevens CF (1997): Quantitative ultrastructural analysis of hippocampal excitatory synapses. J Neurosci 17, 5858-5867

Schikorski T, Stevens CF (1999): Quantitative fine-structural analysis of olfactory cortical synapses. Proc Natl Acad Sci USA 96, 4107-4112

Schikorski T, Stevens CF (2001): Morphological correlates of functionally defined synaptic vesicle populations. Nat Neurosci $\underline{4}, 391-395$

Schlossman DM, Schmid SL, Braell WA, Rothman JE (1984): An enzyme that removes clathrin coats: purification of an uncoating ATPase. J Cell Biol $\underline{99}, 723-733$

Schmidt R, Wurm CA, Jakobs S, Engelhardt J, Egner A, Hell SW (2008): Spherical nanosized focal spot unravels the interior of cells. Nat Methods $\underline{5}, 539-544$

Schmitt U, Tanimoto N, Seeliger M, Schaeffel F, Leube RE (2009): Detection of behavioral alterations and learning deficits in mice lacking synaptophysin. Neuroscience $\underline{162}, 234$ 243

Seitz KJ, Rizzoli SO (2019): GFP nanobodies reveal recently-exocytosed pHluorin molecules. Sci Rep $\underline{9}, 7773$

Selak S, Paternain AV, Aller IM, Picó E, Rivera R, Lerma J (2009): A role for SNAP25 in internalization of kainate receptors and synaptic plasticity. Neuron $\underline{63}, 357-371$ 
Shibaguchi H, Takemura K, Kan S, Kataoka Y, Kaibara M, Saito N, Taniyama K (2000): Role of synaptophysin in exocytotic release of dopamine from xenopus oocytes Injected with rat brain mRNA. Cell Mol Neurobiol 20, 401-408

Shin M, Wang Y, Borgus JR, Venton BJ (2019): Electrochemistry at the Synapse. Annu Rev Anal Chem (Palo Alto Calif) $\underline{12}, 297-321$

Shupliakov O, Bloom O, Gustafsson JS, Kjaerulff O, Low P, Tomilin N, Pieribone VA, Greengard P, Brodin L (2002): Impaired recycling of synaptic vesicles after acute perturbation of the presynaptic actin cytoskeleton. Proc Natl Acad Sci USA 99, 1447614481

Shupliakov O, Löw P, Grabs D, Gad H, Chen H, David C, Takei K, Camilli PD, Brodin L (1997): Synaptic vesicle endocytosis impaired by disruption of dynamin-SH3 domain interactions. Science 276, 259-263

Simunovic M, Voth GA, Callan-Jones A, Bassereau P (2015): When physics takes over: BAR proteins and membrane curvature. Trends Cell Biol 25, 780-792

Škrlec K, Štrukelj B, Berlec A (2015): Non-immunoglobulin scaffolds: a focus on their targets. Trends Biotechnol 33, 408-418

Smith JE, Reese TS (1980): Use of aldehyde fixatives to determine the rate of synaptic transmitter release. J Exp Biol $\underline{89}$, 19-28

Sograte-Idrissi S, Schlichthaerle T, Duque-Afonso CJ, Alevra M, Strauss S, Moser T, Jungmann R, Rizzoli SO, Opazo F (2020): Circumvention of common labelling artefacts using secondary nanobodies. Nanoscale $\underline{12}, 10226-10239$

Söllner T, Bennett MK, Whiteheart SW, Scheller RH, Rothman JE (1993a): A protein assembly-disassembly pathway in vitro that may correspond to sequential steps of synaptic vesicle docking, activation, and fusion. Cell $\underline{75}, 409-418$

Söllner T, Whiteheart SW, Brunner M, Erdjument-Bromage H, Geromanos S, Tempst P, Rothman JE (1993b): SNAP receptors implicated in vesicle targeting and fusion. Nature $\underline{362}$, $318-324$

Sorre B, Callan-Jones A, Manzi J, Goud B, Prost J, Bassereau P, Roux A (2012): Nature of curvature coupling of amphiphysin with membranes depends on its bound density. Proc Natl Acad Sci USA 109, 173-178

Soykan T, Kaempf N, Sakaba T, Vollweiter D, Goerdeler F, Puchkov D, Kononenko NL, Haucke V (2017): Synaptic vesicle endocytosis occurs on multiple timescales and is mediated by formin-dependent actin assembly. Neuron $\underline{93}$, 854-866.e 4

Squire LR (1992): Memory and the hippocampus: A synthesis from findings with rats, monkeys, and humans. Psychol Rev 99, 195-231

Squire LR, Alvarez P (1995): Retrograde amnesia and memory consolidation: a neurobiological perspective. Curr Opin Neurobiol $\underline{5}, 169-177$

Squire LR, Zola SM (1996): Structure and function of declarative and nondeclarative memory systems. Proc Natl Acad Sci USA 93, 13515-13522

Staras K, Branco T, Burden JJ, Pozo K, Darcy K, Marra V, Ratnayaka A, Goda Y (2010): A vesicle superpool spans multiple presynaptic terminals in hippocampal neurons. Neuron $\underline{66}, 37-44$ 
Stevens RJ, Akbergenova Y, Jorquera RA, Littleton JT (2012): Abnormal synaptic vesicle biogenesis in drosophila synaptogyrin mutants. J Neurosci $\underline{32}$, 18054-18067

Südhof TC (2012a): Calcium control of neurotransmitter release. Cold Spring Harb Perspect Biol $\underline{4}$, a011353

Südhof TC (2012b): The presynaptic active zone. Neuron $\underline{75}, 11-25$

Südhof TC, Rothman JE (2009): Membrane fusion: Grappling with SNARE and SM proteins. Science $\underline{323}, 474-477$

Südhof TC, Lottspeich F, Greengard P, Mehl E, Jahn R (1987): A synaptic vesicle protein with a novel cytoplasmic domain and four transmembrane regions. Science $\underline{238}, 1142-1144$

Sugita S, Janz R, Südhof TC (1999): Synaptogyrins regulate Ca2+-dependent exocytosis in PC12 cells. J Biol Chem 274, 18893-18901

Sun Y, Martin AC, Drubin DG (2006): Endocytic internalization in budding yeast requires coordinated actin nucleation and myosin motor activity. Dev Cell 11, 33-46

Sundborger AC, Hinshaw JE (2014): Regulating dynamin dynamics during endocytosis. F1000Prime Rep $\underline{6}, 85$

Sundborger AC, Soderblom C, Vorontsova O, Evergren E, Hinshaw JE, Shupliakov O (2011): An endophilin-dynamin complex promotes budding of clathrin-coated vesicles during synaptic vesicle recycling. J Cell Sci $\underline{124}, 133-143$

Sutton MA, Ito HT, Cressy P, Kempf C, Woo JC, Schuman EM (2006): Miniature neurotransmission stabilizes synaptic function via tonic suppression of local dendritic protein synthesis. Cell 125, 785-799

Sutton RB, Fasshauer D, Jahn R, Brunger AT (1998): Crystal structure of a SNARE complex involved in synaptic exocytosis at $2.4 \AA$ resolution. Nature $\underline{395}, 347-353$

Szule JA, Harlow ML, Jung JH, De-Miguel FF, Marshall RM, McMahan UJ (2012): Regulation of synaptic vesicle docking by different classes of macromolecules in active zone material. PLoS One 7, e33333

Takamori S, Rhee JS, Rosenmund C, Jahn R (2000): Identification of a vesicular glutamate transporter that defines a glutamatergic phenotype in neurons. Nature $\underline{407}, 189-194$

Takamori S, Rhee JS, Rosenmund C, Jahn R (2001): Identification of differentiation-associated brain-specific phosphate transporter as a second vesicular glutamate transporter (VGLUT2). J Neurosci 21, RC182

Takamori S, Malherbe P, Broger C, Jahn R (2002): Molecular cloning and functional characterization of human vesicular glutamate transporter 3. EMBO Rep $\underline{3}, 798-803$

Takamori S, Holt M, Stenius K, Lemke EA, Grønborg M, Riedel D, Urlaub H, Schenck S, Brügger B, Ringler P (2006): Molecular anatomy of a trafficking organelle. Cell 127, 831-846

Takei K, Mundigl O, Daniell L, De Camilli P (1996): The synaptic vesicle cycle: a single vesicle budding step involving clathrin and dynamin. J Cell Biol 133, 1237-1250

Takei K, Slepnev VI, Haucke V, De Camilli P (1999): Functional partnership between amphiphysin and dynamin in clathrin-mediated endocytosis. Nat Cell Biol 1, 33-39 
Tanaka T, Fillmore D, Sun ST, Nishio I, Swislow G, Shah A (1980): Phase transitions in ionic gels. Phys Rev Lett $\underline{45}, 1636-1639$

Tang J, Maximov A, Shin OH, Dai H, Rizo J, Südhof TC (2006): A complexin/synaptotagmin 1 switch controls fast synaptic vesicle exocytosis. Cell $\underline{126}, 1175-1187$

Tao-Cheng JH, Du J, McBain CJ (2000): Snap-25 is polarized to axons and abundant along the axolemma: an immunogold study of intact neurons. J Neurocytol $\underline{29}, 67-77$

Tarsa L, Goda Y (2002): Synaptophysin regulates activity-dependent synapse formation in cultured hippocampal neurons. Proc Natl Acad Sci USA 99, 1012-1016

Taylor MJ, Perrais D, Merrifield CJ (2011): A high precision survey of the molecular dynamics of mammalian clathrin-mediated endocytosis. PLoS Biol $\underline{9}$, e1000604

Thiele C, Hannah MJ, Fahrenholz F, Huttner WB (2000): Cholesterol binds to synaptophysin and is required for biogenesis of synaptic vesicles. Nat Cell Biol 2, 42-49

Thomas L, Hartung K, Langosch D, Rehm H, Bamberg E, Franke WW, Betz H (1988): Identification of synaptophysin as a hexameric channel protein of the synaptic vesicle membrane. Science 242, 1050-1053

Tillberg PW, Chen F, Piatkevich KD, Zhao Y, Yu CC, English BP, Gao L, Martorell A, Suk HJ, Yoshida F (2016): Protein-retention expansion microscopy of cells and tissues labeled using standard fluorescent proteins and antibodies. Nat Biotechnol 34, 987-992

Tomasoni R, Repetto D, Morini R, Elia C, Gardoni F, Di Luca M, Turco E, Defilippi P, Matteoli M (2013): SNAP-25 regulates spine formation through postsynaptic binding to p140Cap. Nat Commun 4, 1-13

Truckenbrodt S, Rizzoli SO (2014): Spontaneous vesicle recycling in the synaptic bouton. Front Cell Neurosci $\underline{8}, 409$

Truckenbrodt S, Viplav A, Jähne S, Vogts A, Denker A, Wildhagen H, Fornasiero EF, Rizzoli SO (2018a): Newly produced synaptic vesicle proteins are preferentially used in synaptic transmission. EMBO J $\underline{37}$, e98044

Truckenbrodt S, Maidorn M, Crzan D, Wildhagen H, Kabatas S, Rizzoli SO (2018b): X10 expansion microscopy enables $25-\mathrm{nm}$ resolution on conventional microscopes. EMBO Rep 19, e45836

Truckenbrodt S, Sommer C, Rizzoli SO, Danzl JG (2019): A practical guide to optimization in X10 expansion microscopy. Nat Protoc $\underline{14}, 832-863$

Ungewickell E, Ungewickell H, Holstein SEH, Lindner R, Prasad K, Barouch W, Martini B, Greene LE, Eisenberg E (1995): Role of auxilin in uncoating clathrin-coated vesicles. Nature $\underline{378}, 632-635$

Valtorta F, Pennuto M, Bonanomi D, Benfenati F (2004): Synaptophysin: leading actor or walkon role in synaptic vesicle exocytosis? Bioessays $\underline{26}, 445-453$

Van der Kloot W (2003): Loading and recycling of synaptic vesicles in the Torpedo electric organ and the vertebrate neuromuscular junction. Prog Neurobiol 71, 269-303 
Verderio C, Pozzi D, Pravettoni E, Inverardi F, Schenk U, Coco S, Proux-Gillardeaux V, Galli T, Rossetto O, Frassoni C, Matteoli M (2004): SNAP-25 modulation of calcium dynamics underlies differences in GABAergic and glutamatergic responsiveness to depolarization. Neuron $\underline{41}, 599-610$

Voglmaier SM, Kam K, Yang H, Fortin DL, Hua Z, Nicoll RA, Edwards RH (2006): Distinct endocytic pathways control the rate and extent of synaptic vesicle protein recycling. Neuron $\underline{51}, 71-84$

von Gersdorff H, Matthews G (1994): Dynamics of synaptic vesicle fusion and membrane retrieval in synaptic terminals. Nature $\underline{367}, 735-739$

Walter AM, Wiederhold K, Bruns D, Fasshauer D, Sørensen JB (2010): Synaptobrevin N-terminally bound to syntaxin-SNAP-25 defines the primed vesicle state in regulated exocytosis. J Cell Biol 188, 401-413

Wan QF, Zhou ZY, Thakur P, Vila A, Sherry DM, Janz R, Heidelberger R (2010): SV2 acts via presynaptic calcium to regulate neurotransmitter release. Neuron $\underline{66}, 884-895$

Wang X, Hu B, Zieba A, Neumann NG, Kasper-Sonnenberg M, Honsbein A, Hultqvist G, Conze T, Witt W, Limbach C (2009): A protein interaction node at the neurotransmitter release site: Domains of aczonin/piccolo, bassoon, CAST, and rim converge on the Nterminal domain of munc13-1. J Neurosci 29 , 12584-12596

Washbourne P, Schiavo G, Montecucco C (1995): Vesicle-associated membrane protein-2 (synaptobrevin-2) forms a complex with synaptophysin. Biochem J $\underline{305}, 721-724$

Washbourne P, Thompson PM, Carta M, Costa ET, Mathews JR, Lopez-Benditó G, Molnár Z, Becher MW, Valenzuela CF, Partridge LD et al. (2002): Genetic ablation of the tSNARE SNAP-25 distinguishes mechanisms of neuroexocytosis. Nat Neurosci $\underline{5}, 19$ 26

Watanabe S (2016): Flash-and-freeze: Coordinating optogenetic stimulation with rapid freezing to visualize membrane dynamics at synapses with millisecond resolution. Front Synaptic Neurosci $\underline{8}, 24$

Watanabe S, Boucrot E (2017): Fast and ultrafast endocytosis. Curr Opin Cell Biol 47, 64-71

Watanabe S, Liu Q, Davis MW, Hollopeter G, Thomas N, Jorgensen NB, Jorgensen EM (2013a): Ultrafast endocytosis at caenorhabditis elegans neuromuscular junctions. eLife $\underline{2}, \mathrm{e} 00723$

Watanabe S, Rost BR, Camacho-Pérez M, Davis MW, Söhl-Kielczynski B, Rosenmund C, Jorgensen EM (2013b): Ultrafast endocytosis at mouse hippocampal synapses. Nature $\underline{504}, 242-247$

Watanabe S, Trimbuch T, Camacho-Pérez M, Rost BR, Brokowski B, Söhl-Kielczynski B, Felies A, Davis MW, Rosenmund C, Jorgensen EM (2014): Clathrin regenerates synaptic vesicles from endosomes. Nature $\underline{515}, 228-233$

Whitlock JR, Heynen AJ, Shuler MG, Bear MF (2006): Learning induces long-term potentiation in the hippocampus. Science $\underline{313}, 1093-1097$

Wiedenmann B, Franke WW (1985): Identification and localization of synaptophysin, an integral membrane glycoprotein of $\mathrm{mr} 38,000$ characteristic of presynaptic vesicles. Cell $\underline{41}$, $1017-1028$ 
Wienisch M, Klingauf J (2006): Vesicular proteins exocytosed and subsequently retrieved by compensatory endocytosis are nonidentical. Nat Neurosci $\underline{9}, 1019-1027$

Wigge P, McMahon HT (1998): The amphiphysin family of proteins and their role in endocytosis at the synapse. Trends Neurosci 21, 339-344

Wigge P, Köhler K, Vallis Y, Doyle CA, Owen D, Hunt SP, McMahon HT (1997): Amphiphysin heterodimers: Potential role in clathrin-mediated endocytosis. Mol Biol Cell $\underline{8}$, 2003-2015

Wilhelm BG, Mandad S, Truckenbrodt S, Kröhnert K, Schäfer C, Rammner B, Koo SJ, Claßen GA, Krauss M, Haucke V (2014): Composition of isolated synaptic boutons reveals the amounts of vesicle trafficking proteins. Science $\underline{344}, 1023-1028$

Willig KI, Rizzoli SO, Westphal V, Jahn R, Hell SW (2006): STED microscopy reveals that synaptotagmin remains clustered after synaptic vesicle exocytosis. Nature $\underline{440}, 935-939$

Willox AK, Royle SJ (2012): Stonin 2 Is a major adaptor protein for clathrin-mediated synaptic vesicle retrieval. Curr Biol 22, 1435-1439

Wiser O, Bennett MK, Atlas D (1996): Functional interaction of syntaxin and SNAP-25 with voltage-sensitive L- and N-type Ca2+ channels. EMBO J 15, 4100-4110

Wu LG, Hamid E, Shin W, Chiang HC (2014): Exocytosis and endocytosis: Modes, functions, and coupling mechanisms. Annu Rev Physiol 76, 301-331

Wu W, Wu LG (2007): Rapid bulk endocytosis and its kinetics of fission pore closure at a central synapse. Proc Natl Acad Sci USA 104, 10234-10239

Wu Y, Matsui H, Tomizawa K (2009): Amphiphysin I and regulation of synaptic vesicle endocytosis. Acta Med Okayama 63, 305-323

Wu Y, O’Toole ET, Girard M, Ritter B, Messa M, Liu X, McPherson PS, Ferguson SM, De Camilli P (2014): A dynamin 1-, dynamin 3- and clathrin-independent pathway of synaptic vesicle recycling mediated by bulk endocytosis. eLife $\underline{3}$, e01621

Wu YE, Huo L, Maeder CI, Feng W, Shen K (2013): The balance between capture and dissociation of presynaptic proteins controls the spatial distribution of synapses. Neuron $\underline{78}$, 994-1011

Xie Z, Long J, Liu J, Chai Z, Kang X, Wang C (2017): Molecular mechanisms for the coupling of endocytosis to exocytosis in neurons. Front Mol Neurosci 10, 47

Xing Y, Böcking T, Wolf M, Grigorieff N, Kirchhausen T, Harrison SC (2010): Structure of clathrin coat with bound Hsc70 and auxilin: mechanism of Hsc70-facilitated disassembly. EMBO J 29, 655-665

Xu H, Tong Z, Ye Q, Sun T, Hong Z, Zhang L, Bortnick A, Cho S, Beuzer P, Axelrod J et al. (2019): Molecular organization of mammalian meiotic chromosome axis revealed by expansion STORM microscopy. Proc Natl Acad Sci USA 116, 18423-18428

Xu J, McNeil B, Wu W, Nees D, Bai L, Wu LG (2008): GTP-independent rapid and slow endocytosis at a central synapse. Nat Neurosci $11,45-53$

Yeow MBL, Peterson EH (1991): Active zone organization and vesicle content scale with bouton size at a vertebrate central synapse. J Comp Neurol $\underline{307}, 475-486$ 
Yoshida Y, Kinuta M, Abe T, Liang S, Araki K, Cremona O, Di Paolo G, Moriyama Y, Yasuda T, De Camilli P et al. (2004): The stimulatory action of amphiphysin on dynamin function is dependent on lipid bilayer curvature. EMBO J $\underline{23}, 3483-3491$

Zamponi GW (2003): Regulation of presynaptic calcium channels by synaptic proteins. J Pharmacol Sci $\underline{92}, 79-83$

Zeisel A, Muñoz-Manchado AB, Codeluppi S, Lönnerberg P, Manno GL, Juréus A, Marques S, Munguba H, He L, Betsholtz C (2015): Cell types in the mouse cortex and hippocampus revealed by single-cell RNA-seq. Science $\underline{347}, 1138-1142$

Zhang Q, Li Y, Tsien RW (2009): The dynamic control of kiss-and-run and vesicular reuse probed with single nanoparticles. Science $\underline{323}, 1448-1453$

Zhang Z, Wang D, Sun T, Xu J, Chiang HC, Shin W, Wu LG (2013): The SNARE proteins SNAP25 and synaptobrevin are involved in endocytosis at hippocampal synapses. J Neurosci 33, 9169-9175

Zhao Y, Bucur O, Irshad H, Chen F, Weins A, Stancu AL, Oh EY, DiStasio M, Torous V, Glass B et al. (2017): Nanoscale imaging of clinical specimens using pathology-optimized expansion microscopy. Nat Biotechnol 35, 757-764

Zhou K, Stawicki TM, Goncharov A, Jin Y (2013): Position of UNC-13 in the active zone regulates synaptic vesicle release probability and release kinetics. eLife $\underline{2}$, e01180

Zhu F, Cizeron M, Qiu Z, Benavides-Piccione R, Kopanitsa MV, Skene NG, Koniaris B, DeFelipe J, Fransén E, Komiyama NH, Grant SGN (2018): Architecture of the mouse brain synaptome. Neuron $\underline{99}, 781-799 . e 10$

Zucker RS, Regehr WG (2002): Short-term synaptic plasticity. Annu Rev Physiol 64, 355-405

Zwettler FU, Reinhard S, Gambarotto D, Bell TDM, Hamel V, Guichard P, Sauer M (2020): Molecular resolution imaging by post-labeling expansion single-molecule localization microscopy (Ex-SMLM). Nat Commun 11, 3388 


\section{Danksagung}

Allen voran möchte ich mich herzlich bei Herrn Prof. Dr. rer. nat. S. O. Rizzoli für seine ausgezeichnete Betreuung, seine Unterstützung bei der Entstehung dieser Arbeit, seine Anregungen und Hilfestellungen bedanken. Danke, dass Sie mir die Möglichkeit zur Durchführung dieser Arbeit gegeben haben.

Besonderer Dank geht zudem an Dr. Sven Truckenbrodt, der durch seine Kooperation die Durchführung dieser Arbeit mit ermöglichte und dafür, dass er meine Fragen bezüglich der Expansionsmikroskopie stets beantwortete.

Ich bedanke mich bei Herrn Prof. Dr. S. Jakobs, der sich dazu bereiterklärte diese Arbeit als Korreferent zu betreuen. 